\title{
III Schaukal in Netzwerken und Feldern der Moderne
}

\section{Verlagsstrukturen und Verlagsnetzwerke}

Richard Schaukals dichterische Tätigkeit fällt in eine Zeit tiefgreifender drucktechnischer Neuerungen, die Mitte des 19. Jahrhunderts eingesetzt hatten. Die Industrialisierung der Druckverfahren setzte sich bis zur Jahrhundertwende in ganz Österreich-Ungarn durch. Aufgrund der steigenden Nachfrage bei gleichzeitigem Preisdruck nahm die Materialqualität der massenhaft produzierten Zeitschriften und Bücher - meist Kolportageromane mit geringem literarischem Anspruch - zunächst ab. Verlage reagierten auf die wachsende Ökonomisierung von Literatur mit einem stärkeren Fokus auf die Gestaltung der Druckerzeugnisse. So wurden beispielsweise schmückende Jugendstilelemente verwendet, um den Verkauf anzukurbeln und um das Image eines hochwertigen, modernen Verlagshauses zu unterstreichen. ${ }^{1}$

Schaukals Affinität für Themen der Dekoration und seine technischen Kenntnisse spiegeln sich nicht nur in den zahlreichen Essays über Wohnraumgestaltung und städtische Architektur wider, sondern auch in seinen Beiträgen über den Buchschmuck. Das Buch als technisches Produkt müsse ein Kunstwerk bleiben und dürfe nicht zum Massenartikel degradiert werden, so seine an Walter Benjamins Kunstwerkaufsatz erinnernde Argumentation. ${ }^{2}$ In der Funktion als Sektionsrat (seit 1909) lernte Schaukal die technischen Produktionsprozesse des Buchdrucks aus unmittelbarer Nähe kennen. Der Essayist schöpfte seine theoretische wie praktische Expertise also auch aus dem beruflichen Umfeld, wie ein kurzer Zeitungsartikel über seinen Besuch in der Graphischen Lehr- und Versuchsanstalt belegt. Schaukal war Mitglied einer Delegation des Arbeitsministers Karl Marek (1850-1936 oder 1937), die sich vor Ort moderne Druckmethoden vorführen ließ. ${ }^{3}$

Auf den gestalterischen Schwerpunkt junger Verlage deutet auch Schaukals 1897 bei Fischer und Franke in Berlin herausgegebene Lyrik-Anthologie Heinrich

1 Vgl. Bachleitner/Eybl/Fischer: Geschichte des Buchhandels in Österreich, S. 211. Siehe auch Georg Müller: Einiges über Buchausstattung. In: Sein Dämon war das Buch. Der Münchner Verleger Georg Müller. Hg. von Eva von Freeden und Rainer Schmitz. München 2003, S. 25-28. 2 Vgl. Schaukal: Das Buch. In: Wiener Abendpost. Beilage zur Wiener Zeitung, Nr. 1/1904 (2. Januar 1904), S. 1-2, hier S. 1.

3 Vgl. [Anon.]: Graphische Lehr- und Versuchsanstalt in Wien. In: Österreichisch-Ungarische Buchdrucker-Zeitung, 39. Jg, Nr. 43 (26. Oktober 1911), S. 528.

○ Open Access. ๑ 2020 Cornelius Mitterer, publiziert von De Gruyter. $($ cc) BY lizenziert unter der Creative Commons Attribution 4.0 Lizenz.

https://doi.org/10.1515/9783110619744-004 
Heine. Sein Leben in seinen Liedern hin. Das mit Jugendstilornamenten verzierte Titelblatt steht im Zeichen des zu jener Zeit florierenden Buchschmucks. ${ }^{4}$ Auch der Kontakt zwischen dem Worpsweder Jugendstilgraphiker und Maler Heinrich Vogeler und dem um 1900 ebenso noch der Jugendstilästhetik verhafteten Dichter ist ein Resultat der Wechselwirkung von literaturbetrieblichem Kalkül und ästhetischem Anspruch. ${ }^{5}$ Die Dekorationen zielten nicht nur auf eine kaufkräftige Klientel der höheren Bildungsschichten, sie bereiteten Künstlern auch den Weg zu Veröffentlichungen bei prestigeträchtigen Verlagen. Es ist anzunehmen, dass Schaukal abgesehen von seinem starken Interesse für die Malerei und einem neuromantischen Hang zur Universalpoesie - den Kontakt zu Vogeler gesucht hatte, um seine Verse in einem angesehenen Verlag unterzubringen. Vogeler war bereits für die Zeitschriften Jugend und Die Insel tätig und hatte auch für Eugen Diederichs (1867-1930) und Samuel Fischer (1859-1939) Illustrationen angefertigt.

Der Graphiker und der Dichter, beide keine unbeschriebenen Blätter im künstlerischen Feld, korrespondierten seit Juni 1900 miteinander und arbeiteten bereits an Pierrot und Colombine, als der Leipziger Verleger Hermann Seemann die Veröffentlichung zusagte. Seemann zeigte sich zunächst begeistert von der intermedialen Koproduktion, plante sogar eine exklusive Edition von Schaukals Werken und publizierte neben Pierrot und Colombine (1902) rasch aufeinanderfolgend Vorabend (1901) sowie Von Tod zu Tod und andere kleine Geschichten (1902). In zweiter Auflage veröffentlichte er den zunächst 1899 bei Tiefenbach in Leipzig erschienenen Band Tage und Träume (1902) und plante einen Neudruck der 1901 publizierten Intérieurs aus dem Leben der Zwanzigjährigen. ${ }^{6}$ „Ihre Gedichtsammlung ,Pierrot" nehme ich gerne in Verlag“, so Seemann am Beginn der Korrespondenz. Er stellte 25 \% vom Buchhändlerpreis pro verkauftes Exemplar in Aussicht, um dann ironisch anzumerken: „Wenn Ihnen Vogeler Worpswede die Bilder nicht aus Freundschaft gratis geliefert hat, müssten Sie sich dann allerdings von Ihrer Seite mit dem Künstler auseinandersetzen.“ Denn bei einem Verkaufspreis von 2 bis 3 Mark könne er „selbstverständlich kein Künstlerhonorar bezahlen.“7

4 Vgl. Heinrich Heine. Sein Leben in seinen Liedern (1797-1856). Ein Breviarium zum 100. Geburtstag. Hg. von Richard Schaukal. Berlin 1897.

5 Das für Schaukals Werk so bezeichnende Zusammenspiel von Literatur und bildender Kunst setzte sich über seinen Tod hinaus bis in die 1960er Jahre fort. 1965 illustrierte Joseph Beuys (1921-1986) Schaukals Erzählungen aus dem Prosaband Von Tod zu Tod; vgl. Juliane Oestreich: Joseph Beuys illustriert Richard Schaukal. In: Eros Thanatos, Bd. 5-6 (2001/2002), S. $57-65$.

6 Vgl. Leitner: Richard von Schaukal und Heinrich Vogeler, S. 10-11.

7 Brief Seemanns an Schaukal, 5. September 1901, zit. nach Leitner: Richard von Schaukal und Heinrich Vogeler, S. 11. Schaukal beteiligte Vogeler am Honorar. 
Die Zusammenarbeit zwischen Schaukal/Vogeler und Seemann wirft ein erhellendes Licht auf die divergierende Auffassung über die Anfertigungsprozesse eines Buches. Während der Verleger möglichst rasch und profitorientiert arbeiten wollte, verzögerte Schaukal die Produktion durch penible Korrekturen und entwertete schließlich sogar die auf Japanpapier gedruckte Luxusausgabe, weil er sie an der falschen Stelle signiert hatte, sodass der Druck einer zweiten Auflage der Sonderedition erforderlich war. Seemann drohte infolge des Missgeschicks und wegen der langwierigen Arbeitsprozesse, die geplanten Neuauflagen von Tage und Träume (die er dann doch verlegte) und Tristia (1898 bei Friesenhahn erschienen) abzulehnen. Das Arbeitsverhältnis endete im Streit. Der Verleger verzichtete ausdrücklich auf die Publikation weiterer Manuskripte, die Schaukal dennoch regelmäßig schickte, und er bot dem Autor schließlich die Restauflage seiner unverkauften Bücher zu einem niedrigen Preis an - in Schaukals Augen ein Affront. ${ }^{8}$ Vogeler beruhigte den aufgebrachten Briefpartner mit der fatalistischen Gelassenheit des Künstlers, der die ökonomischen Unwägbarkeiten zu kennen schien: „Von Seemann hätte ich übrigens kaum besseres erwartet; es thut mir sehr leid, aber bei dieser Art Verträgen, wie Sie es mit einem derartigen Verleger gemacht haben werden, kommt für den Autor nie etwas heraus.“9

Die literaturbetrieblichen Leitlinien des Verlegers waren mit Schaukals distinguiertem Dichterhabitus, der die Markt- und Vermarktungsprozesse mit stoischer Gelassenheit ignorierte, nicht kompatibel. In einem seiner letzten Schreiben hebt Seemann die Aussichtslosigkeit hervor, aus dem Vertrieb von Lyrikbänden Profit zu schlagen. Abgesehen davon, dass Schaukal einer Gattung treu blieb, die vom wachsenden und sich verändernden Lesepublikum weniger konsumiert wurde, verzichtete er ausdrücklich auf Werbemaßnahmen. ${ }^{10}$ Seemann beklagte sich daher am 17. Juni 1903 bei Schaukal:

Sie selbst haben sich die Versendung mit Waschzetteln verbeten, und bei unserem Rezensionsversand an die Presse war selbstverständlich dementsprechend das Resultat ein miserables, indem kaum $2 \%$ Besprechungen resp. Notizen eingegangen sind. Jeder Fachmann wird Ihnen selbst bestätigen, dass es heute geradezu Wahnsinn und hinausgeworfenes Geld ist, wenn man an die Tagespresse, speciell die kleine Provincpresse Rezensionsexemplare ohne irgendwelche Begleitschreiben, resp. Prospekt verschickt. ${ }^{11}$

Auch wenn Schaukal ökonomische Verluste mit dem Verlag Seemann machte und vice versa -, kam es immerhin zur Zusammenarbeit mit einem angesehenen

8 Vgl. Leitner: Richard von Schaukal und Heinrich Vogeler, S. 16.

9 Zit. nach Leitner: Richard von Schaukal und Heinrich Vogeler, S. 17.

10 Vgl. Leitner: Richard von Schaukal und Heinrich Vogeler, S. 13-14.

11 Zit. nach Leitner: Richard von Schaukal und Heinrich Vogeler, S. 14-15, Fußnote 27. 
Maler, der Pierrot, das Buch der Tage und Träume sowie das (verschollene) Titelblatt zu Tristia gestaltete. Nicht zuletzt ebnete er den Weg zu Deutsche Kunst und Dekoration, eine der führenden europäischen Kunstzeitschrift der Zeit. ${ }^{12}$

In diesem frühen Verlegerkontakt sind Momente gegeben, die Schaukals lebenslangen Umgang mit Verlagen, Buchhändlern und Redakteuren sowie mit den gängigen Werbe- und Verkaufsmaßnahmen im literarischen Feld bestimmen sollten.

Schaukals Korrespondenzpartner legten ihm immer wieder nahe, sich an die literarische Großform $\mathrm{zu}$ wagen. Verlage erhofften und erwarteten sich geradezu einen Roman, wie ihn etwa Thomas Mann oder Jakob Wassermann (1873-1934) im deutschen Sprachraum mit Buddenbrooks (1901) beziehungsweise Die Geschichte der jungen Renate Fuchs (1900) vorgelegt hatten, oder wie er in Österreich Otto Stoessl (1875-1936) mit Das Haus Erath zwei Jahrzehnte später gelingen sollte. Doch die kleine Form und vor allem die Lyrik gehörten zu Schaukals Distinktionsmerkmalen. Auch seine Essays versperrten sich ostentativ der breiten Rezeption. Leopold Husinsky bezeichnete 1926 Schaukals Stifter-Essays dementsprechend zwar als das „Beste und Reifste der Stifterliteratur. Eben darum ist es [jedoch] herzlich zu bedauern, daß Schaukal die stilistische Formung dieser Aufsätze zum größten Teil so esoterisch gestaltet hat, daß sich ihre ganze Bedeutung nur dem Fachmann erschließt. “13

Für Schaukal war der Akt des Schreibens gleichzusetzen mit einer prononcierten Geste der Abgrenzung, mit Bourdieu gesprochen: eine Praxisform der Distinktion sowohl von bürgerlichen ,Philistern' als auch von den neuen Leserschichten. In diesem Punkt stimmte seine Poetik mit der des Jungen Wien überein. Andererseits versuchte er vor allem in der Frühphase seines Schaffens einen Roman vorzulegen, und noch 1910 kündigte er die Publikation einer großen Erzählung an. ${ }^{14}$ Später wurde Schaukal ausdrücklich dafür gelobt, dass er der Dichtung ein Leben lang treu geblieben war. „Ich glaube nicht, daß Schaukal je ein Theaterstück oder ein Roman glückte“, so ein Redakteur in der dem Dichter positiv gesinnten Reichspost:

Er hat auch, in kluger Selbsterkenntnis, keinerlei ernsten Versuch unternommen, sich einem Genre anzuzwingen, das ihm nicht adäquat ist. Und beharrt, darin sich selbst vom Anfang an getreu [...] dabei, was ihm der Augenblick, höchstens die kurze und zuhöchst die lange Weile zuträgt, die Impressionen und Empfindungen in wenig umfangreiche

12 Vgl. Leitner: Richard von Schaukal und Heinrich Vogeler, S. 17.

13 Leopold Husinsky: Richard v. Schaukal: Adalbert Stifter. In: Reichspost, Nr. 33/1926 (1. März 1926), S. 8.

14 Etwa an Max Brod, wie aus dessen Brief an Schaukal vom 20. Januar 1910 hervorgeht, S-NL, WB. 
Kunstwerke zu bannen. Seltener in Novellen, der Regel nach ins Essai, in den Aphorismus oder in den spielend gemeisterten Vers. ${ }^{15}$

Was in diesem 1926 verfassten Beitrag über Schaukal nachwirkt, ist die zur Jahrhundertwende vorherrschende Ausrichtung der Wiener Dichter auf die impressionistische kleine Form. Dagmar Lorenz sieht darin eine antihistoristische Position, die auch für Schaukal bezeichnend war und sich in seinen späten Werken fortsetzte:

Dem auf Dauer und Verewigung angelegten künstlerischen Entwurf, wie er in den SteinMonumenten der Ringstraße zu besichtigen war, wie er sich aber auch im bedeutungserheischenden Pathos des Historien-Dramas ausdrückte, antworteten die auf Flüchtigkeit intensiver Momente angelegten ,kleinen Formen' der Wiener Moderne, wie etwa die feuilletonistisch-impressionistische Skizze (Altenberg) oder der lyrische Einakter (Schnitzler, Hofmannsthal). ${ }^{16}$

1902 und 1903 ermutigten Franz Blei und Thomas Mann Schaukal, einen Roman zu verfassen. ${ }^{17}$ Auch der Autor des Insel Verlags Arthur Schurig (1870-1929) empfahl wenige Jahre darauf, er solle „endlich das Gebiet betreten, was nun einmal den wirklich großen Erfolg allein zu verleihen im Stande ist, das Gebiet des Romans.“18 „Sie entwickeln sich jetzt sehr ins Große, wirklich Große“, empfindet nach der Lektüre von Großmutter (1906) Alfred Kubin, der seinem Freund die kulturkritischen Essays austreiben wollte: „Abhandlungen über ,Kleider‘ etc. - so sehr sie auch recht schaukalisch sind, befremden mich. ${ }^{119}$ Auch der seinerzeit einflussreiche Schriftsteller Karl Hans Strobl (1877-1946) stand Schaukals fragmentarischer Prosa ablehnend gegenüber und empfahl ihm, einen Roman zu schreiben: „Entgegen Ihrer Ansicht bin ich auch der Meinung, daß der Roman keineswegs eine überlebte Kunstgattung sei, im Gegenteil, ich halte ihn für die Kunstgattung, die in unserer Zeit noch am allermeisten zu sagen hat und zu sagen haben wird, mehr als im Drama, dessen Verfall doch von Tag zu Tag deutlicher wird. “20

Abgesehen von seinen Novellen veröffentlichte Schaukal keine längeren Prosaarbeiten. In einem späten Aufsatz fasste Schaukal seine Abneigung gegen

15 X. Y. Z.: Richard Schaukal. Eine Studie über ein österreichisches Dichterschaffen. In: Die Quelle. Sonntag-Beiblatt für Literatur, Heimatkunde und Kultur der Reichspost, Nr. 341/1926 (12. Dezember 1926), S. 19-20, hier S. 20.

16 Lorenz: Wiener Moderne, S. 75.

17 Vgl. den Brief Bleis an Schaukal, 23. März 1902, S-NL, WB; und den Brief Manns vom 1. August 1903 an Schaukal in: Girardi (Hg.): Thomas Mann: Briefe an Richard Schaukal, S. 71 (TMSch 42).

18 Brief Schurigs an Schaukal, 25. Juni 1906, S-NL, WB.

19 Brief Kubins an Schaukal, 13. Juni 1906, S-NL, WB.

20 Brief Strobls an Schaukal, 11. Juni 1914, S-NL, WB. 
den Roman in programmatische Worte. Er könne Texte dieser Gattung nicht einmal lesen, heißt es darin, weil sie ihn mit ihrer Absicht $\mathrm{zu}$ fesseln langweilen. Schaukal bezeichnet auto-/biographische Einflüsse, historische Begebenheiten und vor allem die ästhetische Form als entscheidende Kriterien für literarische Werke. Stoff und Gestaltung sollten übereinstimmen, so seine Auffassung als Kritiker und Dichter in Personalunion:

Zweierlei such' ich in einem Buche: Tatsachen und Kunst der Darstellung. Tatsachen, seien es geschichtliche oder sonst wissenschaftliche aus dem Bereich meiner Neigung und Kenntnisse, befriedigen mich als Mitteilungen, sie fesseln und bereichern mich: ebenso Angaben über Drucke wie Berichte über Geschehnisse (Meinungen darüber nur, wenn sie scharf gefaßte Ergebnisse sachlicher Forschung, zumal Kritik sind). ${ }^{21}$

Doch in seinen Briefen ist immer wieder die Rede von einem früh verfassten und beim Verlag Friesenhahn in Leipzig verschollenen Roman-Manuskript. Die 1904 bei Insel erschienene Novelle Mimi Lynx sei ein Rest jener verloren gegangenen, größeren Prosaarbeit, wie Schaukal am Rande eines Briefes, den er 1897 von Rilke erhalten hatte, notierte. ${ }^{22}$ In der Vorrede zu den Intérieurs beschreibt er die Entstehungsgeschichte seines angedachten Romans, der im Jahr 1895 begonnen worden sei und 1899 seine „Eingeweide eingebüßt“ habe:

Man erklärte dieses unselige Ereignis [den Verlust des Manuskripts] mit dem Bankrott eines Druckers. Da ich so unvorsichtig gewesen, das Originalmanuskript nicht zu kopieren, der Drucker aber so liebenswürdig, die Skripturen zu verlieren, [...] hinterblieb ein Torso. Es sind die ersten neun Bogen, teilweise schon 1898 ausgedruckt. ${ }^{23}$

Die Verlage und ihre wirtschaftlichen Interessen waren Schaukal auch wegen dieses Negativerlebnisses suspekt. Andererseits wollte er seine Werke, allen voran seine Lyrik, auf die er große Stücke hielt, nicht für die Schreibtischlade verfasst haben. Der von den Verlagen ausgehende zeitliche Druck widersprach jedoch seinem peniblen Arbeitsethos. Opus operatum und modus operandi verschmolzen bereits beim Jungdichter zu einer festen Einheit, wie der Konflikt mit Hermann Seemann zeigte. Im gedehnten und sorgfältigen, dabei durchaus egozentrischen Arbeitsprozess lag Schaukals gesamter Habitus, seine Mentalität und auch die Erwartungshaltung, als Künstler ein gewisses Entgegenkommen von der industriell-ökonomischen Instanz der Buchproduktion zu erhalten. In einem Essay über Frank Wedekind (1903) formulierte Schaukal seine fundamentale Kritik am

21 Schaukal: Romane. In: Schaukal: Erkenntnisse und Betrachtungen, S. 377.

22 Vgl. den Brief Rilkes an Schaukal, 17. Mai 1897, S-NL, WB.

23 Schaukal: Vorrede. In: WE. Bd. 2: Um die Jahrhundertwende. München/Wien 1965, S. 33-35, hier S. 33. 
Unterhaltungszweck der Kunst. Er mokierte sich über die zwei Jahre zuvor in Berlin und München eröffneten literarischen Kabaretts ,Elf Scharfrichter' beziehungsweise ,Überbrettl`, deren Theaterparodien großen Zulauf erhielten. ${ }^{24}$ Diesen stellte er die Lyrik als geniale Gattung von rein künstlerischem Wert entgegen:

Lyrik hat aber mit dem „Brettl“ nichts zu tun. (Trotz aller „Überbrettl-Bewegung“, die übrigens schon lange nichts mehr „bewegt“, kein Glied und keine „Interessenten“.) Wedekind singt „mit Gefühl“. Aber das ist Artistengefühl, „Berufs“-Freude gewissermaßen. Lyrik ist aber gar nichts Berufsmäßiges (wenn heute auch die Literaturknaben einem fast die Überzeugung aufdrängten). Lyrik ist Rausch. ${ }^{25}$

\subsection{Erfolge in München}

Dass, wie so oft bei Schaukal, auch in dieser Aussage persönliche Kränkung und poetische Stellungnahme eng miteinander verbunden sind, offenbaren seine Briefwechsel zur Entstehungszeit jener „Porträtskizze“, als er sich in der literarischen Szene Münchens zu etablieren begann. Aus den Korrespondenzen mit Franz Blei sowie mit Thomas und Heinrich Mann geht hervor, dass Schaukal in der Isarstadt zunächst als Dramatiker reüssieren wollte und dabei keineswegs die Kabarettszene außer Acht ließ. Zu diesem Zweck hatte er mit Marc Henry (eigtl. Achille d'Ailly Vaucheret, 1873-1943), dem Mitbegründer und Geschäftsführer der ,Elf Scharfrichter` Kontakt aufgenommen. Dass Schaukal noch 1901 an einer Vermittlung seiner Gedichte an die später geschmähte Kabarettbühne interessiert war, belegt ein Brief Thomas Manns: „Eine Dame, die auf dem hiesigen Überbrettl der ,11 Scharfrichter` auftreten soll, sucht nach passenden Gedichten, und [ich] bemühe mich, ihr einiges von den Ihrigen nahe zu legen. “26

Henry war zudem Verlagsleiter und gab die Zeitschrift Revue franco-allemande heraus, für die auch Schaukal Beiträge lieferte. Der Publizist war im Besitz von Schaukal-Manuskripten (und vermutlich auch der Rechte), die der Dichter für eine geplante Veröffentlichung des Lyrikbandes Sehnsucht bei Seemann zurückforderte. Weil Henry nicht antwortete, aktivierte Schaukal seine Kontakte in München, doch weder Heinrich noch Thomas Mann oder Franz Blei intervenierten. Blei, der zwischen 1901 und 1904 als Regisseur der ,Scharfrichter‘ tätig war, meinte resignativ: „Henry ist ein sehr liebenswürdiger Mensch, aber Geschäfte darf man mit ihm nicht machen. Ich kann Ihnen nur den Rat geben, sich um die

24 Vgl. Peter Sprengel: Literatur im Kaiserreich. Studien zur Moderne. Berlin 1993, S. 132.

25 Schaukal: Frank Wedekind. Eine Porträtskizze, S. 9.

26 Brief Manns an Schaukal vom 7. Juli 1901, in: Girardi (Hg.): Thomas Mann: Briefe an Richard Schaukal, S. 29 (TMSch 4). 
Sache gar nicht zu kümmern, wenn Sie sich längeren Ärger ersparen wollen“, vermutlich werde er die Manuskripte nicht mehr wiedersehen, so Blei. ${ }^{27}$

Auffallend ist der schon im Konflikt mit dem Leipziger Verleger Seemann wahrnehmbare fatalistische Grundton, der mit dem eklatanten Mangel an Rechtsschutz für Künstlerinnen und Künstler zu begründen ist. Erst zu Beginn des 20. Jahrhunderts sollte dieser festgeschrieben werden. Auch wenn Schaukals Kontakte in München nicht in allen Belangen zu seinen Gunsten intervenieren konnten, profitierte er doch von deren Verbindungen mit den dort ansässigen Institutionen und Akteuren des literarischen Feldes. Zwar blieben Thomas Manns Vermittlungsversuche bei der Zeitschrift Jugend sowie seine Fürsprache bei Samuel Fischer, Albert Langen (1869-1909) und bei Oscar Bie (1864-1938) wegen einer Publikation in der Neuen Deutschen Rundschau erfolglos, ${ }^{28}$ andererseits empfahl er Schaukal Verlagshäuser, die besser zu ihm passen würden, etwa den Wiener Verlag, Seemann und vor allem Diederichs. ${ }^{29}$ Möglich, dass Schaukal aufgrund dieser Empfehlungen Kontakt zu den genannten Verlagen aufnahm, von denen lediglich Diederichs eine Publikation ablehnte. Zudem gewann er in Thomas Mann einen Fürsprecher bei Reinhold Geheeb (1872-1939), dem Chefredakteur der von Albert Langen 1896 gegründeten Zeitschrift Simplicissimus und - wie Mann - redaktioneller Mitarbeiter im Langen-Verlag.

Zur gleichen Zeit bemühte sich Schaukal darum, den Kontakt zu Heinrich Mann für die Verbreitung seines dramatischen Schaffens in München zu nutzen. Dieser war von den Werken des österreichischen Schriftstellers zunächst angetan und bekundete halb ironisch, halb anerkennend: „Lieber Herr Doktor, man muß Ihnen, glaube ich, gratulieren, denn Sie scheinen in München in Mode zu kommen.“30

Heinrich Mann verfügte als Vorstandsmitglied der Münchner Dramatischen Gesellschaft über Einfluss, den er jedoch für die Vermittlung Schaukals beim Akademischen Dramatischen Verein nicht geltend machen konnte. Der Theaterverein hatte sich in der Szene einen Namen gemacht, da er in unregelmäßigen

27 Zit. nach Girardi (Hg.): Thomas Mann: Briefe an Richard Schaukal, S. 127. Henry sollte 1906 in Wien das Kabarett Nachtlicht eröffnen. Aufgrund einer negativen Äußerung verprügelte Henry Karl Kraus; vgl. Ludwig Greve und Werner Volke: Jugend in Wien. Literatur um 1900. Ausst.-Kat., Marbach am Neckar 1987, S. 383.

28 Vgl. Girardi (Hg.): Thomas Mann: Briefe an Richard Schaukal, S. 29-30 (2. Oktober 1901, TMSch 5) sowie S. 86 und S. 88 (5. Januar 1904, TMSch 54 und 13. Februar 1904, TMSch 56). Siehe auch die erhaltenen Absagen von Bie im Schaukal-Nachlass der Wienbibliothek (6. Oktober 1899, 11. Januar 1901 und eine ohne Datum).

29 Vgl. die Briefe Manns an Schaukal vom 17. und 28. April 1902, in: Girardi (Hg.): Thomas Mann: Briefe an Richard Schaukal, S. 42-44 (TMSch 17 und 18).

30 Brief Heinrich Manns an Schaukal, 25. Mai 1902, S-NL, WB. 
Abständen das Münchner Schauspielhaus pachtete und unter Mitwirkung der dort angestellten Schauspieler innovative Stücke auf die Bühne brachte. Diese wurden dann unter Umständen ins Hauptprogramm des gut frequentierten Schauspielhauses übernommen. Heinrich Mann verweist auf Gabriele D’Annunzios (1863-1938) La città morta und Schnitzlers Der grüne Kakadu, die auf diesem Weg einem größeren Publikum vorgestellt werden konnten. ${ }^{31}$ Doch weder Heinrich noch Thomas Mann, der ebenfalls über Beziehungen zum Münchner Theater verfügte, konnten oder wollten Schaukal dort als Dramatiker etablieren. ${ }^{32}$

\subsection{Nutzen des München-Netzwerks}

Um 1902 erreichte Schaukals literarisches Schaffen einen ersten Höhepunkt. Das war auch auf seine unermüdliche und offensive Netzwerktätigkeit zurückzuführen, die ihn Anschluss an eine der pulsierenden Kulturmetropolen der Jahrhundertwende finden ließ. Doch seine gewinnbringenden Kontakte in München standen untereinander kaum in Verbindung oder richteten sich in Momenten des Konfliktes gegen ihn, wie die Auseinandersetzung Schaukals mit Thomas und Heinrich Mann zeigt. Franz Blei sei ihm, Thomas Mann, „nur flüchtig aus der ,Insel‘ bekannt; persönlich weiß ich nichts von ihm“, so der Mitarbeiter Albert Langens in einem Brief vom 14. November 1901, „nicht einmal, ob er in München lebt.“33

In den Jahren 1901/1902 tauschten sich auch erstmals Stefan Zweig und Schaukal wegen der Vorbereitung einer Verlaine-Anthologie aus. Der Briefverkehr zwischen Zweig und Mann setzte erst 1911 ein, aus diesem Jahr stammt der älteste gegenwärtig bekannte Brief der Korrespondenz. ${ }^{34}$ In den insgesamt 58 Schriftstücken fällt der Name Schaukal ebenso wenig wie im Briefwechsel zwischen Zweig und Alfred Kubin, der immerhin zu Schaukals wenigen treuen Freunden zählte. ${ }^{35}$

Anhand der Korrespondenzen mit Thomas und Heinrich Mann erschließt sich einerseits Schaukals Netzwerkstruktur, die andererseits verdeutlicht, wie

31 Vgl. den Brief Heinrich Manns an Schaukal, 11. Mai 1902, S-NL, WB.

$32 \mathrm{Zu}$ Schaukals Wirken als Dramatiker vgl. Cornelius Mitterer: „... mein Behagen und meine Heiterkeit wuchsen von Seite zu Seite“ - Richard Schaukal und das Theater. In: Interplay. A Journal of Languages, Linguistics, and Literature, 1. Jg., Nr. 2 (Mai 2016), S. 43-62.

33 Brief Th. Manns vom 14. November 1901 an Schaukal, in: Girardi (Hg.): Thomas Mann: Briefe an Richard Schaukal, S. 32 (TMSch 6).

34 Vgl. Katrin Bedenig und Franz Zeder (Hg.): Thomas Mann - Stefan Zweig. Briefwechsel, Dokumente und Schnittpunkte. Frankfurt am Main 2016.

35 Vgl. Franz Hamminger und Klemens Renoldner (Hg.): Alfred Kubin - Stefan Zweig. Briefwechsel 1909-1937. Mit einem Essay von Helga Thieme. Brunnenthal 2015. 
sein Netzwerkmanagement die Positionenwechsel im literarischen Feld aktiv mitbestimmte. Die Kontakte lassen sich in erster Linie als dünne und uniplexe Netzwerke bezeichnen. Das bedeutet, dass seine Briefpartner untereinander wenig Austausch hatten und kein dichtes Beziehungsgeflecht bildeten, selbst der Kontakt zwischen den Brüdern Mann gestaltete sich bekanntlich schwierig und war seit 1904 von zunehmender Entfremdung geprägt. ${ }^{36}$ Der Verfasser der Buddenbrooks und Schaukal pflegten zwischen 1900 und 1905 einen Briefwechsel, von dem lediglich Manns Korrespondenzen erhalten sind. Es wird jedoch klar, dass sich beide Akteure berufliche wie ästhetisch-intellektuelle Vorteile voneinander versprachen. Nur einen Monat später, im November 1900, setzte der knapp drei Jahre anhaltende Briefwechsel mit Heinrich Mann ein, von dem ebenso Schaukals Schriftstücke fehlen.

Thomas und Heinrich Manns Lobesworte für Schaukals Werk sind unter einem anderen Licht zu betrachten, sobald man auf die parallel dazu laufende Korrespondenz der Brüder blickt. So schreibt Thomas Mann am 25. November 1900:

Schaukal ist ein kurioser Kauz. Mir hat er ebenfalls seine Werke geschickt und sein Portrait dazu: wahrscheinlich infolge seiner Bekanntschaft mit Lobgott Piepsam [d.i. die Hauptfigur in Thomas Manns Der Weg zum Friedhof]. Weißkirchen liegt in Mähren, und S., reich verheiratet, bekleidet dort, wie ich höre, ein staatliches Amt. Gott weiß, was er an mir findet, denn daß er Dir viel näher steht, ist ja sicher. Ich habe bei flüchtigem Durchblättern seiner Bücher manches Ansprechende gefunden; aber ich lese Verse überhaupt sehr schlecht, und mein Tolstojismus läßt mich beinahe schon Reim und Rhythmus als ruchlos empfinden. ${ }^{37}$

Thomas Manns Faszination für die Wiener Autoren der Jahrhundertwende, denen er sich ästhetisch nahe fühlte, ${ }^{38}$ könnte, abgesehen von der Tatsache, dass er in Schaukal einen geeigneten Literaturvermittler sah, der Grund dafür gewesen sein, dass er diesen nicht einfachen Kontakt mehrere Jahre lang pflegte. Die Korrespondenz wurde von Thomas Mann beendet, als Schaukal dessen

36 Vgl. Peter de Mendelssohn: Der Zauberer. Das Leben des deutschen Schriftstellers Thomas Mann. Erster Teil: 1875-1918. Frankfurt am Main 1996, S. 910-911.

37 Hans Wysling (Hg.): Thomas Mann - Heinrich Mann. Briefwechsel 1900-1949. Frankfurt am Main 1995, S. 62-63. Vgl. auch Andreas Wicke: „Schaukal ist ein kurioser Kauz“. Zum Verhältnis Thomas Manns zu Richard Schaukal. In: Eros Thanatos, Bd. 1 (1997), S. 105-112; sowie Franz Zeder: ,Erlebtheit‘ versus ,Mache‘. Die Richard Schaukal-Thomas Mann-Kontroverse im Spannungsfeld zwischen ,Dichter‘ und ,Literat‘. In: Eros Thanatos, Bd. 3-4 (1999/2000), S. 51-70.

38 Vgl. Joëlle Stoupy: ,Brüder in der Zeit‘. Über Thomas Mann und Hugo von Hofmannsthal. In: Überschreitungen. Dialoge zwischen Literatur- und Theaterwissenschaft, Architektur und Bildender Kunst. Festschrift für Leonhard M. Fiedler. Hg. von Jörg Sader und Anette Wörner. Würzburg 2002, S. 163-169. 
Renaissance-Drama Fiorenza negativ rezensierte. Diese Kritik hat zum abrupten Bruch einer generell nicht sehr starken Verbindung beigetragen. Abgesehen von einem kurzen Treffen in München entwickelte sich die Beziehung schriftlich und in einem uniplexen Verhältnis. Während der Jahre, die der Briefwechsel andauerte, steigerte sich Thomas Manns Bekanntheitsgrad beträchtlich, sodass er auf Schaukals Kritikertätigkeit nicht mehr angewiesen war. Dieser erhoffte sich jedoch weiterhin Rezensionen seiner Werke und die Vermittlung an ein angesehenes deutsches Verlagshaus, da die Lage für Dichter in Österreich nicht gerade vielversprechend war. ${ }^{39}$

Schaukals Kritik am Renaissancismus besiegelte nicht nur das Ende des brieflichen Austausches mit Thomas, sondern zwei Jahre vorher auch mit Heinrich Mann. Offenbar hatte sich Schaukal zu Die Göttinnen oder Die drei Romane der Herzogin von Assy (1902) wegen des darin verarbeiteten historisierenden Italienbildes negativ geäußert. ${ }^{40}$ Darauf konfrontierte Heinrich Mann den österreichischen Kritiker und Dichter mit dessen eigener Epochen- und Traditionenfixierung. ${ }^{41}$ Eventuell wurde Schaukal von Thomas Mann zu diesen Äußerungen angeregt, der in einem Brief - den Empfänger zur Verschwiegenheit gemahnend - das Werk seines älteren Bruders kritisiert hatte. ${ }^{42}$ Thomas Mann brachte diese Indiskretion zur Sprache:

Für Ihren schönen Aufsatz in der „Rheinisch-Westf. Zeitung“ schulde ich Ihnen noch meinen Dank, der herzlicher ausfallen würde, wenn Sie mich durch den Ausfall gegen meinen Bruder, zu dem Sie sich verleiten ließen, nicht so sehr in Verlegenheit gesetzt hätten. Habe ich Ihnen je Veranlassung gegeben, zu glauben, ich könnte, besonders wenn von mirselbst [sic!] die Rede ist, an einer Herabsetzung der Leistungen meines Bruders Wohlgefallen haben oder sie irgend gutheißen ${ }^{43}$

Während der Briefwechsel mit Schaukal noch zwei Jahre andauerte, endete der Kontakt zu Heinrich Mann an diesem Punkt, auch wenn Schaukal mit einer (nicht erhaltenen) schriftlichen Erklärung die Wogen zu glätten versuchte, wie Thomas Manns Schreiben vom 25. September $1903 \mathrm{zu}$ entnehmen ist:

39 Vgl. den Brief Manns vom 8. Januar 1901 an Schaukal, in: Girardi (Hg.): Thomas Mann: Briefe an Richard Schaukal, S. 36 (TMSch 10).

40 Vgl. Pietzcker: Richard von Schaukal, S. 201.

41 Vgl. den Brief Heinrich Manns an Schaukal, 27. September 1903, S-NL, WB.

42 Am 26. Januar 1903 schreibt Thomas Mann an Schaukal: „Was den Roman meines Bruders betrifft, so gestehe ich Ihnen, daß ich dieses Buch nur mit dem heftigsten inneren Widerstande lese. Nichts auf der Welt ist mir fremder. Selbst dem d'Annunzio fühle ich mich noch verwandter"; Girardi (Hg.): Thomas Mann. Briefe an Richard Schaukal, S. 61 (TMSch 33).

43 Brief Th. Manns an Schaukal, in: Girardi (Hg.): Thomas Mann: Briefe an Richard Schaukal, S. 76 (TMSch 46). 
Ihren Brief haben mein Bruder und ich neulich, nachdem wir die Duse gesehen, im Rathskeller bei einem guten Glase Wein mit einander gelesen und Ihrer mit warmen Empfindungen gedacht. Ihre Ehrlichkeit, Ihre Leidenschaft leuchtete zu klar aus diesem Schreiben hervor, als daß Einer von uns Ihnen noch böse sein könnte [. . . ${ }^{44}$

Im Gegensatz zu multiplexen Verbindungen, die einen hohen Grad an Konformität, sozialer Kontrolle und Konfliktlösungsbereitschaft bewirken, prallen in uniplexen Netzwerken die Interessen von Streitparteien unmittelbar aufeinander. In diesen dünn besaiteten Strukturen wird der sozialen Beziehung zum Widersacher ein geringerer Wert beigemessen als der Erfüllung von Eigeninteressen. ${ }^{45}$ Dies ist im Verhältnis zwischen Thomas Mann und Schaukal ersichtlich. $\mathrm{Zu}$ einem Zeitpunkt, als beide Akteure publizistischen Tätigkeiten nachgingen, um die Etablierung im literarischen Feld voranzutreiben, profitierten sie vom Informationsaustausch. Der Kontakt zwischen Schaukal und Thomas Mann ist trotz aller persönlichen Färbung und dem literaturästhetischen Austausch - über weite Strecken als Geschäftskorrespondenz zu lesen. Beide Dichter sahen um 1900 im jeweils anderen einen potentiellen Garanten für die vorteilhafte Karriereentwicklung. Aber erst Beziehungen, die zwischen mehreren Netzwerken eine Brücke schlagen und somit strukturelle Löcher (zum Beispiel Informationsdefizite) schließen, tragen entscheidend zu einem Informationsvorsprung bei, aus dem dann alle weiteren Kapitalsorten akquiriert werden. ${ }^{46}$ Schaukal konnte aus Thomas Manns Sicht eine solche Brückenfunktion nach Wien nicht erfüllen, da dieser ihm anfangs ungefähr ebenbürtig und später sogar unterlegen war. In der Beziehung zwischen Mann und Schaukal stellte sich spätestens 1904, als der deutsche Schriftsteller zu einem der erfolgreichsten Autoren des deutschsprachigen Raumes aufgestiegen war, eine netzwerkstrukturelle Schieflage ein. Verlief der Austausch in den ersten Jahren noch symmetrisch, da beide von den Informationen und Vermittlungsanstrengungen des anderen profitierten, nahm der Austauschprozess bald darauf eine asymmetrische Wendung. Während Schaukal in knapp zweieinhalb Jahrzehnten 13 (anfangs positive, ab der Zwischenkriegszeit negative) Rezensionen von Thomas Manns Werken verfasste, ${ }^{47}$ befasste sich jener nie öffentlich mit Schaukals Wirken. Mit seinem Erfolg wurden Mann die Bittsuchen des Wiener Kollegen sichtlich zuwider. ${ }^{48}$

44 Brief Th. Manns an Schaukal in: Girardi (Hg.): Thomas Mann: Briefe an Richard Schaukal, S. 78 (TMSch 47).

45 Vgl. Schweizer: Muster sozialer Ordnung, S. 115-116.

46 Vgl. Schweizer: Muster sozialer Ordnung, S. 123.

47 Vgl. Girardi (Hg.): Thomas Mann: Briefe an Richard Schaukal, S. 209-210.

48 Vgl. den Brief Manns vom 14. Oktober 1905 an Schaukal, in: Girardi (Hg.): Thomas Mann: Briefe an Richard Schaukal, S. 107-109 (TMSch 75). 
Neben der asymmetrischen Netzwerkstruktur beeinflusste vor allem auch die kognitive Netzwerkkategorie Neid Schaukals Bestrebungen im dichterischen Feld negativ. In den Intérieurs setzte er sich mit diesem Thema auseinander und lieferte dabei eine treffende Selbstanalyse:

Es gibt nichts Häßlicheres als den Neid. Und der Neid ist zu allem fähig. . . Diese bösen Menschen kommen alle vom Neide. Sie geben dir das nie zu [...]. Du willst ihnen aus Liebe für den allzubeschämten Menschen in ihnen diese groben Beispiele nicht sagen [Schaukal meint damit seine Kritikerurteile, CM]. Aber ich rate dir: Sag sie ihnen! Sag sie ihnen nur ins Gesicht. Erschrick nicht über deine Herbheit. Sei rücksichtslos! Sei grausam! Sie verdienen nichts Besseres... Deine Seele wirst du ihnen ja doch nicht zeigen. $^{49}$

Im Austausch mit Mann wird des Weiteren ersichtlich, dass Schaukal die in seinen Werken häufig postulierte autonomieästhetische Programmatik nicht uneingeschränkt vertrat. Mit der provokativen Nonchalance des mittlerweile ökonomisch Unabhängigen schrieb Mann:

Lieber Freund, was liegt daran ob nun die Rundschau oder ein anderes Blatt oder zunächst gar kein Blatt Ihre Verse drucken will, was liegt an dem unmittelbaren äußeren Schicksal unserer Arbeiten! Sie haben sie gedichtet, Sie leisten täglich Neues [...]. Und beneiden Sie mich nicht um die „Absatzquellen“, die mir infolge meines „Bombenerfolges“ zu Gebote stehen! Es würde Ihnen nach einem solchen Erfolge nicht anders gehen, als mir: das anfängliche erheiterte Staunen würde bald dem Ekel weichen [...] und der Abscheu, in den modernen litterarischen „Großbetrieb“ hineingezerrt zu werden würde Sie vor der schamlosen Dienstfertigkeit der Journale, Zeitschriften, der Theater, der Verleger, vor der verliebten Zudringlichkeit des Publikums empfindlich zurückschrecken lassen. [...] Die Öffentlichkeit hat nicht das geringste Interesse an der Erziehung und Conservierung des Talentes; sie will einfach ihre Sensation. ${ }^{50}$

Mann ergänzt im selben Brief: „Niemals war es für einen ernsten Künstler, der vom Erfolg betroffen wird, in höherem Grade eine sittliche Notwendigkeit, den Erfolg zu verachten.“51

Sechs Monate nach diesem Brief beendete Mann wegen Schaukals besagter Kritik an Fiorenza den Kontakt. ${ }^{52}$ Ein Zusammenhang zwischen Manns Erfolgs-

49 Schaukal: Intérieurs aus dem Leben der Zwanzigjährigen. In: WE. Bd. 2: Um die Jahrhundertwende. München/Wien 1965, S. 31-174, hier S. 171-172.

50 Brief Manns vom 30. April 1905 an Schaukal, in: Girardi (Hg.): Thomas Mann: Briefe an Richard Schaukal, S. 101 (TMSch 70).

51 Girardi (Hg.): Thomas Mann. Briefe an Richard Schaukal, S. 101.

52 Der letzte Brief, in dem Mann Schaukal die Freundschaft aufkündigt, datiert auf den 14. Oktober 1905; vgl. Girardi (Hg.): Thomas Mann: Briefe an Richard Schaukal, S. 107-109 (TMSch 75). 
gestus in den Briefen und der Negativkritik ist denkbar. Der drohende Misserfolg seines Dramas ließ den erfolgsverwöhnten Schriftsteller nicht unberührt und zog die erwähnte öffentliche Fehde nach sich, in der Thomas Mann seinen älteren Bruder Heinrich einschaltete.

Wie Norbert Christian Wolf in seiner Arbeit darlegt, setzte sich auch Musil in Der Mann ohne Eigenschaften eingehend mit den Konkurrenz- und Marktdynamiken in den Netzwerken der literarischen Felder seiner Zeit auseinander. ${ }^{53}$ Dabei gelangte Musil zu dem ironisch gefärbten Schluss:

Die unerläßlichste Voraussetzung, um ein Großschriftsteller zu werden, bleibt also die, daß man Bücher oder Theaterstücke schreibt, die sich für hoch und niedrig eignen. Man muß wirken, ehe man das Gute wirken kann; dieser Grundsatz ist der Boden eines jeden Großschriftstellerdaseins. Und das ist ein wundersames, gegen die Versuchungen der Einsamkeit gerichtetes Prinzip, geradezu das Goethesche Prinzip des Wirkens, daß man sich nur in der freundlichen Welt regen müsse, so komme dann alles andere von selbst. ${ }^{54}$

Mit Bezug auf Thomas Manns Betrachtungen eines Unpolitischen (1918) hebt Wolf das Verfahren der „doppelten Optik“ als entscheidendes Erfolgsfaktum hervor. Der literarische Doppelerfolg gründe auf dem Prinzip, sowohl den „Artisten“ als auch den „Bürger“ mit einem Werk anzusprechen. ${ }^{55}$ Thomas Mann formulierte gegenüber Schaukal ganz ähnlich sein Anliegen, nicht nur von einer „Corona von Universitätsprofessoren“ gerühmt zu werden, ${ }^{56}$ sondern auch „aus dem Publicum“ Lob zu erhalten. „Ein ganz Naiver schrieb: ,Sie haben es verstanden, [...] mir und jedenfalls vielen anderen Durchschnittsmenschen Schiller menschlich so nahe $\mathrm{zu}$ bringen, wie er selbst es nie vermocht hat““, um dann zufrieden festzustellen: „Was will ich mehr?“57

Der Doppelerfolg gelinge, so Musils ironischer Seitenhieb auf Thomas Mann, mit einem national ausgerichteten Wirken in den „Großschriftstellerfeldern“, in dem in erster Linie „Essayisten, Biographen und Schnellhistoriker [reüssieren], die ihr Bedürfnis an einem großen Mann verrichten. “58

Wolf kommt zu dem auch für die Untersuchung Schaukals wesentlichen Schluss, dass Musil versucht habe, den eigenen Autonomieansprüchen treu zu

53 Vgl. Wolf: Kakanien als Gesellschaftskonstruktion, S. 1028.

54 Musil: Der Mann ohne Eigenschaften, S. 185.

55 Wolf: Kakanien als Gesellschaftskonstruktion, S. 1028, Fußnote 692.

56 Brief Manns vom 30. April 1905 an Schaukal, in: Girardi (Hg.): Thomas Mann: Briefe an Richard Schaukal, S. 102 (TMSch 70).

57 Brief Manns vom 13. Mai 1905 an Schaukal, in: Girardi (Hg.): Thomas Mann: Briefe an Richard Schaukal, S. 103 (TMSch 71).

58 Musil: Der Mann ohne Eigenschaften, S. 186. 
bleiben. Dieses Vorhaben mündete jedoch in einer Überforderung und Überschätzung des Lesepublikums, das einen sozialen Wandel vollzogen hatte. ${ }^{59}$ Trotz des hohen Stellenwertes von Der Mann ohne Eigenschaften erzielte Musil nicht dieselbe internationale Resonanz wie etwa Thomas Mann oder Bertolt Brecht (1898-1956), deren (auch posthume) Erfolge sich mit jener - bewusst oder indirekt eingesetzten - „doppelten Optik“ erklären ließen, die Musil im Mann ohne Eigenschaften ironisch aufgreift. ${ }^{60}$ In Abgrenzung vor allem zu Thomas Mann, dessen Werk und Wirken Wolf als entscheidende poetologische Reibfläche Musils ausmacht, wollte jener nicht sein „geistiges Kapital zu hohen Zinsen [anlegen]“, wie der Autor in Vorwegnahme der Bourdieu'schen Terminologie konstatiert. ${ }^{61}$ Musils Intention, die literarische Großform mit fragmentarisch-aphoristischer Prosa zu versöhnen, generierte kulturelles und symbolisches, jedoch kaum ökonomisches Kapital. Ähnlich verhält es sich mit Schaukals erfolgreichem Andreas von Balthesser, der zum Teil im Lichte einer doppelten Optik stand. Das Buch vertrat einen konservativen sozialpolitischen sowie einen innovativen artistischen Anspruch und erfüllte im Prinzip ,hohe“ wie ,niedere، Lesebedürfnisse. Aus diesem Grund war Andreas von Balthesser Schaukals einziger Verkaufserfolg, der auch nach seinem Tod, abgesehen von der Aufnahme in die Werkausgabe Mitte der 1960er Jahre, ${ }^{62} 1986$ von Cotta und 2013 von Minerva als wiederentdeckungswürdig erachtet und erneut auf den Markt gebracht wurde.

Wie Musil blickte auch Schaukal neidvoll und anerkennend auf den ,Großschriftssteller Thomas Mann. Mann kokettierte bereits zu Beginn des Briefwechsels mit seinem angehenden Dichterruhm. Am 1. April 1901 verkündete er, dass bald bei S. Fischer ein Roman erscheine, der wohl „drei bis vier Bände“ umfassen werde. „Ihre Tagebuch-Bemerkung, daß mehrbändige Werke Ihnen Grauen einflößen, könnten mich zwar einschüchtern“, so Mann. „Aber vielleicht war das nur damals die Ungeduld des ,Zwanzigjährigen“, und vielleicht halten Sie es jetzt bei Einem, zu dem Sie Ja sagen, auch mehrere Bände lang aus. “63

59 Vgl. Bachleitner/Eybl/Fischer: Geschichte des Buchhandels in Österreich, S. 245-247.

60 Vgl. Wolf: Kakanien als Gesellschaftskonstruktion, S. 1167-1168.

61 Robert Musil: Gesammelte Werke in neun Bänden. Bd. 8: Essays und Reden. Hg. von Adolf Frisé. Reinbek bei Hamburg 1978, S. 1199.

62 Vgl. WE. Bd. 2: Um die Jahrhundertwende. München/Wien 1965, S. 229-312.

63 Brief Manns an Schaukal, in: Girardi (Hg.): Thomas Mann: Briefe an Richard Schaukal, S. 28-29 (TMSch 3). Thomas Mann spielt auf Schaukals Intérieurs aus dem Leben der Zwanzigjährigen an, die dieser ihm zuvor zugesandt hatte. 


\title{
1.3 Verlagssuche in Zeiten politischer Umbrüche
}

Schaukal versuchte, sich bis zum Ersten Weltkrieg den ästhetischen wie gewerblichen Strukturen des literarischen Feldes im deutschen Kaiserreich anzunähern, was zu geringer Präsenz im österreichischen Verlagswesen führte. Beim befreundeten Dichter Hugo Salus (1866-1929) beklagte er sich: „Überhaupt Verleger! Ich ,geh' halt gar nicht und zerstreite mich mit jedem. Literarisch persönliche Anknüpfungen find ich nicht. Deshalb wohl weiß auch Wien (wer ist der?) nichts von mir hier. Mich langweilen Literaten. “64

Infolge der eingangs erwähnten Industrialisierungs- und Vermarktungsprozesse der Buchproduktion waren österreichische Schriftsteller besser beraten, im Nachbarland zu publizieren. In seinem 1900 publizierten Aufsatz über die neu erschienene österreichische Literaturgeschichte von Johann Nagl (1856-1918) und Jakob Zeidler (1855-1911) bringt Hermann Bahr das Verlagsdilemma zur Sprache:

\begin{abstract}
An dem Unternehmen, von dem bis jetzt drei Hefte vorliegen, hübsch ausgestattet und leserlich geschrieben, freilich ein bischen schwerer und gravitätischer, als es die Sache gerade verlangt hätte, ist zunächst eins sehr erfreulich: dass überhaupt wieder einmal ein Buch in Wien erscheint. Dies haben wir schon gar nicht mehr für möglich gehalten, so rar ist es geworden. Man bedenke doch, dass seit Jahren unsere Autoren alle mit ihren Büchern ins Exil nach Deutschland gehen müssen: man hat uns gezwungen, in der Fremde daheim zu sein. Saar bei Weiss in Heidelberg, die Ebner-Eschenbach bei Paetel in Berlin, Karlweis, Hevesi und Chiavacci bei Bonz in Stuttgart, Pötzl bei Bonz und Reclam, Burckhard, J. V. Widmann und Ebermann bei Cotta in Stuttgart, Kalbeck, Beer-Hofmann und die Marriot bei Freund und Jeckel in Berlin, die delle Grazie bei Breitkopf u. Härtel in Leipzig, die Suttner, Torresani, Dörmann, Engel, Brèe, Groller und Lothar bei Pierson in Dresden, Langmann bei Friese in Leipzig, Schaukal und Lindner bei Schuster und Löffler in Berlin, Pichler, Wertheimer und Grasberger bei Meyer in Leipzig, Schnitzler, Andrian, Altenberg, Hofmannsthal, die Fanny Gröger und ich bei Fischer in Berlin, und so weiter. Ist das nicht - sprechen wir unsere Empfindung nur aus - ist das nicht eine Schmach? Müssen wir uns nicht schämen? Nicht für uns - denn man glaubt doch nicht, dass wir uns gern verbannt haben? Aber für diese Wiener Verleger, von denen man nicht weiss: sind sie so dumm oder sind sie so faul, die besten Geschäfte auszulassen? Nun, nach und nach scheint es doch, dass sie anfangen, sich ein wenig zu besinnen, und ich denke, sie werden es nicht zu bereuen haben. ${ }^{65}$
\end{abstract}

64 Brief Schaukals an Hugo Salus, 3. Juni 1903, zit. nach Warum: Briefe eines Mährers aus Wien in die Heimat und nach Böhmen, S. 78.

65 Hermann Bahr: Oesterreichisch. In: KS. Bd. VII: Bildung. Essays. Weimar 2010, S. 83-87, hier S. 84. 
Warum aber herrschten in Österreich-Ungarn unzulängliche Verlagsbedingungen? Das hing mit ästhetischen wie sozioökonomischen und nicht zuletzt auch mit hegemonialpolitischen Dynamiken während der konstitutionellen Ära (1860-1918) zusammen. Eine auf die deutsche Sprache ausgerichtete nationalistische Politik, die besonders auch in den Bereichen der Kunst, Kultur und Bildung Vormachtstellung beanspruchte, führte zu Widerständen in den Kronländern der Monarchie. „Auch für den Buchhandel brachte die seit den siebziger Jahren [des 19. Jahrhunderts, CM] verstärkt spürbare Tendenz zu nationaler Abkapselung Probleme, sah er doch wichtige Absatzgebiete dahinschwinden und orientierte sich in der Folge noch stärker als bisher am deutschen Markt. “66 Hinzu kam eine veraltete Gesetzgebung für Buchhandel und Zeitungswesen: Das Preßgesetz vom 17. Dezember 1862 bestand bis zum Ende der Monarchie und entschärfte die Zensur nur marginal. Für Autoren, Herausgeber, Verleger und Drucker konnte das Gesetz sogar größeren finanziellen Schaden anrichten. Die Zensur musste zwar nicht mehr in die Produktionsprozesse der Veröffentlichung eines Manuskriptes eingebunden werden und diese erst genehmigen. Allerdings konnten bereits gedruckte Auflagen beschlagnahmt werden, wenn der Verdacht auf Verstöße gegen das Strafgesetz bestand, etwa bei Ehrenbeleidigung oder Verstößen gegen die öffentliche Sittlichkeit und Ruhe. Die Beschlagnahmung bereits produzierter Bücher schadete den Verlegern weitaus mehr als die Intervention der Zensur vor der Anfertigung. ${ }^{67}$

Abgesehen von dieser Verlagerung der staatlichen Zensur auf eine zunehmende Selbstzensur der Autoren und Verleger zeigte der Staat zudem wenig Interesse, das Urheberrecht zu modernisieren. ${ }^{68}$ Die Autorenrechte waren mit dem 1895 verabschiedeten Urheberrecht nur zum Teil abgesichert. Erst im Laufe des 20. Jahrhunderts wurden auch internationale Vereinbarungen getroffen, doch im deutschen Kaiserreich - mit dem Sonderabkommen für den Buchhandel bestanden waren etwa in Österreich hergestellte Übersetzungen bereits nach zehn Jahren urheberrechtsfrei. Die Weigerung des österreichischen Staates, sich internationalen Urheberrechtsabkommen (konkret: der 1886 unterzeichneten Berner Übereinkunft) anzuschließen, ist mit der Mehrsprachigkeit in der Monarchie zu begründen, die eine verstärkte Zufuhr von im Ausland produzierten und damit in Österreich höherpreisiger vertriebenen Büchern notwendig gemacht hätte. Neben diesen rechtlichen Unsicherheitsfaktoren wanderten deutschsprachige österreichische Schriftsteller ins Ausland ab, da der Schutz der Berner Übereinkunft

66 Bachleitner/Eybl/Fischer: Geschichte des Buchhandels in Österreich, S. 202.

67 Vgl. Bachleitner/Eybl/Fischer: Geschichte des Buchhandels in Österreich, S. 202.

68 Vgl. Murray Hall: Österreichische Verlagsgeschichte 1918-1938. Bd. 1. Wien/Köln/Graz 1985, S. 31. 
automatisch in Kraft trat, sobald ein österreichischer Staatsbürger bei einem Verlag im deutschen Kaiserreich unter Vertrag stand. ${ }^{69}$ Darüber hinaus lockten ein größerer Absatzmarkt und höhere Honorare in der insgesamt stärkeren MarkWährung. ${ }^{70}$

Karl Kraus war der Meinung, dass sich in Wien Feuilleton und Zeitungswesen ungünstig auf die Entwicklung des freien Schriftstellers auswirkten. Berlin verfügte hingegen über vorteilhaftere Verlagsstrukturen und somit auch über eine avancierte Literatur, die das Publikum direkter ansprechen würde. ${ }^{71}$ Bis zur Gründung des Zsolnay-Verlages im Jahr 1924 existierte in Österreich-Ungarn beziehungsweise der Ersten Republik kein nennenswerter belletristischer Verlag. Autoren suchten meist in Deutschland nach geeigneten Veröffentlichungsmöglichkeiten. ${ }^{72}$ Das trifft auch auf Schaukal zu, der den Großteil seiner Werke im Nachbarland drucken ließ und über Thomas Mann Kontakte zu Samuel Fischer und Albert Langen knüpfen wollte. ${ }^{73}$ Der ungünstigen Verlagssituation in Österreich stand ein prosperierender Markt im deutschen Kaiserreich gegenüber. Thomas Mann wunderte sich in einem Brief an Schaukal: „Ich begreife nicht, wie es Ihnen so schwer fallen kann, für Ihre Sachen Verleger zu finden. Insel-V., Seeman [sic!], Diederichs etc, - die Nachfrage ist ja zur Zeit vonseiten der Verleger größer, als von unserer!“74

Im Gegensatz zu Mann kam Schaukal bei keinem der angesehenen Kulturverlage der Zeit dauerhaft unter. Seine Publikationsliste offenbart eine kontinuierliche Suche nach dem einen, richtigen Verlagshaus. Er veröffentlichte in den frühen Jahren seines Schaffens nicht nur bei Schuster \& Löffler, einem 1895 in Berlin gegründeten Verlag, der jungen Dichtern der Neuromantik eine Publikationsmöglichkeit bot, ${ }^{75}$ sondern auch bei den in Leipzig angesiedelten

69 Österreich trat erst nach Ende des Krieges der Berner Übereinkunft bei; vgl. Bachleitner/ Eybl/Fischer: Geschichte des Buchhandels in Österreich, S. 250.

70 Vgl. Bachleitner/Eybl/Fischer: Geschichte des Buchhandels in Österreich, S. 204-205.

71 Vgl. Karl Kraus: Lieber, verehrter Herr Harden. In: Die Fackel, Nr. 2 (April 1899), S. 6-18, hier S. 8.

72 Vgl. Peter Sprengel und Gregor Streim: Berliner und Wiener Moderne. Vermittlungen und Abgrenzungen in Literatur, Theater, Publizistik. Wien/Köln/Weimar 1998, S. 31.

73 Vgl. den Brief Manns an Schaukal, in: Girardi (Hg.): Thomas Mann: Briefe an Richard Schaukal, S. 43 (TMSch 18).

74 Brief Manns vom 19. Mai 1903 an Schaukal, in: Girardi (Hg.): Thomas Mann: Briefe an Richard Schaukal, S. 67 (TMSch 38).

75 Neben Schaukal veröffentlichte Schuster \& Löffler auch Richard Dehmel, Detlev von Liliencron und Otto Julius Bierbaum. Nach dem Ersten Weltkrieg wurde der Verlag von der Deutschen Verlags-Anstalt aufgekauft. Vgl. Das Junge Wien. Österreichische Literatur- und Kunstkritik 1887-1902. 2 Bde. Hg. von Gotthart Wunberg. Tübingen 1976, Bd. 2, S. 761. 
Verlagen Hermann Seemann Nachfolger, Insel und Tiefenbach. Zu den weiteren Verlagshäusern/Verlegern, die meist aber nur ein Werk Schaukals publizierten, zählten Jakob Hegener (Leipzig), Georg Westermann (Braunschweig), Pierson (Dresden und Leipzig), Friesenhahn (Leipzig), Ferdinand Schöningh (Paderborn), Alexander Koch (Darmstadt) und Max Hesse (Leipzig).

Die Publikationsorte von Schaukals Monographien und Sammelbänden vor dem Ersten Weltkrieg zeugen von der florierenden Verlagslandschaft in Deutschland, aber auch von dem immensen Konkurrenzdruck in einem wachsenden Markt, der von den Verlegern auf die Schriftsteller übertragen wurde. Lediglich bei dem von Georg Müller (1877-1917) 1903 in München gegründeten Verlag konnte sich Schaukal zwischen 1906 und 1918 als Autor etablieren. Der auch international ausgerichtete Georg Müller Verlag war unter anderem auf literarische newcomer und neuromantische Dichter spezialisiert. In den rund 15 Jahren seines Wirkens edierte Georg Müller rund 1.900 Bücher in mehrfacher Millionenauflage. Nach seinem Tod im Jahr 1917 und aufgrund der mit dem Kriegsende einhergehenden Inflation und Papierknappheit bei gleichzeitiger Abnahme der Kaufkraft der Bevölkerung geriet der Verlag in eine Krise. ${ }^{76}$

$\mathrm{Zu}$ den wenigen österreichischen Verlagen, die Schaukal publizierten, gehörte auch der bedeutende Wiener Verlag, der zwischen 1899 und 1908 existierte. Felix Salten (1869-1945), Hermann Bahr, Hugo von Hofmannsthal, Robert Musil, Theodor Herzl (1860-1904) und viele weitere Protagonisten der Moderne veröffentlichten dort ihre Werke. Der Wiener Verlag publizierte vor allem in Deutschland verbotene Belletristik in hoher Auflage und sicherte sich damit einen nicht unwesentlichen Platz im literarischen Feld des beginnenden 20. Jahrhunderts. ${ }^{77}$ Wenn es so etwas wie einen Hausverlag für Jung-Wien gegeben hat, das sich allerdings nach 1900 als ohnehin informelle Gruppe aufzulösen begann, dann war dies der Wiener Verlag. Da Fischer eine Publikation von Schnitzlers Reigen ablehnte, veröffentlichte der Wiener Verlag 1903 erstmals den Skandaltext, von dem davor nur 200 Exemplare als Privatdruck erschienen waren. Schaukals Novellenband Eros Thanatos, der thematisch wie ästhetisch mit Schnitzlers frühen Werken vergleichbar ist, erschien ebenfalls dort im Jahr 1906 und ist Ausdruck seiner seit circa 1902 insgesamt günstig verlaufenden Positionierung im literarischen Feld. Thomas Mann hatte Schaukal in einem Brief vom 4. Oktober 1905 nahegelegt, nicht bei Fischer, sondern im Wiener Verlag zu publizieren. Dieser passe besser zu

76 Vgl. Konrad Fuchs: [Art.] Müller, Georg. In: Neue Deutsche Biographie. Bd. 18. Berlin 1997, S. 392-393.

77 Vgl. Murray Hall: Österreichische Verlagsgeschichte. Bd. 1: Entwicklung des Verlagsbuchhandels in Österreich bis 1918. Online: http://verlagsgeschichte.murrayhall.com/?page_id=38 (zuletzt aufgerufen am 31. Juli 2019). 
ihm und sei „nicht zu verachten“, schließlich würden auch die Bücher seines Bruders Heinrich dort verlegt. ${ }^{78}$

Die Verlagssuche sollte sich für Schaukal nach 1918 nicht viel einfacher gestalten. Dabei herrschten in der Nachkriegszeit Unternehmergeist und Risikobereitschaft, die bis 1925 zu vielen Neugründungen, aber auch zu Verlagskonkursen führten. ${ }^{79}$ Und selbst die steigende Inflation wirkte sich zumindest in der ersten Zeit nicht sehr drastisch auf den Umsatz im Sortiment aus. Das Buch gehörte $\mathrm{zu}$ den wenigen Konsumgütern, die nach wie vor produziert wurden. Der Mangel an Papier und die damit verbundenen geringen Auflagen waren anfangs sogar förderlich für die ökonomische wie symbolische Wertsteigerung des Buches. Spätestens seit den 1930er Jahren verzeichneten Verlage und Sortiment erhebliche Umsatzrückgänge, die allgemeine Rezession hatte auch den Buchhandel erreicht. ${ }^{80}$

Diese Entwicklungen zeichnen sich in Schaukals Publikationsliste ab. Nach 1918 veröffentlichte er nur mehr zwölf selbstständige Werke, davon acht in der bis etwa 1930 anhaltenden stabilen Phase des Buchdrucks und vier in der Krisenzeit des Buchhandels. Des Weiteren konzentrierten sich Schaukals Publikationsaktivitäten nicht speziell auf österreichische Verlage, sondern teilten sich exakt auf je sechs Verlagsorte in Deutschland und Österreich auf. ${ }^{81}$ Trotz des vor allem ab 1925 sich stabilisierenden Buchmarktes, wanderten österreichische Autoren weiter zu deutschen Verlagen ab, um von den nach wie vor besseren Honoraren und dem größeren Resonanzraum zu profitieren. ${ }^{82}$ Die politisch unruhigen 1930er Jahre wirkten sich besonders negativ auf Schaukals ökonomische Situation aus; am 19. März 1935 teilt er seinem vertrauten Leidensgenossen Kubin mit, er habe sein gesamtes schriftstellerisches Einkommen verloren und auch die unbezahlte Mitarbeit an diversen österreichischen Zeitungen eingestellt. ${ }^{83}$

\section{Publizistische Netzwerke}

Mit dem zunehmenden Einsatz von Rotations- und Falzmaschinen stiegen besonders um 1900 auch die Absatzzahlen im Zeitungsmarkt deutlich an. Als ein

78 Brief Manns an Schaukal, in: Girardi (Hg.): Thomas Mann: Briefe an Richard Schaukal, S. 106-107 (TMSch 74).

79 Vgl. Bachleitner/Eybl/Fischer: Geschichte des Buchhandels in Österreich, S. 263-267.

80 Vgl. Bachleitner/Eybl/Fischer: Geschichte des Buchhandels in Österreich, S. 277.

81 Siehe die Liste von Schaukals Werken im Anhang.

82 Vgl. Bachleitner/Eybl/Fischer: Geschichte des Buchhandels in Österreich, S. 282-283.

83 Schaukal in einem Brief an Kubin vom 19.3.1935, K-S, BSB. 
Beispiel für die technisch bedingten Innovationen der Druckverfahren gilt die Neue Freie Presse, die als erste Zeitung Europas auf Endlospapierrollen gedruckt wurde. ${ }^{84}$ Dies führte gemeinsam mit dem Anstieg der Alphabetisierungsrate zu einer „zweiten Leserevolution“ (1880-1914). ${ }^{85}$ Technologische, sozioökonomische und bildungspolitische Veränderungen vergrößerten also das allgemeine Lesepublikum, was ein verändertes Kauf- und Rezeptionsverhalten nach sich zog und Neugründungen von Printmedien in großer Zahl zur Folge hatte.

Bis zum Ersten Weltkrieg blieb die Zeitung noch vor dem Film das wichtigste klassenübergreifende Massenmedium und dementsprechend auch für den Kulturbetrieb von entscheidender Bedeutung. Gleichzeitig blickte das Wiener Zeitungswesen zu Beginn des 20. Jahrhunderts auf eine lange und lebendige Tradition sowie auf bedeutende Kritikerpersönlichkeiten zurück. Neben Daniel Spitzer (1835-1893), Friedrich Uhl (1825-1906) und Ludwig Speidel (1830-1906) setzte sich vor allem auch Ferdinand Kürnberger (1821-1879) mit dem kulturellen wie gesellschaftspolitischen Wert der Zeitung auseinander. 1873 schrieb Kürnberger:

Die Kultur erzeugt die Buchpresse, aber die demokratisierte Kultur die Zeitungspresse. Je mehr das Mittelmaß, man könnte richtiger sagen, die Mittelmäßigkeit, der literarischen Kultur ihre Ufer ausdehnt, desto gewisser ergießt sich die Literatur unaufhaltsam und stromweise aus dem Buch in die Zeitung. ${ }^{86}$

Zur selben Zeit veröffentlichte Friedrich Nietzsche seine Unzeitgemäßen Betrachtungen. Darin kritisiert er die Gleichsetzung von militärischer und kultureller Überlegenheit, die nach dem Deutsch-Französischen Krieg 1870-1871 den deutschen Geist zugunsten des Deutschen Reichs zu beseitigen drohe ${ }^{87}$ und im gesamten publizistischen Feld einen Glückstaumel ausgelöst habe:

Ich empfinde diesen Taumel und dieses Glück in dem unvergleichlich zuversichtlichen Benehmen der deutschen Zeitungsschreiber und Roman-, Tragödien-, Lied- und Historienfabrikanten: denn dies ist doch ersichtlich eine zusammengehörige Gesellschaft, die sich verschworen zu haben scheint, sich der Muße- und Verdauungsstunden des modernen Menschen, das heißt seiner „Kulturmomente“ zu bemächtigen und ihn in diesen durch bedrucktes Papier zu betäuben. ${ }^{88}$

84 Vgl. Timms: Dynamik der Kreise, S. 52.

85 Harro Segeberg: Literatur im technischen Zeitalter. Darmstadt 1997, S. 228.

86 Ferdinand Kürnberger: Glosse zum Wiener Zeitungswesen [10. Mai 1873], zit. nach Greve/ Volke: Jugend in Wien, S. 24.

87 Vgl. Friedrich Nietzsche: Unzeitgemäße Betrachtungen. Erstes Stück: David Strauss. Der Bekenner und der Schriftsteller. In: Nietzsche: Werke in drei Bänden. Hg. von Karl Schlechta. Darmstadt 1982, Bd. 1, S. 137-207, hier S. 137.

88 Nietzsche: Unzeitgemäße Betrachtungen, S. 138-139. 
Das Verhältnis des Nietzsche-Lesers Schaukal ${ }^{89}$ zur florierenden Zeitungs- und Zeitschriftenkultur des beginnenden 20. Jahrhunderts gestaltete sich - obwohl von größeren Erfolgen geprägt - ambivalenter, als zu den Buchverlagen. Er war sich dessen bewusst, dass die Zeitung zum zentralen Austragungsort für die Positionenkämpfe der literarischen Akteure avanciert war. Um den kunst- und kulturkritischen, später auch politischen Diskurs mitzugestalten und um Teil dieses Diskurses zu sein, war eine aktive Partizipation mit Kommentaren, Glossen, Rezensionen und literarischen Beiträgen unabdingbar. In dem bereits erwähnten Artikel „Wien ohne Zeitung“ ironisierte Anton Kuh 1918 die unzertrennliche Raumsyntax von Wien, Zeitung und Kaffeehaus: Wien ohne Zeitung, so Kuh, „das heißt: Wien ohne Wien. Denn die Zeitung ist Wien, Wien eine Zeitung. Die Stadt lebt erst dann, wenn sie sich gedruckt liest.“ Bemerkenswert ist Kuhs Vorwegnahme der poststrukturalistischen Position, dass Diskurse jene Sachverhalte erzeugen, die sie zunächst abbilden. Streik, Krieg oder die „Klauenseuchen aus dem Gmündner Bezirk“ sind in ihrer Dringlichkeit nicht auseinanderzuhalten und sogar inexistent, sobald die Leserschaft auf Urlaub weilt, so die satirische Pointe Kuhs. $^{90}$

Dass sich die Konflikte allerdings nicht allein auf Auseinandersetzungen im diskursiven Raum beschränkten, musste der Verleger des Neuen Wiener Tagblatts Moritz Szeps (1835-1902) am eigenen Leib erfahren. Szeps war in besonderem Maße antisemitischen Anfeindungen durch Georg von Schönerer (1842-1921) ausgesetzt, die unter anderem zur Verwüstung seiner Redaktionsräume führten. Politisch-ideologische Grabenkämpfe und die nach wie vor prävalenten Zensurmaßnahmen dämmten das sich ausbreitende Medium jedoch nicht ein, ${ }^{91}$ und der Aufstieg der Presse brachte ein stetig wachsendes Heer von Journalisten hervor. Auch Schriftsteller, die sich selbst als Buchautoren verstanden, konnten nicht länger an den Verlockungen der vergleichsweise hohen Honorare vorbeisehen. ${ }^{92}$ Autoren und Autorinnen wie Ada Christen (1839-1901) fanden in der Unterhaltungsliteratur zwar ihr Auskommen, doch die Akzeleration der Produktionsprozesse und die dem Quantitätsprinzip folgende Entlohnung per geschriebener Zeile begünstigten das „literarische Manchestertum“ des Pressebetriebs, in dem sich die „Phrase“ ausbreiten konnte, so die kulturkritische Polemik von Karl Kraus. ${ }^{93}$ Die Industrialisierung stellte also nicht nur

\footnotetext{
89 Vgl. Pietzcker: Richard von Schaukal, S. 76-77.

90 Kuh: Zeitgeist im Literatur-Café, S. 26-29.

91 Vgl. Lorenz: Wiener Moderne, S. 34-35.

92 Vgl. Bachleitner/Eybl/Fischer: Geschichte des Buchhandels in Österreich, S. 235.

93 Karl Kraus: Die Vertreibung aus dem Paradiese. In: Die Fackel, Nr. 1 (April 1899), S. 12-23, hier S. 15.
} 
das Kleinhandwerk, sondern auch den Literaturbetrieb und seine Akteure vor den Scheideweg, „entweder starr an traditionellen Fertigungsweisen [festzuhalten] und damit ins soziale Abseits [zu geraten], oder aber sich den standardisierten Technologien [auszuliefern], selten als selbständige Fabrikanten, meist als subalterne Arbeiter." 94

In der Folge häuften sich metakritische Reflexionen über die Mediatisierungsprozesse. Die Branche steigere die Kommerzialisierung der Literatur, Konkurrenzdruck und Zeitmangel verringerten den Qualitätsanspruch, so die Vorwürfe, die bis auf Kürnberger zurückgehen. ${ }^{95}$ Ambitionierte Schriftsteller konnten sich um 1900 den merkantilen Bedingungen noch viel weniger entziehen, als die der vorangegangenen Generationen. Abgesehen von Karl Kraus verfügten wenige Akteure zugleich über die finanziellen Möglichkeiten wie unternehmerischen und auch literarischen Qualitäten, um die essentielle Instanz des künstlerischen Feldes autonom mitgestalten zu können.

Schaukal versuchte bereits in jungen Jahren, das Medium für seine Zwecke zu verwenden. In einem frühen Zeitungsaufsatz von 1899 bezieht er Stellung gegen die angesprochenen Entwicklungen: „Über die Forderung von sogenannten Gedanken in der Dichtung“ ist eine pessimistische Zeitdiagnose, in der sich der Verfasser gegen die Vermarktung von Literatur und gegen die massenwirksame Verbreitung von Kunst durch das Feuilleton ausspricht. ${ }^{96}$ Der bereits erwähnte Beitrag erschien in der Wiener Rundschau, die während ihres fünfjährigen Bestehens auch Gedichte von Vertretern des Jungen Wien publizierte. Werke von Schaukal, Hofmannsthal, Altenberg, aber auch Kraus' Kritik an Jung-Wien (Die demolirte Literatur) sind im ersten Jahrgang der Kulturzeitschrift verewigt. Ihre programmatische Ausrichtung stimmt mit der zeit- und kulturkritischen Auffassung des jungen Schaukal überein. In Heft 1 des dritten Jahrgangs (1898/1899) formuliert die Wiener Rundschau ihre Mission:

Sie will überdies zu einer Zeit, da das Verständnis des Wesens der Kunst fast gänzlich abhandengekommen ist, der Kunst an sich eine Zufluchtstätte bieten, gänzlich entrückt den Masstäben, welche die herrschende Halbbildung, auf ihre materielle Macht gestützt, auch an die Werke der Kunst zu legen geneigt ist. Das Gefühl für Distanzen, für Zwischenräume und Rangunterschiede, diese Grundlage jeder Cultur, ist uns verloren gegangen;

94 Reinhard Wittmann: Geschichte des deutschen Buchhandels. Ein Überblick. München 1991, S. 257.

95 Vgl. Oliver Pfohlmann: Literaturkritik in der literarischen Moderne. In: Literaturkritik. Geschichte, Theorie, Praxis. Hg. von Thomas Anz und Rainer Baasner. München 2004, S. 94-113, hier S. 104-105; vgl. auch Mitterer: Richard Schaukal - Literaturkritiker der Moderne, S. 55.

96 Vgl. Schaukal: Über die Forderung von sogenannten Gedanken in der Dichtung. In: Wiener Rundschau, 3. Jg, Nr. 7 (15. Februar 1899), S. 171-173. 
die Pfaidler schwatzen über die Wissenschaft, und die Handwerksleute der öffentlichen Meinung über die Kunst; ohne die Stütze einer sicheren Weltanschauung verliert die Gegenwart die Fähigkeit Werte zu beurtheilen; im Schlamm der alles überflutenden Mittelmässigkeit versinkt die Ehrfurcht vor dem Recht der Persönlichkeit. Der dereinstigen Herrschaft der Geistigen die Wege zu bahnen:das war und ist unser Programm. ${ }^{97}$

Neben der Wiener Rundschau publizierten auch andere Blätter in unregelmäßigen Abständen Beiträge von Jung-Wien. An der schönen blauen Donau (1886-1896), die 1890 in Brünn gegründete Moderne Dichtung, die nach einem Jahrgang in Wien als Moderne Rundschau für ebenfalls nur ein Jahr erschien und dann in Berlin als naturalistische Freie Bühne für den Entwicklungskampf der Zeit fortgesetzt wurde, außerdem die Wiener Literaturzeitung (1891-1893), die Liebelei (1896) und eben die Wiener Rundschau (1896-1901): Sie alle zeugen von einem schnelllebigen Markt, der durch Konkurrenzdruck und eine hohe Frequenz an Gründungen, Neugründungen und Konkursen geprägt war.

Im Feld der literarisch ausgerichteten Zeitschriften wiederholte sich die marginale Rolle österreichischer Verlage. Das aus der Neuen Revue (1893-1898) hervorgegangene Wochenblatt Die Waage steht symptomatisch für einen allgemeinen Schwerpunktwechsel von literarisch-kulturellen zu vermehrt tagespolitischen und wirtschaftlichen Inhalten. ${ }^{98}$

Mit Blick auf den Hochbetrieb im Zeitungswesen spielte für die Verbreitung der Werke Jung-Wiens und für die theoretischen Vorgaben der Moderne Hermann Bahr eine gewichtige Rolle als Stichwortgeber und Literaturvermittler. Als einflussreicher Akteur in - und Mitinitiator des Kulturtransfers zwischen Berlin, Paris und Wien lenkte er sowohl die Zirkulation bestimmter Themen und Programme als auch die Erfolge der von ihm protegierten Dichter und beeinflusst somit bis heute das Bild der Literatengruppe Jung-Wien. ${ }^{99}$ Das 1894 von Bahr, Isidor Singer (1857-1927) und Heinrich Kanner (1864-1930) gegründete Wochenblatt Die Zeit stellte eine wichtige Publikationsmöglichkeit für die Akteure des Jungen Wien dar; die ästhetische Ausrichtung bestimmte ihr leitender Kulturredakteur - Hermann Bahr. ${ }^{100}$ Solchen dynamischen und prozessualen Bemühungen um kulturelle beziehungsweise literarische Vermittlung standen Ausschlussmechanismen gegenüber, die - ob aus qualitativen, strategischen

97 Wiener Rundschau H. 1, 3. Jg. (1898/1899). Hervorh. im Orig. durch Sperrschrift. Pfaidler war die Bezeichnung für Hemdenmacher und wird hier ironisch verwendet, um einen Kontrast zwischen den Berufsgruppen (Handwerker und Wissenschaftler) herzustellen. Gemeint ist damit der ,Laie‘.

98 Vgl. Lorenz: Wiener Moderne, S. 106-107.

99 Vgl. Sprengel/Streim: Berliner und Wiener Moderne, S. 103.

100 Vgl. Lorenz: Wiener Moderne, S. 107. 
oder subjektiven Gründen - auch Schaukal erfahren musste. ${ }^{101}$ Wie aus einer Postkarte Strobls vom 16. Juli 1904 hervorgeht, hatte Schaukal den Redakteur der Zeit um eine Besprechung seiner Novelle Mimi Lynx gebeten. ${ }^{102}$ Zwei Monate später musste Strobl Schaukal jedoch berichten, ihm sei mündlich mitgeteilt worden, dass die Zeitung für „ein so minderes Talent keine Reklame mache.“103

Nichtsdestotrotz suchte Schaukal weiter nach Wegen, kritische und literarische Beiträge öffentlichkeitswirksam zu positionieren. Der Großteil seiner Kontaktpflege war von der Absicht bestimmt, mit dichterischen oder essayistischen Beiträgen in verschiedenen deutschsprachigen, aber auch internationalen Periodika zu erscheinen. Dieser Widerspruch zwischen schriftstellerischer Ambition und autonomieästhetischer Medienkritik wurde bereits von Schaukals Kollegen ironisiert: In seiner Rezension von Großmutter merkt Franz Eckardt süffisant an, dass Schaukal ihm das Buch habe zukommen lassen, obwohl er die „Zeitungsschreiber“ doch eigentlich verachte. ${ }^{104}$ Auch Armin Friedmann (1863-1939) lässt es sich nicht nehmen, in einer an Schaukals Giorgione angelehnten DialogRezension festzuhalten: „Aber - er ist auch ein ganz brillanter Journalist. Im besten Sinne des verrufenen Wortes. Wer für die Zeitung schreibt, gern schreibt, oft schreibt, gut und viel schreibt, den darf man doch wohl einen Journalisten nennen, und wenn er es unter dem Strich tut, einen Feuilletonisten.“105

\subsection{Simplicissimus}

Schaukals publizistische Anfänge waren literarisch motiviert. Im ersten Jahrgang des Simplicissimus ist 1896 neben dem Gedicht „Frühling“ seine Karikatur „Statt einer Kritik. Junge Lyrik“ abgebildet. Bis zu seinem Tod veröffentlichte Schaukal

101 Leonhard Adelt rezensierte Schaukal 1902 in der Wochenzeitung Die Zeit, Bd. 32, Nr. 412 (23. August 1902), S. 120; Schaukal veröffentlichte in derselben Nummer der Zeit einen Aufsatz mit dem Titel „Der Baron Clemens M. erzählt der Gräfin Kathi F.“ (ebd., S. 127-128). Zu unterscheiden ist in diesem Jahr die Wochenzeitung von der Tageszeitung mit demselben Titel, die 1894-1904 wöchentlich am Samstag beziehungsweise 1902-1919 täglich in Wien erschien. Ab 1904 wurde die Wochenzeitung als Österreichische Rundschau (1904-1924) weitergeführt.

102 Vgl. Schreiben Strobls an Schaukal vom 16.71904, S-NL, WB.

103 Brief Strobls an Schaukal, 18. August 1904, S-NL, WB.

104 Franz Eckhardt: „Großmutter“. In: Salzburger Chronik, Nr. 203, 43. Jg (7. September 1907), S. 1-3.

105 Armin Friedmann: Vom Kunst-Dichter. Ein Gespräch zwischen einer feingebildeten Dame und einem trockenen Fachmenschen. In: Wiener Abendpost. Beilage zur Wiener Zeitung, Nr. 55/1907 (7. März 1907), S. 1-3, hier S. 1. 
in unregelmäßigen Abständen Beiträge in der Münchner Satirezeitschrift mit der roten Bulldogge. ${ }^{106}$ Das von Albert Langen - „eine noch nicht geklärte Mischung von Mäzen und Geschäftsmann“107 - gegründete Blatt entwickelte sich vor allem in der frühen Phase seines Bestehens zum Sprachrohr für subversive, satirische und moralische Beiträge ersten Ranges. ${ }^{108}$ Die „große Zeit“ der Zeitschrift beläuft sich auf die Jahre zwischen 1896 und 1914, danach übernahm der Simplicissimus die nationalpatriotische Vorgabe des Deutschen Reichs, rief dazu auf, Kriegsanleihen zu zeichnen und versank während des Nationalsozialismus in linientreue Bedeutungslosigkeit. ${ }^{109}$

In der Frühphase veröffentlichte der Simplicissimus literarische und gezeichnete Beiträge von Künstlern, zu denen Schaukal dann auch Kontakte knüpfte oder bereits geknüpft hatte, etwa Richard Dehmel (1863-1920), Thomas Theodor Heine (1867-1949), Alexander Roda Roda (1872-1945), Hermann Hesse, Arno Holz, Karl Kraus, Alfred Kubin, Heinrich und Thomas Mann, Rainer Maria Rilke, Hugo Salus und Arthur Schnitzler, sodass von einer Einbindung Schaukals in das Simplicissimus-Netzwerk durchaus die Rede sein kann. ${ }^{110}$

Mit Blick auf Schaukals frühe Erfolge in der angesehenen Gazette stellte Claudia Girardi zu Recht die Frage: „Wie kommt dieser junge, relativ unbekannte Verfasser reichlich pathetischer unausgereift-schwermütiger Reimereien in den Simplicissimus zwischen die Frank Wedekinds, Thomas Manns, Peter Altenbergs, Richard Dehmels und gar Georg Herweghs?“111 Zum einen, weil Schaukal nach der ästhetischen Mode der Zeit schrieb. Andererseits erfüllte der junge Dichter mit einer zwischen selbstironischer Persiflage und innovativer Tonalität changierenden Lyrik genau die programmatischen Erwartungen des Simplicissimus, vor allem Albert Langens. Der Verleger akzeptierte zwar bei weitem nicht jeden der von Schaukal eifrig nach München gesandten Beiträge. Allerdings zeugen die 15 zum Teil mit Zeichnungen Th. Th. Heines versehenen Veröffentlichungen in der ,großen Zeit' des Simpl von einem nicht unerheblichen

106 Alle Ausgaben sind online abrufbar unter www.simplicissimus.info (zuletzt aufgerufen am 31. Juli 2019).

107 Hermann Sinsheimer: Der Simplicissimus. In: Literatur in Bayern, Sonderheft Simplicissimus (1996), S. 4-16, hier S. 4.

108 [Anon.]: Der Name Simplicissimus und die Entstehung der satirischen Zeitschrift. In: Literatur in Bayern, Sonderheft Simplicissimus (1996), S. 2-3.

109 Sinsheimer: Der Simplicissimus, S. 16.

110 Versuchte sowie einmalige Kontaktaufnahmen beziehungsweise nicht mehr auffindbare weitere Korrespondenzstücke betreffen Emanuel von Bodman (1874-1946) und Selma Lagerlöf (1858-1940).

111 Claudia Girardi: Schwüle Leidenschaft. Richard Schaukal und der „Simplicissimus“. In: Literatur in Bayern, Sonderheft Simplicissimus (1996), S. 67-69, hier S. 67. 
Erfolg des angehenden Dichters. Doch auch dieses Netzwerk war von uniplexer, nicht sehr dichter Struktur, die aus dem symbolischen Kapital - ein Dichter der vielbeachteten Zeitschrift in einer pulsierenden Metropole Europas zu sein - kaum Vorteile für das Wirken im literarischen Feld einbrachte. Immerhin nahm Alexander Roda Roda Schaukal in seine Humor-Anthologie auf, und auch Rilke versuchte, ihn für sein eigenes Zeitschriftenprojekt Wegwarten als Mitarbeiter zu gewinnen. Spätestens mit dem Ende der Monarchie hatten sich diese Kontakte jedoch verflüchtigt.

Ein gelungenes Beispiel für eine über die Netzwerke zustande gekommene Vermittlung ist Thomas Manns Intervention beim Chefredeakteur des Simplicissimus Reinhold Geheeb. Vom Kollegen gedrängt, veröffentlichte dieser schließlich weitere Gedichte Schaukals, die in der Schreibtischschublade zu verstauben drohten. Mann war vermutlich auch deshalb erfolgreich, weil zwischen ihm und Geheeb ein doppelter Konnex bestand; sie waren nicht nur über den Simplicissimus miteinander verbunden, sondern beide auch Mitarbeiter beim LangenVerlag, begegneten sich also regelmäßig in den jeweiligen Redaktionsbüros. $\mathrm{Ob}$ Hermann Hesses Tätigkeit als Redaktionsmitglied (seit 1905) ausschlaggebend für Schaukals Veröffentlichungen im Simplicissimus war, lässt sich kaum mehr ermitteln. Im seit 1903 geführten Briefwechsel deuten lediglich die Nennung des Mitarbeiters Carl Busse (1872-1918) sowie ein aus dem Redaktionsbüro der Zeitschrift abgeschickter Brief Hesses an Schaukal auf das Münchner Satireblatt hin. $^{112}$

\subsection{Jugend}

Eine weitere, wie auch der Simplicissimus 1896 in München gegründete Kunstund Literaturzeitschrift, zu der Schaukal erst einige Jahre später Zugang erhielt, ist die Jugend, die Namensgeberin der Kunstrichtung Jugendstil. Zwar trug sie nicht so entscheidend zu den literarischen Impulsen der frühen Moderne in München bei wie der Simplicissimus. Doch trotz der vordergründig konservativ-bürgerlichen Ausrichtung zählte sie vor allem in der Frühphase ihres Bestehens zu den Verkünderinnen eines künstlerischen Aufbruchs, der die Überwindung des gründerzeitlichen Historismus zum Ziel hatte. ${ }^{113}$

112 Vgl. den Brief Hesses an Schaukal, 28. Oktober 1902, S-NL, WB.

113 Alle Ausgaben von Jugend sind online abrufbar unter http://www.jugend-wochenschrift. de/index.php?id=24 (zuletzt aufgerufen am 31. Juli 2019). 
Unter dem Pseudonym ,Karlchen` bezieht sich 1904 ein Autor der Zeitschrift dezidiert auf zwei Kronzeugen des Antihistorismus: auf Stefan George und Richard Schaukal. Das Stilempfinden des Verfassers sei an diesen beiden geschult, deshalb könne er auch den „mittelmäßigen Poeten und schlechten Historikern“ nichts abgewinnen, so ,Karlchen'. Die Rede ist hier - und das dürfte Schaukal geschmeichelt haben - von Friedrich Schiller. ${ }^{114}$

Kunst und Leben kamen gemäß der ästhetischen Linie um 1900 säuberlich getrennt voneinander zur Sprache. „Die ,Jugend“ ist somit als Publikation zu beschreiben, die avantgardistisch ist, ohne doch agitatorisch zu sein.“115 $\mathrm{Ab}$ 1914 häuften sich Beiträge, die in patriotischer Diktion den Krieg befürworteten. Zwar konnte die Jugend in den 1920er Jahren unter der Ägide des Schriftleiters Franz Schoenberner (1892-1970) an die avantgardistischen Ansprüche der frühen Zeit anknüpfen, doch zugleich sank die Auflagenzahl erheblich. In den 1930er Jahren fiel sie der Gleichschaltung zum Opfer, ehe sie 1940 ganz eingestellt und ihr verantwortlicher Redakteur Arnold Weiss-Rüthel (1900-1949) ins Konzentrationslager Sachsenhausen deportiert wurde. ${ }^{116}$

Während Jugend in den ersten fünf Jahren ihres Bestehens keinerlei Notiz von Schaukal nahm, führte die von Vogeler gestaltete Veröffentlichung von Pierrot und Colombine im Jahr 1902 erstmals zu einer Nennung seines Namens. Dabei offenbarte das Blatt seine satirisch-kritische Schärfe, die sich gegen die prätentiöse Aufmachung des Buches richtete. Unter dem Titel „Kaviar fürs Volk“ wurde Schaukals „schwindsüchtiges Bändchen“ als ebenso „naiv“ wie in seiner luftigen Gestaltung anmaßend bezeichnet. ${ }^{117}$ Schaukal entgegnete dem Vorwurf der Ausstattung Anfang 1904 in der Wiener Zeitung: ,[M]an spare nicht mit weißen Blättern (drucke nicht - scheußlicher Mißbrauch - auf die letzte Seite Anzeigen); sie sind Schmuck und Schutz zugleich.“118

Zwischen 1905 und 1909 lieferte Schaukal 16 Beiträge für die Zeitschrift Jugend, im längeren Zeitraum der Jahre 1929 bis 1937 waren es lediglich vier. Allein 1907 erschienen neun Texte, darunter im ersten Heft des Jahres ein Vorabdruck in Auszügen von Andreas von Balthesser. Das letzte in Jugend veröffentlichte Gedicht trägt den Titel „Sternennacht“ und stellt eine entrückte Erfolgsreflexion des lyrischen Ichs dar:

114 Karlchen: Liebe Jugend! In: Jugend, 9. Jg., H. 37 (8. September 1904), S. 757.

115 [Anon.]: Über die Zeitschrift Jugend. http://www.jugend-wochenschrift.de/index.php?id= 21 (zuletzt aufgerufen am 31. Juli 2019).

116 Vgl. [Anon.]: Über die Zeitschrift Jugend.

117 [Anon.]: Kaviar fürs Volk. In: Jugend, 7. Jg., H. 22 (27. Mai 1902), S. 368.

118 Schaukal: Das Buch, S. 1. 
Wieder bin ich unter hohen Sternen / eine Weile feierlich gewesen: / Weltenweithin Flimmern stiller Fernen / hab ich, eine Rätselschrift, gelesen. // Meine Sterne, fremdeste Gefährten, / unermeßlich durch das All verbreitet, / die mir schon so manche Ruh gewährten, / wann wird mir der Weg durch euch bereitet? ${ }^{119}$

Kaum verhüllt fragt der alternde Lyriker sehnsuchtsvoll nach der Aufnahme in den literarischen Kanon und vergleicht seine Werke mit denen, die bereits als bleibende Sterne aufgegangen sind. Sein beachtlicher Erfolg zwischen der Jahrhundertwende und dem Ausbruch des Ersten Weltkriegs hatte sich jedoch in der zweiten Hälfte der Dichterkarriere nicht fortgesetzt.

\subsection{Die Gesellschaft, Die Insel und Avalun}

Für Schaukals vielversprechendes Frühschaffen im literarischen Feld Münchens sprechen auch seine ab 1896 veröffentlichten Beiträge in Die Gesellschaft. In den 17 Jahren seines Bestehens (1885-1902) wechselte das Blatt mehrmals Herausgeber, Untertitel und programmatischen Kurs und prägte vor allem in den ersten Jahren das geistige Klima Münchens sowie anderer deutschsprachiger Städte. Die Gesellschaft nahm eine führende Rolle in der Verbreitung naturalistischer Literatur ein und brachte auch sozialpolitische Themen. Die Beiträge verbanden Positionen des Naturalismus mit zeit- und kapitalismuskritischen Gedanken und nahmen gegenüber dem Berliner ,Konsequenten Naturalismus“ eine kritische, konkurrierende Haltung ein. Vor allem nach der Gründung der Freien Bühne für modernes Leben in Berlin im Jahr 1890 büßte das Monatsblatt jedoch seinen Stellenwert als naturalistisches Leitmedium ein, distanzierte sich vom Realismus/Naturalismus der Frühzeit und näherte sich zusehends der Heimatkunst an. ${ }^{120}$

Schaukal verfasste mindestens ein Dutzend Beiträge aller Gattungen für die Zeitschrift - von Lyrik über die kleine Prosaform und den Essay bis zum Drama - und stellte ihr zu Reklamezwecken Vorabdrucke unveröffentlichter Werke zur Verfügung. Wie die 1899 ebenfalls in München begründete und unter anderem von Otto Julius Bierbaum (1865-1910) herausgegebene, nicht minder bedeutende, aber schlussendlich weitaus kurzlebigere Zeitschrift Die

119 Schaukal: Sternennacht. In: Jugend, 42. Jg., H. 13 (30. März 1937), S. 202.

120 Vgl. Oliver Pfohlmann und Barbara Pfister: Die Gesellschaft (1885-1902). In: Literaturkritik. Geschichte, Theorie, Praxis. http://www.online.uni-marburg.de/literaturkritik/forschung/ modul.php (Zugriff begrenzt auf Online-Abonnenten von literaturkritik.de; zuletzt aufgerufen am 31. Juli 2019). 
Insel stellte auch Die Gesellschaft ihr Erscheinen mit dem Jahr 1902 ein. Schaukal, der in beiden Blättern veröffentlichte, verlor so auf einen Schlag gleich zwei für den Erwerb und Austausch von symbolischem, sozialem und ökonomischem Kapital entscheidende Publikationsorgane.

$\mathrm{Zu}$ den Akteuren, die ungefähr zur selben Zeit wie Schaukal in der Gesellschaft veröffentlichten und mit ihm in Kontakt standen, zählen Peter Altenberg, Otto Julius Bierbaum, Thomas Mann, Kurt Martens, Friedrich von OppelnBronikowski, Hugo Oswald (1873-1924), Wilhelm von Scholz, Georg Stolzenberg (1857-1941), Maria Stona (eigentlich Scholz, 1861-1944), Karl Hans Strobl und Bodo Wildberg (1862-1942). Zu den Schaukal nahestehenden Insel-Beiträgern gehören neun Akteure: Bierbaum, Blei, Dehmel, Arno Holz, Heinrich Mann, Julius Meier-Graefe (1867-1935), Hans von Müller (1875-1944), Gerhard Ouckama Knoop (1861-1913) und Heinrich Vogeler.

Zu Dehmel hatte Richard Schaukal bereits 1894 mit der Bitte um eine Rezension seines Einakters Rückkehr Kontakt aufgenommen. Der arrivierte Dichter antwortete, dass er ihn zwar aus diversen Zeitungsveröffentlichungen kenne, wegen der Strapazen seiner eigenen journalistischen „Brotarbeit“ die Bitte allerdings ausschlagen müsse. Auch bezüglich Schaukals „Verlagsverlegenheiten“ könne er nichts ausrichten, ringe er doch selbst um die Publikation seiner eigenen Werke. ${ }^{121}$ Dass Dehmel nicht die richtige Ansprechperson war, machte dieser im sich entwickelnden Briefverkehr immer wieder deutlich. Er wollte weder gemeinsam mit Schaukal die Übertragung von Verlaines (1844-1896) Gedichten herausgeben, ${ }^{122}$ noch war er gewillt, den jungen Kollegen für die Freie Bühne zu empfehlen, da seine Beziehungen nicht ausreichten; der Fischer-Verlag hege ihm gegenüber prinzipiell „Antipathien“, so Dehmel. ${ }^{123}$ Am 17. März 1902, zu einer Zeit also, als Schaukal erste dichterische Erfolge vorweisen konnte, brach Dehmel den von beiden Seiten nicht gerade herzlich geführten Briefwechsel ab: „Anbei, geehrter Herr, erhalten Sie Ihr Buch zurück. Ich verbitte mir hier doch ein für allemal Ihre ,Herzlichkeiten‘. Sie sollten sich doch schämen, daß Sie sich einem so ,unreinen Menschen', wie ich Ihrer Meinung nach bin, immer wieder aufdrängen. “" ${ }^{124}$ Schaukals Brief an Dehmel ist nicht erhalten, doch die Reaktion lässt darauf schließen, dass er auch in diesem Schreiben seine übliche Strategie der verehrenden Kritik verfolgt hatte.

121 Brief Dehmels an Schaukal, 11. Juni 1894, S-NL, WB.

122 Brief Dehmels an Schaukal, 22. Juni 1894, S-NL, WB.

123 Brief Dehmels an Schaukal, 11. September 1894, S-NL, WB.

124 Brief Dehmels an Schaukal, 17. März 1902, S-NL, WB. Bei dem genannten Buch handelt es sich vermutlich um Pierrot und Colombine. 
Der Zwist hielt Schaukal nicht davon ab, im Januar 1905 einen für seine eigene poetologische Auffassung erhellenden Aufsatz über Dehmel in der Österreichischen Rundschau zu veröffentlichen, der die Grundlage seiner 1908 publizierten Studie Richard Dehmels Lyrik darstellt. ${ }^{125}$ Doch erst nach dem Krieg traten die beiden Dichter erneut in Kontakt. Nach den historischen Veränderungen der Umwelt, die Thomas Schweizer als ersten Baustein der Netzwerkanalyse bezeichnet, ${ }^{126}$ erinnerte sich Dehmel seiner vermeintlich ideologischen Verbündeten (Kognitionen) und bat Dichter wie Hofmannsthal, Schnitzler, Franz Werfel (1890-1945), Altenberg, Rilke und eben Schaukal, einen am 12. Dezember 1918 verfassten öffentlichen Aufruf mit der Forderung zu unterzeichnen, dass Gebiete wie ElsassLothringen deutsch bleiben sollten (Handlung). Gemeinsam mit Schaukal unterschrieben auch Arno Holz, Emil Ludwig (1881-1948), Thomas Mann und Jakob Wassermann den Aufruf „Deutsche Dichter gegen einen Gewaltfrieden“, den die Münchner Zeitung am 27. Dezember 1918 abdruckte. Vor dem Hintergrund der politischen Umbrüche söhnten sich Schaukal und Dehmel aus und führten ihre früheren Kontroversen auf ,jugendliches Ungestüm“ und „Eigensinn“ zurück. ${ }^{127}$ Als letzte Handlung, die einem gemeinsamen kognitiven Movens entsprang, vermittelte Schaukal Dehmel im Frühjahr 1919 als Beiträger an die Zeitschrift Das Gewissen. Am 8. Februar 1920 verstarb der deutsche Schriftsteller, der zu Beginn des 20. Jahrhunderts dem literarischen München-Netzwerk angehörte, aber in jener frühen Phase mit Schaukal noch nicht interagieren wollte.

Eine weitere publizistisch-literarische Institution, die ebenfalls in München angesiedelt und für Schaukals zunehmende Etablierung im Feld der Literatur nicht unbedeutend war, ist die 1901 von Richard Scheid (1879-1962) herausgegebene Zeitschrift Avalun. Schaukal veröffentlichte 17 Gedichte in den insgesamt nur neun Hefte umfassenden „Blättern für die neue deutsche lyrische Wortkunst“, so der programmatische Untertitel. ${ }^{128}$ In einer in Das litterarische Echo veröffentlichten Rezension der Zeitschrift bezeichnete er vor allem Rainer Maria Rilke, der seinerseits fünf Beiträge in Avalun veröffentlichte, ${ }^{129}$ als einen der „befähigtesten Jüngeren“, der unter den Dichtern eine Vorreiterrolle für die anderen einnehme. ${ }^{130}$ Weitere Akteure wie Emanuel von Bodman, mit dem

125 Vgl. Schaukal: Richard Dehmels Lyrik. Versuch einer Darstellung der Grundzüge. Leipzig 1908.

126 Vgl. Schweizer: Muster sozialer Ordnung, S. 147-149.

127 Brief Dehmels an Schaukal, 12. Januar 1919, S-NL, WB.

128 Vgl. Thomas Dietzel und Hans-Otto Hügel: Deutsche literarische Zeitschriften 1880-1945. Ein Repertorium. Bd. 1. München u. a. 1988, S. 105.

129 Vgl. George C. Schoolfield: Young Rilke and His Time. Rochester (NY) 2009, S. 198.

130 Schaukal: Avalun. In: Das litterarische Echo, 3. Jg. (1900/1901), S. 1578-1579, hier S. 1578. 
auch Rilke in Kontakt stand und der ebenfalls für den Simplicissimus schrieb, hätten sich ,aus dem sonnenfunkelnden gesunden Revier wohl nur verirrt in diese mond-silbern überflossenen Traumgehege.“131

\subsection{Deutsche Kunst und Dekoration und Der Sturm}

Über die Vermittlung Heinrich Vogelers gelangte Schaukal zu einer weiteren, im deutschen Kaiserreich erscheinenden Kunst- und Kulturzeitschrift. Die vom Darmstädter Verleger Alexander Koch seit 1897 publizierte Deutsche Kunst und Dekoration entwickelte sich zum Sprachrohr des dekorativen Jugendstils. Die Zeitschrift behandelte Fragen der Architektur und Innendekoration und stellte innovative künstlerische Techniken vor. Begleitet wurde dies von fotografischen und gemalten Anschauungsbeispielen beziehungsweise von literarischen und kulturkritischen Beiträgen. ${ }^{132}$

Zwischen 1905 und 1912 veröffentlichte Schaukal in Deutsche Kunst und Dekoration insgesamt zehn Arbeiten, die als Glosse oder in fiktiver Dialogform (innen-)architektonische sowie künstlerische Themen behandelten. 1908 erschien in der vormals der Jugendstilästhetik verpflichteten Zeitschrift die an Adolf Loos angelehnte Polemik „Gegen das Ornament“. Schaukal gehörte zu den frühen Verehrern des ebenfalls aus Brünn stammenden Architekten und vertrat dessen Position und Linie vehement.

Auch im ersten Jahrgang der ab 1910 in Berlin erscheinenden und von Herwarth Walden herausgegebenen expressionistischen „Monatsschrift für Kultur und die Künste“ Der Sturm veröffentlichte Schaukal einen Beitrag über Loos. Darin huldigte er dem „starken Einsamen“, der sich als Einziger gegen die ziellosen künstlerischen Bestrebungen Wiens gerichtet und einen ebenso simplen wie kultivierten Stil entwickelt habe. Die alle geistigen wie künstlerischen Bereiche umfassenden Impulse der Metropole empfand Schaukal aufgrund des Fehlens einer einheitlichen moralischen Linie als problematisch:

Die wechselnde Farbe des öffentlichen Lebens ist bedingt durch zahlreiche unkontrollierbare Strömungen, Stimmungen unter der Oberfläche. Alle Gegenstände ordnen sich symphonisch in den nachgiebigen Rahmen ein. Selbst der politische und soziale Haß enträt nicht der - so leicht in die Roheit umzuschlagen geneigten - Gemütlichkeit. Und alles,

131 Schaukal: Avalun, S. 1579.

132 Vgl. die Information zur Zeitschrift auf der Website des Digitalisierungsprojektes: http:// www.ub.uni-heidelberg.de/helios/fachinfo/www/kunst/digilit/artjournals/dk_deko.html (zuletzt aufgerufen am 31. Juli 2019). 
bis auf das Schlendern der Bummler - man sieht hier selten Menschen, die eilen - hat ein leicht künstlerisches Gepräge. ${ }^{133}$

Weitere Akteure, die regelmäßig in Der Sturm publizierten, waren Loos und Karl Kraus, die eine nicht konfliktfreie Beziehung verband. In der Fackel wurde der Architekt vor allem wegen seiner Rezensionen für die Neue Freie Presse mehrfach kritisiert. Noch 1904 schrieb Kraus:

Der Architekt Adolf Loos hat eine Zeitlang in der ,Neuen Freien Presse‘ Modewaren und kunstgewerbliche Gegenstände in seiner leichtfertig glücklichen und interessanten Art rezensiert. [...] Seit Loos ist aber das Blatt, dessen Herausgeber sich offenbar noch nicht reich genug dünken, auf den Geschmack des von literarischer Feder besorgten Warenlobs gekommen. ${ }^{134}$

Diese Invektiven endeten 1906. Etwa zur gleichen Zeit trafen Loos und Kraus regelmäßig in der Wiener „Löwenbräu Bierhalle“ zusammen. Am 23. April 1911, 25. April 1911 und 1. Mai 1911 sandte Loos an den Stammtisch in der Teinfaltstraße 12 (bzw. an Karl Kraus direkt adressierte) Postkarten aus dem algerischen Biskra und aus Tunis, Ziele, die er gemeinsam mit dem Maler Carl Leopold Hollitzer (1874-1942) bereiste. ${ }^{135}$

Lina Loos (1882-1950), die Frau des Architekten, bezeichnete die Tischrunde als Peter-Altenberg-Stammtisch, an dem Egon Friedell (1878-1938) und zeitweise auch Erich Mühsam (1878-1934) saßen. ${ }^{136}$ Der Kreis etablierte sich um 1905 in jenem nach der Münchner Biermarke benannten Gasthaus, welches das gesamte Erdgeschoß eines Zinshauses einnahm. Der Abriss im Jahr 1911 bedeutete vermutlich auch das Ende der Künstlertreffen rund um Altenberg, Kraus und Loos. ${ }^{137}$ Eine Teilnahme Schaukals an den Stammtischrunden ist nicht belegt; allerdings ist eine kurze Korrespondenz mit Loos erhalten, der sich in einem Brief ohne Datum mit einer Bitte an den bereits bekannten Rezensenten wendet:

133 Schaukal: Geistige Landschaft mit vereinzelter Figur im Vordergrund. In: Der Sturm, 1. Jg., Nr. 13 (26. Mai 1910), S. 101-102, hier S. 101.

134 Karl Kraus: Der Glanzlederfauteuil. In: Die Fackel, Nr. 161 (5. Mai 1904), S. 8-13, hier S. 9. 135 Diese Briefe lagen in einer Mappe gemeinsam mit weiteren von Kraus an Schaukal adressierten Telegrammen, die sich im Schaukal-Nachlass in der Wienbibliothek befinden.

136 Vgl. Lina Loos: Das Buch ohne Titel. Erlebte Geschichten. Hg. von Adolf Opel. Wien 2013, S. 75; vgl. auch Hans Veigl: Karl Kraus, die Wiener Moderne und das Wiener Kabarett nach der Jahrhundertwende. In: Hundert Jahre Kabarett. Zur Inszenierung gesellschaftlicher Identität zwischen Protest und Propaganda. Hg. von Joanne McNally und Peter Sprengel. Würzburg 2003, S. 39-50, hier S. 46.

137 Vgl. die unveröffentlichten Erinnerungen des Juristen Adolf Seitz in: Timms: Dynamik der Kreise, S. 67-68. 
Sie würden mich zum Dank verpflichten, wenn Sie [...] in den Buchbesprechungen der Sonntagszeitung meines Artikels über die Kunstgewerbeschule in der Weise gedenken wollten, dass Sie den Verfasser als jungen Brünner Architekten (oder ähnlich) bezeichnen. $\mathrm{Zu}$ jedem Gegendienste gern bereit zeichne ich mit besten Grüssen Euer Wohlgeb. ergebenster Adolf Loos. ${ }^{138}$

Am 18. Dezember 1907 und am 17. Dezember 1912 bedankte sich Loos bei Schaukal für Büchersendungen mit Widmung und am 22. Dezember 1910 für einen positiven Artikel im Merker. ${ }^{139}$ Doch der Kontakt blieb spärlich und die wenigen Briefe im Ton höflich distanziert.

Ähnlich wie bei Kraus gab sich Schaukal auch hier mit einer mehr geistigen Verbindung zufrieden; gegen seine Art behelligte er den polarisierenden, aber gut vernetzten Architekten ebenso wenig mit Vermittlungsanfragen wie den Herausgeber der Fackel, mit dem sich eine aus der Ferne grüßende, geistige Verbindung eingestellt habe, wie Schaukal 1933 festhielt. ${ }^{140}$

\subsection{Blätter für die Kunst, Der Brenner und Das Gewissen}

Am 28. April 1896 schickte Schaukal Carl August Klein, Herausgeber der vier Jahre zuvor von Stefan George begründeten Blätter für die Kunst, einige Proben seines dichterischen Schaffens. ${ }^{141}$ Selbstbewusst stellte er sich in dem Schreiben vor: „Sie dürften mich übrigens aus dem modernen Schriftwesen kennen. “142

Diesem offensichtlichen Fauxpas, sich als bereits bekannter Dichter einführen zu wollen, folgte ein zweiter, als sich Schaukal nach den Abonnementbedingungen der auf ein ausgesuchtes Publikum ausgerichteten Blätter erkundigte. ${ }^{143}$ Es war durchaus keine Seltenheit, dass Dichter ihre Werke an Stefan George oder an die Blätter für die Kunst adressiert einsandten, auf diesem Wege konstituierte sich im Wesentlichen sogar die Gruppe des Blätter-Kreises. Allerdings erforderte eine Publikation entweder die Bekanntschaft Georges oder die Empfehlung eines

138 Brief Loos' an Schaukal, undatiert, S-NL, WB.

139 Vgl. die Briefe Loos' an Schaukal, 18. Dezember 1907, 22. Dezember 1910 und 17. Dezember 1912, S-NL, WB. Im Brief vom 17. Dezember 1912 lädt Loos Schaukal überdies zu einem Vortrag in die Schule von Eugenie Schwarzwald (1872-1940) ein.

140 Vgl. Schaukal: Karl Kraus, S. 18.

141 Vgl. Oesterheld: Schaukal und der George-Kreis, S. 77.

142 Zit. nach Oesterheld: Schaukal und der George-Kreis, S. 78.

143 Vgl. Oesterheld: Schaukal und der George-Kreis, S. 78. 
Freundes, eine Hürde, an der auch Dichter wie Hans Carossa (1878-1956) oder die Brüder Heinrich und Julius Hart (1855-1906 bzw. 1855-1930) scheiterten. ${ }^{144}$

Schaukal berief sich bei seiner Kontaktaufnahme nun auf Hofmannsthal, der ihm die Adresse Kleins habe zukommen lassen. Tatsächlich stand er zu dieser Zeit mit Hofmannsthal in Kontakt, wie aus Schaukals Briefwechsel mit Arthur Schurig ersichtlich wird. Schaukal war demnach im Besitz von mindestens drei Briefen des gleichaltrigen Dichters, die Schurig einzusehen bat, da er Hofmannsthals Schriftbild für einen geplanten Essay studieren wollte. ${ }^{145}$

Indes ebnete die Nennung Hofmannsthals keineswegs den Weg zum zentralen Organ des Kreises, schließlich verband den Dichter seit der Begegnung in Wien zum Jahreswechsel 1891/1892 ein schwieriges Verhältnis mit Stefan George. Klein bedankte sich für die lyrischen Sendungen und begründete die Absage folgendermaßen: „[Z]um Abdruck für die ,Blätter für die Kunst“ pflegen wir nur solche Dichter zu bringen, die noch nicht oder nicht mehr in jenen bekannten Kunst- und Schönheitswidrigen modernen Veröffentlichungen ihre Muse anboten oder anbieten. “146

In dieser Ablehnung liegt das gesamte Dilemma des um Anerkennung und literarische Teilhabe buhlenden jungen Schaukal. Zwar brachte er sich früh im Feld der Literatur ein und setzte sich unentwegt mit der Stilfindung und (seiner) dichterischen Einzigartigkeit auseinander. Doch immer wieder wurden seine Werke von den für ihn entscheidenden Akteuren als Imitation, seine Lyrik als ,modern“ und seine Poetik als zu beliebig und gefällig abgekanzelt. So unterbanden Carl August Klein und auch Hermann Bahr Schaukals Anschlussbemühungen an zwei bedeutende Gruppierungen der deutschsprachigen Moderne, an das Junge Wien und an den George-Kreis. Vor allem der letztgenannte Zirkel dürfte ein Sehnsuchtsort für Schaukals Dichterambitionen gewesen sein, wie Christian Oesterheld mit Bezug auf die unveröffentlichten Briefe an Klein herausarbeitet. ${ }^{147}$ Ungewöhnlich liest sich die beinahe devote Haltung des seine Anliegen ansonsten ungestüm vorbringenden Dichters. Als letzte Maßnahme glich Schaukal seine Handschrift der im George-Kreis verbreiteten Kalligraphie an und verzichtete mit Ausnahme der Eigennamen auf Großschreibung. Im Herbst 1897 bekannte er in beinahe religiöser

144 Vgl. Achim Aurnhammer u. a. (Hg.): Stefan George und sein Kreis. Ein Handbuch. Berlin/ Boston 2016, S. 837.

145 Vgl. die Briefe Schurigs an Schaukal, vor allem jene vom 7. Dezember, 12. Dezember und 14. Dezember 1906, S-NL, WB.

146 Brief Kleins an Schaukal, Oktober 1897, S-NL, WB.

147 Vgl. Oesterheld: Schaukal und der George-Kreis. 
Diktion, auf die Veröffentlichung seiner Werke andernorts verzichten $\mathrm{zu}$ wollen, um nur den einen Wunsch erfüllt zu bekommen:

[...] dem befangenen und bearbeiteten, armseligen eklen publikum gänzlich zu entrinnen und als ein von dem lästigen und ärgernden verleger-verkehre aufathmenden befreiter in die heiter-stillen hallen Ihrer von mir mit liebe und anerkennung besessenen und oftmals gelesenen und vor nächsten vorgelesenen blätter zu treten, wenn mich die runde würdigt einzugehen und sitz und stimme zu behalten. ${ }^{148}$

Trotz der Ablehnung zählte Schaukal Stefan George weiterhin - mit Ausnahme der Übersetzungen - zu seinen Modellpoeten. ${ }^{149}$ Er schrieb über den ,Meister essayistische Beiträge und rühmte die Blätter für die Kunst als Kaderschmiede für talentierte Dichter. ${ }^{150}$ In zwei erhaltenen Widmungsexemplaren bezeichnete er sich 1902 als „,innige[n] Anhänger“, ${ }^{151}$ „,treuen Verkünder“ und „Vorleser des hochverehrten Stefan George.“152

Schaukal empfand in ästhetischer wie moralischer Hinsicht lediglich Karl Kraus als noch größere dichterische, moralische und kritische Idealfigur. In einer von der Innsbrucker Zeitschrift Der Brenner 1913 initiierten und veröffentlichten „Rundfrage über Karl Kraus“ bekundete der Angefragte - nach einem Seitenhieb gegen das unliebsame Format der Umfrage -, dass nach seinem Empfinden Kraus zu den wenigen deutschen Schriftsellern gehöre, „die von dieser viel und ungemein schlecht schreibenden Uebergangsepoche unseres Schrifttums geschichtlich dauern werden. “153

Abgesehen von diesem kurzen Kommentar erscheint kein weiterer Beitrag Schaukals in der 1910 von Ludwig von Ficker (1880-1967) ins Leben gerufenen Zeitschrift, auch nicht, als er fast zwei Jahrzehnte später direkt darum ansuchte. Auf die gemeinsame Faszination für Kierkegaard (1813-1855), für Theodor Haecker und vor allem für Kraus, dessen Fackel dem Brenner sozusagen

148 Brief Schaukals an Klein, 6. Oktober 1897, zit. nach Oesterheld: Schaukal und der GeorgeKreis, S. 82.

149 Vgl. Oesterheld: Schaukal und der George-Kreis, S. 72; zu Schaukals Kritik an Georges Übertragungen siehe ebd., S. 73-74.

150 Vgl. Schaukal: Avalun, S. 1578.

151 Handschriftliche Widmung im Band Meine Gärten. Einsame Verse (Berlin 1897) mit dem Datum 14. Februar 1902.

152 Mit dem Datum 14. März 1902 versehene handschriftliche Widmung in Von Tod zu Tod und andere kleine Geschichten (Leipzig/Berlin 1902). Beide Widmungsexemplare bewahrt das Stefan George Archiv in der Württembergischen Landesbibliothek, Stuttgart, auf.

153 Schaukal: [Antwort auf] Rundfrage über Karl Kraus. In: Der Brenner, 3. Jg., Nr. 19 (1. Juli 1913), S. 898-899, hier S. 899. 
voran leuchtete, bezieht sich Schaukal in seinem Schreiben vom 27. April 1931 an den Herausgeber, ehe er im zweiten Teil zum eigentlichen Anliegen seiner Kontaktaufnahme kommt: dem „Brenner-Kreis näherzutreten“ und eine „hoffentlich andauernde Verbindung“ zu knüpfen. ${ }^{154}$ Mehr noch, Schaukal zählte sich neben Haecker und Kraus zur „Trias der Maßgebenden“, die durch Stefan George und Rudolf Borchardt (1877-1945) erweitert werden könne. Er schlug Ficker die Publikation seines im Verein ,Altösterreich“ gehaltenen Vortrags über Marie von Ebner-Eschenbach und Adalbert Stifter (1805-1868) vor und offerierte darüber hinaus auch den Wiederabdruck eines beigelegten Aufsatzes zu André Gide. ${ }^{155}$ Ein Jahr später wiederholte Schaukal sein Ansuchen und verstärkte die unglückliche Strategie des Selbstlobes. Er brauche sich nicht vorzustellen, da er mit Haecker und Kraus zu den drei großen „Prosaikern“ der Zeit gehöre und „als Lyriker für die Einsichtigen längst den ersten Platz nicht nur in Österreich“ einnehme, so die Eröffnung des Schreibens. Dem mehrere Sätze umfassenden Präludium über sein Reüssieren im Georg Müller Verlag folgt das Bekenntnis: „Ich bilde mir ein, daß ich seit je [. . .] in den Brenner Verlag gehört hätte, zumal da Haecker der einzige deutsche Schriftsteller ist, den ich außer Kraus, meinem wahlverwandten weltanschaulichen Antipoden, unbedingtermaßen schätze und liebe.“ Was Schaukal dem Publizisten und Herausgeber dann anbietet, wirkt nicht sehr attraktiv, handelt es sich doch abermals um bereits veröffentlichte und neu kompilierte essayistische sowie lyrische Beiträge, die der Empfänger des Briefes gerne auch in geringer Stückzahl als Liebhaberoder Luxusausgaben drucken lassen könne. ${ }^{156}$

Ficker muss sich bei Haecker nach Schaukal erkundigt haben, der - wie übrigens auch im Falle der bereits kurz erwähnten Widmung des Kraus-Essays verhalten reagierte. ${ }^{157}$ Am 9. Juni 1934 erteilte der Brenner-Herausgeber Schaukal eine Absage. Die vorgeschlagenen Texte seien für den Brenner zu abseitig und darüber hinaus bereits veröffentlicht. Abschließend deutet Ficker den Beginn einer unsicheren Zeit an, die sich auch auf die Zeitschrift negativ auswirken

154 Brief Schaukals an Ficker, 27. April 1931, in: Ignaz Zangerle u. a. (Hg.): Ludwig von Ficker: Briefwechsel 1926-1939. Innsbruck 1991 (= Brenner-Studien XI), S. 187. Online: https://www. uibk.ac.at/brenner-archiv/bibliothek/pdf/ficker-bd-3-gesamt-neu.pdf (zuletzt aufgerufen am 31. Juli 2019).

155 Vgl. den Brief Schaukals an Ficker, 27. April 1931, in: Zangerle u. a. (Hg.): Ludwig von Ficker: Briefwechsel 1926-1939, S. 187.

156 Brief Schaukals an Ficker, 5. März 1932, in: Zangerle u. a. (Hg.): Ludwig von Ficker: Briefwechsel 1926-1939, S. 219-220.

157 Vgl. den Brief Haeckers an Ficker, 25. Januar 1933, in: Zangerle u.a. (Hg.): Ludwig von Ficker: Briefwechsel 1926-1939, S. 227. 
könnte. Tatsächlich sollte die Pfingstnummer des Jahres 1934 für zwölf Jahre die letzte Ausgabe bleiben. Ficker schrieb Schaukal:

Ich kann auch künftig nur berücksichtigen, was in der Linie dieser Entwicklung nicht schon offenbar, sondern noch verhüllt ist. Es sind doch erst die ersten Schleier, die sich vor dem neuen, schon bang geahnten und bald sich mehr verdichtenden Weltbild heben. Ich selbst konzipiere meinen kleinen, aber gewagten Beitrag, wie ich immer wieder betonen muß, ganz ins Unsichere und Ungewollte hinein. ${ }^{158}$

Schaukal reagierte gekränkt und versicherte in einem Schreiben vom 13. Juni 1934, keinerlei Publikationsanfragen mehr an Ficker richten $\mathrm{zu}$ wollen. ${ }^{159}$

In lediglich einem Fall wurde Richard Schaukal zum wichtigsten Mitarbeiter einer Kulturzeitschrift, nämlich im Jahr 1919 für Das Gewissen von Alois Essigmann und Rudolf Falk. Bereits seit Ende Juli 1916 stand er mit dem Schriftsteller und Publizisten Essigmann in Verbindung. Dieser Kontakt sollte sich zu einem der wesentlichen Bezugspunkte in der Zwischenkriegszeit und Essigmann zum ersten Fürsprecher für Schaukals konservative Neupositionierung im literarischen, aber auch im politisch-ideologischen Feld entwickeln. Gegenüber Kubin bezeichnete Schaukal rückblickend sein Wirken für Das Gewissen als Höhepunkt seiner „scharfen Opposition gegen die demokratisch-republikanisch-verjudete Zeit.“160

Der Maler Maximilian Liebenwein, Essigmanns Schwager, mit dem Schaukal 1914 den illustrierten Band Kindergedichte herausgegeben hatte, ${ }^{161}$ hatte den Kontakt zwischen dem zu der Zeit noch in Berlin lebenden Schriftsteller und dem in Wien tätigen Beamtendichter vermittelt. Die ersten Briefe sind von gegenseitigen weltanschaulichen, kulturellen und ästhetischen Bekenntnissen geprägt. Essigmann und Schaukal debattierten über die Bedeutung Otto Weiningers (1880-1903) und vor allem über Karl Kraus. Wie Essigmann seinem Briefpartner mitteilte, hatte er sich in Berlin mit dem Herausgeber der Fackel getroffen, dabei sei auch von Schaukal die Rede gewesen. ${ }^{162}$ Nicht zuletzt versicherten sie sich in

158 Brief Fickers an Schaukal, 9. Juni 1934, in: Zangerle (Hg.): Ludwig von Ficker: Briefwechsel 1926-1939, S. 255-256, hier S. 256.

159 Vgl. den Brief Schaukals an Ficker, 13. Juni 1934, in: Zangerle (Hg.): Ludwig von Ficker. Briefwechsel 1926-1939, S. 256.

160 Brief Schaukals an Kubin, 18. Juli 1933, K-S, BSB.

$161 \mathrm{Vgl}$. Schaukal: Kindergedichte. Aus den fernen Tagen der tannengrünen Kindheit ... (Werke 1892-1896). Mit Bildern von Maximilian Liebenwein. Wien 1914. Der Gedichtband gelangte nicht in den Buchhandel, sondern wurde an diverse Bibliotheken in Österreich und Deutschland vergeben. Drei Exemplare wurden zu je 200 Mark verkauft. Schaukal spendete den Gesamterlös dem Roten Kreuz; vgl. [Anon.]: [ohne Titel]. In: Neue Freie Presse, Nr. 17961 (26. August 1914), S. 11.

162 Vgl. den Brief Essigmanns an Schaukal, 14. Februar 1917, S-NL, WB. 
den ersten Briefen gegenseitig ihrer antisemitischen Gesinnung, ${ }^{163}$ die auch in der später gegründeten Zeitschrift Das Gewissen zum Prinzip erhoben werden sollte. Am 16. November 1918 erwähnte Essigmann gegenüber Schaukal sein Vorhaben, zusammen mit Rudolf Falk eine Zeitschrift ins Leben rufen zu wollen. Er bat den Kollegen um dessen Mitarbeit und um die Vermittlung von potentiellen Beiträgern, die dem Geist und der Programmatik von Das Gewissen entsprechen. Die in Wien aufgelegte Halbmonatsschrift erschien erstmals im März 1919, wurde aber nach nur fünf Monaten mit dem Juli-Heft, der Nummer 9/10, wieder eingestellt.

Das Gewissen widmete sich literarischen und kulturellen, aber auch politischen und wirtschaftlichen Themenfeldern. Bereits die in der BuchhändlerCorrespondenz geschaltete Ankündigungsannonce trägt Schaukals antisemitische und kulturkritische Handschrift:

\begin{abstract}
„Das Gewissen“ soll über allen Parteien und Meinungen stehend, unbeirrt durch alle Vorteile, die dies oder jenes System, sei’s in Politik oder Wirtschaft, verspricht, seine Stimme warnend erheben und in ehrlicher Kritik stets darauf hinweisen, welche ungeheuren Opfer an Kultur unsere Zeit der Zivilisation bringt. Immer wieder soll es erinnern, daß nicht alles gut ist, was notwendig ist, daß des Lebens Notdurft keine geistige Angelegenheit ist - Zivilisation nicht Kultur - Organisation nicht Wachstum! [. . . In der Überflutung alles öffentlichen Lebens mit jüdischem Geist, sehe ich [. . . ] eine ungeheure Gefahr für unser Wesen [. . .]. Das gute Gewissen, der rein künstlerische Teil, soll unsere Sehnsucht ausschreien [...]. ${ }^{164}$
\end{abstract}

Schaukals Einfluss auf die von Essigmann und Falk geleitete Zeitschrift war groß. Auf seine Veranlassung hin veröffentlichte Richard Dehmel, mit dem er wegen des erwähnten politischen Aufrufs ohnehin in Kontakt stand, einen seiner letzten Beiträge im ersten Heft von Das Gewissen.

Die Liste der Beiträger deckt sich weitestgehend mit Schaukals ästhetischer Affinität und seiner rechtskonservativen, später auch faschistischen Ideologie. ${ }^{165}$ Rudolf Huch (1862-1943), Jörg Lanz von Liebenfels (1874-1954), Emil Wohlgemuth, Hans Paul Freiherr von Wolzogen (1848-1938) und Arthur Schurig befanden sich zu jener Zeit im selben Netzwerk wie Schaukal. Von

163 Vgl. die Briefe Essigmanns an Schaukal vom 20. Juli sowie vom 5., 15. und 26. Oktober 1916, S-NL, WB.

164 Anzeige in: Buchhändler-Correspondenz, Nr. 9/1919 (26. Februar 1919), S. 125; Hervorh. im Orig. durch Fettung. Siehe auch Dietzel/Hügel: Deutsche literarische Zeitschriften 1880-1945, S. 497.

$165 \mathrm{Zu}$ Schaukals Annäherung an den und Distanzierung vom Nationalsozialismus vgl. Christian Neuhuber: Der „Fall Schaukal“. Richard von Schaukals Auseinandersetzungen mit der NS-Presse um „Anschluss“ und „Österreich-Idee“ 1932-1934. In: Modern Austrian Literature, Bd. 38, Nr. 3-4 (2005), S. 13-36. 
einer Anfrage bei Thomas Mann riet er ab, obwohl Essigmann einen Beitrag des deutschen Schriftstellers befürwortet und als symbolischen Gewinn für die Zeitschrift erachtet hätte. Generell scheint die Resonanz bei den angefragten Akteuren nicht sonderlich groß gewesen zu sein, sahen sich die Herausgeber doch bemüßigt, in der Vorankündigung ihrer Zeitschrift festzuhalten: „Mit anderen unserer Großen, die durch die Ungunst der Verkehrsverhältnisse schwerer zugänglich sind, schweben aussichtsreiche Unterhandlungen." 166 Gemeint ist hier der nach Kriegsende zum Erliegen gekommene postalische Verkehr. Doch nicht nur technische Hindernisse, auch Schaukals Animositäten waren für die Rekrutierung oder Ablehnung von Beiträgern für Das Gewissens ausschlaggebend. Auch eine mögliche Anfrage bei Gerhart Hauptmann (1862-1946) wurde diskutiert und - aufgrund Schaukals ablehnender Haltung - verworfen. ${ }^{167}$

Schaukals Reaktionen als Schriftsteller und Beamter auf die Gründung der Republik stehen ganz im Zeichen seiner zunehmenden Politisierung, wie noch ausführlicher zu zeigen sein wird. Der Kontakt zu Essigmann und seine Mitarbeit am Gewissen veranschaulichen erste Etappen jener neuen Verbindung von politischem Engagement und schriftstellerischen Bestrebungen. Nachdem Schaukal Essigmann eine Liste potentieller Mitarbeiter für das Blatt hatte zukommen lassen, reagierte der Gründer verwundert:

Die Liste weist ja fast nur Polemiker auf! Bitte lassen Sie dem „Gewissen“ auch etwas von dem Dichter Schaukal zukommen. Ich begreife, dass die bewegte Zeit den Polemiker in Ihnen aufwühlt, aber das G. muss gleich im Anfang zeigen, dass es mindestens zur Hälfte auch der Schönen Literatur gehört. ${ }^{168}$

Essigmann bekräftigte immer wieder sein Anliegen, dass auch dichterische Erzeugnisse Platz im Gewissen einnehmen müssten und die politischen Essays kein Übergewicht haben sollten. „Sie haben kein polemisches Talent!“, so der Schriftleiter in aller Deutlichkeit. ${ }^{169}$

Die Existenz von Das Gewissen stand mit seiner Gründung bereits auf der Kippe, zum einen wegen der Papierknappheit, dann aufgrund der allgemeinen Teuerung und nachlassenden Kaufkraft, nicht zuletzt auch wegen der andauernden Kohlennot in der unmittelbaren Nachkriegszeit. ${ }^{170}$ Möglich, dass auch programmatische Unstimmigkeiten zwischen Schaukal und Essigmann zum Scheitern des Zeitschriftenprojekts beigetragen haben.

166 Anzeige in: Buchhändler-Correspondenz, Nr. 9/1919 (26. Februar 1919), S. 125.

167 Vgl. den Brief Essigmanns an Schaukal, 17. Januar 1919, S-NL, WB.

168 Brief Essigmanns an Schaukal, 4. Januar 1919, S-NL, WB.

169 Brief Essigmanns an Schaukal, 13. Januar 1919, S-NL, WB.

170 Vgl. den Brief Essigmanns an Schaukal, 3. Januar 1919, S-NL, WB. 
In einem Brief an Kubin blickt Schaukal 1933 resignativ und verklärend auf die ökonomische und symbolische Position jener Jahre zurück:

Bis etwa 1913 war ich ein sorgenloser, seitdem ein wohlhabender, ja nach dem Tode meines Schwiegervaters fast ein reicher Mann. Ob man mir - der ich von 1896 (Simplicissimus-Gründung) bis 1908 gepriesen und überall gedruckt wurde - ein Honorar zahlte oder nicht, war mir gleichgiltig. Die Blätter nützten mich weidlich aus. $)^{171}$

Dabei hatte ihn sein Erfolg als Lyriker sogar kurzzeitig mit dem Initiator des Futurismus Filippo Tommaso Marinetti (1876-1944) in Kontakt gebracht. 1905 erschienen im ersten Jahrgang der von Marinetti gegründeten italienischen Kunstzeitschrift Poesia Gedichte von Schaukal im deutschen Original. Vielleicht war der Futurist 1903 in seiner Funktion als Sekretär der Pariser Zeitung La critique internationale auf Schaukal aufmerksam geworden. Immerhin veröffentlichte das einflussreiche Periodikum in diesem Jahr auch eine Übersetzung von Schaukals zuvor im Magazin für Litteratur erschienenen Artikel „Die deutsche Litteratur der Gegenwart“. ${ }^{172}$

Dieser überwiegend literarisch geprägten Phase, die Schaukal zum Beiräger in relevanten Zeitungen und Zeitschriften der europäischen Moderne erhob, folgte ein Engagement gegen die parlamentarische Demokratie und für den Katholizismus, das sich zunehmend in Essaybänden und Aufsätzen ausdrückte, die etwa in Der Christliche Ständestaat, Die Reichspost, Schönere Zukunft und Der Gral erschienen. Mit der Politisierung, so lässt sich resümieren, wechselte Schaukal auch die Gattung, ohne sich jedoch vom Format des Gedichtbandes zu distanzieren, wie dies etwa bei Hofmannsthal der Fall war. ${ }^{173}$

\section{Schaukal als Objekt der Kritik}

Ein erster umfassender Artikel über Schaukals Dichtung erschien 1902 in der Wiener Zeitung. Der Literaturkritiker und spätere Chefredakteur Rudolf Holzer (1875-1965) widmete dem lyrischen Werk des Dichters hier knapp sechs Spalten. Dabei rückte er Schaukal in die Nähe von Jung-Österreich. Gegenüber den anderen steche er allerdings aufgrund einer „schlichteren“ Poetik angenehm hervor: „Im Blumengarten der jüngeren österreichischen Lyrik blühen ein paar prächtige, exotische Zierstücke, einige buntschillernde Nichtigkeiten, und dann - verborgen

171 Brief Schaukals an Kubin, 18. Juli 1933, K-S, BSB.

172 Vgl. Pietzcker: Richard von Schaukal, S. 194, Fußnote 11.

173 Hofmannsthal blieb der lyrischen Gattung lediglich in seinen Libretti treu. 
stehend - liebe, schlichte Wiesenblumen.“174 Die florale Symbolik war, wie auch das Gartenmotiv, bei Kritikern und Schriftstellern des Jugendstils en vogue und prägte auch Schaukals eigenes essayistisches sowie lyrisches Schaffen.

$\mathrm{Zu}$ Beginn des 20. Jahrhunderts wurde sein Werk, vor allem aber seine streitbare Persönlichkeit zunehmend Gegenstand in einer der meistgelesenen und einflussreichsten Zeitungen Österreichs, der Neuen Freien Presse. ${ }^{175}$ Stefan Zweig, mit dem Schaukal ein schwieriges persönliches Verhältnis, aber auch eine produktive Zusammenarbeit als Übersetzer verband, war im März 1907 in einer Rezension des Novellenbandes Eros Thanatos zunächst voll des Lobes. Das Künstlertemperament sei darin endlich zum Durchbruch gelangt und der „Dichter“ habe den „Artisten“ überwältigt. Dies mache sich vor allem in der Novelle „Die Sängerin“ bemerkbar, die Zweig schlichtweg „superb“ fand. Im zweiten Teil der Rezension bezeichnete er Eros Thanatos als Werk einer zwar talentierten, aber zwiespältigen Dichterpersönlichkeit. Schaukal bescheinigte er

ein nicht zur Harmonie gewordenes, wunderbar reiches Können, dem es irgendwie versagt ist, sich in seiner ganzen Fülle geeinigt auszuströmen. Noch immer ist Richard Schaukal bedeutender als seine Bücher, noch immer gibt nie das einzelne Werk, sondern nur alle zusammen den Umriß seiner vielseitigen Kunst. Das einzelne Werk löst nie reine Befriedigung aus, sondern reizt immer mit Mängeln und Vorzügen zur Diskussion, zwingt stets zu kritischer und oft ärgerlicher Auseinandersetzung. Was aber gleichzeitig am sichersten beweist, daß Schaukal eine durchaus eigenartige Persönlichkeit ist, gleich reizvoll in ihrer Veränderlichkeit wie in ihrer sich selbst getreuen Beharrlichkeit der Kunst bedeutsam - interessant, weil eine dichterische Persönlichkeit, oder eine Persönlichkeit, weil in allen ihren Emanationen interessant und bezwingend. ${ }^{176}$

Einen ähnlichen personenzentrierten Standpunkt nimmt im selben Jahr die ebendort veröffentlichte Balthesser-Rezension von Otto Hauser (1876-1944) ein. Der von Theodor Herzl geförderte Schriftsteller und Übersetzer ${ }^{177}$ verfolgte und kommentierte Schaukals literarischen Werdegang in der Neuen Freien Presse seit $1904 .{ }^{178}$ Schaukal habe seine Pose sowie die Nachahmung literarischer

174 Rudolf Holzer: Neue österreichische Lyrik. In: Wiener Abendpost. Beilage zur Wiener Zeitung, Nr. 55/1902 (7. März 1902), S. 7-8, hier S. 7.

175 Die vermutlich früheste Rezension in der Neuen Freien Presse bespricht Schaukals Intérieurs; vgl. a. d.: „Intérieurs aus dem Leben der Zwanzigjährigen“. Von Richard Schaukal. In: Neue Freie Presse, Nr. 13297 (1. September 1901), S. 24.

176 Stefan Zweig: Literarische Notizen. In: Neue Freie Presse, Nr. 15304 (31. März 1907), S. 83.

177 Vgl. [Anon.]: [Art] Hauser Otto. In: Österreichisches Biographisches Lexikon 1815-1950 (ÖBL). Bd. 2. Wien 1959, S. 220.

178 Vgl. Otto Hauser: Richard Schaukal. „Vorabend“. In: Neue Freie Presse, Nr. 14136 (3. Januar 1904), S. 36-37; Hauser: Richard Schaukal. „Literatur“ und „Giorgione“. In: Neue Freie Presse, Nr. 15277 (3. März 1907), S. 37. 
Traditionen abgelegt und sei auf dem Weg zu einem eigenen Stil, so Hauser im Mai 1907 über Leben und Meinungen des Herrn Andreas von Balthesser. ${ }^{179}$

Schon aus der fünf Jahre zuvor in Westermanns illustrirten deutschen Monatsheften veröffentlichten Rezension über Schaukals Interiéurs spricht eine gewisse Ratlosigkeit, wie das Werk des aus Brünn stammenden Schriftstellers zu bewerten sei. Das von „Absonderlichkeiten strotzende Buch“ verkörpere den „Typus des Dekadenten, Bleichen, Müden und Aparten um jeden Preis“, entbehre aber nicht der „lyrischen Stimmung“, die immerhin „Bruchstücke aus einem Dichterherzen“ darstellen, so der auf die fragmentarische Form der Intérieurs anspielende Schlusssatz einer insgesamt negativen Kritik. ${ }^{180}$

Seit der Veröffentlichung seiner ersten Gedichtsammlung im Jahr 1893 war Schaukal mit dem Vorwurf des Epigonal-Modischen konfrontiert worden; er segle im „Fahrwasser der Modernsten, der Tagesrealisten“, heißt es etwa im Juni 1893 in der Zeitschrift Die Lyra. Er müsse sich andere Muster wählen, „um nicht in dem breiten Sumpfe moderner Gewöhnlichkeit“ zu versinken. ${ }^{181}$

Rilke entzog sich zwölf Jahre später einem eindeutigen Urteil. Er bezeichnete Schaukals 1904 veröffentlichte Sammlung ausgewählter Gedichte zurückhaltend als „gutes Buch“, spielte aber ironisch auf die poetische Prätention des Verfassers an: „[J]e öfter ich las, desto deutlicher fühlte ich das feine und gleichmäßige Korn dieser Silben, die wie durch ein Sieb aus Frauenhaar gegangen waren.“182

Wie disparat die Einschätzungen und Meinungen um 1900 darüber ausfielen, welche Literatur als modern zu klassifizieren und was die Moderne überhaupt sei, belegt auch eine 1906 veröffentlichte Rezension in der Badener Zeitung. Dort heißt es, Schaukal sei mit seinem Erinnerungsbuch Großmutter auf den „Irrwegen des modernen Geschmacks gewandelt“, es hätten ihn die „Irrlichter der literarischen Secession genarrt. “183 Rudolf Zauzal urteilte ebenfalls in der Badener Zeitung fast zwei Jahrzehnte später zwar wohlwollender, wählte für seine Besprechung aber einen nicht minder paradoxen Modernebegriff: Schaukals Hoffmann-Biographie

179 Vgl. Hauser: Richard Schaukal. „Leben und Meinungen des Herrn Andreas von Balthassar [sic!], eines Dandy und Dilettanten“. In: Neue Freie Presse, Nr. 15345 (12. Mai 1907), S. 35, sowie die positive Kritik über Literatur und Giorgione in: Neue Freie Presse, Nr. 15277 (3. März 1907), S. 37.

180 F. D.: Interieurs aus dem Leben Zwanzigjähriger von Richard Schaukal. In: Westermanns illustrirte deutsche Monatshefte, Bd. 91 (1901/1902), S. 160.

181 N.: Neues lyrisches Allerlei aus Deutsch-Oesterreich. In: Die Lyra, 16. Jg., Nr. 17 (1. Juni 1893), S. 7.

182 Rilke: Ausgewählte Gedichte. Von Richard Schaukal. In: Die Zukunft, Bd. 51 (1905), S. 39-40.

183 Peter Enslein: Literarische Kreuz- und Querzüge. XI. In: Badener Zeitung, Nr. 90/1906 (10. November 1906), S. 1-4, hier S. 1-2. 
sei „die erste moderne und volkstümlich geschriebene“ Lebensschilderung. ${ }^{184}$ Eine Gleichsetzung von modern mit unmoralisch vollzog hingegen 1902 die Linzer Tages-Post. „Schaukal ist eben ein ganz Moderner“, so die abschätzige Bewertung seiner dramatischen Skizzen, die durchaus gegen den Strich der um 1900 gängigen sexualmoralischen Konventionen gebürstet waren. „Aber er ist in der Wahl seiner Stoffe so gesucht modern, so geflissentlich bemüht, recht Absonderliches zu bringen, daß er uns Menschen vorführt und Szenen bietet, die geradezu widerlich sind." 185 Hauser rühmte hingegen 1907 in der Neuen Freien Presse Schaukals Werke Literatur und Giorgione als Ausweg „aus dem Wirrwar der soitdisant-Moderne“ in Richtung „Kunst, der ewigen Moderne.“" ${ }^{186}$ Auch das Neue Wiener Journal sah im Herbst 1913 gerade in dessen Rückwärtsgewandtheit die Vorzeichen einer im Grunde genommen modernen Literatur: „Schaukal ist ein Abseitsstehender im literarischen Leben Wiens. [...] Mit der Melancholie eines Verspäteten sinnt er vergangenem Leben nach und schuf sich aus historischen Sentiments eine Romantik, die in ihrer Kühle, ihrer Ironie und spöttischen Ueberlegenheit als modernes Produkt anmutet.“187

Im Laufe des ersten Jahrzehnts des 20. Jahrhunderts nahm Schaukals Sichtbarkeit im literarischen Feld deutlich zu, wie die an seine Person geknüpften, widersprüchlichen Modernediskurse in österreichischen Zeitschriften zeigen. Mehr noch als sein schriftstellerisches Schaffen provozierte seine Persona geteilte Meinungen. Dem 1907 im deutschen Sprachraum entfachten BalthesserHype entzog sich ein Redakteur des Neuen Wiener Tagblatts, dem vor allem Schaukals forcierte Abkehr von literarischen Gruppierungen und Moden wenig glaubwürdig erschien. Schaukal geriere sich als „Outsider [und] Eigenbrötler unter den Modernen. Er hat so vieles mit ihnen gemein, betet zu denselben Göttern wie sie, und geht doch seine eigenen Wege. Er ist völlig ein Kind seiner Zeit, ihrer materiellen wie literarischen Kultur, erklärt sich aber durchaus nicht einverstanden mit ihr." ${ }^{188}$ Der Aufsatz thematisiert außerdem den Habitus Schaukals, der „sehr skeptisch vom Werte des literarischen Ruhmes“ denke

184 Rudolf Zauzal: E.T.A. Hoffmann - Sein Werk. In: Badener Zeitung, Nr. 21/1923 (25. Mai 1923), S. 5-6, hier S. 6.

185 Adolf Schwayer: Neue Bücher. In: Tages-Post, Nr. 108/1902 (11. Mai 1902), S. 9-10, hier S. 10.

186 Hauser: Richard Schaukal. „Literatur“ und „Giorgione“.

187 Hermann Menkes: Moderne Erzähler. In: Neues Wiener Journal, Nr. 7187 (26. Oktober 1913), S. 13-14, hier S. 14.

188 M. N-r.: Ein Eigenbrötler der Modernen. In: Neues Wiener Tagblatt, Nr. 47/1908 (17. Februar 1908), S. 16. 
und in seinem „Aesthetentum [...] gründlicher, radikaler als mancher andere“ sei. Die Verbindung von jenen Merkmalen, die Bourdieu in objektivierte und inkorporierte unterteilt, lag für den Verfasser des Artikels in Schaukals Wunsch begründet, die schöne Form der Literatur auf alle Lebensbereiche auszudehnen: „Er will nicht bloß eine schöne Prosa schreiben, sondern auch die Hand mit den wohlgepflegten Fingernägeln, die diese Prosa schreibt, soll auch schön sein. “189

Eine Zeitschrift von großer Reichweite, die sich ebenfalls kritisch mit Schaukals gesellschaftlicher Rolle auseinandersetzte, war die sozialdemokratische Arbeiter-Zeitung, die am 9. April 1908 das Nostalgiebuch Großmutter rezensierte. Die literaturkritische Betrachtung entwickelt sich $\mathrm{zu}$ einer ideologisch durchdrungenen Analyse von Schaukals elitärem Dichterhabitus. Der anonyme Verfasser mokiert sich über den larmoyanten Ton von Großmutter, die Vergangenheitsverklärung sei Ausdruck einer „Melancholie der Impotenz“, die Vergleiche zwischen der guten alten Zeit und der Gegenwart seien schlichtweg schief. Denn als „Typus der Vergangenheit wird nämlich gewöhnlich das Mitglied einer ruhigen, reichen Patrizierfamilie hergenommen, dem dann ein Proletar [sic!] von heute gegenübergestellt wird. “190 Schaukal zeichne somit nicht moralische oder gesellschaftliche Entwicklungen nach, sondern entwerfe ein negatives Telos der soziostrukturellen Transformation seit dem Ende des 19. Jahrhunderts. Es stelle sich die Frage, so der Verfasser weiter, warum Schaukal in Großmutter kein Kapitel über das Lesen verfasst habe, zumal ihm die „Lesefreude“ wohl verleidet worden sei, „seit sie ganz demokratisiert ist“, denn:

Der Dandy empfindet ja nur jenen Genuß, der einem gesellschaftlichen Vorrecht entspringt. Welche Ströme von Behagen fließen aber aus Büchern mitten ins Volk! Das Lesen, ein viel höherer Genuß als das Theater [. . .], ist nun wirklich längst ein demokratisches Vergnügen geworden, und zwar das edelste. Seit Großmutters Zeiten hat sich darin freilich viel geändert - aber nicht zum Schlimmeren. ${ }^{191}$

Die Kritik endet mit der Bemerkung, dass von Schaukal momentan viel die Rede sei, weil er „Mitarbeiter an sämtlichen deutschen Zeitungen ist.“ Der dichtende Ministerialbeamte war also nicht nur aus einer ästhetischen Abwehrhaltung heraus zum Feindbild der Arbeiter-Zeitung avanciert, er wurde auch aufgrund seines kulturpolitischen Wirkens als Bedrohung wahrgenommen. Die

189 M. N-r.: Ein Eigenbrötler der Modernen, S. 16.

190 st. gr.: Die Bücher des deutschen Hauses. In: Arbeiter-Zeitung, Nr. 99/1908 (9. April 1908), S. 1-2.

191 st. gr.: Die Bücher des deutschen Hauses. 
Gegendiskurse in der Arbeiter-Zeitung belegen Schaukals ideologisch durchdrungenes Schaffen als Dichter und Literaturkritiker.

Am 19. Januar 1910 parodierte dieselbe Zeitung Schaukals drei Jahre zuvor erschienenen, dialogisch konzipierten Kulturglossen Literatur und Giorgione. Die Kritik ist dabei ebenfalls in Form eines Dialoges zwischen einem Maler und einem Schriftsteller verfasst, ironisiert also Schaukals in fiktiver Gesprächsform ausgebreiteten Paragone, der formalästhetisch auf die Renaissance verweist. Abgesehen von der Kritik, dass Literatur und Giorgione ihren eigenen Standpunkt unterlaufen, da sie mit Phrasen gegen die Phrase argumentierten, ärgert den Rezensenten, dass Schaukal

das Kunstreferat für eine große Tageszeitung anstrebt. Erhielte er ein solches übertragen, würde er zu einer Kalamität, zu einer Kunstgefahr, denn das Podium, von dem aus er dann dem Publikum seine Expektorationen über Kunst zurufen würde, gäbe seinen Worten eine Bedeutung und Wirkung, die sie heute glücklicherweise noch nicht haben. ${ }^{192}$

Woraufhin der fiktive Schriftsteller dem Maler zustimmt: „Damit mögen Sie recht haben und auch ich halte ihn zur Ausübung eines derartigen Amtes für nicht berufen, als sei er zu leichtfertig. “193

Während Zeitschriften wie die Wiener Rundschau, Vaterland und vor allem Die Reichspost zu den Befürwortern von Schaukals Dichtung zählten - und andere wie die Neue Freie Presse oder die Wiener Zeitung eine überwiegend neutrale Position einnahmen -, gehörten die Arbeiter-Zeitung und insbesondere auch Der Sturm zum ideologischen wie ästhetischen Gegenlager. Dass die politischen Grabenkämpfe bis etwa 1910 auch Spielraum für objektive Artikel gestatteten, zeigt eine wertschätzende Rezension von Schaukals Schlemihle (1908) in der Jüdischen Volksstimme, deren Publikum sich hauptsächlich aus jüdischen Arbeitern zusammensetzte und die in ihren Beiträgen auch den Zionismus thematisierte. $^{194}$

Doch die (kultur-)politischen Fronten, die sich in der Ersten Republik zusehends verhärteten, begannen sich bereits kurz vor Ausbruch und dann

192 A. R.-r.: Ein Gespräch über vier Bücher. In: Arbeiter-Zeitung, Nr. 18/1910 (19. Januar 1910), S. 1-2.

193 A. R.-r.: Ein Gespräch über vier Bücher. Bereits drei Jahre zuvor hatte Armin Friedmann einen ähnlichen formalen Zugang gewählt, als er in der Wiener Abendpost Schaukals Giorgione in Form eines fiktiven Dialoges besprach; vgl. Friedmann: Vom Kunst-Dichter.

194 Siehe die Rezension von Dr. M. Scherlag: Erzählende Bücher. In: Jüdisches Literaturblatt. Beilage zu „Jüdische Volksstimme“, Nr. 28/1910 (13. Juli 1910), S. 9-10, hier S. 10. Informationen zum Blatt liefert Avraham Greenbaum: [Art.] Jüdische Volksstimme. In: The YIVO Encyclopedia of Jews in Eastern Europe. http://www.yivoencyclopedia.org/article.aspx/Judische_Volksstimme (zuletzt aufgerufen am 31. Juli 2019). 
verstärkt während des Weltkrieges zu bilden. Zählte Schaukal 1910 noch zu den Autoren des Sturm, veröffentlichte Albert Ehrenstein 1914 in demselben Organ die bereits erwähnte, zuerst im Pester Lloyd abgedruckte große Abrechnung, die der Kraus-Schüler mit der gesamten ihm zur Verfügung stehenden satirischen Energie munitionierte. ${ }^{195}$ Schaukal, schreibt Ehrenstein mit Blick auf dessen 1913 erschienene Märchen von Hans Bürgers Kindheit, sei der „Talentvollste und Genieloseste“ unter den zeitgenössischen Dichtern. Er imitiere beliebig Otto Stoessl, Ernst Weiß (1882-1940) und Hermann Graedener (1878-1956), sei im Prinzip aber vor allem „ein anderer Hofmannsthal“. Schaukals Werke überhaupt zu drucken, käme reiner Papierverschwendung gleich, denn „wir haben es in diesem Brünner Dichter nämlich mit einer Art literarischem Tierstimmenimitator zu tun, einem routinierten Fregoli und Verwandlungskünstler“. Schaukal gehe, so Ehrenstein, zur Stilfindung „nach Eichendorff aufs Land“ und sein „momentanes Stilsurrogat ist als ein treffliches Biedergemeier anzusprechen.“196

Die Kritiken über Schaukals Werk und seine Person drückten bisweilen auch die Befürchtung aus, dieser stünde kurz vor dem literarischen Durchbruch. So veröffentlichte der dem Prager Kreis um Max Brod (1884-1968) nahe stehende Camill Hoffmann (1878-1944) 1912 eine Rezension in der Neuen Freien Presse, die Schaukals Position im literarischen Feld als nicht greifbar bezeichnet. Er zieht die vorausblickende Bilanz, dass dieser ein „zwar reichlich begabter, aber von aller Gnade verlassener Literat“ bleiben würde, sollte er seine Pose des überheblichen Kritikers nicht überwinden. Ansonsten drohe Schaukal als „Könner“ zu enden, „der freiwillig verarmt“. Für Hoffmann gründet Schaukals Isolation in dessen produktivem Zorn, den er jedoch mit herablassender Gleichgültigkeit zu kaschieren versuche:

Schaukal hat kein beschauliches, stilles, versöhnliches Temperament. Er tut sich Gewalt an. Er lebt von Impetus, von polemischer Kraft, von Unbeständigkeit, Laune, Unbeherrschtheit - doch er findet es nobler, die nachdenkliche, ,abgeklärte' weisheitsvolle Pose zur Schau zu trage. Dieser Zwiespalt zehrt an ihm, macht ihn wirklich so unglücklich und einsam, wie es so viele seiner Verse sagen [. . .]. ${ }^{197}$

Nach 1918 erfuhr Schaukals Präsenz als negatives wie positives Objekt von Rezensionen und Aufsätzen einen langsamen, aber kontinuierlichen Rückgang.

195 Vgl. Ehrenstein: Oesterreichische Prosa. In: Pester Lloyd, Nr. 189/1913 (10. August 1913), S. 33-34.

196 Ehrenstein: Österreichische Prosa. In: Der Sturm (1914), S. 99.

197 Camill Hoffmann: „Neue Verse“ (1908 bis 1912) - „Beiläufig“. Zwei Bücher von Richard Schaukal. In: Neue Freie Presse, Nr. 17365 (25. Dezember 1912), S. 112. 
Zu Beginn der 1920er Jahre beschäftigten sich auch wohlmeinende Akteure mit dessen begrenzten dichterischen Erfolgen. Johann Černy etwa argumentierte 1924 in der Reichspost, dass sich Schaukals Wert symbolisch, nicht aber an Verkaufszahlen messen lasse. An ihm wiederhole sich das Schicksal Grillparzers (1791-1872), so der nicht zufällig gewählte Vergleich Černys, der dann das von Schaukal selbst nach außen vertretene Imago des einsamen und verkannten Dichtergenies bestärkt: „Dennoch bedeutete es einen Gewinn für den Dichter, der im stillen Frieden seiner vier Wände mit gesteigertem Eifer an sich weiter arbeitete [...].“ Den Glückwünschen würden sich nicht die „hundert Leser“ anschließen, die Schaukal würdig seien, „sondern alle, auf die es ihm und auf die es überhaupt ankommt: und deren sind mehr, viel mehr, als sich aus dem Dunkel des Publikums melden. “198

Auch die Oesterreichische Illustrierte Zeitung widmete Schaukal 1924 anlässlich seines 50. Geburtstags ein Portrait, in dem der Verfasser ganz ähnlich die mangelnde Würdigung seines Gesamtwerks hervorhebt. ${ }^{199}$ Die Linzer Tages-Post beurteilte sechs Jahre später Schaukals Rückzug aus dem literarischen Feld als deutliches Anzeichen einer aus Amerika importierten Gleichsetzung von Verkaufserfolg mit dichterischem Gelingen: „So ist alles einsam geworden, das wahren Wert besitzt, so auch Richard Schaukal.“200

Vor dem Ersten Weltkrieg sah es noch ganz so aus, als würde sich Schaukal zu einem nicht unwesentlichen Akteur im Feld der literarischen Moderne entwickeln, auch als Übersetzer, Herausgeber und Mitarbeiter an Anthologien arbeitete er mit heute kanonisierten Autoren der Zeit zusammen.

\section{4 Übersetzer- und Anthologiennetzwerke}

\subsection{Schaukal als Übersetzer}

$\mathrm{Zu}$ den Akteuren, die Schaukals symbolisches Kapital als Übersetzer steigerten und selbst davon profitierten, zählte Stefan Zweig. Auch diese berufliche Relation sollte sich im Laufe der Zusammenarbeit als problematisch erweisen und in späteren Jahren zu antisemitischen Ausfällen gegen den emigrierten Dichter führen.

198 Johann Černy: Richard Schaukal. Zu seinem 50. Geburtstag. In: Reichspost, Nr. 31/1924 (27. Mai 1924), S. 5.

199 Vgl. Franz Alfons Gayda: Richard von Schaukal. Zum 50. Geburtstag. In: Oesterreichische Illustrierte Zeitung, H. 30/1924 (27. Juli 1924), S. 9.

200 -mm-: Richard von Schaukal: Gedanken. In: Tages-Post, Nr. 292/1930 (19. Dezember 1930), S. 9. 
Um das Jahr 1901 traten sie für ein nicht näher ausgeführtes Übersetzungsprojekt miteinander in Kontakt, vermutlich handelte es sich um den Band Paul Verlaine: Gedichte. Eine Anthologie der besten Übertragungen, der 1902 unter Beteiligung Schaukals bei Schuster \& Löffler in Berlin verlegt wurde. ${ }^{201}$ Zweig arbeitete zu dieser Zeit mit Dichtern und Übersetzern zusammen, die zum Teil auch zu Schaukals Bekanntenkreis gehörten, wie ein Brief an Richard Dehmel vom April 1902 zeigt:

Ich will nun - da die meisten Gedichte mehrfach übersetzt sind - immer die besten für einen schmalen billigen Band wählen, der Deutschland den wesensverwandtesten aller französischen Dichter in annähernder Vollkommenheit repräsentieren soll. Dazu bedarf ich aber der Zustimmung der Dichter und wende mich vor allem an Sie, sehr verehrter Herr Dehmel, als den berühmtesten und besten unserer Übersetzer. Sonst nehme ich noch in Aussicht: Franz Evers, Richard Schaukal, Max Bruns, Johannes Schlaf, Paul Wiegler, Hedwig Lachmann, Otto Hauser und vielleicht noch den einen oder anderen, aber wie bereits gesagt, stets nur das Beste des Besten. ${ }^{202}$

Im selben Jahr gab Zweig mit Camill Hoffmann, der ebenfalls mit Schaukal in Kontakt stand und ihn für die Mimi-Lynx-Übertragung an den tschechischen Übersetzer Hugo Kosterka (1867-1956) vermittelt hatte, ${ }^{203}$ einen deutschsprachigen Baudelaire-Band bei Seemann in Leipzig heraus. Und Hermann Hesse berief sich auf Zweigs „Landsmann“, als er mit ihm in Verbindung trat. ${ }^{204}$ Zweig wiederum rühmte im Februar 1902 gegenüber Hesse seine Büchersammlung, die unter anderem Widmungsexemplare von Schaukal enthalte, und beendete den Brief mit einer wertschätzenden Bemerkung, in der Schaukal indes nicht gut wegkommt:

Haben Sie einmal in Ihrem Leben eine trübe Stunde, da Sie sich ängstigen, ob Ihr Lied und Leben nicht ohne Nachhall verrauscht, so lassen Sie sich aufrichten durch die Gewißheit, daß Sie einem mehr gegeben haben als viele in Deutschland Vielgenannte - mehr wie Falke, Hartleben, Schaukal, Bierbaum etc. etc. - nämlich Ihrem Sie in herzlicher Verehrung begrüßenden Stefan Zweig. ${ }^{205}$

201 Eine Korrespondenz aus jener Zeit findet sich weder im Schaukal-Nachlass in der Wienbibliothek noch im Nachlass Stefan Zweigs im Literaturarchiv Salzburg.

202 Brief Zweigs an Dehmel, 7. April 1902, in: Knut Becker u. a. (Hg.): Stefan Zweig: Briefe 1897-1914. Frankfurt am Main 1995, S. 40.

203 Vgl. die Briefe Camill Hoffmanns an Schaukal, 11. Oktober 1904 und 2. Januar 1905, S-NL, WB.

204 Brief Hesses an Zweig, Januar 1903, in: Volker Michels (Hg.): Hermann Hesse - Stefan Zweig: Briefwechsel. Frankfurt am Main 2006, S. 7.

205 Brief Zweigs an Hesse, 2. Februar 1902, in: Michels (Hg.): Hermann Hesse - Stefan Zweig: Briefwechsel, S. 11. 
Auch in einem im Jahr darauf verfassten Brief zählte Zweig Richard Schaukal zu den überschätzten Dichtern der Gegenwart. Das Schreiben greift die - mehr Hesse als Zweig betreffende - Verunsicherung einer Dichtergeneration auf, die mit dem geschriebenen Wort ihre Existenz sichern, dabei aber keine moralischästhetischen Abstriche machen wollte:

Hermann Hesse ist heute einer der Ersten in Deutschland, ein Junger und Großer, mehr Dichter als Holz und Bierbaum und Schaukal und Otto Ernst und alle, die heute mit klappernden Glockenschwengeln ins Land geläutet werden. Sind das nicht auch Erfolge, wenn Fischer einen Roman acceptiert? Ich wollte ich wäre schon so weit! Wollen Sie materielle Erfolge? Auch diese werden nicht ausbleiben, denn Ihre Bücher werben Freunde; die Gabe, die Sie mir mit Ihren Werken gespendet haben, hat schon vierfache Zinsen getragen, hat Ihnen vier Exemplare abgesetzt und achtfache, zwanzigfache Bewunderung und Verehrung gebracht. Ich weiß Freunde, die Verse von Ihnen auswendig können - ich kann auch nicht wenige - und sie recitieren, wenn man von guten Werken spricht. Ich glaube, Sie sitzen zu sehr im Schwarzwald, um das alles zu wissen. ${ }^{206}$

Wie Hesse stand auch Zweig am Beginn einer großen Karriere, die durch sein Geschick als Netzwerker, durch die großbürgerliche Herkunft und nicht zuletzt durch sein Talent als Übersetzer und Schriftsteller begünstigt wurde. Seit 1906 war er mit eigenen Werken sowie als Herausgeber und Übersetzer Autor des renommierten Insel-Verlags - das Sehnsuchtsziel der dichterischen Ambitionen Richard Schaukals. Umso erstaunlicher mutet dessen erste Reaktion an, als Zweig im Frühjahr 1914 in einem offiziellen Schreiben mit dem gewichtigen Briefkopf des Leipziger Verlagshauses den Empfänger um dessen Mitarbeit an einer vom französischen Verleger autorisierten deutschen Gesamtausgabe der Gedichte Paul Verlaines bat. ${ }^{207}$ Da Schaukal nicht reagierte, wiederholte Zweig in einem weniger formellen Schreiben sein Anliegen:

Sehr verehrter Herr Dr. Zu meinem Bedauern ist sowohl meine als des Insel-Verlags Aufforderung, an unserer großen Verlaine Ausgabe mitzuarbeiten, ohne Antwort geblieben. Ich möchte heute nur noch sagen, wie leid es mir täte, wenn wir Ihre so schönen Übertragungen bei diesem Werke entbehren müßten und wie wichtig es doch für diese Übertragungen selbst wäre, daß sie in dieser Form einem weiten Kreise vermittelt würden. Der InselVerlag hat von dem französischen Verleger alle Rechte auf die einzelnen Werke Verlaines sowie die Ausgabe einer Anthologie erworben, so daß ausser den schon bestehenden eine neue bis [Wort durchgestrichen] Ablauf der gesetzlichen Schutzfrist nicht mehr erscheinen

206 Brief Zweigs an Hesse, 1. November 1903, in: Michels (Hg.): Hermann Hesse - Stefan Zweig: Briefwechsel, S. 24.

207 Brief Zweigs beziehungsweise des Insel-Verlags an Schaukal, datiert auf Frühling 1914, S-NL, WB. 
kann. Nur daß diese eine würdige wird, ist nun meine Sorge und Mühe, die mich auch dringlich verpflichtet, Sie nochmals um Ihre Beteiligung zu bitten. ${ }^{208}$

Daraufhin verfasste Schaukal eine aufwendige Absage in drei handschriftlichen, einer maschinengetippten sowie einer auf offiziellem Briefpapier übertragenen Fassung. Da sich auch diese nicht unterschriebene Letztversion im Nachlass Schaukals befindet, Zweig die Absage aber sichtlich erhalten hat, handelt es sich dabei entweder um eine Kopie oder um das retournierte Original. Die akribische Vorgehensweise belegt jedenfalls, dass es sich dabei um keine gewöhnliche Reaktion auf die Anfrage eines weniger prestigeträchtigen Verlagshauses handelte, wie sie bei Schaukal regelmäßig einlangten. In dem auf den 3. Mai 1914 datierten Brief begründete er das Ausbleiben einer Antwort so ironisch wie selbstsicher mit dem Hinweis darauf, dass er auf unpersönliche Einladungen nicht reagieren zu müssen glaubte; er wolle nun aber, da Zweig insistierte, seine Ablehnung näher begründen. Erstens sei er enttäuscht, dass die Einladung in Form eines standardisierten Schreibens und demzufolge auch an eine ganze Reihe weiterer Übersetzer ausgesandt worden sei. Zudem befürchte er, seine Nachdichtungen könnten ihre künstlerische Eigenständigkeit verlieren, wenn sie in einer Anthologie erscheinen, an der sich ebendiese anderen Dichter beteiligten. Schaukal sah die Einheit durch ein beliebiges Nebeneinander unterschiedlicher Beiträger durchbrochen, wodurch der „tiefere Sinn künstlerischer Notwendigkeit“ nicht erfüllt werde. Zudem äußerte er urheberrechtliche Bedenken, da Georg Müller die Rechte seiner Übertragungen bereits erworben hatte. Nicht zuletzt fürchtete Schaukal - berechtigterweise, wie der weitere Schriftverkehr zeigt -, dass durch seine Beiträge die zweijährige Sperrfrist für die Herausgabe einer eigenen projektierten Verlaine-Anthologie in Kraft trete. ${ }^{209}$

Schaukals anfängliche Skepsis ist also nicht allein mit einem empfindlichen Künstlerego zu begründen. Seine Einwände waren auch ästhetischer und vor allem vermarktungsstrategischer Natur. Zweig äußerte am 5. Mai 1914 sein Bedauern über die Absage und versuchte, mit einer auf Schaukals Habitus und Mentalität abgestimmten Argumentation, den Dichter doch noch zur Mitarbeit zu bewegen:

Sehr verehrter Herr Doktor, ich zögere nicht, zu sagen, dass Ihre Absage mir ungemein bedauerlich ist. An weitere Kreise herantretend, in der Annahme und Aufnahme aber auf den engsten beschränkt, den der relativen Vollendung, wollte diese Ausgabe die Frage endgültig stellen (viel eher als sie beantworten) ob lyrische Nachbildung überhaupt möglich ist. Selbst die Gewissenhaftesten, wie Rilke, haben sich durch diese Aufgabe diesmal angereizt

208 Brief Zweigs an Schaukal, 2. Mai 1914, S-NL, WB.

209 Brief Schaukals an Zweig, 3. Mai 1914, S-NL, WB. 
gefühlt und Sie mögen sich denken, wie drückend es mir ist, einzelne Gedichte, die Sie für mein Empfinden restlos vollendet gegeben haben, durch andere Versuche darzustellen oder (was wahrscheinlich ist) bei Seite lassen zu müssen.

Ich wage da natürlich nicht, Sie umstimmen zu wollen und persönliche Argumente gegen die Ihren zu stellen, die, solange Ihr Empfinden vorhält, selbstverständlich einzig maßgebende sind. Ich will nur wiederholen, dass ich Ihr Fernbleiben so sehr bedauere als möglich und eine dem Unternehmen freundlichere Auffassung - etwa die in sich geschlossene Nachdichtung eines einzelnen Gedichtkreises - sehr begrüßen würde. Die an Sie ergangene und sehr aufrichtig gemeinte Bitte um Ihre Mithilfe bleibt bei mir bestehen und ich wäre sehr erfreut, fände sich doch eine Form, die sie Ihnen wünschenswert macht. Mit den besten Empfehlungen Ihr sehr ergebener Stefan Zweig. ${ }^{210}$

Dieser Brief muss einen Sinneswandel herbeigeführt haben, da Schaukal (in einer nicht erhaltenen Antwort) zusagte, gleichzeitig aber auch seinen Wunsch mitteilte, die älteren Übertragungen vollständig zu erneuern. Damit dürfte wiederum der unter Zeitdruck stehende Herausgeber nicht einverstanden gewesen sein, wie in der Antwort vom 13. Mai 1914 zwischen den Zeilen durchklingt:

Sehr verehrter Herr Doktor [...]. Ich bewundere sehr Ihre Unduldsamkeit gegen sich selbst: mir erschienen die Übertragungen fast alle vollendet und ich staune eigentlich, dass Sie nochmals sie neumachen wollen [...]. Die Übertragungen stellen sich jetzt langsam ein, ich hoffe bald Übersicht zu haben für Wahl und Wunsch. ${ }^{211}$

Nachdem Schaukal seine Zusage zur Mitarbeit erneut zurückgezogen hatte, reagierte Zweig am 25. Mai 1914 mit einem langen, emotionalen Brief. Er gestand darin, vom Plan der Ausgabe anfangs selbst nicht begeistert gewesen zu sein. Doch als er sich die erfolgreiche Anthologie aus dem Jahr 1902 in Erinnerung gerufen habe, sei in ihm die Überzeugung gereift, dass sich auch Übersetzungen durch einen ästhetischen Wert auszeichnen könnten. Um dem französischen Dichter gerecht zu werden und um zu zeigen, „wo unsere deutsche Sprachkunst in unserem Jahrhundert steht“, habe er die Anfrage des InselVerlags angenommen. Wie sehr Zweig über Schaukals ästhetische Orientierung informiert war, beweist die Nennung der Schlegel-Tieck-Übersetzungen Shakepeares, die für dessen translatorisches Selbstverständnis prägend waren. Sie würden eindrucksvoll demonstrieren, wie erst das Zusammenwirken von Dichtern die Fähigkeiten des Einzelnen übertreffe:

Das nun möchte ich an diesem Problem Verlaine erproben - Sie wissen selbst, dass es im Lyrischen keinen besseren Prüfstein gibt. Einer prinzipiellen Ablehnung der Mitarbeit kann ich mich natürlich nicht verschließen. Nicht der Georges, der niemals seine Verse anders

210 Brief Zweigs an Schaukal, 5. Mai 1914, S-NL, WB.

211 Brief Zweigs an Schaukal, 13. Mai 1914, S-NL, WB. 
als in eigener Ausgabe seit dem ersten Tage gab und gibt; nicht der Hofmannsthals, der die einmalige Übersetzung eines Gedichtes als ein Wunder der Wiedergeburt betrachtet und solche Wunder nicht durch den Willen erzeigt wissen will. Wohl aber möchte ich mich der Ihren entgegenstellen, denn Ihr Werk ist da, Sie haben einiges von Verlaine unübertrefflich gegeben, können aber doch andererseits niemals den ganzen Verlaine in höchster vollendetster Form geben - einfach schon deshalb, weil z.B. die Gedichtübertragung Dehmels „An Gott“ unübertrefflich ist, weil da jenes Höchste, das Wunder, schon einmal erreicht ist, das ein zweitesmal nicht geschieht. Sie haben den französischen Verlaine in Ihre Form gegossen, ganz darauf die Glut Ihres eigenen Sprachwillens getrieben [. . . . ${ }^{212}$

Zweig versicherte Schaukal, dass er seine Verlaine-Übertragungen als „Ursubstanz" begreife, anhand derer die deutsche literarische Sprache um 1900 exemplifiziert werden könne:

[D]enn Sie als Dichter sind doch beides, Ihre Persönlichkeit und doch gleichzeitig auch ein Stück crystallisierten Sprachgeistes unseres Jahrhunderts. Und da ich die Essenz aller deutschen lyrischen Melodie, die Synthese der sprachlichen Errungenschaft unserer Zeit gerne ganz geben möchte, würde ich Ihr Fernbleiben um dieser Gemeinsamkeit willen doppelt bedauern. ${ }^{213}$

Und dann verleiht er der anfangs ästhetisch fundierten Bitte mit einer unmissverständlichen Warnung besonderen Nachdruck:

Es soll, wie ich's mir denke, ein repräsentatives Werk sein und ich gebe Ihnen willig zu, dass Ihr Fernbleiben demonstrativ wirken würde. Ich werde in diesem Falle nicht zögern, im Nachwort mein Bedauern zu sagen, dass Sie und George uns fehlen: ein Gedicht von Ihnen wird (ich scheue nicht, es Ihnen zu verraten berdies doch noch in einem nachgestellten Aufsatz von mir abgedruckt sein, in dem ich, die Principien der Auslese erhärtend, von einem Gedicht (La lune blanche alle Versionen der Übertragung, also auch die George und die Ihre citiere [sic!]. So wird da mit erstaunlicher Vielfalt dargestellt sein, wie verschiedenartig ein und dasselbe Gedicht werden kann. Sie sehen also, dass ich keineswegs, auch im Falle der Ablehnung nicht, Ihre Übertragung als Werk herabzusetzen oder zu verschweigen gedenke: im Gegenteil.

[...] Das Niveau wird selbstverständlich ein anderes sein wie vor 10 Jahren - Rilke, Vollmoeller, Werfel, Alfred Kerr, Ernst Stadler, Ludwig Fulda, Carossa, Pagnet, und ein paar Jüngere haben schon rege neue Mithilfe zugesagt und sich heroisch bereit erklärt, eventuelle Refus zu erdulden. Von den vielen bösen Übertragungen der früheren Ausgabe bleibt nichts - schließlich bin ich doch nicht mehr zwanzig Jahre alt und sehe mich anders unterstützt wie damals, wo Dehmel, Henckell, Schlaf, Hauser und Sie die einzigen Pfeiler waren, auf die ich das ganze Gebäude aufbaute, meine Honorarvorstellung 100 Mark umfasste, indess [sic!] sie heute ein[e] wesentlich andere sein wird [...].

212 Brief Zweigs an Schaukal, 25. Mai 1914, S-NL, WB.

213 Brief Zweigs an Schaukal, 25. Mai 1914, S-NL, WB. 
Ich habe mit dem I. V. [Insel-Verlag] keinen Termin vereinbart, weil ich nicht abschließe, ohne daß ich etwas wirklich Repräsentatives für unsere deutsche Sprachcultur von heute sehe. Ich habe keinerlei Honorar mit ihm vereinbart, um immer noch zurücktreten zu können, falls das Resultat mir nicht genügt und die Vollendung und Verantwortung einem andern zu überlassen. Die Zeit ist vorbei, wo ich leicht an Dinge herangieng und ich spüre die Verantwortung, die eine definitive Formung fordert. ${ }^{214}$

Zweig wiederholte das Ansuchen um Mitarbeit, äußerte die Hoffnung, dass die Ablehnung keine künstlerischen Gründe habe und garantierte, dass er die Gedichte sensibel auswählen und auf Schaukal als Urheber dezidiert eingehen werde. Zuletzt stellte er in Aussicht, dass Schaukals Verlaine „vielleicht dann gesondert als ganzes bei der Insel erscheinen“ oder „eine Form neben der grossen Ausgabe gefunden werden könnte." Diesen Satz hat Schaukal rot unterstrichen, eventuell war er ausschlaggebend dafür, dass der kapriziöse Briefverkehr eine neuerliche Wendung erfuhr. Unter der Bedingung, dass die Rechte bei ihm bleiben, zog er schließlich seine Absage zum zweiten Mal zurück. Zweig überbrachte daraufhin die Gegenforderung aus Leipzig: eine eigene VerlaineAusgabe durfte - wie Schaukal zu Beginn bereits befürchtet hatte - frühestens zwei Jahre nach der von Zweig bei der Insel herausgegebenen Anthologie erscheinen. Zugleich versprach Zweig aber, auf Schaukals Nachdichtung gesondert hinzuweisen, den Text würde er ihm sogar vorab „zur Begutachtung vorlegen.“ Er hege keinen Anspruch auf das „Monopol“ an Verlaine-Übertragungen und befürworte ausdrücklich das Erscheinen von Schaukals selbständigem Übersetzungsprojekt. ${ }^{215}$ Da die Veröffentlichung der Gedichtausgabe auf das Jahr 1915 anberaumt wurde, wäre er ab 1917 ,in keiner Weise mehr gebunden. Ich hoffe die Verhandlungen [sind] jetzt abgeschlossen: wir alle drei [auch der InselVerleger Anton Kippenberg, CM] sind wohl froh, künstlerische Bemühungen nicht mehr durch rechtliche Fragen gehemmt zu wissen“, so Zweig im vermutlich letzten Brief vor Kriegsausbruch, der das Projekt dann ohnehin für sieben Jahre zum Erliegen bringen sollte. ${ }^{216}$

Am 7. Mai 1921 nahm Zweig erneut Kontakt zu Schaukal auf und erhielt postwendend die Zusage, an der Verlaine-Anthologie mitzuwirken. Dann ging alles sehr rasch, Korrekturbögen wurden trotz des eingeschränkten postalischen Verkehrs, der, wie in den Briefen steht, auf die Einstellung des

214 Brief Zweigs an Schaukal, 25. Mai 1914, S-NL, WB.

215 Brief Zweigs an Schaukal, 25. Mai 1914, S-NL, WB.

216 Brief Zweigs an Schaukal, undatiert, S-NL, WB. Die WB datiert den Brief auf 1912, was wohl ein Irrtum ist. Vermutlich stammt er aus der Zeit Frühling/Sommer 1914. 
Eisenbahnverkehrs zurückging, zwischen Salzburg und Wien hin und her geschickt. ${ }^{217}$ Ein Jahr später erschienen im Insel-Verlag die Gesammelten Werke Paul Verlaines mit Gedichtübertragungen des Wiener Lyrikers.

Zweig erwähnte auch nochmal Schaukals Projekt einer eigenständigen, deutschsprachigen Anthologie mit Gedichten des französischen Poeten. Doch scheinbar hatte Stefan George die Veröffentlichung verhindert. ${ }^{218}$ Zweig meinte beiläufig am Ende einer Postkarte vom 13. Mai 1921: „Georges Übertragungen liebe ich sehr, doch weiß ich, dass er beharrlich ist, Ihren antologischen [sic!] Nachdruck zu versagen. Mit den besten Empfehlungen. Ihr sehr ergebener Stefan Zweig.“219

Im Feld der literarischen Übersetzungen speziell Verlaines bestand ein nicht zu unterschätzendes Konfliktpotential. Bereits 1894 war Schaukal mit dem Vorschlag einer gemeinsamen Verlaine-Ausgabe an Dehmel herangetreten, wurde von diesem aber brüsk abgewiesen. ${ }^{220}$ Dichter wie Rilke, Hesse und eben Zweig wagten sich an Nachdichtungen des französischen Symbolisten, wobei der Kreis seiner Verehrer noch viel weiter $\mathrm{zu}$ fassen ist; gemeinsam mit Dehmel und George zählte Schaukal zu den frühesten Verlaine-Übersetzern im deutschen Sprachraum. ${ }^{221}$ Hinzu kommt, dass Schaukal Stefan Georges eigene Lyrik zwar schätzte, dessen Übertragungen aus den Jahren 1901 (Die Blumen des Bösen) und 1905 (Zeitgenössische Dichter) bei ihm aber auf massive Kritik gestoßen waren. ${ }^{222}$

Schaukal konnte seine Position im literarischen Feld nicht nur als Kritiker und Rezensent, sondern auch als Übersetzer aus dem Französischen stärken. Sein 1906 bei Oesterheld in Berlin veröffentlichter Band Nachdichtungen vereinte neben Verlaines Versen auch Gedichte des wiederentdeckten französisch-kubanischen Schriftstellers José-Maria de Heredia (1803-1839).

Zu Schaukals 50. Geburtstag rühmte Johann Černy in der Reichspost vor allem dessen Leistungen als Übersetzer: „Daß in Schaukals Nachdichtungen aus dem Französischen [...] die deutsche Uebersetzungskunst ihren höchsten Gipfel

217 Vgl. den Brief Zweigs an Schaukal, 13. Mai 1921, S-NL, WB.

218 Wie genau, ließ sich aufgrund der lückenhaften Quellenlage nicht mehr ermitteln.

219 Postkarte Zweigs an Schaukal, 13. Mai 1921, S-NL, WB.

220 Vgl. den Brief Dehmels an Schaukal, 22. Juni 1894, S-NL, WB.

221 Siehe seine Übertragungen „Pierrot“ und „Der Himmel ist über dem Dache“ in: Moderner Musen-Almanach, Bd. 2 (1894), S. 181-182. Vgl. dazu Warum: Richard von Schaukal als Kritiker und Übersetzer aus dem Französischen, S. 133-135.

222 Vgl. Oesterheld: Schaukal und der George-Kreis, S. 73. 
erklimmt, konnten nicht einmal die vielen Gegner bestreiten, die sich der Fehdelustige durch seine ehrliche Draufgängerei zugezogen hatte.“223

\subsection{Schaukal in Anthologien}

In Richard Schaukals Nachlass finden sich neben Briefen und Verträgen zu Übersetzungsprojekten auch zahlreiche Anfragen von Schulbuch-Herausgebern, die in erster Linie um Abdruckgenehmigungen für seine Gedichte ansuchten. Diese Ansuchen nahmen vor allem nach der Gründung der Ersten Republik zu. Zum einen mögen der formbewusste Stil, die inhaltliche Zugänglichkeit und literaturhistorische Verankerung von Schaukals Lyrik die Herausgeber zur Veröffentlichung der Gedichte bewogen haben. Neben den poetologischen Gründen spielten gewiss auch ideologische Faktoren eine Rolle für das kleine ,Schaukal-Revival' in Schulbuchformat. Bereits 1908 war der Dichter gemeinsam mit Hugo von Hofmannsthal und Karl Schönherr (1867-1943) als literarischer Beirat an der Mittelschulreform beteiligt. ${ }^{224}$

Mit Beginn der Ersten Republik setzten innovative bildungspolitische Initiativen ein, die unter anderem den Ausbau des Schulwesens betrafen, wobei es ,auf dem Gebiet der Schulpolitik [...] zu erbitterten Kämpfen zwischen katholischer Kirche und Sozialdemokratie“ kam. ${ }^{225}$ Aufgrund der sozialen Lage in der Nachkriegszeit war es nicht möglich, eine Preiserhöhung für Schulbücher durchzusetzen, obwohl dies die Buchhändlerfunktionäre anstrebten. Das Vermarktungsvolumen wäre beträchtlich gewesen, bewirkten die Schulreformen doch eine steigende Nachfrage und erhöhte Produktion an Lehrwerken. ${ }^{226}$ Die schulpolitische Situation, mit der auch Veränderungen im Verlagswesen und Buchhandel einhergingen, führte zu der erstaunlichen Situation, dass Schaukal zwar von der lesenden Öffentlichkeit und im literarischen Feld der Zwischenkriegszeit sukzessive weniger rezipiert wurde, jedoch zum Unterrichtsgegenstand und somit zumindest im schulischen Umfeld keineswegs seltener gelesen wurde.

223 Černy: Richard Schaukal. Zu seinem 50. Geburtstage, S. 5.

224 Vgl. [Anon.]: Die Mittelschulreform. In: Neues Wiener Tagblatt, Nr. 17/1908 (18. Januar 1908), S. 4-5, hier S. 4. Bei jener Reform ging es um die Angleichung der Lehrpläne von Gymnasium und Realschule sowie um eine Ausdehnung der Realschule auf acht Jahre, vgl. Hans Altenhuber: Die Geschichte des Faches Pädagogik an der philosophischen Fakultät der Universität Wien von 1850 bis 1922. Diss. Univ. Wien, 1949, S. 117 und S. 121.

225 Bachleitner/Eybl/Fischer: Die Geschichte des Buchhandels in Österreich, S. 247.

226 Vgl. Bachleitner/Eybl/Fischer: Die Geschichte des Buchhandels in Österreich, S. 269-270. 
Bereits 1905, also zu einer Zeit vermehrt einsetzender sozialistischer Bildungsbestrebungen, die im selben Jahr zur Eröffnung der ersten Abendvolkshochschule Europas im Ottakringer Volksheim führte, fragte Helene Scheu-Riesz (1880-1970) bei Schaukal an, ob er an einer Anthologie „künstlerisch wertvoller Jugendschriften“ mitwirken wolle. Nach anfänglicher Zusage lehnte der Dichter zwar ab, allerdings nicht, weil die Ausgabe unter dem „Protektorat des Wiener Volksbildungs-Vereins“ stand, wie Scheu-Riesz schrieb, sondern aufgrund zu geringer Honoraraussichten. ${ }^{227}$ Ein knappes Jahr später verzichtete hingegen der Schriftsteller und Kritiker Arthur Roessler (1877-1955) von sich aus auf einen angefragten Beitrag Schaukals für die Monographien-Sammlung Die Frau, da Schaukals Honorarforderungen zu hoch waren. ${ }^{228}$

Die allgemeine Politisierung und soziale Segmentierung in allen Bereichen des gesellschaftlichen Lebens intensivierte sich vor allem nach 1918 und betraf auch Richard Schaukal. Sein Wirken in den sich überschneidenden Feldern Bildung und Literatur verdeutlicht die zunehmende ideologische Instrumentalisierung seiner Dichtung und (im Sinne Gramscis) Assimilierung seiner Person. Die Felder im sozialen Raum transformierten sich zu Austragungsorten divergierender Weltanschauungen von Parteien, die nicht nur um politischen Einfluss, sondern auch um kulturelle Hegemonie stritten. Schaukal war, wie bereits angedeutet, an den ideologisch-kulturellen Machtkämpfen der Zwischenkriegszeit beteiligt. Diese Konflikte fanden vermehrt im kulturellen Bereich statt und betrafen3 auch die seit Jahrhunderten das literarisch-künstlerische Feld stark beeinflussende Zensur. Am 30. Oktober 1918 konsolidierte die Republik ihr Freiheitsbestreben mit der per Dekret erlassenen Abschaffung der Zensur. Auch wenn strafrechtliche Verstöße nach wie vor geahndet werden konnten, „schien doch endgültig ein Hemmnis des geistig-kulturellen Lebens beseitigt, das im 19. Jahrhundert der Entwicklung des österreichischen Verlagswesens und Buchhandels im höchsten Maße hinderlich gewesen war.“229 Was Autoren wie Hugo Bettauer als liberalen Meilenstein für die publizistisch-literarische Tätigkeit empfanden, betrachtete Schaukal als kulturelle wie moralische Degeneration. Ende der 1920er Jahre entbrannte ein regelrechter Kampf, bei dem auf der einen Seite die Forderung nach einem Schmutz- und Schundparagraphen laut wurde, gegen den auf der anderen Seite Schriftstellerorganisationen schlussendlich erfolgreich protestierten. ${ }^{230}$

227 Briefe Scheu-Riesz' an Schaukal, 8. Juni, 14. Juni und 21. August 1905, S-NL, WB.

228 Vgl. den Brief Roesslers an Schaukal, 12. Juni 1906 und den von Schaukal unterzeichneten Vertrag im S-NL, WB.

229 Bachleitner/Eybl/Fischer: Die Geschichte des Buchhandels in Österreich, S. 248.

230 Vgl. Bachleitner/Eybl/Fischer: Die Geschichte des Buchhandels in Österreich, S. 248. 
Im Fall Bettauer intervenierte vor allem der 1920 gegründete Schutzverband Deutscher Schriftsteller in Österreich, kurz SDSOe. Diesem war es gelungen, „die Autoren aller Prominenzgrade und ungeachtet ihrer Weltanschauungen unter ein organisatorisches Dach zu bringen“, ${ }^{231}$ so Richard Schaukal. Der SDSOe war Ausdruck einer zunehmenden Emanzipation der Autoren, die ihre Stellung im Produktionsprozess des Buches zunehmend reflektierten und eine stärkere Rechtsgrundlage für ihren Berufsstand einforderten. ${ }^{232}$ In Anbetracht dessen erscheint es besonders paradox, dass Schaukal als Mitglied des Schutzverbandes von genau diesem die Intervention gegen Bettauer, einen Kollegen und ebenfalls Mitglied des Verbandes, forderte. Schließlich war gerade der Erhalt der Meinungsfreiheit und die Bekämpfung wiedererstarkender Zensurbestrebungen in Österreich das erklärte Ziel des SDSOe.

Das Ende der Ersten Republik war letztlich das Ergebnis kontinuierlicher antidemokratischer Prozesse, Diskurse und Gewalthandlungen, an deren destruktiver Dynamik auch Schaukal Anteil hatte. Mit der Errichtung des christlichen Ständestaates am 1. Mai 1934 ging eine zunehmende Förderung des patriotischen Bewusstseins der Bevölkerung einher, die sich außerdem gegen die Propaganda der Nationalsozialisten richtete. In diesem Zusammenhang legte der austrofaschistische Ständestaat ein besonderes Augenmerk auf die Kulturarbeit, vor allem auf die Beförderung eines sinn- und gemeinschaftsstiftenden antiurbanen, alpenländischen Österreichbildes. ${ }^{233}$

Die Instrumentalisierung der Kulturbereiche und Bildungseinrichtungen sowie von Instanzen der Buchdistribution lässt sich unter anderem an der Anthologie Das Herz Europas. Ein österreichisches Vortragsbuch (1934) ablesen. ${ }^{234}$ Ihre nationalstaatliche Österreich-Ideologie legt das Vorwort der Anthologie offen, an der unter anderem Peter Rosegger (1843-1918), Bahr und Schaukal, aber auch Zweig, Werfel und Salten mitwirkten.

Diese Österreich-Ideologie war freilich nicht ganz neu. Bereits ab 1917 entstanden ideologisch durchdrungene Sammelwerke, in denen vermehrt die Österreich-Idee propagiert wurde. Der Militärhistoriker Alois Veltzé (1864-1927) publizierte in den letzten beiden Kriegsjahren (mit den vorausgreifenden

231 Vgl. Bachleitner/Eybl/Fischer: Die Geschichte des Buchhandels in Österreich, S. 284.

232 Vgl. Martina Salomon: Die Produktionsbedingungen österreichischer Schriftsteller von 1918 bis heute. Der Schriftsteller zwischen Beruf und Berufung. Diss. Univ. Salzburg, 1986.

233 Vgl. Karlheinz Rossbacher: Programm und Roman der Heimatkunstbewegung. In: Sprachkunst, 5. Jg. (1974), S. 301-326.

234 Robert Lohan, Walther Maria Neuwirth und Viktor Trautzl (Hg.): Das Herz Europas. Ein österreichisches Vortragsbuch. Mit einer kulturkundlichen Einleitung von Oskar Benda. Wien 1934. 
Jahreszahlen 1918 beziehungsweise 1919) seinen Donauland-Almanach, der in der gleichnamigen Zeitschrift unter anderem auch Beiträge von Schaukal und Hofmannsthal („Der Österreicher und der Preuße“) enthielt. Der Almanach belegt dabei auch die hohe Materialqualität, die trotz finanzieller Engpässe in der ersten Zeit nach dem Krieg die Buchproduktion hemmte. So freute sich ein Rezensent vor allem über die gelungene Ausstattung und den angenehmen haptischen Effekt des Almanachs: „Der steife Einband ist von bester Friedensqualität und der Druck der Bilder [...] durch Unterlegung einer Tonplatte in der ästhetischen Wirkung gehoben.“235

Das anthologische Format erfreute sich zweifelsohne großer Beliebtheit, wie auch der Sammelband Österreichische Lyrik der Gegenwart belegt, der 1934 bei Saturn mit einem Beitrag Schaukals erschien. 1938 wurde Saturn, der in der völkischen Presse als ,Judenverlag، verächtlich gemacht wurde, ,arisiert‘. Tatsächlich vereinte der in Wien ansässige Verlag unter seinem Dach sowohl Schriftsteller aus dem konservativen Spektrum als auch Vertreter des liberalen Lagers, die Ablehnung des Nationalsozialismus und Befürwortung der österreichischen Eigenstaatlichkeit führte sie in unfreiwilliger Eintracht zusammen. ${ }^{236}$

Ein weiterer Verlag, der sich die Förderung junger österreichischer Lyrik in Form von Anthologiepublikationen und Dichterwettbewerben zum Ziel setzte, war Krystall. Für die 1930 von dem Lyriker, Erzähler und Essayisten Friedrich Sacher (1899-1982) herausgegebene Anthologie junger Lyrik aus Österreich, die unter anderem Gedichte von Josef Weinheber (1892-1945) und Otto Basil (1901-1983) umfasste, schrieb Schaukal das Vorwort. Aus dem Umfeld des Verlages etablierte sich kurzfristig ein Zirkel, der sich unter der Leitung Sachers zum Dichterkreis ,Die Gruppe‘ zusammenschloss. Der Gründer unternahm den Versuch, Schaukal als Spiritus Rector zu gewinnen. In Briefen spricht er den älteren Kollegen mit „Meister“ an, bezeichnet ihn als „Haupt“ der österreichischen Gegenwartslyrik und bittet ihn schließlich um ein Vorwort für die geplante Sammlung. Die Anthologie junger Lyrik aus Österreich orientiere sich an den von Klaus Mann (1906-1949) im Reclam-Verlag herausgegebenen Sammelwerken, so Sacher, der den Markt als „seltsam aufnahmefreudig“ für Lyrikbücher bezeichnete. ${ }^{237}$ Am 1. März 1930 teilte er Schaukal mit, dass Krystall unter

235 [Anon.]: Donauland-Almanach 1919. In: Feldkircher Anzeiger, Nr. 51/1918 (18. Dezember 1918), S. 2.

236 Vgl. Murray G. Hall: Saturn-Verlag (Phaidon Verlag) (Wien). In: Hall: Österreichische Verlagsgeschichte. Bd. 2, 1985. Online: http://verlagsgeschichte.murrayhall.com/?page_id=562 (zuletzt aufgerufen am 31. Juli 2019).

237 Briefe Sachers an Schaukal, 8. März 1929 und 13. Januar 1930, S-NL, WB. Mit der KlausMann-Anthologie meint Sacher vermutlich die gemeinsam mit Erich Ebermayer (1900-1970) 
ziemlich ungünstigen Bedingungen den Druck zugesagt habe, einige der weniger bekannten Autoren müssten jedoch „subscribieren“. 238

Die Subskription, also die Übertragung des finanziellen Risikos von Verlagsseite auf die Autoren (oder private Fördergeber) hatte sich in der Zwischenkriegszeit zur gängigen Praxis vor allem für die ertragsärmere Gattung Lyrik entwickelt. Der Kunsthistoriker und Geschäftsführer des Krystall-Verlages, Franz Juraschek (1895-1959), erläutert diese unternehmerische Vorgehensweise folgendermaßen: die Autoren sicherten dem Verlag Vorausbestellungen auf ihre Werke zu,

die 2/3 der Verlagskosten - die Verlagsregie nicht gerechnet - decken mußten. Wer die Schwierigkeiten Lyrik zu vertreiben kennt, weiß, daß diese Verlagstätigkeit nicht auf Gewinn bedacht war, sondern einerseits einer kulturellen Aufgabe dienen sollte, andererseits den Namen des Verlages bekanntzumachen berufen war. Beides ist in gewissen Grenzen, die die schwierigen wirtschaftlichen Verhältnisse der Systemzeit bedingten, auch gelungen. ${ }^{239}$

In Anbetracht des nicht geringen finanziellen Risikos stimmte Sacher die Liste der Beiträger mit dem in seinen Augen erfahrenen Lyriker Schaukal ab. Von Verlagsseite wurde der Herausgeber wiederum aufgefordert, Gedichte von Otto Basil aufzunehmen.

Im Mai 1930 wurde die Anthologie schließlich bei der Verlags-Druckerei Jahoda \& Siegel in Auftrag gegeben, die bereits in zweiter Generation für die Vervielfältigung und den Vertrieb der Fackel verantwortlich zeichnete. ${ }^{240}$

Nach der Veröffentlichung der Lyrik-Anthologie wandte sich Sacher mit seiner Idee, einen Dichterzirkel zu gründen, erstmals an Schaukal. In einem mit „Bitte streng vertraulich!“ überschriebenen Brief führte er seine Pläne aus:

Ich gehe eben daran, einen neuen Buchtyp, das Gruppenbuch, zu schaffen. - 8 jungösterreichische Lyriker vereinigen sich zu einer dauernden Arbeitsgruppe, die in regelmäßiger Wiederkehr (2 oder 3 Jahre) ihr Gruppenbuch vorlegt [... ]. In unserem kollektivistischen Zeitalter ist es mit der Einzelgängerei vorbei [...]. Als Einzelgänger waren wir Jungen, wir 30- und 40jährigen, wir verfluchte Kriegsgeneration, einfach zum völligen Untergange verdammt, wir zwischen zwei Geschlechterfolgen beinahe Zerriebenen. ${ }^{241}$

und Hans Rosenkranz im Berliner Spaeth-Verlag herausgegebene Anthologie jüngster Prosa (1927).

238 Brief Sachers an Schaukal, 1. März 1930, S-NL, WB.

239 Zit. nach Murray G. Hall: Krystall-Verlag (Wien-Leipzig). In: Hall: Österreichische Verlagsgeschichte. Bd. 2, 1985. Online: http://verlagsgeschichte.murrayhall.com/?page_id=348 (zuletzt aufgerufen am 31. Juli 2019).

240 Vgl. den Brief Sachers an Schaukal, 22. März 1930, S-NL, WB.

241 Brief Sachers an Schaukal, 12. Juli 1930, S-NL, WB. 
Es sollte sich dabei nicht um eine Anthologie oder einen Almanach im engeren Sinne handeln. Die Beiträger würden mehr Raum erhalten, um in längeren Abständen, dafür aber regelmäßig, ein geeignetes Publikationsorgan zur Verfügung gestellt $\mathrm{zu}$ bekommen. Sacher bezeichnete folgende acht Personen als Gruppenmitglieder: Wilhelm Franke (1901-1979), Josef Kalmer (1898-1959), Theodor Kramer (1897-1958), Erika Mitterer (1906-2001), Hans B. (konnte nicht ermittelt werden), Friedrich Sacher (1899-1982), Wilhelm Szabo (1901-1986) und Julius Zerzer (1889-1971). ${ }^{242}$

Der erwähnten Anthologie junger Lyrik aus Österreich (1930) folgten dann Dichtungen in niederösterreichischer Mundart (1931), Die neue Lyrik in Österreich (1932), schließlich Die Gruppe. Neun Lyriker aus Österreich (1932), eine Anthologie, die bereits im Titel auf den Gruppencharakter verweist, sowie zuletzt Zwölf Lyriker aus Österreich (1935).

Im weiteren Umfeld der Sacher-Krystall-Gruppe publizierten außerdem Paula Ludwig (1900-1974) und Rudolf Henz (1897-1987). Sacher versicherte Schaukal, dass er nur jene Lyriker für die Anthologien berücksichtige, die dieser befürwortet, und er bat ihn um ein weiteres Nachwort für das Gruppenbuch.

Ein erstes Zusammentreffen des literarischen Zirkels sollte im Herbst 1930 stattfinden, Schaukal war zur Inauguration des Dichterkreises eingeladen. ${ }^{243}$ Doch schon am 26. November 1930 teilte Sacher mit, dass er die Gruppe aufgelöst habe, da der Gemeinschaftsgedanke nicht funktioniere. Anscheinend ging der Entschluss auf Schaukals Ratschlag zurück, Sacher bedankte sich jedenfalls für die Empfehlung. ${ }^{244}$ Dass noch 1932 die Anthologie Die Gruppe. Neun Lyriker aus Österreich erschien, könnte mit einer verzögerten Produktion des Verlags zusammenhängen.

Das Engagement von Krystall für dezidiert junge Lyrik aus Österreich war aus ökonomischer Sicht nicht sehr ertragreich. Literaturhistorisch betrachtet erlaubt das auf Anthologien spezialisierte Verlagshaus aber einen bemerkenswerten Blick auf die lebendige österreichische Lyrikproduktion der 1930er Jahre und auf die Bestrebungen einer literarischen Gruppenkonstituierung im Umfeld Richard Schaukals. Dass dieser sich nicht im Mittelpunkt einer Künstlergruppe positionieren (lassen) wollte, zeigt die Zurückhaltung gegenüber Sacher, dem er schließlich die Auflösung seines lyrischen Kreises nahelegte.

Der jüngere Schriftsteller Friedrich Schreyvogl (1899-1976) hatte schon 1926 mit Schaukals strengem Urteil gehadert, das der Jugend keine Zugeständnisse

242 Vgl. den Brief Sachers an Schaukal, 12. Juli 1930, S-NL, WB.

243 Vgl. den Brief Sachers an Schaukal, 25. August 1930, S-NL, WB.

244 Vgl. den Brief Sachers an Schaukal, 26. November 1930, S-NL, WB. 
mache: „Eins freilich verstehe ich nicht ganz: warum hat ein Künstler Ihrer Größe und Überlegenheit eine solche Härte für die Jugend dieser chaotischen Zeit? Warum hat neben Ihrem Nein zur Unreife nicht auch eine wärmende Freundschaft für das schwer Reifende (wie könnte es in dieser Zeit anders sein!) Platz?“ 245

Der Krystall-Verlag, bei dem auch Schreyvogl Gedichte veröffentlichte, setzte mit dem 1938 publizierten Bekenntnisbuch österreichischer Dichter, in dem über 70 Autorinnen und Autoren den sogenannten Anschluss Österreichs an Nazideutschland begrüßten, seinen unrühmlichen Schlusspunkt. Zu den Beiträgern, die mit Schaukal (der darin nicht verzeichnet ist) in Kontakt standen, zählen neben Sacher und Schreyvogl auch Wilhelm Franke, Franz Karl Ginzkey (1871-1963), Rudolf List (1901-1979), Max Mell (1882-1971), Franz Staude (1886-1947), Karl Hans Strobl (1877-1946), Friedrich Winterholler (1882-1945) und Josef Weinheber $(1892-1945) .^{246}$

\section{Vereine, Verbände und Organisationen}

Vor dem Ersten Weltkrieg erstreckte sich Schaukals Agieren im literarischen Feld in erster Linie auf das deutsche Kaiserreich. Im Gegensatz zu Hofmannsthal wurde er nicht in die bekannten Wiener Salons eingeführt, die zu Beginn des 20. Jahrhunderts auch für Dichter von erheblicher netzwerkstrategischer Bedeutung waren. Zwar stand er mit Marie von Ebner-Eschenbach und Ferdinand von Saar in Verbindung, doch begünstigten diese Kontakte keineswegs seine Karriere als Beamter oder Schriftsteller.

In Schaukals Briefen an Hugo Salus, Hermann Hesse und Max Brod kommt dessen Abneigung gegen eigene Dichterlesungen und gegen die bloße Teilnahme an den Vorlesungen anderer Dichter in literarischen Gesellschaften und Künstlervereinigungen immer wieder zur Sprache. Doch während er Vortragstätigkeiten in Österreich-Ungarn mied, reiste er für solche Zwecke sehr wohl nach Deutschland. Besonders hervorzuheben ist hier Herwarth Waldens Einladung nach Berlin, die den Verfasser des erfolgreich lancierten Andreas von Balthesser vor ein Dilemma stellte. Walden bat Schaukal, am 28. November 1907 für den im Salon von Paul Cassirer (1871-1926) zusammenkommenden ,Verein für Kunst' aus seinem Dandybuch vorzulesen. ${ }^{247}$ Schaukals Antwort auf Waldens Schreiben vom 3. Juli 1907 blieb zunächst aus. Daraufhin wiederholte Walden am 15. Juli mit der Bitte

245 Brief Schreyvogls an Schaukal, 16. Februar 1926, S-NL, WB.

246 Vgl. Hall: Krystall-Verlag (Wien-Leipzig). Online: http://verlagsgeschichte.murrayhall. com/?page_id=348 (zuletzt aufgerufen am 31. Juli 2019).

247 Vgl. den Brief Waldens an Schaukal, 3. Juli 1907, S-NL, WB. 
um Bestätigung sein Anliegen, doch der Angefragte entpuppte sich als schwieriger Korrespondenzpartner, der vermutlich nähere Informationen über die Veranstaltung einholte, wie demselben Brief zu entnehmen ist. Walden führte aus, dass der Zweck des Vereins „die Propaganda für zeitgenössische Kunst“ sei und lockte mit dem Argument, dass die öffentlichen Abende gut besucht seien und stets von der gesamten Presse besprochen würden. Richard Dehmel, Frank Wedekind, Richard Muther (1860-1909), Georg Brandes (1842-1927), Georg Simmel (1858-1918), Detlev von Liliencron (1844-1909), Gustav Mahler (1860-1911) und Richard Strauss (1864-1949) hätten bereits an den Abenden mitgewirkt. Das Honorar betrage 100 Mark Reisevergütung plus Reingewinn des Kartenverkaufs. ${ }^{248}$ Eine beworbene öffentliche Lesung, die unter dem Label ,zeitgenössische Kunst' firmierte und nicht zuletzt in einem jüdischen Umfeld stattfand, dürfte Schaukal, der in Balthesser gerade ein solches Szenario ironisiert hatte, befremdet haben. Allerdings stimmte die ästhetische Ausrichtung des ,Vereins für Kunst' mit seiner literarischen Präferenz weitestgehend überein. Nicht zuletzt versprach der Vortrag eine stärkere Anbindung an die künstlerischen sowie publizistischen Kreise in Berlin.

Waldens Verein war am 18. April 1904 mit einer Lesung Liliencrons ins Leben gerufen worden und ließ weitere Leseabende mit Beiträgen der zu jener Zeit von Schaukal nicht minder geschätzten Dichter Max Brod, Arno Holz und Rainer Maria Rilke folgen. ${ }^{249}$ Dass der Autor seine dichterisch ausgedrückten zweckentbundenen Kunstideale realiter nicht als letzten Maßstab nahm, beweist seine Reaktion auf die Einladung: Schaukal feilschte um ein höheres Honorar. Walden lehnte zwar ab, kam seinem Ansinnen aber mit dem Vorschlag einer Vorverlegung der Lesung entgegen. $\mathrm{Zu}$ Beginn der Saison sei mit mehr Publikum und dementsprechend mit höheren Einnahmen aus dem Kartenverkauf zu rechnen. ${ }^{250}$ Doch Schaukal erbat erneut ein höheres Honorar, worauf Walden anmerkte, dass der Zweck des Vereins darin liege, bedeutende zeitgenössische Künstler einem großen Publikum bekannt zu machen und der Verein kein Geschäftsunternehmen sei. ${ }^{251}$ Darauf schickte Schaukal zwei weitere Briefe, auf die Walden Anfang September nur noch gereizt antwortete, dass der ganze Abend schon geplant sei und Änderungen nicht mehr in Betracht kämen. ${ }^{252}$ Im Endeffekt fand die

248 Brief Waldens an Schaukal, 15. Juli 1907, S-NL, WB.

249 Vgl. Friedrich Pfäfflin: Herwarth Walden und Karl Kraus, Adolf Loos und Oskar Kokoschka. Die Anfänge im Kunstsalon Paul Cassirer - 1910. In: Ein Fest der Künste. Paul Cassirer. Der Kunsthändler als Verleger. Hg. von Rahel Feilchenfeldt und Thomas Raff. München 2006, S. 165-176, hier S. 165-166.

250 Vgl. den Brief Waldens an Schaukal, 20. Juli 1907, S-NL, WB.

251 Vgl. den Brief Waldens an Schaukal, 20. August 1907, S-NL, WB.

252 Vgl. den Brief Waldens an Schaukal, 9. September 1907, S-NL, WB. 
Balthesser-Lesung nicht statt. Für denselben Zeitraum sind stattdessen ein Vortrag von Henry van der Velde (1863-1957) am 14. November 1907 sowie eine Dichterlesung Heinrich Manns am 21. November 1907 verzeichnet, ein Ersatzprogramm, das Schaukal gegen den Strich gegangen sein dürfte. ${ }^{253}$

Auch wenn es 1907 zu keinem Berlin-Besuch kam, unterstreicht die Einladung dennoch seine Position als Dichter im literarischen Feld Deutschlands, und sie erstaunt, da Walden für die Dichterlesungen und Vorträge im ,Verein für Kunst‘ ansonsten auf den Freundes- oder näheren Bekanntenkreis zurückgriff. Walden war auf den österreichischen Schriftsteller aufmerksam geworden, kurz bevor er sein Sturm-Netzwerk aufzubauen begann, über das sich in der Folge einige der einflussreichsten Künstler profilieren sollten. ${ }^{254}$ Karl Kraus las erstmals am 13. Januar 1910 im ,Verein für Kunst', doch hatte auch er zu Beginn des Kontaktes skeptisch auf die Einladung aus Berlin reagiert.

Walden hatte während einer Wien-Reise im Jahr 1909 den Herausgeber der Fackel und Adolf Loos kennengelernt, kurz darauf begann er sich für die Vermittlung von Kraus' Schriften einzusetzen. Der erste Schritt zur Förderung talentierter, in Deutschland wenig bekannter Künstler war die Organisation regelmäßig stattfindender Dichterabende im ,Verein für Kunst‘, der bis 1913 existierte und dann in den Sturm-Kreis überging. ${ }^{255}$ Schaukals $1910 \mathrm{im}$ Sturm publizierter Aufsatz über Loos ist der Nachhall seiner kurzfristigen Einbindung in den Berliner Künstlerzirkel, der vor allem später mit dessen ästhetischer und weltanschaulicher Position stark differierte. Es ist sehr wahrscheinlich, dass Franz Blei oder Alfred Kubin, der 1901/1902 Werke im Salon Cassirer ausgestellt hatte, den Kontakt zwischen Walden und Schaukal hergestellt hatte. Kraus und auch Loos kommen als Vermittler nicht in Betracht, da Walden mit beiden erst zwei Jahre nach der Korrespondenz mit Schaukal Bekanntschaft schloss.

Um 1910 war Schaukal zu einer zeitkritischen Instanz avanciert, dabei machte er sich vermehrt auch mit Blick auf stadtbildnerische Fragen sowie als Kenner und Förderer bildender Künstler einen Namen. 1911 besuchte er zum Beispiel die Hagenbund-Ausstellung in der Wiener Zedlitzhalle, die Werke von

253 Vgl. Irene Chytraeus-Auerbach: Herwarth Waldens frühe Aktivitäten: Networking im Namen des „Verein für Kunst“. In: Der Aufbruch in die Moderne. Herwarth Walden und die Europäische Avantgarde. Hg. von Irene Chytraeus-Auerbach und Elke Uhl. Berlin 2013, S. 13-34, hier S. 30.

254 Vgl. Chytraeus-Auerbach: Herwarth Waldens frühe Aktivitäten; siehe auch Peter Sprengel: Verein für Kunst. In: Handbuch literarisch-kultureller Vereine, Gruppen und Bünde 1825-1933. Hg. von Wulf Wülfing, Karin Bruns und Rolf Parr. Stuttgart/Weimar 1998, S. 465-469.

255 Vgl. Pfäfflin: Herwarth Walden und Karl Kraus, Adolf Loos und Oskar Kokoschka, S. 165-166. 
Anton Faistauer (1887-1930), Oskar Kokoschka (1886-1980) und Anton Kolig zeigte. $^{256}$ Der um 1908 an die Öffentlichkeit getretene Hagenbund entwickelte sich in den folgenden Jahren zu einer Künstlervereinigung moderner Ausprägung, die Schaukal mit Interesse verfolgte. Nach dem Besuch der Ausstellung von 1911 wandte er sich an Ministerialrat Georg von Förster mit der Bitte, das Gemälde Der nackte Knabe von Anton Kolig, dem späteren Begründer des expressionistischen Nötscher Kreises, zu erwerben, ob als Privatier oder im staatlichen Auftrag, konnte nicht ermittelt werden. Mit Kolig entspann sich ein reger Briefwechsel, aus dem hervorgeht, dass der Beamte auch dessen Befreiung vom Militärdienst erwirkte und Kolig als Kriegsmaler in die Kunstgruppe des K.u.k.Kriegspressequartiers berufen wurde.

Kolig portraitierte Schaukal und seine Familie; Schaukals erstgeborener Sohn Wolfgang (1900-1981), der in den 1920er Jahren als Kolig-Schüler im Nötscher Kreis verkehrte, wurde selbst Maler. Richard Schaukals Affinität für Koligs religiös expressionistische Kunst verwundert insofern, als der Hagenbund vor allem ab 1912 durch explizite Körperdarstellungen die staatlichen Sittenwächter auf den Plan rief. Der Künstlerkreis musste die von der Stadt zur Verfügung gestellte Zedlitzhalle räumen. „Das markierte einen Wendepunkt im Ringen um kulturelle Hegemonie“, zumal die katholisch-konservative Christlichsoziale Partei die Halle für eigene Ansprüche zu nutzen begann, so Edward Timms: „Diese Episode signalisierte einen Sieg des alten Österreichs über die heimatlos gewordene Wiener Moderne. Ohne Raum keine Resonanz!“‘257

Schaukals Interesse für bildende Kunst und Architektur - und seine zunächst auch recht progressiven Meinungen hierzu - waren recht avanciert. $\mathrm{Zu}$ seinen propagierten Anliegen zählte etwa, eine fortschrittliche Stadtraumästhetik mit dem Anspruch auf Bewahrung des alten Stadtbildes zu versöhnen. Auf diese Weise erregte Schaukal auch außerhalb Österreichs die Aufmerksamkeit von Architekturvereinigungen. Ein Jahr nach der Gründung des Deutschen Werkbundes nahm Wolf Dohrn (1878-1914) im Namen der am 6. Oktober 1907 in München ins Leben gerufenen und in Darmstadt ansässigen Vereinigung Kontakt zu Schaukal auf, um ihn über die „Erfolge der modernen Bewegung in Deutschland“ zu unterrichten und als Mitglied zu gewinnen. ${ }^{258}$

$\mathrm{Zu}$ den Werkbund-Mitgliedern zählten neben den Künstlern Heinrich Vogeler und Josef Hoffmann (1870-1956) auch anerkannte Architekten wie Walter Gropius (1883-1969) und Otto Wagner, außerdem Politiker wie Walther Rathenau, Gustav

256 Vgl. Timms: Dynamik der Kreise, S. 108-109.

257 Timms: Dynamik der Kreise, S. 110.

258 Brief Dohrns an Schaukal, o. J., S-NL, WB. 
Stresemann (1878-1929) sowie Verleger wie Eugen Diederichs. In der Gründungssatzung wurden die „Veredelung der gewerblichen Arbeit“ sowie die Erziehung, Förderung und Verbreitung des Gewerbes und seiner Akteure postuliert. „Vom Sofakissen bis zum Stadtplan“ reichte die Vision, Kunst und industrielle Produktion miteinander in Einklang zu bringen. ${ }^{259}$ Der Werkbund war antihistoristisch ausgerichtet und versuchte, Fragen der moralisch fundierten Warenästhetik mit der Anwendung moderner Technologien zu beantworten. Ein sichtbares Zeichen seines Wirkens in Wien ist die 1932 eröffnete Werkbundsiedlung im Stadtbezirk Hietzing, an der auch Adolf Vetter (1897-1963) beteiligt war.

Der Architekt und Fachphilosoph Vetter war der Verbindungsmann zwischen dem Werkbund und Richard Schaukal. Vetter betätigte sich dichterisch, verkehrte in Kaffeehauszirkeln und prägte als Vordenker einer schlichten wie humanen Architektur theoretisch und praktisch die Wiener Stadtraumgestaltung der 1920er Jahre. ${ }^{260}$ Er stand ab 1912 mit dem architekturbegeisterten Dichter in Kontakt und gehörte später dem Gründungsvorstand der RichardSchaukal-Gesellschaft an. Obwohl Schaukal sein „Unbehagen“ gegen „,solche Bünde“ gegenüber Vetter äußerte, gleichviel ob literarischer oder architektonischer Natur, blieben sie ein Leben lang in Verbindung; Vetter sandte seinem Briefpartner bauliche Gutachten zu und tauschte sich mit ihm über detaillierte baugewerbliche Themen und Fragen der Materialbearbeitung aus. ${ }^{261}$

Doch aus der fachlichen Korrespondenz entwickelte sich im Jahr 1920 kurzfristig eine „freundliche Gegnerschaft“. ${ }^{262}$ Unwissentlich sei Vetter Schaukals Bewerbung um das Amt des Staatstheaterpräsidenten im Wege gestanden, wie er dem Dichter im selben Brief rückblickend mitteilte. Eigentlich hatte sich nur Vetter um die Leitung der nach dem Krieg umstrukturierten Staatstheaterverwaltung beworben. ${ }^{263}$ Nachdem Vetters alleinige Kandidatur be-

259 Der Ausspruch stammt von dem Architekten Hermann Muthesius: Wo stehen wir? In: Jahrbuch des Deutschen Werkbundes 1912, S. 11-26, hier S. 16. Zur Geschichte des Werkbundes siehe Joan Campbell: Der Deutsche Werkbund 1907-1934. Aus dem Amerikan. von Toni Stolper. Stuttgart 1981.

260 Vgl. Ursula Prokop: [Art.] Hans Adolf Vetter. In: Architektenlexikon Wien 1770-1945 Online, 2005/2007. http://www.architektenlexikon.at/de/664.htm (zuletzt aufgerufen am 31. Juli 2019).

261 Vgl. die Briefe Vetters an Schaukal, 31. Mai 1912, 29. Mai 1920 und 3. September 1930, S-NL, WB.

262 Vetter in einem Brief an Schaukal, 29. Mai 1929, S-NL, WB.

263 Siehe dazu die Übersicht zu den komplexen administrativen Veränderungen von Elisabeth Großegger: [Art.] Bundestheaterverband, Österreichischer (ÖBTV). In: Österreichisches Musiklexikon Online, 2002. http://www.musiklexikon.ac.at/ml/musik_B/Bundestheaterver band.xml (zuletzt aufgerufen am 31. Juli 2019). 
kanntgegeben worden war, legte die Christlichsoziale Partei Einspruch ein und erhob aus politischen Gründen Schaukal zum Gegenkandidaten. ${ }^{264}$ Dessen ungeachtet wurde Vetter zum ersten Staatstheaterpräsidenten der neu gegründeten Republik ernannt, was aber dem freundschaftlichen Kontakt zu Schaukal keinen Abbruch tat. ${ }^{265} 1933$ gestand Vetter Schaukal seinen Neid auf dessen unverrückbare katholisch-konservative Prinzipien und stimmte seinem Briefpartner in der Abneigung gegen alles Jüdische $\mathrm{zu}$, vor allem gegen Wassermann und Zweig. ${ }^{266}$ In einem weiteren Brief aus dem Jahr 1933 beschreibt Vetter zudem seinen ungünstigen Eindruck von Thomas Mann und verfällt dabei in eine dem Empfänger willkommene Kritik an dessen literaturbetrieblicher Konsekration:

Th. Mann, den ich vor ein paar Jahren näher persönlich kennen lernte, missfiel mir damals sehr. Ich habe dieses Unangenehme an ihm vor allem dem Erfolg angelastet, dem grossen industriellen Vertrieb von „Geist“. Für Dich liegt was Tröstliches in diesem Abstieg Th. Manns! Deine nach innen wie nach aussen gleich reinlich und krystallhart sein wollende Art schliesst ,Erfolg‘ aus, hättest Du ihn, so wärst Du nicht Du; Du hattest ihn ja schon und musstest ihn verwirken [... . ${ }^{267}$

Die Bewerbung um das Amt des Staatstheaterpräsidenten zeigt letztlich, dass Schaukal, der nach Kriegsende den Staatsdienst quittiert hatte, auf andere Erwerbsquellen angewiesen war. Sohn Wolfgang, soeben knapp dem Militärdienst entgangen, wurde im selben Jahr volljährig, die beiden jüngeren Kinder, Georg (1907-1983) und Lotte (1908-1993), besuchten noch das Wiener Schottenstift-Gymnasium. Dass die Familie nach dem Krieg in nicht gerade wohlhabenden Verhältnissen lebte, wird in den Briefen sehr deutlich. Gleichwohl konnten sie die Villa in Grinzing (ein Umzug stand mehrmals zur Debatte) und auch das Sommerfrische-Anwesen am Semmering behalten, in dem die Familie mehrere Monate des Jahres verbrachte.

Ein Teil des ökonomischen Kapitals, das nach Kriegsende sowohl Einbußen im literaturkritischen als auch im schriftstellerischen Bereich erfuhr, wurde von staatlicher Seite ausgeglichen. Am 4. März 1919 beschloss das Kuratorium der Eduard-von-Bauernfeld-Stiftung, den Bauernfeldpreis auf fünf Schriftsteller aufzuteilen. Julius Bittner (1874-1939), Rudolf Holzer, Otto Stoessl, Paul Wertheimer (1874-1937) und Schaukal empfingen den mit insgesamt 1.500 Kronen

264 Vgl. [Anon.]: [ohne Titel]. In: Illustriertes Wiener Extra-Blatt, Nr. 152/1920 (4. Juni 1920), S. 3. 265 Vgl. den Brief Vetters an Schaukal, 7. Oktober 1921, S-NL, WB.

266 Vgl. den Brief Vetters an Schaukal, 23. Februar 1933, S-NL, WB.

267 Brief Vetters an Schaukal, 3. März 1933, S-NL, WB; Hervorh. im Orig. als Unterstreichung. 
dotierten Förderpreis. ${ }^{268}$ Neben dieser einmaligen Unterstützung erhielt Schaukal eine von Bundeskanzler Ignaz Seipel persönlich abgesegnete Monatsrente für seine Verdienste als Schriftsteller und Staatsbediensteter. Am 12. Februar 1926 hatte der Dichter beim Generalsekretariat der Christlichsozialen Partei Österreichs um eine „außerordentliche Pensionszulage“ angesucht und am 19. April die Bewilligung in der Höhe von jährlich 1.800 Kronen erhalten. $^{269}$ Im Mai 1926 wurde er vom amtierenden Bundespräsidenten Michael Hainisch (1858-1940) offiziell mit dem Titel eines Sektionschefs in den Ruhestand verabschiedet. $^{270}$

Nach Kriegsende konzentrierte Schaukal sein dichterisches Wirken und seine zunehmende (kultur-)politische Tätigkeit auf Österreich. Am 1. Februar 1922 hielt er seine erste öffentliche Dichterlesung mit gesungenen Einlagen der Kammersängerin Marie Gutheil-Schoder (1874-1935) in der Secession ab, die seit ebendiesem Jahr von Christian Ludwig Martin (1890-1967) geleitet wurde. Der Buchillustrator Martin war ein Schüler von Rudolf Jettmar (1869-1939), der wiederum zwischen 1899 und 1906 mit Schaukal wegen einer Gedichtillustration für die Zeitschrift Ver Sacrum in Kontakt stand. ${ }^{271}$

Dass Schaukal nach Kriegsende bereit war, Dichterlesungen abzuhalten, die er ansonsten ostentativ mied, ${ }^{272}$ mag erstaunen. Und dass seine erste Vorlesung ausgerechnet im für den künstlerischen Jugendstil emblematischen Gebäude der Wiener Secession stattfinden sollte, ist nicht weniger verwunderlich. Doch während die Anfänge der neuen Kunst im Gebäude mit der goldenen Blätterkuppel von einem avantgardistischen Geist geprägt waren, den Gustav Klimt (1862-1918), Koloman Moser (1868-1918), Josef Hoffmann, Joseph Maria Olbrich (1867-1908) und andere im Gründungsjahr 1897 verkörperten, kam es 1905 zur Spaltung zwischen den ,Raumkünstlern“ und einer Fraktion konservativer Akteure rund um Josef Engelhart (1864-1941), die sich

268 Vgl. [Anon.]: Der Bauernfeldpreis . In: Neues Wiener Tagblatt, Nr. 76/1919 (18. März 1919), S. 9.

269 Vgl. den Briefwechsel zwischen Schaukal und Seipel im S-NL, WB.

270 Vgl. [Anon.]: [ohne Titel]. In: Neue Freie Presse, Nr. 22164 (30. Mai 1926), S. 13.

271 Vgl. die Briefe zwischen Jettmar und Schaukal im S-NL, WB, zum Beispiel vom 17. Januar 1901 und 14. Oktober 1901.

272 Als großen Sympathiebeweis gegenüber Hesse besuchte Schaukal 1908 dessen Vorlesung im Wiener Kunstsalon Heller (vgl. Brief Schaukals an Hesse, 16. Oktober 1908, H-NL, LAM), während er den in mehr oder weniger zeitlicher Nähe stattfindenden Veranstaltungen von Max Brod und Hugo Salus fernblieb, worauf Salus ihm die Freundschaft aufkündigte (siehe den Brief von Brod an Schaukal vom 5. Februar 1909 und Salus' Brief an Schaukal vom 13. März 1907, S-NL, WB). 
schließlich durchsetzte. ${ }^{273}$ „Die konservative Nachfolge-Secession wurde erfolgreich fortgeführt - allerdings für ein anderes Publikum.“274

Der Gründungsakt dieser neuen Ausrichtung war die im November 1905 eröffnete „Ausstellung moderner religiöser Kunst“, die unter Richard Kraliks (1852-1934) Schirmherrschaft stand und an der überwiegend katholische Künstler beteiligt waren. ${ }^{275}$ Das neue konservative Kunstverständnis, das Präsident Christian Ludwig Martin verkörperte, erklärt, warum Schaukal gerade dort eine Bühne für seine spärlich gehaltenen Auftritte bereitet wurde.

Alois Essigmann war jedenfalls begeistert, dass Schaukal eine Dichterlesung in der Secession plante. ${ }^{276}$ Der Freund sollte an die Öffentlichkeit treten, um das Etikett des „esoterischen“ Dichters zu korrigieren, so Essigmann an Schaukal: „Um einen Ruf zu haben wie etwa Gerhart Hauptmann, müßten Sie - grob gesprochen - zehnmal mehr leisten als er, der Dramatiker! Für solche Nuancen aber haben die ,Vermittler` zwischen Künstler und Publikum keinen Sinn. “277

Als ,Vermittler' bezeichnete Essigmann die den Literaturbetrieb ökonomisch verwaltenden Akteure, also Verleger, Redakteure und die Vorsitzenden künstlerischer Vereinigungen, die - wie er im selben Brief fortfährt - die Geschmacksbedürfnisse der „Masse“ im Blick behalten müssten. Doch eben jene Rücksicht auf eine Käuferklientel war Schaukal sein gesamtes dichterisches Leben lang zuwider; beim Publikum liege die Schuld am sowohl inhaltlichen wie formalen Niedergang des Buches, so ein Befund aus dem Jahr 1904:

Das Bedürfnis nach guter Buchware fehlt in der Zeit der Leihbibliotheken und Tagesblätter. Das Buch ist nicht mehr der ehrliche Freund des stillen Lesers. Schreiende Titelbilder räkeln sich in den Auslagfenstern. [...] Die teuren Luxusbände sind für die Menschen da, die schon so wie so um das Wesen der Buchschönheit wissen. Für die anderen arbeitet die Dampfpresse nach „bewährter“ Schablone. Ist es denn besser bestellt um Artikel des Hausbedarfs? Geschmack ist heute mehr denn je bei den Wenigen. ${ }^{278}$

Die Situation dürfte sich knapp zwei Jahrzehnte später in Schaukals Augen kaum gebessert haben. Doch Essigmann insistierte, dass er sich den Reklamemaßnahmen nicht widersetzen sollte, und er erteilte dem Freund eine väterliche Rüge: Als er Karten für die Dichterlesung im Konzertbüro Gronner besorgte, stellte er fest, dass ein Kamerad aus Kriegszeiten Inhaber und Hauptverantwortlicher des

273 Vgl. Timms: Dynamik der Kreise, S. 84-101.

274 Timms: Dynamik der Kreise, S. 101.

275 Vgl. Timms: Dynamik der Kreise, S. 101.

276 Vgl. den Brief Essigmanns an Schaukal, 26. Dezember 1921, S-NL, WB.

277 Brief Essigmanns an Schaukal, 25. Januar 1922, S-NL, WB.

278 Schaukal: Das Buch, S. 2. 
Kartenverkaufs für den Schaukal-Abend sei. Dieser beklagte sich bei Essigmann über Schaukals Eigenheit, nur eine Lesung anberaumen und von Werbemaßnahmen gänzlich absehen zu wollen. Essigmann versuchte, den Freund von der Notwendigkeit der Reklame zu überzeugen, schließlich werde selbst im „Judenblatt“, wie er das Wiener Journal bezeichnete, eine Anzeige geschaltet. Außerdem forderte er Schaukal auf, eine Lesetournee durch die „Tschechei“ (Brünn, Prag, Troppau) in Betracht zu ziehen. Der befreundete Dichter und Publizist drängte dem Protegé seine Vermittlerdienste mit allem Nachdruck auf:

Dieser Zufall, dass Ihr Manager ein alter Kamerad von mir ist und dass Sie und er einander gefunden haben, ohne meine Zuthun, erscheint mir wie eine Fügung Gottes. Denn nun kann ich meine Dienste als Puffer anbieten. [...] Sie halten vielleicht einen solchen Puffer überhaupt für überflüssig. Ich aber nicht! Sie sind in Punkto Berührung mit der Öffentlichkeit heikler zu behandeln als ein rohes Ei. Und dazu kommt, dass Sie in Ihrem tiefsten Innern doch immer die größte und breiteste Öffentlichkeit ersehnen, obwohl Sie sie (und mit Recht) verachten und verachten können. ${ }^{279}$

Die Dichterlesung in der Secession verlief nicht sonderlich zufriedenstellend, einige der Besucher verließen bereits vor Veranstaltungsende den Saal. Essigmann begründete dies mit der Größe des Raumes, der schlechten Akustik, den $\mathrm{zu}$ hohen Eintrittspreisen und einem Programmfehler. ${ }^{280}$ Ein anwesender Redakteur schilderte seine Eindrücke des Abends im Neuen Wiener Journal folgendermaßen:

\footnotetext{
Man sah vor sich einen sehr soignierten Herrn, der inzwischen Hofrat geworden ist, eine Gestalt wie aus einer Brummelästhetik [sic!], mit eingeklemmtem Monokel und einem eben so sonoren wie herrischem Organ. Für die schönen Gedichte konnte man sich herzlich erwärmen; sie sind zuweilen von erster Qualität. „Balthesser“ wirkte schon ein wenig wie vieux jeu. Einige schöne Lieder sang Frau Gutheil-Schoder mit großer Anmut und Intelligenz. ${ }^{281}$
}

Die wechselseitige Überlagerung von diversen fiktiven wie realen Dandytypologien, von George Brummell (1778-1840) über Andreas von Balthesser bis zu Richard Schaukal, war Teil der durchdachten Performance des Vortragenden. Ihr Effekt verfehlte seine Wirkung zumindest auf den Verfasser des kurzen Artikels im Neuen Wiener Journal nicht. Allerdings vertrat der Autor auch die geläufige

279 Brief Essigmanns an Schaukal, 25. Januar 1922, S-NL, WB; Hervorh. im Orig. als Unterstreichung.

280 Vgl. die Briefe Essigmanns an Schaukal vom 25. Januar 1922 und 3. Februar 1922, S-NL, WB.

281 [Anon.]: Vortragsabend Richard Schaukal. In: Neues Wiener Journal, Nr. 10145 (3. Februar 1922), S. 8. 
Meinung, dass nur Schaukals Lyrik überdauern werde und dass die Lesung einer nostalgischen Inszenierung gleichgekommen sei. „Schaukal gehört der Reihe jener Wiener Dichter an, die in den neunziger Jahren als Neutöner auftraten“, heißt es schon im ersten Satz. Auch bringt der Artikel die Verbindung von sozialer Subjektivierung und poetischer Verortung zur Sprache:

$\mathrm{Zu}$ seinen aphoristischen Sachen zeigte er einen gewissen aristokratischen wie Kulturhochmut. So kam dieser geistvoll soignierte Schriftsteller auf die Seite der Eigenbrötler. In dieser Haltung schrieb er sein Buch vom Herrn v. Balthesser. Es ist dies jetzt eine Geste von vorgestern, der Aesthetizismus einer jetzt gealterten Generation. ${ }^{282}$

Mit Blick auf die Dichterlesung in der Secession tritt der Widerspruch zwischen Schaukals Elitebewusstsein und den geläufigen Marktmechanismen zutage. Immer wieder drängten ihn die sehr viel pragmatischer denkenden Freunde, Hilfe anzunehmen, um seine Handlungspläne, die in den 1920er Jahren vermehrt mit der Akquise von ökonomischem Kapital gleichbedeutend sind, zu erfüllen.

Gerade der Briefwechsel mit Essigmann verdeutlicht Schaukals zunehmend prekäre Situation. In den Briefen vom 15. und 20. August 1919 besprechen sie die Brennholzbeschaffung für den „unter Heizkalamitäten“ leidenden Freund, wie sich Essigmann diskret ausdrückt. ${ }^{283}$ Der einstige Förderer und finanzielle Unterstützer wurde mehr und mehr selbst zum Bittsteller. 1936 wandte sich Schaukal mit der Bitte um finanzielle Unterstützung an Theodor Herzmansky (1900-1974), einen Freund seines Sohnes Wolfgang und wie dieser Schüler Anton Koligs. In einem zweiten Brief nahm er das Ansuchen beschämt wieder zurück. ${ }^{284}$ Auch soziale Rendite bezog Schaukal zu dieser Zeit nur noch aus dem nostalgischen Kapital. Am 17. November 1940 suchte seinerseits Herzmansky Schaukals Kontakt, da er den Altwien-Film Ein Leben lang mit Paula Wessely (1907-2000) gesehen hatte und an die Zeit vor dem Ersten Weltkrieg erinnert worden war. Schaukal, so Herzmansky ein Jahr nach Beginn des Zweiten Weltkrieges, sei für ihn das „Symbol“ und „Wahrzeichen“ einer glücklicheren Epoche. ${ }^{285}$

Die ökonomischen Misslichkeiten dürften von der Öffentlichkeit zunächst unbemerkt geblieben sein. Schaukal verkörperte auch nach Ende des Ersten Weltkrieges noch den altösterreichischen Hofratstypus, so das Neue Wiener Jour-

282 [Anon.]: Vortragsabend Richard Schaukal.

283 Brief Essigmanns an Schaukal, 11. Dezember 1918, S-NL, WB.

284 Vgl. den Brief Herzmanskys an Schaukal, 12. August 1936, S-NL, WB.

285 Brief Herzmanskys an Schaukal, 17. November 1940, S-NL, WB. 
nal 1922, das milde über eine skurrile Figur von „,vorgestern“ berichtete. ${ }^{286}$ Blieb der Dichter in Wien noch eine altbekannte Gestalt, die in der Presse nicht mehr nur mit Kritik oder Lob bedacht, sondern der nostalgisch gedacht wurde, hing ihm in Deutschland zu Beginn der 1930er Jahre bereits der Ruf „eines exotischen Vogels von Uebersee“ an, wie der in Hamburg lebende Schaukal-Fan Carlos Darapsky sich ausdrückte. ${ }^{287}$ Der Rechtsanwalt und Schriftsteller Darapsky, mit dem sich ein reger Briefaustausch entwickelte, projizierte auf Schaukal seine Sehnsucht nach aristokratischer Dichtergröße. Am 22. Juli 1931 schrieb er dem verehrten Dichter: „Ich selbst habe eine Reihe Ihrer Bücher hier vor Jahren mit Bitterkeit im Ramschverkauf bei Karstadt gesehen. “288

Nicht viel besser erging es Schaukal bei seinen Versuchen, in Deutschland mit Dichterlesungen für das eigene Werk zu werben. Kurz nach dem nicht gerade glänzend verlaufenen Vortragsabend in der Secession reiste Schaukal nach Leipzig, um am 20. Februar 1922 eine ebenso wenig erfolgreiche Lesung vor dem Schiller-Verein zu halten. Essigmann tröstete den Freund mit den altbekannten Argumenten: Es liege am „Lärm“ der Zeit, dass manch dichterische Stimme von Wert nicht gehört werde, wohingegen andere wie Karl Kraus Erfolg durch Lautstärke und stimmliche Präsenz erzielten. ${ }^{289}$

Neben der Verlagsstadt Leipzig war auch Dresden einer der präferierten Orte für Leseauftritte. Doch Schaukals Prestige und Kontakte reichten nicht aus, um dorthin vermittelt zu werden. Christian Gaehde (1875-?), Leiter der Literarischen Gesellschaft in Dresden, lehnte Schaukals Offerte einer Dichterlesung ab und bot dem Anfragenden aus Wien an, er könne bei einem Ausfall als kurzfristiger Ersatz einspringen, was wiederum Schaukal ablehnte. ${ }^{290}$

Der eigentliche Ort für Schaukals literarisch-politische Neupositionierungen nach dem Krieg war also Wien. Ein Teil seiner Selbsteinschreibung in den dichterischen Kanon dieser Zeit erfolgte über Vorträge, die jedoch nicht viel mehr waren als nostalgische Gesten und ästhetizistische Reminiszenzen. Der zweite Teil der öffentlichen Inszenierungen war von katholisch-zeitkritischer Ideologie geprägt und dabei nicht minder rückwärtsgewandt.

Am 24. September 1925 erhielt Schaukal von Adolf Innerkofler (1872-1942) die Einladung, auf dem Schriftstellertag des Verbands katholischer Schriftsteller und Schriftstellerinnen Österreichs, der auf den 11. Mai des Folgejahres angesetzt war, den Festvortrag zu halten. Das Gros der geplanten Vorträge am

286 [Anon.]: Vortragsabend Richard Schaukal.

287 Brief Darapskys an Schaukal, 23. Juni 1931, S-NL, WB.

288 Brief Darapskys an Schaukal, 23. Juni 1931, S-NL, WB.

289 Briefe Essigmanns an Schaukal, 21. Februar 1922 und 23. Februar 1922, S-NL, WB.

290 Vgl. den Brief Gaehdes an Schaukal, 8. August 1921, S-NL, WB. 
Schriftstellertag, der im kleinen Saal des Militärkasinos eröffnet wurde, widmete sich dem Themenkomplex Presse und der Stellung der Schriftsteller zum Medium Zeitung. Anschließend sollte im großen Festsaal das zeitsatirische Mysterienspiel An der Schwelle des Gerichts von Eduard Hlatky (1834-1913) aufgeführt werden.

Hinter dem Verband katholischer Schriftsteller und Schriftstellerinnen Österreichs stand der von Richard Kralik und Franz Xaver Eichert (1857-1926) ins Leben gerufene Gralbund, eine von 1905 bis 1937 bestehende katholische Schriftstellervereinigung neuromantischer Prägung. Das zentrale Organ bildete die in Wien und dann in Münster verlegte Zeitschrift Der Gral, ${ }^{291}$ an der sich auch Schaukal mit mehreren Beiträgen beteiligte. Der Brünner Dramatiker Hlatky gehörte ebenso dem Gralbund $a^{292}$ wie der Südtiroler Schriftsteller Adolf Innerkofler, ${ }^{293}$ der mit Schaukal in Verbindung getreten war.

Bereits seit 1907 standen Kralik und Schaukal unregelmäßig in Kontakt, ihre publizistischen Wege kreuzten sich erneut 1911, als sie im Auftrag des Verbandes katholischer Schriftsteller und Schriftstellerinnen am von Josef Neumair (1877-1960) herausgegebenen Jahresbericht literarischer Neuerscheinungen mitarbeiteten. „Fast der ganze Gralbund [und] alles, was unter den katholischen Dichtern Österreichs einen Namen hat“, sei darin vertreten, so Josef Weingartner (1885-1957) in der Reichspost. ${ }^{294}$

Neun Jahre später hatte sich der Austausch zwischen Kralik und Schaukal intensiviert. Hauptthema des Briefwechsels war die Reform der katholischen Presse, sie sandten sich aber auch literarische Texte zu und tauschten sich über missliebige Zeitgenossen aus, etwa über Hermann Bahr und Josef Redlich (1869-1936), die in der „österreichischen Frage Zwillinge“ seien und aufgrund ihres „Opportunismus“ Kralik offenkundig ärgerten. ${ }^{295}$ Der Begründer des Gralbundes lud Schaukal schließlich am 9. Oktober 1920 in seine am Carl-LudwigPlatz - seit 1934 Richard-Kralik-Platz - gelegene Wohnung ein, wo in engem Kreis kulturphilosophische Vorträge und Debatten abgehalten wurden. Zu den Teilnehmern der ,Dienstags-Abende‘ gehörten unter anderem Ignaz Seipel und

291 Vgl. Felix Czeike: [Art.] Gralbund. In: Historisches Lexikon Wien. Online: https://www. geschichtewiki.wien.gv.at/Gralbund (zuletzt aufgerufen am 31. Juli 2019).

292 Vgl. Czeike: [Art.] Eduard Hlatky. In: Historisches Lexikon Wien. Online: https://www. geschichtewiki.wien.gv.at/Eduard_Hlatky (zuletzt aufgerufen am 31. Juli 2019).

293 Vgl. Czeike: [Art.] Adolf Innerkofler. In: Historisches Lexikon Wien. Online: https://www. geschichtewiki.wien.gv.at/Adolf_Innerkofler (zuletzt aufgerufen am 31. Juli 2019).

294 Josef Weingartner: Literarische Post. Ein literarischer Jahresbericht. In: Reichspost, Nr. 583/1911 (17. Dezember 1911), S. 37.

295 Brief Kraliks an Schaukal, 11. Dezember 1920, S-NL, WB. 
Kardinal Gustav Piffl (1864-1932). Kraliks Einladung war gleichbedeutend mit der Aufforderung, sich dem katholischen Bund anzuschließen. Doch in Schaukals Nachlass finden sich keine Belege für eine Teilnahme. Die Gralbund-Treffen waren stets auf denselben Wochentag (dienstags) und die gleiche Uhrzeit (zwischen 6 und 8 Uhr) angesetzt. Dies scheint Schaukal vergessen oder ignoriert zu haben, denn er lud seinerseits Kralik für Dienstag, den 10. Juni 1924, zu sich nach Grinzing ein. Dieser antwortete am 6. des Monats mit einer Absage, die zwischen Vorwurf und neuerlicher Einladung schwankte. Kralik betonte, dass jeden Dienstag „Vorträge mit Debatte“ in seiner Wohnung stattfänden, das Treffen am 10. Juni sei bereits das zweihundertzehnte seiner Art. ${ }^{296}$ Schaukals Interesse am Gralbund und an den gemeinschaftsstiftenden Zusammenkünften in Kraliks Wohnung dürfte nicht sonderlich groß gewesen sein. Auch beim Thema Journalismus waren Schaukal und Kralik bei weitem nicht immer einer Meinung. Zwar einigten sie sich darauf, dass auch der katholische Journalismus reformiert gehöre, doch störte Kralik offenbar Schaukals Antihaltung, die sich auch gegen solche Gruppierungen richtete, die in ideologischen Fragen mit der Linie des Dichters übereinstimmten. Am 27. Dezember 1920 schrieb Kralik:

Bedenken Sie, daß Sie sich doch selber als über den Parteien Stehender erklären! Damit können Sie weder die Katholiken noch die Juden gewinnen. Manche Ihrer Bücher und Gedichte sind gewiß nicht sehr katholisch; das tut mir nichts, aber man kann Sie dann nicht so unbedingt den Katholiken als katholischen Dichter empfehlen, wie man gern wollte. ${ }^{297}$

Er kritisierte außerdem Schaukals positive Erwähnung des insbesondere in den 1840er Jahren aktiven Schriftstellers und evangelisch-lutherischen Geistlichen Karl Stöber (1796-1865) im Gewissen, womit er der Zeitschrift eine für Katholiken inakzeptable protestantische Ausrichtung verliehen hätte. Im selben Brief übte Kralik auch Kritik an Alois Essigmann, der zu den wenigen Vertrauten Schaukals zählte. Dieser könne mit Schaukals Gedankenwelt nicht Schritt halten. Konflikte bestanden demnach nicht nur zwischen ideologisch divergierenden Akteuren, sondern auch innerhalb derselben Interessensgruppen.

Schaukal suchte in den 1920er Jahren über den Kontakt zu Kralik letztlich aber auch Anschluss an die der Christlichsozialen Partei nahestehende Reichspost. Er hatte begriffen, dass sich nach 1918 alle Sphären des öffentlichen Lebens politisiert hatten ${ }^{298}$ und näherte sich daher dem christlichsozialen Lager

296 Brief Kraliks an Schaukal, 6. Juni 1924, S-NL, WB.

297 Brief Kraliks an Schaukal, 27. Dezember 1920, S-NL, WB; Hervorh. im Orig. als Unterstreichung.

298 Vgl. Timms: Dynamik der Kreise, S. 151. 
an. Kralik versicherte Schaukal 1920 auf dessen Nachfrage, ein Feuilleton über ihn in der Reichspost veröffentlichen zu wollen, ${ }^{299}$ was sich aber offensichtlich zerschlug. Erst 1926 publizierte ein Autor mit dem Pseudonym ,X.Y.Z. in der Reichspost eine „Studie“ über Schaukal. ${ }^{300}$ Schon zwei Jahre zuvor war seine Person anlässlich seines fünfzigsten Geburtstages von seinem Kontaktmann aus dem böhmisch-mährischen Neuromantik-Netzwerk, Johann Černy, im Blatt gewürdigt worden. ${ }^{301}$ Schaukal selbst publizierte keine Beiträge in der Reichspost, doch die Zeitung erwähnte ihn in den 1920er Jahren regelmäßig und besprach seine Werke positiv.

Im katholisch-konservativen Netzwerk Wiens war Schaukal als Vortragender, etwa für den Verband österreichischer Schriftsteller und Schriftstellerinnen, wie auch als Beiträger für die einschlägige Presse aktiv. So hielt er am 22. und 29. März sowie am 5. April 1930 im erzbischöflichen Palais Dichterlesungen. Diese fanden auf Veranlassung von Kardinal Piffl statt, der zwischen 1913 und 1932 Präsident der Leo-Gesellschaft war. ${ }^{302}$ „Der Dichter, der sich nur sehr selten in der Oeffentlichkeit vernehmen läßt“, lese am ersten Abend Prosa, am zweiten Lyrik und zuletzt aus Goethes Faust, so die Ankündigung in der Reichspost. $^{303}$ Auch die Wiener Zeitung berichtete über einen der selten gewordenen öffentlichen Auftritte Schaukals, wobei vor allem seine Person im Zentrum des Artikels stand: „Richard Schaukals Persönlichkeit entspricht [ . . ] der künstlerischen Wesensart der Werke; auch ihm selbst ist einsame, für sich stehende, fast herbe und abweisende Art angeboren. Wie seine Schriften, repräsentiert er selbst Adelstyp. “ Schaukal sei ein feiner, aber kein wirkungsvoller Vorleser, allerdings entbehre der improvisierende Vortragsstil nicht einer gewissen „geistigen Intensität. “304

Eine sowohl literarische als auch ideologisch-politische Verbindung bestand, wie erwähnt, zu Friedrich Schreyvogl, der seit 1924 der literarischen Sektion der Österreichischen Leo-Gesellschaft vorstand und als ihr Obmann auf Kralik folgte. Er stand mit dem Dichter für einen am 21. März 1933 abgehaltenen Leseabend in Kontakt, der im Saal des Österreichischen Büchereiverbandes im

299 Vgl. Postkarte Kraliks an Schaukal, 9. Oktober 1920, S-NL, WB.

300 Vgl. X.Y.Z.: Richard Schaukal. Eine Studie über ein österreichisches Dichterschaffen.

301 Černy: Richard Schaukal. Zu seinem 50. Geburtstage, S. 5.

302 Vgl. Czeike: [Art.] Friedrich Gustav Piffl. In: Historisches Lexikon Wien. Online: https:// www.geschichtewiki.wien.gv.at/Friedrich_Gustav_Piffl (zuletzt aufgerufen am 31. Juli 2019). 303 [Anon.]: Vorlesungen von Richard v. Schaukal. In: Reichspost, Nr. 70/1930 (21. März 1930), S. 5 .

304 E. R.: Theater und Kunst. Vorlesung Dr. Richard Schaukal. In: Wiener Zeitung, Nr. 73/ 1930 (28. März 1930), S. 5. 
erzbischöflichen Kurhaus stattfand. Immerhin 1.500 Einladungen seien ausgesandt worden, so Schreyvogl. ${ }^{305}$

Ein weiterer Vertreter der katholisch-kulturkritischen Bewegung, den Schaukal bewunderte, der aber auf dessen Avancen nicht einging, war Theodor Haecker. 1933 führte Schaukal mit Haeckers Vertrautem, dem Architekten und Philosophen Hans Kestranek (1893-1949), einen Briefwechsel, in dem sich der Wiener Schriftsteller erkundigte, warum Haecker auf die Widmung des KrausEssays nicht reagiert habe. Kestranek entschuldigte seinen Freund, der in Bremen wegen politischer Agitation festgenommen worden sei. Im Briefwechsel entwickelten die Korrespondenzpartner die Vision eines von Österreich ausgehenden „Europäischen Denkens“, das als dritte Kraft dem „Teutonismus“ und Bolschewismus entgegentreten müsse. ${ }^{306}$ Sie tauschten sich außerdem über ökonomische Sorgen aus. Kestranek berichtet im Sommer 1933: „Von der [ ... ] materiellen Not der Zeit sind wir alle mehr oder weniger betroffen. Ich selbst habe auch mein bescheidenes Vermögen fast völlig eingebüßt und lebe in München wie ein armer Student.“307

Trotz der ähnlichen politischen wie ideologischen Auffassungen blieb der Kontakt mit Kestranek und somit die intendierte Anbindung Schaukals an Haecker erfolglos. Nachdem er sich erneut über die mangelnde Anerkennung beklagt hatte, gestand Kestranek:

In Ihrer Nachbarschaft fürchtet man wohl das feindliche Feuer auf sich zu ziehen, - anders ist es mir unerklärlich, daß man von Ihnen „abrückt“, und vielleicht lassen auch Sie sich eine solche ironische Erklärung gefallen. - Ist sie aber falsch, so bleibt noch die Erwägung, ob es nicht besser ist, manche Leute misszuverstehen, um mit ihnen auszukommen. ${ }^{308}$

Schaukals Versuche, sich in den 1930er Jahren den Zirkeln des österreichischen ,Renouveau catholique' anzuschließen, waren von ebenso geringem Erfolg wie seine Anbindungsversuche an literarische Gruppierungen der Vorkriegszeit. Sein forderndes, bisweilen strategisches Werben um die Gunst Richard Kraliks, Hans Kestraneks und vor allem Theodor Haeckers stieß keineswegs auf Gegensympathien, und auch die Erwartung, in den Brenner-Kreis aufgenommen zu werden, wurde schlussendlich enttäuscht. Nach Schaukals Tod erinnerte sich Kestranek gegenüber dem katholischen Theologen Joseph Bernhart (1881-1969) versöhnlich an den schwierigen Briefpartner von einst:

305 Vgl. den Brief Schreyvogls an Schaukal, 16. Januar 1933, S-NL, WB.

306 Brief Kestraneks an Schaukal, 2. August 1933, S-NL, WB.

307 Brief Kestraneks an Schaukal, 25. August 1933, S-NL, WB.

308 Brief Kestraneks an Schaukal, 25. September 1933, S-NL, WB. 
In den Tagen, da Sie in Wien waren, ist Richard von Schaukal dort gestorben. Gestern erhielt ich erst die Todesanzeige. Sein Hinscheiden geht mir sehr nahe. Im September ist Franz Blei in New York gestorben. Bei mir gibt es nun eine Geisterversammlung ehemaliger Freunde. Hofmannsthal ist mit dabei. Die drei, die sich kaum sahen, nur zum Teil mochten, kommen nun bei mir zusammen, auch einem, der sozusagen nicht mehr ist. Eigentlich ein Karambol von vier Kugeln, jede glatt und rund, die sich an einem Punkte vielleicht berühren, nur um sich zu stoßen, abzustoßen. Was für eine Zeit, die so in Unvereinbares zerfällt. ${ }^{309}$

In den letzten Lebensjahren war Schaukal nur mehr im Wiener Volksbildungshaus Urania (1909 eröffnet) zu sehen gewesen, das sich in der Zwischenkriegszeit zu einem wesentlichen politisch-ideologischen und literarischen Resonanzraum etabliert hatte. Die Genehmigung zur Errichtung des rundturmartigen Gebäudes ist als symbolische Maßnahme des bürgerlich-konservativen Wiener Gemeinderats $\mathrm{zu}$ werten. Seit 1904 bemühten sich sozialistische Akteure wie David Josef Bach (1874-1947) und Viktor Adler (1852-1918) um einen schöpferischen Gegenentwurf zu den bürgerlichen Hegemoniebestrebungen im Kultur- und Bildungssektor. Dabei konzentrierte sich die Arbeiterbewegung auch auf kulturelle Initiativen wie den Ausbau der Volkshochschulen. 1905 eröffnete, wie bereits erwähnt, im Ottakringer Volksheim die erste Abendvolkshochschule Europas, wenige Jahre später avancierte die Urania zu ihrem volksbildnerischen Antipoden. ${ }^{310}$ Dort fand am 3. Dezember 1941 auf Vermittlung von Leopold Liegler (1882-1949) einer der letzten öffentlichen Auftritte Schaukals statt. Der Literaturkritiker und Freund von Karl Kraus zählte in seiner späteren Lebensphase zu den christlich geprägten Dichtern und sympathisierte auch mit Richard Schaukal. Er hielt die Einleitung zu dessen Dichterlesung in der Urania und verfasste den im Mitteilungsblatt der Schaukal-Gesellschaft abgedruckten Nachruf auf den Dichter. Ein zweiter Vortragsabend mit Schaukal war zunächst für Mai 1942 geplant, aufgrund des befürchteten Publikumsmangels jedoch nicht realisiert worden. ${ }^{311}$

Die Richard-Schaukal-Gesellschaft veranstaltete regelmäßig Vorleseabende in der Urania. ${ }^{312}$ Sie wurde am 25 . November 1929 ins Leben gerufen, um den (angeblich) in Deutschland etablierten Dichter auch in Österreich einer „breiten Masse bekannt zu machen.“313 Der Gründungsvorstand bestand aus Hans von

309 Brief Kestraneks an Joseph Bernhart aus dem Herbst 1942, abgedruckt in: Der Brenner, H. 18 (1954), S. 197-216, hier S. 205.

310 Vgl. Timms: Dynamik der Kreise, S. 17-18.

311 Vgl. die Briefe Lieglers an Schaukal, 7. November 1941 und 20. März 1942, S-NL, WB.

312 Vgl. den Brief Walther Horwitz' an Schaukal, 8. März 1941, S-NL, WB.

313 [Anon.]: Gründung einer Richard-Schaukal-Gesellschaft. In: Wiener Zeitung, Nr. 273/1929 (27. November 1929), S. 6. 
Arnim (1859-1931), Josef Bick (1880-1952), Emil Wohlgemuth, Wilhelm Haas, Rudolf Ackermann, Alois Essigmann, Viktor Pelz, Hermann Hefele (1885-1936), Rudolf Huch, Hans Vaihinger (1852-1933), Adolf Vetter, Josef Khoss von Sternegg (1862-1931), Rudolf Holzer und Karl Klammer (1879-1959). Sitz der Gesellschaft war die Nationalbibliothek, Reklame sollte nur mündlich verbreitet werden. Zur Zeit der Gründung bestand die Gesellschaft aus 200 Mitgliedern und fünf Stiftern. ${ }^{314}$ In einer auf das Gründungsjahr datierten Postkarte der Gesellschaft sind zudem noch Alfred Kubin, Josef Grünfeld, Hans von Müller und Paul SchultzeNaumburg (1869-1949) verzeichnet, später übernahm Josef Nadler (1884-1963) den Vorsitz. Die Gesellschaft bestand hauptsächlich aus Hof-, Geheim-, Justizund Ministerialräten, weniger aus Künstlern.

Schaukal verfügte demnach ab 1929 über einen institutionalisierten Kreis in Wien, der ein eigenes Mitteilungsblatt herausbrachte, sich für Vortragstätigkeiten und Rundfunklesungen einsetzte und auf den Sortimentsbuchhandel Einfluss zu nehmen versuchte. Am 31. Dezember 1936 mahnte die Schaukal-Gesellschaft in einem öffentlichen Aufruf im Anzeiger für den Buch-, Kunst- und Musikalienhandel, dass das Sortiment an Schaukal-Werken breiter aufgestellt sein sollte. ${ }^{315}$ Doch die sozialen Verschiebungen nach 1918 hatten längst auch den Buchhandel eingeholt, wobei die Verkleinerung der kaufkräftigen Klientel aus dem Besitzbürgertum durch den sozialen Aufstieg bisher unterprivilegierter Schichten nicht kompensiert werden konnte. Hinzu kam nicht nur ein zurückhaltendes Kaufverhalten der ursprünglichen Hauptzielgruppe des Buchhandels, sondern auch ein verändertes Leseverhalten. Immer weniger Vertreter des Kleinbürgertums konnten sich Haushaltshilfen leisten, was die Freizeitaktivität Lesen einschränkte. ${ }^{316}$

Die Schaukal-Gesellschaft war in allen Bereichen des literarischen Feldes tätig und übte Einfluss auf die Produktion, Distribution und Rezeption von Werken Richard Schaukals aus. Zu den Künstlern, die als Mitglieder oder Gäste zur Gründungsversammlung geladen waren, gehörten Maria Delle Grazie (1864-1931), Carl Moll, Otto Stoessl und Richard Specht (1870-1932). Schriftsteller wie Friedrich Winterholler betrachteten die Gesellschaft tatsächlich als „Kreis“, dem anzugehören sie als Privileg empfanden. ${ }^{317}$ Der Verein war - zum Teil auch aus politischen Gründen - alles andere als eine Erfolgsgeschichte. Dies zeigen die Sisyphos-Bemühungen Richard Schaukals, der vor allem ab dem

314 Vgl. [Anon.]: Gründung einer Richard-Schaukal-Gesellschaft. In: Wiener Zeitung, Nr. 273/ 1929 (27. November 1929), S. 6.

315 Vgl. Schaukal-Gesellschaft: Eine Bitte der Schaukal-Gesellschaft. In: Anzeiger für den Buch-, Kunst- und Musikalienhandel, Nr. 32/1936 (31. Dezember 1936), S. 208.

316 Vgl. Bachleitner/Eybl/Fischer: Geschichte des Buchhandels in Österreich, S. 246. 317 Brief Winterhollers an Schaukal, 25. Juni 1931, S-NL, WB. 
Ende der 1930er Jahre buchstäblich um jedes Mitglied kämpfte, Zahlungserinnerungen aussenden und nach den Gründen für die sich mehrenden Austritte fahnden ließ. Zählte die Gesellschaft zum Jahresende 1929 noch 220 Mitglieder, belief sich die Zahl am 9. März 1940 auf nur mehr 70 Personen. ${ }^{318}$ Nicht wenige begründeten ihren Austritt mit Schaukals Ablehnung des Dritten Reichs. Tatsächlich stand die Gesellschaft spätestens seit 1940 unter Beobachtung der NSDAP, wie der Geschäftsführer Rudolf Ackermann in einem Bericht über die im Klubzimmer des Arkaden-Cafés in der Stadiongasse 2 stattfindenden Vollversammlungen Schaukal mitteilte. ${ }^{319}$ Aus politischen Gründen sowie wegen der Homogenität der Gruppe und ihres zu eingeschränkten Wirkungskreises auf ohnehin mit Schaukal verbundene Akteure konnte die Gesellschaft das dichterische Wirken ihres Protegés nicht sonderlich erfolgreich propagieren.

Anders verhielt es sich mit den informellen und nicht-institutionalisierten Netzwerken, in denen sich Schaukal vor dem Krieg bewegt hatte.

\section{Schaukals Netzwerktätigkeiten als Kanon-Agent}

Schaukals Position und Stellenwert als Kritiker war mit seinem Wirken als Literaturvermittler verbunden. Dichter suchten den Kontakt zu ihm, um Bekanntheit zu erlangen oder um sich mit ihm auf einen Kanon zu verständigen. Kanonisierungsprozesse und die Bausteine eines Netzwerkes (Umwelt, Kognitionen, Interessen, Struktur des Netzwerkes und Handlungen) stehen im Wechselverhältnis.

Richard Schaukals Agieren im Kontext der Kanonherstellung um 1900 ist ähnlich komplex wie die Kanonisierungsprozesse an sich, was auf seine zum Teil sich ergänzende, stellenweise aber auch widersprechende Auffassung, Tätigkeit und Position als Kritiker, Schriftsteller, Herausgeber, Übersetzer und, nicht zu vergessen, Biograph zurückzuführen ist. Seine ästhetische Vielseitigkeit zeigt sich am eindrucksvollsten in den essayistischen Beiträgen, die den versierten Leser und Kenner zeitgenössischer europäischer Literatur zu erkennen geben. Schaukals Kritiken sind thematisch breit gefächert und reflektieren ein epochenübergreifendes Spektrum europäischer Kunst und Literatur.

In den 1890er Jahren begann er, kritische Beiträge über Marcel Prévost (1862-1941), Peter Nansen (1861-1918), Gabriele D’Annunzio und Felix Holländer

318 Die Liste befindet sich wie alles weitere Material zur Gesellschaft im Schaukal-Nachlass der Wienbibliothek.

319 Vgl. den Brief Ackermanns an Schaukal, 11. März 1940, S-NL, WB. 
(1867-1931) zu veröffentlichen; er machte früher als andere auf Thomas Mann und Jakob Wassermann aufmerksam, publizierte 1900 in der Zeitschrift Die Insel eine Beschreibung von Velázquez' Portrait eines spanischen Infanten, vergaß 1899/1900 im Litterarischen Echo aber auch nicht, Ferdinand von Saars Novellen aus Österreich zu rezensieren und im selben Text Invektiven über seine dichtenden Zeitgenossen auszuschütten. Themen, Verfahren und Publikationsorgane weisen auf einen im Kontext der Moderne angesiedelten Akteur hin. Dies impliziert eine tiefgreifende Auseinandersetzung mit historischen wie zeitgenössischen Künstlern und Geistesgrößen. Von Schiller (mehrmals zwischen 1904 und 1927) bis Kokoschka (1912) und Nietzsche (unter anderem 1929 und 1932) reicht Schaukals buntes Essaypanorama, wobei seine Orientierung an bildungsbürgerlichen Werken und Dichtern der deutschen Klassik und Romantik, am österreichischen Biedermeier, aber auch an der Dekadenzliteratur des ausgehenden 19. Jahrhunderts prävalent ist. Die zeitgenössische Dichtung wird mit der älteren verglichen und, abgesehen von ein paar wenigen Ausnahmen wie Rilke (der später auch mit Kritik bedacht wurde), abgewertet.

Aus Sicht der Kanontheorie und Klassikforschung war Schaukal als Kritiker ein Förderer literarischer Kanonbildung. Dabei zielte sein Wirken nicht darauf $\mathrm{ab}$, bereits etablierte Klassiker wie Goethe, den er verehrte, zu propagieren. Seine Autorität als Kanon-Agent suchte er vor allem auch über die Beschäftigung mit Dichtern wie Eduard Mörike (1804-1874) und Heinrich von Kleist (1777-1811). Der Fokus über den Rahmen der Romantik und Klassik hinaus gehörte zu seiner Strategie als Literaturvermittler, der auch die Namen zeitgenössischer deutschsprachiger sowie französischer Schriftsteller der décadence und des Symbolismus in Umlauf brachte.

Vor allem aber ist Schaukal als Agent seiner selbst zu bezeichnen. Die Rezensionen dienten ihm als Bekenntnismedium, das seine Position im literarischen Feld indirekt festigen sollte. Ausführungen $\mathrm{zu}$ Inhalt und Tragweite eines bestimmten dichterischen Werkes mündeten in Äußerungen über Schaukal. Indem Bezüge zu prestigeträchtigen Dichtern auf redundante Weise hergestellt wurden und bei seiner eigenen Person ihren argumentativen Zielpunkt erreichten, verfolgte er bewusst die Strategie der Selbsterhöhung und Selbsteinschreibung in Diskurse literarischer Relevanz. Auf die theoretischen Ausführungen von Jan Assmann rekurrierend kann von einer Stabilisierung des eigenen Schaffens im Fahrwasser der Traditionen gesprochen werden. ${ }^{320}$ Schaukal untermauerte mit dem poetologischen Bezug auf mustergültige Schriftsteller seine Kunstauffassung, verglich sich mit ihnen oder stilisierte sich als ihr ästhetischer Nachfolger.

320 Vgl. Assmann: Das kulturelle Gedächtnis. 
Impressionistische Dichterkritiker wie Schaukal oder Hofmannsthal vermengten in ihren Rezensionen den ästhetischen Anspruch mit Elementen des Gebrauchstextes (Literaturempfehlung) und biographischen Selbstbespiegelungen.

Schaukal ist ein Beispiel dafür, dass Dichter zur Jahrhundertwende den literaturkritischen Bereich ästhetisierten und auf die Kanonherstellung Einfluss ausübten. Hinzu kam, dass seit Ende des 19. Jahrhunderts nicht mehr Kirche und Adel, sondern die Zeitung die neuen Regeln der Kunst im literarischen Feld definierte (die auch ökonomische Regeln sind). Ein stabiler und im Sinne Assmanns bewahrender Kanon konnte in diesem neu konstituierten Raum nicht mehr von Bestand sein. „Aber das bedeutet nicht, dass der autonome Autor sich außerhalb der Tradition und des Kanons ansiedelt, ganz im Gegenteil müssen sich alle Autoren in dem situieren, was Bourdieu den ,Möglichkeitsraum“ nennt“, so Ralf Zschachlitz, der an derselben Stelle hinzufügt: „Es ist von nun an der Künstler selbst, der durch seine eigene Arbeit den normativen und kanonischen Wert seines Werkes gewährleisten muss“321 - und der sich in Traditionen stellt, um selbst irgendwann als ,klassisch`zu gelten, wie sich hinsichtlich Schaukal ergänzen ließe. Diese methodische Selbstzentrierung, die ein Ringen um künstlerische Autonomie ist, und der Bezug auf literarische Vorbilder sind in Schaukals schriftstellerischem Werk evident. Lyrik, Prosa und Drama stützten sich auf leicht erkennbare Ideale aus Romantik, Symbolismus und Biedermeier; zudem verfasste er Nachdichtungen von Shakespeare (1564-1616), Verlaine, Maurice Maeterlinck (1862-1949), Flaubert und anderen.

Im Umfang bescheidener fällt Schaukals selbständige philologisch-editorische Tätigkeit aus, die sich auf nur wenige Autoren vor allem des 19. Jahrhunderts konzentrierte, allen voran Heinrich Heine und E.T.A. Hoffmann. Christian Neuhuber hat den Wandel von der Verehrung bis zum Bruch mit Heine, die damit einhergehenden antisemitischen Implikationen sowie eine an Karl Kraus orientierte sprachund kulturkritische Haltung Schaukals gegenüber dem nach Paris geflohenen Dichter nachgezeichnet. $^{322}$

Anders als im Falle Heines bezeichnete Schaukal E.T.A. Hoffmann Zeit seines Lebens als Wahlverwandten, über den er dann auch gleich zwei biographische Studien (1904, 1923) sowie die Einleitung zu den Ausgewählten Werken in acht

321 Zschachlitz: „Kanonische Stillstellung“, „Symbolisches Kapital“, „Dialektik im Stillstand“, S. 18-19.

322 Vgl. Christian Neuhuber: „... eine nicht unbedeutende Wandlung“. Kulturkonservative Heine-Rezeption am Beispiel Richard von Schaukals. In: Heine-Jahrbuch, Bd. 45 (2006), S. 142-164. 
Bänden (1908) verfasste. 1924 gab er überdies in zwei Bänden Hoffmanns Märchen und Dichtungen heraus. ${ }^{323}$ Das Interesse an Hoffmann war im deutschen Sprachraum aufgrund von Goethes Negativurteil aus dem Jahr 1827 zwischenzeitlich auf den Nullpunkt gesunken, ${ }^{324}$ erst Ende des 19. Jahrhunderts wurde er wiederentdeckt und spätestens zu Beginn des 20. Jahrhunderts beeinflussten seine Werke Literatur, Musik, Malerei und Psychoanalyse sehr stark. ${ }^{325}$ Weniger bekannt dürfte in diesem Kontext Schaukals Beitrag als Philologe, Dichter und Netzwerker an der Revitalisierung Hoffmanns sein. ${ }^{326}$

In seinem Aufsatz über „Klassikermacher“, also über Agenten des Kanons, erläutert Robert Charlier die komplexen Abläufe literarischer Kanonbildung. Er verweist dabei auf drei größere, diachrone und aufeinander aufbauende Entwicklungsstufen: Prägung, Propagierung und Rezeptionsgeschichte. Prägung meint den Inspirationsprozess, der von Werk und Autor ausgeht und auf ein Individuum oder auf ein Kollektiv wirkt. Die Überzeugung von der herausragenden Qualität der Werke eines Autors führt dann zu einer auf unterschiedlichen Ebenen angesiedelten Propagierung des von den Exegeten gleichzeitig reduzierten Euvres. Zuletzt erfolgt die Einbindung in den rezeptionsgeschichtlichen Prozess, etwa in Form von Editionen oder Biographien. Zeitpunkt und Intensität sind starke Indikatoren für den Grad der Kanonisierung, wie der Romantikbezug zu Beginn des 20. Jahrhunderts zeigt. Schaukals verstärkte Prägung und Propagierung sowie seine Rezeption von Hoffmann vollzogen sich weder chronologisch noch aufeinander aufbauend, die drei Faktoren beeinflussten und verstärkten sich aber gegenseitig. Die literarische wie biographische Beschäftigung und der produktive Austausch mit anderen Hoffmann-Verehrern, die ebenfalls von

323 Schaukal: Hoffmann. Berlin/Leipzig 1904; E.T.A. Hoffmanns ausgewählte Werke in acht Bänden. Mit einem Bildnis des Dichters und einer Einleitung von Richard Schaukal. Leipzig 1908; Schaukal (Hg.): E.T.A. Hoffmann: Ausgewählte Dichtungen. Bd. 1: Märchen. Der goldene Topf; Klein Zaches; Meister Floh. Bd. 2: Nußknacker und Mausekönig; Das fremde Kind; Die Brautwahl; Prinzessin Brambilla; Die Königsbraut. Berlin 1924; Schaukal: E.T.A. Hoffmann. Sein Werk aus seinem Leben dargestellt von Richard Schaukal. Zürich/Leipzig/Wien 1923.

324 Hartmut Steinecke: Kommentar. In: E.T.A. Hoffmann: Sämtliche Werke in sieben Bänden. Bd. 3: Nachtstücke. Werke 1816-1820. Hg. von Hartmut Steinecke. Frankfurt am Main 1985, S. 921-1194, hier S. 949.

325 Vgl. Jörg Marquardt u. a.: Hoffmanns literarische Rezeption im 19. und in der Neuromantik des frühen 20. Jahrhunderts. In: E.T.A. Hoffmann. Leben - Werk - Wirkung. Hg. von Detlef Kremer. Berlin/New York 2009, S. 563-580, hier S. 578-579.

326 Dass sich der „formvollendete, kühle und klare Lyriker“ zu dem „verworrenen, abenteuerlich dämonisch rätselhaften Spätromantiker“ hingezogen fühlte, erschien dabei manch einem Kritiker seltsam, siehe hier Dr. J. W. [d.i. Josef Weingartner]: Bücher von Dichter und Dichterschicksalen. In: Reichspost, Nr. 41/1923 (12. Februar 1923), S. 5. 
der außerordentlichen Qualität des Künstlers überzeugt waren, erzeugte einen „Wirkungskomplex“, der die Tradierung eines literarischen Akteurs zum Ziel hatte. „Damit diese Rezeptionskette zu einer im literaturgeschichtlichen Sinne epochalen Kanonisierung führt, bedarf es vieler Vermittlerinstanzen, die eine Erwählung des Dichters und seines Werkes anstoßen und ausführen“, so Charlier. Schaukal ist in diesem Sinne ein Glied dieser vielen „Vermittlerinstanzen“, die in einen nicht vollständig überschaubaren Prozess eingebunden sind. Schließlich bleibt jedoch offen, ,in welchem Maße sich in diesem Prozess historisch kontingente und - mentalitäts- oder ideologiegeschichtlich betrachtet - inkontingente Einflüsse überlagern und vermengen“ und es bleibt „unauflösbar, inwieweit die Fülle und der farbige Facettenreichtum dieser Wirkungen eine Ursache oder Folge der Klassikerwerdung darstellen.“327 Daraus leitet sich eine zentrale Frage der Kanontheorie ab: Lassen sich „hergestellte“, also konstruierte Kanons, von jenen unterscheiden, die sich aus einer Vielzahl parallel und unkoordiniert ablaufender Prozesse „herausgebildet“ haben? ${ }^{328}$ Es geht also um das gegenseitige Abwägen dessen, was schließlich zum Kanon und auch zur - vom Kanon ableitbaren - Biographiewürdigkeit führt: der äußere Einfluss (Konstruktion) oder die persönliche Leistung (Genie)?

\section{Positionen und Netzwerke der Neuromantik}

Das Konzept der poetischen Wiederaufnahme, das für viele Dichter der Jahrhundertwende so bezeichnend ist, drückt sich bei Schaukal unter anderem in Form von inhaltlichen und ästhetischen Rekursen auf die historische Romantik aus. Mit Neuromantik ist Schaukals literarische Adaption von antinaturalistischen, irrationalen Themen und Motiven, aber auch eine historisierende und eklektizistische Formsprache, die vor allem seine Lyrik prägte, gemeint. ${ }^{329}$ Die Begriffe Ästhetizismus, Symbolismus, Jugendstil oder Dekadenz, die ebenso auf den Antinaturalismus in der Literatur angewendet werden können, erweiterte er durch die bewusste Wiederaufnahme von Friedrich Schlegels literaturkritischer

327 Charlier: Klassikermacher, S. 53-54.

328 Alfred K. Treml: Klassiker: „Herstellung‘ oder ,Herausbildung‘? Über die Evolution einflussreicher Semantik. In: Kanonbildung, S. 143-160, hier S. 143.

329 Vgl. Peter Sprengel: Neuromantik. In: Moderne Literatur in Grundbegriffen. Hg. von Dieter Borchmeyer und Viktor Žmegač. Tübingen 1994, S. 335-339. Neuromantik ist ein in politischer Hinsicht komplexer Begriff, eine dahingehende Einordnung würde den Rahmen der vorliegenden Arbeit übersteigen. Hier soll lediglich Schaukals innerliterarische Hinwendung zur historischen Romantik thematisiert werden. 
Konzeption. Nicht zuletzt wird Schaukal hier als Neuromantiker bezeichnet, da er sich als Dichter, Philologe und Biograph mit der historischen Romantik befasste. Auch für seine Verbindung zu Dichtern, Kritikern und Forschern, die sich mit ähnlichen literaturhistorischen und ästhetischen Themen beschäftigten, spielte die Romantik (und zum Teil auch die Ablehnung einer Neuromantik) eine wesentliche Rolle.

\subsection{Wahlverwandtschaften: E.T.A. Hoffmann als Verbindung zu Kubin}

Richard Schaukal war mit einem Gutteil der um 1900 etablierten E.T.A.Hoffmann-Community bestens vernetzt. Er stand mit dem Literaturwissenschaftler Georg Ellinger (1859-1939) sowie mit dem Herausgeber der unvollendet gebliebenen historisch-kritischen Ausgabe von Hoffmanns Werken, Carl Georg von Maassen (1880-1940), in Verbindung. Darüber hinaus korrespondierte Schaukal mit vielen weiteren Hoffmann-Experten wie Hans Dahmen, ${ }^{330}$ Erwin Kroll (1886-1976), ${ }^{331}$ Felix Hasselberg, ${ }^{332}$ Friedrich Schnapp (1900-1983) 333 sowie - bis kurz vor Ausbruch des Ersten Weltkrieges - Johann Černy, der Schaukal immer wieder anregte, eine Hoffmann-Biographie zu verfassen. ${ }^{334}$

Der Maler und Schriftsteller Alfred Kubin, mit dem Schaukal über vier Jahrzehnte eine intensive Korrespondenz führte, bezeichnete in seiner autobiographischen Skizze meines Lebens (1926) Hoffmanns phantastische Geschichten als maßgebliche Inspirationsquelle für seine düsteren Illustrationsentwürfe. ${ }^{335}$ Kubin war seit circa 1901 mit dem Hoffmann-Forscher Hans von Müller befreundet, vermutlich haben sie sich anlässlich einer zwischen Dezember 1901 und Februar 1902 im Salon von Paul Cassirer gezeigten Ausstellung kennengelernt, die unter anderem auch Bilder des zu dieser Zeit in München lebenden Künstlers

330 Siehe etwa Hans Dahmen: E.T.A. Hoffmanns Weltanschauung. Marburg 1929.

331 Siehe etwa Erwin Kroll: E.T.A. Hoffmanns musikalische Anschauungen. Königsberg 1909; sowie Kroll: E.T.A. Hoffmann. Leben und Werk. Leipzig 1923.

332 Siehe etwa Felix Hasselberg: Hoffmann als Kammergerichtsrat. In: Mitteilungen des Vereins für die Geschichte Berlins, 39. Jg. (1922), S. 63-64.

333 Schnapp war gemeinsam mit Hans von Müller Herausgeber von Hoffmanns Briefwechsel; siehe E.T.A. Hoffmann: Briefwechsel. 3 Bde. Gesammelt und erläutert von Hans von Müller und Friedrich Schnapp. München 1967-1969.

334 Vgl. Mühlher: Ungedruckte Briefe Johann Černys an Richard Schaukal, S. 178 und S. 180-181. 335 Vgl. Marquardt u. a.: Hoffmanns literarische Rezeption, S. 563. Auch mit dem Maler, Graphiker und Dichter Hanns Meinke (1884-1974) verband Schaukal die Vorliebe für religiöse Poesie und E.T.A. Hoffmann. Der Briefwechsel mit Graphiken befindet sich im S-NL, WB. 
zeigte. $^{336} 1902$ setzte der Briefwechsel Schaukals sowohl mit Kubin als auch mit Hans von Müller ein. Das Bindeglied zwischen Kubin und Schaukal war Franz Blei, wie Schaukal 1903 in einem Kubin gewidmeten Aufsatz vermerkt. ${ }^{337}$ Blei vermittelte auch Hans von Müller an den Insel-Verlag in Leipzig, wo dieser ebenfalls 1903 Das Kreislerbuch veröffentlichte. ${ }^{338}$

Wie entscheidend gerade die künstlerische Szene in München für Schaukals Vernetzung im Neuromantik-Kreis war, belegt die von Blei ausgehende und von Kubin überbrachte Aufforderung, der Freund möge im dortigen Akademischen Verein für bildende Künste einen Vortrag über ihn halten. ${ }^{339}$

Der 40 Jahre währende Briefwechsel zwischen Schaukal und Kubin ist von gegenseitiger künstlerischer Wertschätzung und derselben skeptisch-solitären Attitüde geprägt. ${ }^{340}$ In den ersten beiden Jahren sind die Briefe Kubins, der in dieser Zeit seine Ehefrau verlor und unter finanziellen Nöten litt, melancholisch und düster. Die Wesensverwandtschaft der Korrespondenzpartner lässt sich an Aussagen wie dieser bemessen: „Hier hat gestern der Carneval angefangen [...], eine fette Zeit für jeden Pessimisten. [...] [J]e lustiger es zugeht um so ärger blick ich und mein Hass, eine unmenschliche Wuth gegen diese verbuhlte Bande [...] - einfach jeder Mensch ist mein persönlicher Feind. “341

Die pessimistische Grundstimmung in Kubins Briefen hellte sich ein Jahr später wieder auf, als er erneut heiratete und sich seine finanzielle Situation aufgrund künstlerischer Erfolge zu bessern begann. Zu dieser Zeit machte er Hans von Müller mit Schaukal bekannt; beide beschäftigten sich intensiv mit Hoffmann und ließen sich von diesem zu literarischen Adaptionen inspirieren. ${ }^{342}$ Kubin nahm an ihrem Werk regen Anteil. Als Schaukal ihm die Befürchtung mitteilte, der anerkannte Experte könnte ob seiner 1904 veröffentlichten Hoffmann-Studie indigniert sein, zumal er keine Reaktion auf die an Müller gesandten Werke erhalten hatte, beruhigte ihn der Maler. ${ }^{343}$ Kubin zählte zu

336 Diesen Hinweis verdanke ich Karl Koweindls Kommentar zum unveröffentlichten Briefwechsel Kubin - Schaukal.

337 Vgl. Schaukal: Ein österreichischer Goya. In: Wiener Abendpost. Beilage zur Wiener Zeitung, Nr. 2/1903 (3. Januar 1903), S. 7.

338 Das Kreislerbuch. Texte, Compositionen und Bilder von E.T.A. Hoffmann. Zusammengestellt von Hans von Müller. Leipzig 1903.

$339 \mathrm{Zu}$ einem solchen Vortrag dürfte es jedoch nicht gekommen sein; vgl. den Brief Kubins an Schaukal, 17. November 1902, S-NL, WB.

340 Vgl. Koweindl: Alfred Kubin und Richard von Schaukal.

341 Brief Kubins an Schaukal, 8. Januar 1903, S-NL, WB.

342 Vgl. Schaukal: Kapellmeister Kreisler. Dreizehn Vigilien aus einem Künstlerdasein. München/Leipzig 1906.

343 Vgl. den Brief Kubins an Schaukal, 16. November 1904, S-NL, WB. 
den wenigen, die Schaukals Tendenz zur Neuromantik, von der dieser sich eigentlich lossagte, offen ansprechen durften. Wahrscheinlich auch deshalb, weil Kubin selbst Poe (1809-1849), Hoffmann und William Blake (1757-1827) zu seinen „Wahlverwandten“ zählte, ${ }^{344}$ sich aber auch bemühte, die romantische Ausprägung in eine „Kubinsche Klassik“ zu überführen, worunter eine Reduktion des Stils zu verstehen ist, die auch auf einen sich verschlechternden Zustand seiner Augen zurückzuführen war:

[M]it dem Älterwerden macht sich eine Wandlung in meiner ganzen Romantik auf deutlichste bemerkbar. Das Problematische tritt immer mehr zurück, der Ausdruck strebt immer reinere Harmonie an. - Ich erlebe einfach die Klassik meiner Romantik gewiß und so solls sein: Eine Kubinsche Klassik! ${ }^{345}$

Nachdem Kubin Schaukals Kapellmeister Kreisler. Dreizehn Vigilien aus einem Künstlerdasein erhalten hatte, schwärmte er: „In seiner Totalität ist es mir das Liebste unter Ihren Werken. Es ist eminent schön und ebenso groß eine neuzeitliche Romantik von ungewöhnlichem Zauber.“346

Schaukals Verbindung zu Kubin regt zu netzwerktheoretischen Überlegungen an, die - abgesehen von persönlichen Sympathien - erklären, warum gerade dieser Kontakt Bestand hatte. In erster Linie sah Schaukal in Kubin keinen Konkurrenten im literarischen Feld, obwohl dieser sich als Buchillustrator und Autor nicht erfolglos darin bewegte. In den ersten zwei Jahren ihrer Beziehung nahm Schaukal die Rolle des verständigen Kunstkritikers ein, der Kubin von seiner Expertise überzeugen konnte. Das Vertrauen des Künstlers hatte Schaukal mit einem am 3. Januar 1903 in der Wiener Zeitung erschienenen Aufsatz gewonnen: „Geradezu frappiert bin ich über dies schlagend richtige Erfassen meiner künstlerischen Persönlichkeit und Production“, schrieb ihm wenige Tage später Kubin. ${ }^{347}$

Auf der Basis von Schaukals kulturellem Kapital vertraute Kubin ihm sogar Informationen über die Bewertung (,nach Klasse 0 und I“) und den Verkauf seiner Graphiken an und nutzte somit auch das Sozialkapital des Ministerialbeamten (die Kontakte), um ökonomisches Kapital zu generieren. ${ }^{348}$ Schaukal, der im

344 Vgl. Koweindl: Alfred Kubin und Richard von Schaukal, S. 41.

345 Brief Kubins an Schaukal, 16. Dezember 1905, S-NL, WB. Das Zitat findet sich auch bei Koweindl: Alfred Kubin und Richard von Schaukal, S. 41.

346 Brief Kubins an Schaukal, 13. Juni 1906, S-NL, WB; Hervorh. im Orig. durch Unterstreichung.

347 Brief Kubins an Schaukal, 8. Januar 1903. Das Zitat findet sich auch bei Koweindl: Alfred Kubin und Richard von Schaukal, S. 29.

348 Koweindl: Alfred Kubin und Richard von Schaukal, S. 30. 
ersten Jahrzehnt des 20. Jahrhunderts im Abstand von wenigen Jahren regelmäßig dienstlich befördert wurde, frequentierte die geeigneten Abnehmerkreise. Er selbst konnte in jenen Kreisen symbolische Statusgewinne verbuchen und den Kontakt zu Kubin, der auf Schaukals Mittlerdienste vertraute, festigen.

Immer wieder diskutierten Schaukal und Kubin die Möglichkeit einer Zusammenarbeit. Der Maler avancierte zu einem der gefragtesten Buchillustratoren im deutschen Sprachraum, der unter anderem Übersetzungen von Poe und Dostojewski (1821-1881) sowie Werke von Thomas Mann und E.T.A. Hoffmann graphisch gestaltete. Hoffmann ist die Konstante im Briefwechsel zwischen Schaukal und Kubin, die Präferenz (Kognition) wirkte sich auf die Netzwerkstruktur aus (Kontakt zu anderen Hoffmann-Enthusiasten) und generierte Handlungspläne (künstlerische Zusammenarbeit, die aber nie zustande kam).

Der Ausbruch des Ersten Weltkrieges markierte für Kubins Schaffen und seine materiellen Erfolge eine Krise:

Rein persönlich bin ich augenblicklich, und auf unbestimmte Zeit hin, materiell ruiniert. Ich verdiene keinen Pfennig alle Werke die ich an Verlage geliefert habe sind in ihrer Herausgabe auf unbestimmte Dauer verschoben, desgleichen alle Pläne, Absichten für die Zukunft, auch Forderungen und Contrakte sind zur Zeit uneinbringlich. Meine 3 Ausstellungen werden überhaupt nicht besucht $[\ldots]^{349}$

Von Anbeginn geißelte Kubin den Krieg als „schreckliche Zeit““ ${ }^{350}$ Im April 1915 schreibt er Schaukal: „Mir ist der Frühling verdorben durch den geistigen Aasgeruch den ich überall wittere. Ich begreife nichts vom Krieg, kann überhaupt kein Volk hassen und es wird mir übel wenn ich näher nachdenke wie es zugeht. “351 Gleichwohl hatte er im Vorjahr noch Schaukals kriegerische Gedichte gelobt, ${ }^{352}$ die dieser auf den Markt $\mathrm{zu}$ werfen begann. Sie waren als patriotischer Akt gedacht, folgten aber auch einer merkantilen Strategie, die aus Schaukal dann zu Kriegsbeginn tatsächlich einen vielgelesenen und bei Veranstaltungen oft vorgetragenen Dichter machten.

Am 1. November 1914 trat Kubin mit dem aus der ökonomischen Notlage geborenen Vorschlag an Schaukal heran, einen illustrierten Sammelband mit

349 Brief Kubins an Schaukal, 19. September 1914, S-NL, WB; Hervorh. im Orig. durch Unterstreichung.

350 Brief Kubins an Schaukal, 19. September 1914, S-NL, WB.

351 Brief Kubins an Schaukal, 9. April 1915, S-NL, WB; Hervorh. im Orig. durch Unterstreichung.

352 Vgl. den Brief Kubins an Schaukal 19. September 1914, S-NL, WB. 
„Kriegsnovellen“ herauszugeben. ${ }^{353}$ Dass es an dieser Stelle zu keiner Verstimmung gekommen ist, da Kubin keine patriotischen Absichten verfolgte, und der sonst so leicht erregbare Schriftsteller ohne große Aufregung ablehnte, mag an der freundschaftlichen Verbindung gelegen haben. Das Ausbleiben einer kleinen Kontroverse kann aber auch mit Bezug auf die Struktur ihrer Relation betrachtet werden. In den 13 Jahren hatte sich eine starke Verbindung ergeben, in der - im Sinne der Strong-ties-Theorie - berufliche Interessen oder weltanschauliche Unstimmigkeiten (wie Kubins opportunistische Haltung zum Krieg sowie der tendenzielle Pazifismus, den Schaukal nicht teilte) der Wahrung persönlicher Beziehungen untergeordnet wurden. Zwischen Schaukal und Kubin bestand eine stabile kognitive Basis, die sich mit Kubins späterem Eintritt in die SchaukalGesellschaft sogar noch festigte; dies trug zur Konfliktvermeidung bei.

Nach dem Krieg wurden ästhetische, zum Teil auch tagespolitische Aspekte angesprochen, doch überwogen persönlich-intime Themen wie Gesundheit, Familie, finanzielle Sorgen und Reisepläne. Stellenweise äußerte sich Kubin über seinen Umgang mit künstlerischer Produktivität.

\begin{abstract}
Alles was mir noch an Kraft bleibt gebe ich an das sehr starke geistige Leben ab, - das mich nicht enttäuscht und mir im Schaffen immer aufs neu Harmonien vorspiegelt. - Ich habe eine ganze Anzahl Blätter gemacht die teils immer wieder die frühern Themen fortsetzen teils aber mich selbst durch eine ganz neue Art „Kubin’scher Klassik“ noch überraschen, welche aus der ungestümen älteren Romantik sich entwickelt. ${ }^{354}$
\end{abstract}

Kubin festigte die Verbindung zu Schaukal mit jovialen Aussprüchen wie: „,Wir Rückwärtsgewandten“ werden eine gewisse Melancholie nie mehr los. “355 Die Nostalgie entwickelte sich zum Bindemittel, das den Briefverkehr - im Gegensatz etwa zu den Kontakten mit Brod oder Hesse - bis zu Schaukals Tod am Laufen hielt.

\title{
7.2 Von Bewunderung zur Distanzierung: Max Brod und Hermann Hesse
}

Ein weiterer Zirkel von Romantik- und vor allem Hoffmann-Enthusiasten, mit dem sich Schaukal Ende des 19. und zu Beginn des 20. Jahrhunderts austauschte, waren ältere (Hugo Salus) sowie gleichaltrige Dichter aus Prag (Rainer Maria Rilke, Max Brod und Camill Hoffmann).

353 Brief Kubins an Schaukal, 1. November 1914, S-NL, WB. Schaukal verfasste zwar Kriegsgedichte, aber keine Kriegsnovellen.

354 Brief Kubins an Schaukal, ohne Datum, vermutlich Dezember 1915, S-NL, WB.

355 Brief Kubins an Schaukal, 8. November 1924, S-NL, WB. 
Brods erster Brief an Schaukal datiert auf den 19. Februar 1906, wobei der gemeinsame Freund Hugo Salus als Referenz für die Kontaktaufnahme diente. Der Briefwechsel mit Brod ähnelt dem mit Hermann Hesse und ist für die Analyse von Schaukals Selbstverständnis als Schriftsteller und für seine Reaktion auf ein Stagnieren im literarischen Feld äußerst aufschlussreich. Wie Hesse suchte auch Brod in Schaukal einen ästhetischen Verbündeten, der als Kritiker in der Lage war, seine Dichtkunst zu propagieren. Beide wandten sich $\mathrm{zu}$ Beginn ihrer Korrespondenzen verehrungsvoll an den Vermittler und Förderer Schaukal, mit dem eine kognitive sowie ästhetische Basis bestand, die sich auf den Begriff Neuromantik subsumieren lässt. Bald überflügelten sie aber Schaukals Reputation, wodurch sich die Haltung der Briefeschreiber zueinander merklich wandelte. Schließlich endeten jene Korrespondenzen zu einer Zeit, als Schaukals dichterische Erfolge insgesamt zurückgingen und sich seine Netzwerke ausdünnten. ${ }^{356}$

Im Zuge seiner Kontaktaufnahme zu Schaukal bedankte sich Max Brod Anfang September 1906 für dessen „braunäugige Zeilen, [. . .] [die] in diesen Tagen der Einsamkeit und schwülen Kühle wie Melodien gekommen [sind].“ Damit dürfte er den richtigen Ton angeschlagen haben. Bescheiden fuhr er fort, dass es bisher still um ihn und um sein Werk gewesen sei, um dann zu ergänzen: „Es wird Sie vielleicht interessieren, daß Blei, Meier-Graefe, Zweig, Josef Popper ähnlich geurteilt haben [über Brods literarische Qualität, CM] wie Sie“ - allerdings nicht öffentlich, sondern ,in Briefen an mich ... “. 357

Der Kontakt zu Brod sollte sich für Schaukal bald schon bezahlt machen, publizierte dieser doch 1906 eine Rezension der Novelle Kapellmeister Kreis$\operatorname{ler}^{358}$ und kurze Zeit später eine Besprechung der 1907 publizierten Essaysammlung Mietwohnung in der Berliner Gegenwart. ${ }^{359}$ Schaukals Studie über Richard Dehmels Lyrik diente Brod zudem als Quelle für einen Vortrag in der Prager Kunstausstellung. ${ }^{360}$ Gleichzeitig entstanden die ersten, für Schaukals Habitus und Vorgehen als Briefeschreiber so bezeichnenden Spannungen. Schaukal begann, Debatten über Kunst und ,Rassenpsychologie‘ zu entfachen und die produktiven Fähigkeiten jüdischer Künstler generell infrage zu stellen. Brod reagierte versöhnlich, wehrte sich aber gegen die ästhetisch kaschierten antisemitischen

356 Der Briefverkehr mit Hesse dauerte von 1903 bis 1910, mit Brod von 1906 bis 1913.

357 Brief Brods an Schaukal, 5. September 1906, S-NL, WB.

358 Vgl. Max Brod: Capellmeister Kreisler. In: Die Gegenwart, Bd. 70 (1906), S. 348.

359 Vgl. den Brief Brods an Schaukal, 2. Dezember 1906, S-NL, WB; Brod: Die Mietwohnung. In: Die Gegenwart, Bd. 71 (1907), S. 206-207.

360 Vgl. den Brief Brods an Schaukal, 24. Februar 1908, S-NL, WB. 
Übergriffe mit einem lakonischen Bekenntnis zur Philanthropie. ${ }^{361}$ Einige Monate später reagierte Brod auf Schaukals Polemik, der „jüdische Intellektualismus“ sei eklektizistisch, mit einer Gleichsetzung von jüdischer Kunst und „deutscher Gemütsromantik“.362

In die Jahre des Briefwechsels fallen entscheidende Veränderungen in Max Brods Schriftstellekarriere, die Schaukal, der mit ähnlichen beruflichen Problemen haderte wie der in Prag tätige Kollege, nicht gleichgültig ließen. Brod quittierte 1907 den Staatsdienst, widmete sich 1908 ganz seinem Roman Schloß Nornepygge, gewann als Kritiker an Bedeutung und trat schließlich regelmäßig als Vortragender in Erscheinung. ${ }^{363}$

Eine ähnliche Inversion der Rollen - vom Bewunderer zum Erfolgsautor ereignete sich im Kontakt mit Hermann Hesse. Die Themen Honorar, persönliches Glück und Erfolg nahmen darin einigen Raum ein, was Hesse bisweilen befremdete. Dies wird mit Blick auf den Grund seiner Wertschätzung für den älteren Dichter plausibel; in der Sammlung Plauderabende (1897) beschreibt Hesse, was ihn an Schaukal so faszinierte:

Schaukal wird nie eine laute Menge entzünden, seine Verse werden nie in's Leben gehen und in Herzen und Schicksale greifen. Sie wollen das auch nicht. Sie lieben es, auf Teppichen zu gehen [. . .]. Lyrik für Lyriker. Kunst für Künstler. Ich liebe Schaukal deshalb [. . .]. Ein solcher Künstler entsagt von Anfang an der Liebe der Vielen, dem breiten Ruhm, den begeisterten Rufen der Masse, [...] Schaukal ist jung und warmblütig und liebt das Leben. Wie könnte er uns sonst so oftmals mit süß bekannten Tönen treffen! $!^{364}$

Der Ruhm sei nicht ausschlaggebend für sein Dichterglück, so Hesse 1904 in einem Brief an Schaukal, in dem er seinem österreichischen Kollegen in einer ironischen Pointe die Hälfte seiner Leser anbot, um dann das Schreiben mit der eindringlichen Bitte zu schließen: „Bleiben Sie mir gut! Warum soll nicht auch Ihnen irgend ein rascher Erfolg blühen?! Niemand wünscht dies mehr als Ihr H. Hesse“. 365

Schaukal mimte im postalischen Gespräch den geschäftskundigen Schriftsteller, der sich, als Hesse seine Einnahmen offen und beinahe gleichgültig mitteilte, über die geringe Summe wunderte. Und er gestand, dass er „laut gelächelt“ habe,

361 Brief Brods an Schaukal, 29. Januar 1907, S-NL, WB.

362 Brief Brods an Schaukal, 6. April 1907, S-NL, WB.

363 Vgl. in der genannten Reihenfolge der Ereignisse die Briefe Brods an Schaukal vom 3. Oktober 1907, 6. April 1908, 11. Dezember 1908 und 5. Februar 1909, S-NL, WB.

364 Hermann Hesse: Plauderabende. In: Hesse: Sämtliche Werke. Bd. 1: Jugendschriften. Hg. von Volker Michels. Frankfurt am Main 2001, S. 115-141, hier S. 122-123.

365 Brief Hesses an Schaukal, 11. September 1904, S-NL, WB. 
über mich nämlich den Sie vor Jahren so freundlich gewissermaßen als einen bekannten „Autor“ ansprachen und der heute froh wäre [...], wenn Sie ihm einen verehrlichen Kliquenverbande (siehe Neue Rundschau, siehe Neue freie Presse, siehe Zeit, siehe Velhagen u. Clasing, siehe Zukunft u.s.w.) gewissermaßen garantierten [.. .]. ${ }^{366}$

Während Hesse und Schaukal einander vermutlich nie persönlich begegnet sind, obwohl Schaukal 1908 einem Leseabend des jüngeren Kollegen in Wien inkognito beiwohnte, kam es im Februar 1909 zu einem Treffen mit Brod, der für eine Dichterlesung in die Hauptstadt gekommen war. Er wisse zwar, dass „es ein allzugroßes Opfer für Sie, wie ich meine, [bedeute], unter Literaten sich zu zeigen“, antizipierte Brod Schaukals Absage. Doch er wollte nichts unversucht lassen und ihn dennoch zu seiner Lesung einladen. ${ }^{367}$

Max Brods Bitte an Schaukal, dieser möge für das „Jahrbuch für Dichtkunst“ Arkadia unveröffentlichte Gedichte oder Novellen zur Verfügung stellen, markierte den Schlusspunkt des postalischen Austauschs. Das 1913 veröffentlichte Jahrbuch vereinte Beiträge von Robert Walser (1878-1956), Robert Musil, Otto Stoessl und anderen; diese Namen listete Brod auch in seinem Schreiben an Schaukal auf, wohl um ihn von der Qualität des Jahrbuchs zu überzeugen. ${ }^{368}$ Vielleicht erwähnte Brod aus Sorge um dessen antisemitische Reaktion nicht, dass auch Franz Kafkas Das Urteil sowie Beiträge von Franz Werfel, Max Mell, Kurt Tucholsky (1890-1935) und Hans Janowitz (1890-1954) in Arkadia erscheinen sollten. Schaukal stellte zwar Gedichte zur Verfügung, doch es kam aus nicht zu eruierenden Gründen - zu keiner Veröffentlichung in der Zeitschrift, die sich nicht einer literarischen Gruppe, sondern dem einzelnen Dichter verpflichtet sah. ${ }^{369}$

Rückblickend fällt Brod ein schmeichelhaftes und nicht ganz zutreffendes Urteil über den „hervorragenden Lyriker“, den „völlig in sich geschlossenen, eigenartigen Richard Schaukal“, ${ }^{370}$ der „,zu jener kleinen Gruppe unter den Sudetendeutschen [gehörte], die den Einflüsterungen des Antisemitismus und des Faschismus kräftig Widerstand geleistet“ hätten. ${ }^{371}$ In seinen Erinnerungen bringt Brod seinen ehemaligen Brieffreund mit einer Dichterin in Verbindung, die er gemeinsam mit Bertha von Suttner (1843-1914) und Božena Nemčova (1820-1862) zu den frühen Einflussgeberinnen des Prager Kreises zählte. Ehrfürchtig erinnert

366 Brief Schaukals an Hesse, 13. September 1904, H-NL, LAM.

367 Brief Brods an Schaukal, 5. Februar 1909, S-NL, WB.

368 Vgl. den Brief Brods an Schaukal, 29. September 1912, S-NL, WB.

369 Vgl. den Brief Brods an Schaukal, 29. September 1912, S-NL, WB.

370 Max Brod: Der Prager Kreis. Göttingen 2016, S. 98.

371 Brod: Der Prager Kreis, S. 277. 
sich Brod an seinen Besuch bei Schaukal in der Spiegelgasse 1, der dort über Marie von Ebner-Eschenbachs Stadtwohnung ein Apartment bewohnte.

Ich glaube mich (ganz undeutlich) daran zu erinnern, daß ich als ganz junger Mensch in dem Eckhaus Spiegelgasse 1 - Graben, als ich dort klopfenden Herzens meinen ersten Besuch bei Richard Schaukal machte, in einem tieferen Stockwerk an einem metallglänzenden Türschildchen vorübergeschritten bin, das ganz unglaubhafterweise, aber doch wirklich den Namen ,Marie von Ebner-Eschenbach` trug. Mein ehrfürchtiges Vorbeigehn kam mir wie ein Traumausflug ins Land der klassischen Dichtung vor und erhöhte damals das Prestige Schaukals und Wiens in meinen Augen ganz gewaltig. ${ }^{372}$

\subsection{Die Grande Dame der Literatur: Marie von Ebner-Eschenbach}

Marie von Ebner-Eschenbach, mit der Schaukal ab 1902 bis zu ihrem Tod im Jahr 1916 sowohl persönlichen Umgang pflegte als auch in Briefkontakt stand, zählte zu den prestigeträchtigen Akteuren seines Netzwerkes. Bis heute verstärken ihr Name und die an den mehr als 40 Jahre jüngeren Dichter adressierten Briefe seine symbolische Bedeutung. Zu Schaukals Lebzeiten war der Kontakt allerdings von keinem großen Nutzen für dessen beruflichen oder künstlerischen Weg. Als sich der Beamte um eine Beförderung ins Unterrichtministerium bemühte und dabei die ihm zur Verfügung stehenden literarischen Kontakte aktivierte (so auch den zu Ferdinand von Saar), sah Ebner-Eschenbach von einer Intervention $\mathrm{ab}^{373}$

Wie die von Claudia Girardi veröffentlichten Tagebucheinträge Schaukals und Briefe an die Schriftstellerin belegen, war auch die ästhetische Verbindung nicht ungetrübt. Ebner-Eschenbach bezeichnete den jungen Besucher beim ersten Treffen zwar großmütig als Kollegen und sprach ihn auf seinen Aufsatz über Ferdinand von Saar an. Doch Schaukal fühlte sich missverstanden, wie er im Tagebuch festhält, denn der Essay wollte keine Gegenüberstellung von Dichtergenerationen zeigen - so Ebner-Eschenbachs Lesart -, sondern von Künstlern und Nicht-Künstlern. ${ }^{374}$

Schaukal nahm dennoch gern die Rolle des literaturkundigen Dialogpartners und Informanten ein, der mit Ebner-Eschenbach über Grillparzer und die geschätzten Romantiker - allen voran Novalis (1772-1801) - fachsimpelte, aber auch die Namen Thomas Mann, Peter Altenberg oder Gerhard Ouckama Knoop erstmals in die mährische Runde trug. Er las in den adeligen Kreisen des mährischen Ortes

372 Brod: Der Prager Kreis, S. 18.

373 Vgl. Girardi: Mährische Salonkultur am Beginn der literarischen Moderne, S. 756.

374 Vgl. Girardi: Mährische Salonkultur am Beginn der literarischen Moderne, S. 746-747. 
Löschna (Lešná) aus eigenen Werken, die zum überwiegenden Teil mit Beifall aufgenommen wurden, ${ }^{375}$ ihm andererseits aber auch den Ruf eines ,Modernen“ eintrugen. Ebner-Eschenbach vermisste in Schaukals Novelle Mimi Lynx den Gedanken des poetischen Realismus: „Herr Doctor, machen Sie mir einmal die Freude, erzählen Sie mir etwas von Menschen, die ich lieben müßte, so recht von Herzen. Sie können voll Fehler sein, das macht mir gar nichts, aber dabei etwas Tüchtiges, etwas Rechtes. “376 Auch Ferdinand von Saar äußerte in einem Brief an die befreundete Dichterkollegin die Auffassung, dass Schaukal zwar persönlich ein „netter, sympathischer Mensch“ sei, der er auch „einen allerliebsten, kleinen Buben [Sohn Wolfgang, CM]“ habe, mit dem er „in einem Freundschaftsverhältniß stehe“. Doch „[mit] seinen papierenen Kindern kann ich aber gar keine Sympathie in mir auftreiben. Sie wachsen aus dem Boden wie die Schwämme und jedesmal hoffe ich etwas Verbindliches über das neue Produkt sagen zu können, und nie bring ich’s heraus.“377 Den ,Modernen“ wünscht Saar „nur guten Appetit“, wie er seiner Freundin mitteilt: „Mir ist solcher wenn auch talentvoller Schwulst unverdaulich.“378

Auch Schaukals unerbittliches Kritikerurteil, für das er Gefälligkeiten erwartete, wie er sie selbst nicht leichtfertig verteilte, wirkte auf Ebner-Eschenbach befremdlich. Als sie den Rezensenten um eine Besprechung von Gedichten der Baronin Josephine Knorr (1827-1908) bat, sandte Schaukal einen harschen Verriss, dessen Veröffentlichung sie unterband. ${ }^{379}$ Der Briefwechsel zwischen EbnerEschenbach und Knorr erhellt die Bemühungen der arrivierten Dichterin um die Etablierung der Freundin, ${ }^{380}$ umso enttäuschender muss Schaukals anfängliche Ablehnung gewesen sein.

Hast du Saars Lenau Gedicht gelesen? Ich finde es sehr schön u. sagte das einem 28 jährigen Vertreter der neuen Richtung: Richard Schaukal. Er ist hier in Weisskirchen bei der Statthalterei angestellt. „Cliché-Arbeit“ meinte er. Explicierte mir auch, daß ein lyrisches

375 Vgl. Girardi: Mährische Salonkultur am Beginn der literarischen Moderne, S. 749.

376 Brief Ebner-Eschenbachs an Schaukal, 9. September 1904, in: Girardi: Mährische Salonkultur am Beginn der literarischen Moderne, S. 756; sowie in: Warum: Briefe eines Mährers aus Wien in die Heimat und nach Böhmen, S. 75-76.

377 Brief Saars an Ebner-Eschenbach, 6. Juli 1906, in: Heinz Kindermann (Hg.): Briefwechsel zwischen Ferdinand von Saar und Marie von Ebner-Eschenbach. Wien 1957, S. 158-159.

378 Brief Saars an Ebner-Eschenbach, 22. Juni 1906, in: Kindermann (Hg.): Briefwechsel zwischen Ferdinand von Saar und Marie von Ebner-Eschenbach, S. 155-159.

379 Vgl. Girardi: Mährische Salonkultur am Beginn der literarischen Moderne, S. 758.

380 Vgl. Ulrike Tanzer u. a. (Hg.): Marie von Ebner-Eschenbach und Josephine von Knorr: Briefwechsel 1851-1908. Kritische und kommentierte Ausgabe. Bd. 1: Texte. Berlin/Boston 2016, S. XXX. 
Gedicht Gedanken nicht enthalten dürfe. Ich habe ihm trotzdem einige deiner Gedichte vorgelesen. Lange hielt er stand $u$. blieb ablehnend. Als aber „Myrrhen“ an die Reihe kam, da gestand er: Ja! Jetzt hat es mich überlaufen! Ja, das ist eine Dichterin! ${ }^{381}$ Zur Belohnung bekommt er Deine Gedichte. Dir schicke ich seinen letzten Band, u. sagen muß ich noch, daß er ein wohlerzogener, netter Mensch ist. Für sehr gescheit halte ich ihn nicht. ${ }^{382}$

Mit dem Vermerk, es handle sich bei Schaukal um einen „[H]ochmodernen“, legte Ebner-Eschenbach dessen „Notiz“, also den Verriss des jungen Kritikers, dem Brief an Josephine Knorr bei. ${ }^{383}$

Trotz der ästhetischen wie persönlichen Interferenzen und obwohl Marie von Ebner-Eschenbach, die keine ökonomischen wie symbolischen Profilierungsbestrebungen im literarischen Feld mehr verfolgte und weder als literarische Informantin noch als Vermittlerin für Schaukal von Nutzen war, blieb der Kontakt bestehen. Die gesellschaftliche Anbindung als Selbstzweck genügte dem Adelsaspiranten. Die Zugehörigkeit zum Kreis der Ebner-Eschenbach erbrachte kulturelles wie prestigeträchtiges soziales Kapital, wie sich im Erinnerungsbuch Großmutter ausdrückt, das nicht nur Schaukals leiblicher Großmutter, sondern auch der geistesverwandten Dichterin gewidmet ist. ${ }^{384}$

\subsection{Die Prager Neuromantiker}

Die Prager Neuromantiker spielten vor allem für die literarische HoffmannRezeption eine wesentliche Rolle, war ihre Stadt doch als literarische Projektionsfläche prädestiniert für den aus dem nachtseitigen Antirationalismus heraufbeschworenen magischen, grotesken und phantastischen Themenkreis. ${ }^{385}$

In Schaukals Nachlass finden sich neben Korrespondenzen mit Rilke und Brod auch Briefwechsel mit Mitgliedern des erweiterten Prager Kreises, mit Camill Hoffmann, Oskar Wiener und Karl Brand (1895-1917). Mit Gustav Meyrink (1868-1932) bestand über Kubin eine Verbindung, sie, Kubin und Meyrink,

381 In einer Anmerkung schreibt Ebner-Eschenbach am unteren Briefrand: „[I]n seinem Widerstand zu wackeln hat er angefangen bei ,Lilien und Schwäne‘.“

382 Brief Ebner-Eschenbachs an Knorr, 16. August 1903, in: Tanzer u.a. (Hg.): Marie von Ebner-Eschenbach und Josephine von Knorr: Briefwechsel 1851-1908, S. 568.

383 Brief Ebner-Eschenbachs an Knorr, 11. Mai 1903, in: Tanzer u. a. (Hg.): Marie von EbnerEschenbach und Josephine von Knorr: Briefwechsel 1851-1908, S. 578.

384 Im Kapitel „Erwachen der Seele“ beschreibt Schaukal seine Begegnung mit Marie von Ebner-Eschenbach. Vgl. Schaukal: Großmutter. In: WE. Bd. 1: Kindheit und Jugend. München/ Wien 1965, S. 112-193, hier S. 121-123.

385 Vgl. Marquardt u. a.: Hoffmanns literarische Rezeption, S. 569. 
trafen sich regelmäßig und es entstand bei diesen Zusammenkünften auch die letztlich nicht ausgeführte Idee, einen Roman des Schriftstellers zu illustrieren. ${ }^{386}$

Ein weiteres Bindeglied zwischen den Prager Literaten und Schaukal war neben Kubin und Brod auch der bereits mehrfach genannte Literaturvermittler Franz Blei, einer der ersten Förderer Kafkas. ${ }^{387}$ Bleis aus 15 biographischen Kurzessays bestehender Band Männer und Masken beginnt mit einer Skizze über Hoffmann. ${ }^{388}$ Der „Vermittler zwischen Vermittlern“ beförderte maßgeblich den Kulturtransfer zwischen den Metropolen der Moderne. ${ }^{389}$ Allerdings begriffen sich die meisten der Akteure, mit denen Schaukal in Verbindung stand, nicht als abgeschlossene, zusammengehörende Gruppe. Ähnlich Hermann Bahr, der sich rückblickend als Gründungsvater des Jungen Wien bezeichnete, prägte auch Max Brod aus der Rückschau ,seinen' Prager Kreis. Beide Beispiele sind als Selbsteinschreibung in einen mythisch erhöhten Dichterzirkel zu werten.

Obwohl sich nicht alle der hier genannten Akteure des Neuromantik- beziehungsweise Hoffmann-Netzwerks als Gruppe empfanden, bildete das Personengefüge nominalistisch betrachtet ein Netzwerk. Ihre Umwelt war von ganz ähnlichen geographisch-politischen Verhältnissen und kulturellen Diskursen geprägt. Sie fanden nicht nur in Hoffmann ein übereinstimmendes literarisches Interesse, sondern auch im Dichter Detlev von Liliencron, den die deutschsprachigen Prager Autoren am 13. Januar $1897 \mathrm{zu}$ einem Leseabend in ihre Stadt einluden: eine gemeinschaftsstiftende Handlung, die darüber hinaus als Spitze gegen den Dichterkreis Concordia gedacht war, eine „Gruppe konservativer Literaten“ rund um Hugo Salus und Friedrich Adler. Liliencron sei nach Prag eingeladen worden, damit er als „Fanal ihres Kampfes“ gegen die ältere Dichtergeneration in der Stadt auftrete. „Schade, daß dieses Fanal so viel von den Schulden erzählte, die ihm auf dem Buckel lagen“, so Max Brod Mitte der 1950er Jahre, der damit ironisch auf Liliencrons ökonomische Erwartungen an den Besuch anspielte. ${ }^{390}$ Diese scheinen sich erfüllt zu haben, denn neben der „Versicherung vieler neuer begeisterter Freunde“ erhielt der Dichter von Rilke, der maßgeblich an der Organisation des Abends beteiligt war, ein Honorar von

386 Vgl. den Brief Kubins an Schaukal, 20. Februar 1907, S-NL, WB.

387 In der von Blei gemeinsam mit Carl Sternheim (1878-1942) herausgegebenen Zeitschrift Hyperion wurden die ersten Werke Kafkas veröffentlicht; vgl. Paul Raabe: Franz Kafka und Franz Blei. In: F. Kafka. Ein Symposion. Datierung, Funde, Materialien. Berlin 1965, S. 7-20. Vgl. außerdem Mitterbauer: Die Netzwerke des Franz Blei, S. 100-105.

388 Vgl. Franz Blei: Männer und Masken. Berlin 1930.

389 Mitterbauer: Die Netzwerke des Franz Blei, S. 92.

390 Brod: Liliencron in Prag. In: Die Zeit, Nr. 28/1955 (14. Juli 1955). https://www.zeit.de/ 1955/28/liliencron-in-prag (zuletzt aufgerufen am 31. Juli 2019). 
300 Mark. Gegenüber Wilhelm von Scholz bezeichnete Rilke das Ereignis als „materiellen und ideellen“ Erfolg. ${ }^{391}$ Wenige Tage später berichtete er Schaukal von der gelungenen Veranstaltung. ${ }^{392}$ Dieser verfasste einen glühenden Artikel über die neue Literatur in Prag und den von ihnen verehrten älteren Dichter, der am 23. Mai und 6. Juni 1897 in der Brünner Sonntagszeitung erschien und in dem er beklagte, dass die Leute noch nicht wüssten, „daß wir schon eine starke junge Literatur haben. Es ist eine Schmach, dass man jetzt für Liliencron sammeln muss, der doch schon ,officiell‘ angenommen ist.“393

Max Brod erinnerte sich noch fast 60 Jahre später lebhaft an den ersten öffentlichen Auftritt des Jungen Prag auf dem bürgerlichen Parkett ihrer Stadt:

\begin{abstract}
Am Sonntagvormittag, da das ganze deutsche Prag sich auf dem „Graben“ versammelte und in zwei langen Kolonnen aneinander vorbeipromenierte (merkwürdiger Kleinstadtbrauch, den ich mir in ein heutiges Stadttempo gar nicht einfügen kann): an solch einem Vormittag erschienen unsere Neo-Romantiker in geschlossener Gruppe auf dem „Bummel“, jeder einen riesigen Kalabreser auf dem Kopf und jeder eine langstielige rosa Rose vor sich hertragend, als gelte es einen neuen Kult der Schönheit zu stiften. Prag war schockiert; aber Liliencron fand die Sache ganz in Ordnung. ${ }^{394}$
\end{abstract}

Rilke, der am provokanten Bummel teilgenommen haben dürfte, agierte seit Mitte der 1890er Jahre als Mittelsmann zwischen den neuromantisch beeinflussten Zeitschriften, Verlagen und dichterischen Akteuren in Prag und München. Er war im Jahr 1896 Beiträger der dort ansässigen literarischen Organe Jugend, Simplicissimus und Der wahre Jacob. Im Dezember desselben Jahres nahm er Kontakt zu Schaukal auf, um ihn als Mitarbeiter für sein eigenes Zeitschriftenprojekt Wegwarten $\mathrm{zu}$ gewinnen, das bereits im Titel die ästhetische Ausrichtung vorwegnimmt. Auch Rilke wandte sich nicht allein deshalb an Schaukal, weil er eine gemeinsame poetologische Linie im lyrischen Schaffen vermutete, sondern vor allem wegen des erhofften Anschlusses an weitere deutschsprachige Zeitungen und Zeitschriften.

Schaukal zeigte sich im Briefwechsel gut informiert über das literarischverlegerische Feld in München, in dem sich Rilke bewegte, und bat ihn sogleich um die Vermittlung seines (dann verschollenen) Romans an den Langen-Verlag. ${ }^{395}$

391 Zit. nach Wolfgang Leppmann: Rilke. Sein Leben, seine Welt, sein Werk. Bern/München 1993, S. 70-71.

392 Vgl. den Brief Rilkes an Schaukal, 5. Februar 1897, S-NL, WB.

393 Schaukal: [ohne Titel]. In: Brünner Sonntagszeitung, Nr. 33 (23. Mai 1897), S. 5; Fortsetzung in: Brünner Sonntagszeitung, Nr. 35, (6. Juni 1897), S. 1-2.

394 Brod: Liliencron in Prag.

395 Vgl. den Brief Rilkes an Schaukal, 17. Mai 1897, S-NL, WB. 
Des Weiteren wurde die (nie realisierte) Herausgabe eines Musenalmanachs bei Schuster \& Löffler diskutiert, dem Verlag neuromantischer Ausrichtung, der unter anderem auch Liliencron, Dehmel und Bierbaum publizierte. ${ }^{396}$

Obwohl die Verbindung zwischen Schaukal und Rilke ein symmetrischer Austausch von zwar geringer Dichte, aber mit nicht unerheblichem Nutzen für beide Seiten war (Wissenstransfer und Literaturkritiken), blieb die Korrespondenz kühl und wurde bald schon von literarischen Meinungsverschiedenheiten getrübt. Die gemeinsamen Bekanntschaften mit Heinrich Vogeler, den Rilke in Worpswede besuchte, und mit der schwedischen Schriftstellerin und Reformpädagogin Ellen Key (1849-1926) geben zwischen 1902 und 1905 Anlass zu freundlichen, aber oberflächlichen Grußsendungen. Wie auch Thomas Mann, der sich von der Verpflichtung entbinden ließ, eine Rezension über Schaukal zu verfassen, klagte im Sommer 1904 der ebenfalls darum gebetene Rilke:

Mir fällt das Schreiben „über“ mit jedem Tag schwerer, der Kreis wird immer kleiner, und schließlich wird es nur zwei oder drei Dinge geben, über die ich mich zu schreiben getrauen werde, und unter diesen Dingen werden wohl keine Bücher sein. Aber wie gesagt, ich will es diesmal versuchen. ${ }^{397}$

Ein Jahr später war die Pflicht dennoch erfüllt, Rilke besprach Schaukals 1904 im Insel-Verlag erschienene Sammlung Ausgewählte Gedichte in Form eines offenen Briefes auf zurückhaltende, ein klares Urteil scheuende Art und Weise:

Lieber Herr Schaukal [. . .], wenn ich auch - in der zweiten Abtheilung Ihre Buches - wie in einem Saal des Louvre ausruhe, jedesmal, wenn mein Blick sich hebt, Bedeutendem begegnend; wenn ich Ihnen auch danke für all Das wie für Etwas, das Sie gerade mir gegeben haben, so weiß ich doch, lieber Herr Schaukal, - nein, ich weiß nicht, wer Sie sind. Ihre Persönlichkeit [. . .] entzieht sich mir. ${ }^{398}$

Nach dem Erscheinen der Kritik in Herwarth Waldens Zeitschrift Die Zukunft sah Rilke sich verpflichtet, Schaukal einen erklärenden Brief nachzureichen: „[J]ene Form des offenen Briefes [wurde] für die Anzeige gewählt, um anzudeuten, daß es sich nur um mein allerpersönlichstes Verhältnis zu Ihnen handelt, um mein Unvermögen, Sie als Gestalt zu erkennen und festzuhalten, um meine Ungeschicklichkeit, wenn Sie wollen.“399

396 Vgl. den Brief Rilkes an Schaukal, 18. Mai 1897, S-NL, WB.

397 Brief Rilkes an Schaukal, 2. August 1904, S-NL, WB.

398 Rilke: Ausgewählte Gedichte. Von Richard Schaukal, S. 39.

399 Brief Rilkes an Schaukal, 11. April 1905, S-NL, WB. 
Im einzigen erhaltenen Antwortschreiben Schaukals an Rilke, von dem allerdings nicht klar ist, ob es in dieser Form oder überhaupt nicht abgeschickt wurde, teilte er seine Enttäuschung über die „tonlose“ Rezension mit, zumal sie von einem der wenigen Dichter stammte, „die mir seelisch etwas zu sagen haben. “400 Am 17. November 1907 fand ein Treffen der beiden Dichter statt, wie die letzten erhaltenen Briefe dokumentieren, danach trennten sich ihre Wege. ${ }^{401}$

Gemeinsame identitätsstiftende Aktionen wie die Organisation und der Besuch des Liliencron-Abends, übereinstimmende künstlerische Vorlieben und das gegenseitige Verfassen von Kritiken sind also die Kanten, die zwischen den Akteuren eine Verbindung herstellen und sie zu einem Netzwerk zusammenschließen. $\mathrm{Zu}$ den der Netzwerkstruktur entspringenden Interessen zählt die Steigerung aller Kapitalsorten.

Ein Beispiel dafür, wie Schaukal auf der Basis einer ähnlichen Umwelt und ähnlicher Kognitionen literarischen Anschluss suchte, ist der Briefwechsel mit Franz Blei. Blei war zur Zeit der Kontaktaufnahme Schaukals (20. Mai 1900) in München als Redakteur der Zeitschrift Die Insel tätig. Sie tauschten sich unter anderem über ästhetische Themen aus (Kognitionen), etwa über Stefan George und den Autor phantastischer Literatur Paul Scheerbart (1863-1915), ${ }^{402}$ außerdem über gemeinsame Bekannte wie den bereits geannten Hans von Müller, der den Insel-Lesern Hoffmann näherbrachte und an einer Edition der Kreislerfragmente arbeitete, die dann im Insel-Verlag erscheinen sollte. In diesem Zusammenhang erwähnte Schaukal gegenüber Blei auch seine eigenen Pläne, sich Hoffmann editorisch und biographisch zu widmen, ein Vorhaben, das später zu Spannungen zwischen dem Dichter und dem Kreisler-Herausgeber führte. Aus den Briefen geht hervor, dass sich Schaukal nach Müllers Reputation als Philologe erkundigte, worauf Blei den Berliner Hoffmann-Forscher als Menschen bezeichnete, der „,alles hat, dem Andenken Hoffmanns nicht zu schaden.“403

Für Schaukal war der Kontakt zum Redakteur der Insel ertragreich. 1900 brachte die Zeitschrift den Essay über Velázquez und zwei Jahre später sieben eigene Gedichte und vier Lyrikübertragungen aus dem Französischen. Der

400 Brief Schaukals an Rilke, undatiert, S-NL, WB.

401 Vgl. die Briefe Rilkes an Schaukal, 15. November und 16. November 1907 (der letzte erhaltene Brief), S-NL, WB.

402 Vgl. die Briefe Bleis an Schaukal, 7. Mai 1902 und 10. Mai 1902, S-NL, WB.

403 Brief Bleis an Schaukal, 10. Mai 1902, S-NL, WB. Die Kreislerfragmente erschienen, wie erwähnt, 1903 bei Insel unter dem Titel Das Kreislerbuch. Texte, Compositionen und Bilder von E.T.A. Hoffmann. 
Mitherausgeber Otto Julius Bierbaum besprach im Doppelheft April/Mai des Jahres 1902 Schaukals Von Tod zu Tod, Pierrot und Colombine sowie Vorabend. ${ }^{404}$

Obwohl die Insel zu den wichtigsten Zeitschriften der literarischen Moderne gehörte, erschien sie lediglich in drei Jahrgängen und stellte ihr Erscheinen, wie erwähnt, bereits 1902 wieder ein. Blei klagte über Finanznöte und erkundigte sich bei Schaukal am 30. April halb ironisch, halb hoffend, ob er nicht „Förderer“ kenne, die 10.000 Mark spenden wollten, um die 400 Abonnenten der Insel weiter beliefern zu können; er berichtete außerdem, dass Bierbaum die Insel verlassen werde, um im Oktober 1902 den belletristischen Teil der Wiener Zeit zu übernehmen. ${ }^{405}$

Mit dem Ende der Zeitschrift verlor Schaukal auch eine wichtige und prestigeträchtige Publikationsmöglichkeit. Sich über Bierbaum dauerhaften Zutritt zur Zeit zu verschaffen, war nicht möglich; bereits 1897 war Schaukal beim Mitherausgeber und Leiter des Kunst- und Kulturressorts Hermann Bahr auf eindeutige Ablehnung gestoßen. ${ }^{406}$

Immerhin profitierte Schaukal von Bleis Kontakten zum Insel-Verlag, der aus der gleichnamigen Zeitschrift hervorgegangen war. In einem Brief vom 3. Mai 1902 deutet der Redakteur an, dass Verlagsleiter Rudolf von Poellnitz auf Schaukals Lyrik aufmerksam geworden sei. ${ }^{407}$ Zwei Jahre später veröffentlichte Schaukal in dem renommierten Verlagshaus die Erzählung Mimi Lynx und einen Band Ausgewählte Gedichte. Doch im darauffolgenden Jahr verstarb Poellnitz und Anton Kippenberg (1874-1950) übernahm die Geschäftsleitung. Trotz einer Reihe von weiteren Fürsprechern sollten diese beiden die einzigen im Insel-Verlag veröffentlichten Werke bleiben.

Dass Schaukals literarisches Schaffen zwischen 1900 und 1904 derart produktiv und erfolgreich war, hing unzweifelhaft mit der günstigen Netzwerkstruktur zu einflussreichen Redeakteuren und Verlegern zusammen. Als sich die Konstellation unter anderem auch wegen äußerer Umstände änderte, wirkte sich dies negativ auf Schaukals Handlungen im literarischen Feld aus und führte zu Verlusten an kulturellem und symbolischem Kapital. Doch es wäre zu kurz gegriffen, Schaukals stagnierenden und dann rückläufigen Erfolg lediglich auf die Netzwerkstruktur zurückführen zu wollen. Sein aggressives Netzwerkverhalten, das zunehmend antisemitisch aufgeladen war, löste Befremden aus

404 Vgl. Otto Julius Bierbaum: Von Tod zu Tod und andere kleine Schriften von Richard Schaukal. In: Die Insel, 3. Jg., H. 7-8 (April/Mai 1902), S. 196-198.

405 Brief Bleis an Schaukal, 7. Mai 1902, S-NL, WB.

406 Siehe die Ausführungen im folgenden Kapitel.

407 Brief Bleis an Schaukal, 3. Mai 1902, S-NL, WB. 
und trug zur Distanzierung einzelner Akteure sowie zum Ausschluss aus Künstlerkreisen bei.

Die relationale Verbindung der Akteure im Neuromantik-Zirkel ergab sich, wie dargelegt, unter anderem aus der Kommunikation über gemeinsame philologische wie ästhetische Interessen. Diese Relationen waren allerdings nicht frei von Spannungen. Die Konflikte entzündeten sich zum Teil an ästhetischen Fragen, den Forschungsgegenständen und auch an wissenschaftlichen Methoden in Bezug auf Dichter der Romantik und ihre Zeit.

So pflegte Schaukal mit dem Dresdner Schriftseller, Übersetzter und Philologen Arthur Schurig über zwei Jahrzehnte einen freundschaftlichen Briefverkehr. Als Schurig aber 1920 Adelbert von Chamissos (1781-1838) Schlemihl in einer Edition herausgab, die erstmals der „Urhandschrift“ folgte, kritisierte Schaukal ihn überraschend heftig. Dabei störte den Wiener Chamisso-Verehrer weniger, dass Schurig auf eine textkritische Edition verzichtete, als vielmehr der Umstand, dass der Herausgeber auf eine Handschrift aus dem Besitz des Erben Helmuth Rogge (1891-1976) zurückgegriffen hatte. Schaukal witterte eine Kommerzialisierung Chamissos - und wahrscheinlich war er auch ein wenig neidisch, wollte er sich doch zur gleichen Zeit selbst als Experte und Herausgeber romantischer Werke profilieren.

Es ist nicht ganz klar, weshalb Schurig das Chamisso-Manuskript ohne Rogges Einverständnis herausgeben konnte. Der Erbe, selbst Philologe, veröffentlichte jedenfalls zwei Jahre später den ,Ur-Schlemihl‘ ${ }^{408}$ Schurig bezeichnete seine Edition rückblickend als „Fehlgriff“, der ihn „öffentlich schwer geschädigt“ habe, und er sorgte sich um eine von Schaukal angedrohte Zeitungskritik, die eine „2. Serie dieser Angriffe“ eröffnen würde und ihn um sein „täglich Brot“ bringen könnte. ${ }^{409}$

Auch das Verhältnis zwischen Hans von Müller und Schaukal war aufgrund unterschiedlicher methodischer Herangehensweisen belastet. Müller warf Schaukal 1912 vor, er sei zu sehr Dichter und konzentriere sich zu stark auf die Biographie, um auch als Wissenschaftler vollauf gelten zu können. Schaukal verwende zu viele rhetorische Stilmittel und seine persönlichen Vorlieben und subjektiven Ansichten würden ihn von philologischer Objektivität und Präzision ablenken. ${ }^{410}$

408 Nikolas Immer und Matthias Glaubrecht: Peter Schlemihl als Naturforscher. Das zehnte Kapitel von Chamissos Märchenerzählung in editionsphilologischer und wissenschaftshistorischer Perspektive. In: Editio, Bd. 26 (2012), S. 123-144. Online: http://www.nikolasimmer.de/ ImmerN_A2012c.pdf (zuletzt aufgerufen am 31. Juli 2019).

409 Brief Schurigs an Schaukal, 20. April 1921, S-NL, WB.

410 Vgl. den Brief Müllers an Schaukal, 29. Oktober 1912, in: Mühlher: Hans von Müller: eine Porträtskizze, S. 120-121. 
Auch der Prager Dichter Hugo Salus, bei dem Schaukal Erkundigungen über Müllers wissenschaftliche Reputation eingeholt und dem er seine erste größere Hoffmann-Arbeit aus dem Jahr 1904 geschickt hatte, kritisierte Schaukals biographische Methodik. Diese habe ihn in seiner Überzeugung bestärkt, dass Poeten keine Literaturhistoriker sein sollten und Biographien von Dichtern über Dichter nur beschränkte Erkenntnisse zutage förderten. ${ }^{411}$

Robert Mühlher (1910-2003), ein Hoffmann-Forscher der nachfolgenden Generation, der mit Müller und Schaukal in Kontakt stand, merkte gegenüber Schaukal 1941 an, dass die biographische Philologie mittlerweile ja doch von einer textkritischen Methode abgelöst worden sei. ${ }^{412}$ Mühlher thematisierte in seiner 1971 veröffentlichten Porträtskizze das ambivalente Verhältnis der beiden Hoffmann-Verehrer. Ihre Geister schieden sich am Begriff des Bürgerlichen im gegenwärtigen wie historischen Kontext. Für Müller sei der Philologe sozial veranlagt und verkörpere die bürgerlichen Tugenden, der Künstler wolle sich hingegen nur als „Individualist“ entfalten. ${ }^{413}$

Pierre Bourdieus soziologische Ausführungen zur sozialen Welt und ihren Machtfeldern antizipierend bemerkte Müller:

Das Herausgeben von inedits ist reine Machtfrage ... und mit Dingen verbunden, die den über Hoffmann schreibenden und Hoffmanniana neu druckenden Herren Schaukal, Ellinger, Cerny, Maassen, Pirker usw. in gleicher Weise fern liegen: Sie betrachten und verarbeiten [...] das gegebene Material, während es mein Geschäft ist, neues Material erstens zu finden, zweitens es dann zu erobern oder erschmeicheln, und erst drittens es zu combinieren und zu erklären [... . ${ }^{414}$

Schaukal versuchte, sich unter den Neuromantikern als cut point zu positionieren und mit seiner Romantik-Expertise eine Brückenfunktion zwischen Wissenschaft, Kritik und Literatur einzunehmen. Sein Ziel war die Verlagerung von sozialem Kapital (also seine mannigfachen Kontakte) und kulturellem Kapital auf die kapitalärmeren Felder. Für die anvisierte Vermittlung zu Verlagen, die den Schriftstellern der Neuromantik offenstanden, reichte die intensive Netzwerktätigkeit jedoch nicht aus. Trotz des generellen Interesses an Schaukals Lyrik lehnte beispielsweise der Diederichs-Verlag Schaukals Manuskripte ab, ebenso Fischer und - bis auf zwei Werke - auch der Insel-Verlag.

411 Vgl. den Brief Salus' an Schaukal, 24. Oktober 1904, S-NL, WB. Aus einem Brief Salus' an Schaukal vom 2. Februar 1904, S-NL, WB, wird ersichtlich, dass Salus Hans von Müller an den Langen-Verlag vermitteln konnte.

412 Vgl. den Brief Mühlhers an Schaukal, 1. Juni 1941, S-NL, WB.

413 Mühlher: Hans von Müller, S. 122.

414 Brief Müllers an Mühlher, undatiert, in: Mühlher: Hans von Müller, S. 124. 
Schaukals Netzwerkaktivitäten stießen in Bezug auf die Neuromantik/Hoffmann-Akteure gerade deshalb auf Widerstand, weil er sich disziplinär breit aufstellte und in übergreifenden Feldern etablieren wollte - also in der Literatur, Philologie und Kritik -, die von anderen Akteuren besetzt waren.

Schaukals Tätigkeiten in jenen Bereichen erbrachten ökonomische wie symbolische Vorteile (vor allem als Literaturkritiker), haben ihm aber auch Kapitalverluste eingetragen, wie Arthur Schurig seinem Briefpartner zu verstehen gab. Am 28. Oktober 1907 erkundigte er sich bei Schaukal: „Was folgt auf Balthesser? Es ist ein prächtiges Zeichen, daß lange von Ihnen nichts erschienen ist. Das war einer Ihrer größten Fehler, dieses zu viel. Auch scheint es mir, arbeiten Sie weniger für Revüen und Tagesblätter. Das ist auch günstig für Sie! “415

Ein Jahr später wurde der Ton des Kontaktmannes zum Insel-Verlag ungehaltener. Schurig hatte sicher nicht unrecht, als er dem um Vermittlung ansuchenden Schaukal vorhielt:

Im Inselverlag hat man gegen Sie intrigiert, höre ich. Daran ist nicht Kippenberg schuld. Das ist ein sehr feiner, charaktervoller Mensch. Er weiß, was er will. Die Schuld liegt an Ihnen selber, an Ihrer Art zu kritisieren. Ich habe Ihnen sehr freundschaftlich schon oft gesagt: entweder ist man Dichter - oder Kritiker. Niemals verträgt sich beides. Und gerade daß Sie das nicht einsehen, daß Sie nach allen Seiten den Kampfhahn machen, das verdirbt Ihnen das Terrain und wird Ihnen immer mehr schaden. ${ }^{416}$

Schurig riet Schaukal abschließend, er solle seine allzu impressionistische „nutzlose kritische Tätigkeit lassen“, da sie nur noch mehr „unbeugsame Feinde“ auf den Plan rufe. ${ }^{417}$

Die Aktivitäten des Neuromantik-Netzwerkes waren des Weiteren nicht allein auf Wien oder Prag begrenzt. Bis zum Ersten Weltkrieg erfolgte der gegenseitige ästhetische Einfluss und Informationsaustausch zwar hauptsächlich zwischen den deutschsprachigen Literaten und Forschern aus Prag, Brünn und Wien. Nach dem Ende der Donaumonarchie verlagerte sich der Transfer aber von den tschechischen Städten nach Deutschland. Die neuromantische Ästhetik, die bis 1918 im Städtedreieck Prag, Brünn, Wien zirkulierte, hörte in Folge der neuen politischen Grenzziehungen nicht etwa auf $z u$ existieren, sondern erzeugte ein mythisches Bild von Alt-Prag, Alt-Brünn und Alt-Wien, das zu gemeinsamen geistigen und sinnstiftenden Konstituenten avancierte. Diesen Prozess könnte man mit Rückgriff

415 Brief Schurigs an Schaukal, 28. Oktober 1907, S-NL, WB.

416 Brief Schurigs an Schaukal, 11. November 1908, S-NL, WB; Hervorh. im Orig. als Unterstreichung.

417 Brief Schurigs an Schaukal, 11. November 1908, S-NL, WB. 
auf Claudio Magris als Teil des Habsburgermythos bezeichnen, ${ }^{418}$ der somit auch als neuromantischer Mythos zu werten ist. Die rückwärtsgewandte Utopie birgt in der Mystifizierung der alten Donaumonarchiestädte nicht nur eine ästhetische Reminiszenz, sondern auch eine ideologische Note, die bis in die 1960er Jahre hinein anhand der Topographie ein sinnstiftendes literarisches Wir-Gefühl erzeugte. Norbert Langer (1899-1975), völkischer und antisemitischer Literaturhistoriker ${ }^{419}$ und Mitherausgeber von Band 4 der gesammelten Werke Richard Schaukals, ordnete den Dichter und sein Schaffen einem altösterreichischen Kulturraum zu:

Wenn man bedenkt, daß der Dichter die ganze Kindheit und Jugend in Brünn verbrachte, in der Hauptstadt des Kronlandes Mähren, das Österreich verlorenging, hat man in den Erinnerungsbüchern Schaukals ein lebendiges Bild dieses Landes, das durch PostlSealsfield, Saar und Ebner-Eschenbach für immer in unsere Literatur eingegangen ist: noch einmal, direkter, ganz im Zeichen des Abschieds. ${ }^{420}$

Nach dem Ersten Weltkrieg wird in der topographischen Verortung der Neuromantik-Diskurse besonders deutlich, dass dieser Vergangenheitsbezug nicht nur auf eine Stadt beschränkt war. Fägt man dem Netzwerk, in dem Schaukal sich bewegte, etwa die Kontakte zu Hermann Hesse und Heinrich Mann hinzu, ergibt sich eine ausgedehnte Kartographie, die auch Leipzig, Dresden, München und die österreichische oder süddeutsche Provinz als Orte der Neuromantik einschließt. Vor allem der Kontakt zu Heinrich Mann war geprägt von der gegenseitigen Versicherung literarischer Gemeinsamkeiten und Vorlieben für französische Romane und die romantische Epoche. Aus Garda schilderte Heinrich Mann zum Beispiel 1902 seinen Eindruck des an Hoffmann angelehnten Schaukal-Dramas Vorabend: „Sie haben mir durch Ihren Einakter noch einmal den Genuß der Romantik ermöglicht, seien Sie bedankt dafür.“421

\section{Wiener Netzwerke}

Edward Timms bezeichnet die vielfältigen Kreise der Wiener Moderne als Kreativzirkel, die zu einem bestimmten Zeitpunkt und an einem Ort in relativ gleich-

418 Vgl. Magris, Il mito asburgico.

419 Vgl. Karl Müller: Literatur und Kultur des Judentums in der Literaturwissenschaft der Zweiten Republik. In: Judentum und Antisemitismus. Studien zur Literatur und Germanistik in Österreich. Hg. von Anne Betten und Konstanze Fliedl. Berlin 2003, S. 167-188, hier S. 175-176.

420 Norbert Langer: Dichter aus Österreich. 5. Folge. Wien/München 1967, S. 83.

421 Brief Heinrich Manns an Schaukal, 17. April 1902, S-NL, WB. 
bleibender Konstellation zusammengekommen seien. Die lebendige Dynamik aus Wissens- und Erkenntnistransfer ließe sich damit begründen, dass die Akteure unterschiedlichen Kreisen angehörten. Die Gruppen funktionierten wie „elektromagnetische Netzwerke“, in denen Informationen und Neuerungen wie in einem Nervensystem schnell die Runde machten. ${ }^{422}$ Diese Metapher ist allerdings nicht auf alle Gruppierungen der Wiener Moderne und ihre Akteure anwendbar; vor allem die Begrenzung auf nur einen Ort (Wien) und auf ein relativ unverändertes Personengefüge, die Timms als sich überschneidende Kreisgraphiken darstellt, mag auf bestimmte Zirkel zutreffen, etwa auf die Psychologische Mittwochs-Gesellschaft. Doch die Einschränkung auf nur wenige Dichter in einer überschaubaren Größenordnung wird der internationalen Transferdynamik der künstlerischen Felder um 1900 nicht gerecht. Ein elektromagnetisches Netzwerk oder Nervensystem, auf das Timms Metaphorik abzielt, besteht gerade aus einer Vielzahl auf mannigfaltige Weise verschalteter und in ständig wechselnder Hierarchie zueinander stehender Knoten. Federico Celestini und Helga Mitterbauer bezeichnen jenes dynamisch prozessuale Gebilde, in das Vermittler eingebunden sind, sogar als „potentiell endloses Netzwerk“.423

\subsection{Jung-Wien / Jung-Österreich}

Die Komplexität der Zuweisung von Akteuren an künstlerische Zirkel der Moderne zeigt sich schon am nicht eindeutig abgrenzbaren Kreis literarischer Generationen in Österreich beziehungsweise in Wien. Schnitzler verwendet in seinem Tagebuch sowohl die Bezeichnung Jung-Österreich als auch Jung-Wien für die Beschreibung informeller Zusammenkünfte unterschiedlicher Personen, bei weitem nicht nur von Dichtern. ${ }^{424}$

Die laut Eduard Michael Kafka (1869-1893) sich aus 42 Schriftstellern zusammensetzende „Jungmannschaft Österreichs“ stellte ein unterschiedlich großes, stark variierendes und von diversen Akteuren geprägtes Netzwerk dar. ${ }^{425}$ Auch Schaukal wurde und wird bisweilen dieser Gruppe, zumindest aber ihrem

422 Timms: Dynamik der Kreise, S. 16.

423 Federico Celestini und Helga Mitterbauer: Einleitung. In: Ver-rückte Kulturen. Zur Dynamik kultureller Transfers. Hg. von Federico Celestini und Helga Mitterbauer. Tübingen 2003, S. 11-18, hier S. 13.

424 Arthur Schnitzler verzeichnet am 2. April 1890 und am 26. Februar 1891 in seinem Tagebuch Treffen von Jung-Wien beziehungsweise Jung-Österreich; vgl. Arthur Schnitzler: Tagebuch. Bd. 1879-1892. Wien 1987, S. 286 und S. 318.

425 Greve/Volke (Hg.): Jugend in Wien, S. 96 und S. 98. 
weiteren Umfeld zugeordnet. ${ }^{426}$ Hugo Salus etwa meinte 1903: „Ich war vor kurzem in Wien, ahnungslos, dass Sie dort wohnen, und Jung-Wien scheint auch von Ihrer Übersiedlung noch nichts gewußt zu haben.“427 Vor allem aber sah das österreichische Feuilleton mit Blick auf den Begriff der Moderne eine Verbindung zwischen Schaukal und Jung-Österreich:

Schaukals Buch aber ist durchaus ein Buch des „jungen“ Österreich. Ein retrospektives Buch mit sehr viel Liebe für die Vergangenheit und sehr wenig Interesse für die IrrungenWirrungen der Gegenwart [...]. Es will ein durchaus unmodernes Buch sein; es wendet sich von der Gegenwart und ihrem „Fortschritt“ ab [...]. Das ist mehr als bloß ein artistisches Moment, es ist der Ausdruck einer Weltanschauung. Schaukals Buch ist ein Bekenntnisbuch und wendet sich gegen den „Geist der neuen Zeit“.428

Noch 1905 stellte der auf Theodor Herzl folgende Feuilletonredakteur der Neuen Freien Presse Franz Servaes (1862-1947) Schaukal ironisch als „unseren jungösterreichischen Lyriker“ vor. ${ }^{429}$

Trotz seiner häufig auch öffentlich bekundeten Distanzierung von der ,Literaten-Clique، verkörperte er vor allem für die ältere Schriftstellergeneration den Typus des jungen Modernen, wie aus dem Briefwechsel zwischen Saar und Ebner-Eschenbach hervorgeht. ${ }^{430}$ Die Ambivalenz, neue Dichtung aus der Überwindung und produktiven Aneignung traditioneller Literaturformen schöpfen $\mathrm{zu}$ wollen, wird besonders in Schaukals Saar-Rezension im Litterarischen Echo deutlich (1899/1900). Einige der darin genannten Bezichtigungen und Vorwürfe an die gleichaltrigen Dichter fallen auf den Verfasser selbst zurück. Die jungen Österreicher seien „gebildete Kosmopoliten, verdorbene Nervenknechte, scheue Hermaphroditen oder aufdringliche, unerquickliche Literaten. Viel Snobismus, ekelhaftes Zeitungstum und manieriertes Aufblähen schädigt die verdiente Achtung vor einem eigenartig frühreifen Geschlechte“, das der „experimentierende ,Europäer““ Hermann Bahr begründet habe. ${ }^{431}$ In diese ambivalente

426 Die Ausführungen in diesem Kapitel basieren auf vom Verfasser bereits veröffentlichten Ergebnissen; vgl. Mitterer: Frühgealtert und spätgeboren. Richard Schaukals Dialog mit dem Dichterkreis des Jungen Wien. In: Studia theodisca, Bd. 21 (2014), S. 45-74.

427 Brief Salus' an Schaukal, 30. Mai 1903, in: Warum: Briefe eines Mährers aus Wien in die Heimat und nach Böhmen, S. 80, Fußnote 54.

428 Karl Hans Strobl: Zwei Bekenntnisbücher österreichischer Dichter. In: Österreichische Rundschau, Bd. 7 (Mai - Juli 1906), S. 51-57, hier S. 54.

429 Franz Servaes: Literarische Notizen. In: Neue Freie Presse, Nr. 14780 (15. Oktober 1905), S. 36-37, hier S. 37. Auch die neuere Wiener-Moderne-Forschung rückt ihn in die Nähe von Jung-Wien; vgl. Lorenz: Wiener Moderne, S. 65.

430 Vgl. Warum: Briefe eines Mährers aus Wien in die Heimat und nach Böhmen, S. 76.

431 Schaukal: Ein Meister der Novelle, S. 1114. 
Kritik passt, dass Schaukal seinem Gedichtband Tristia (1898) als Spitze gegen das Junge Österreich folgende Widmung vorausschickte: „Ferdinand von Saar / ein junger Österreicher / als Zeichen / seiner Ehrfurcht und Liebe“. ${ }^{432}$

Schaukals Aussagen können auch hier wieder als unbewusste Selbstanklage gelesen werden, war er doch ebenso mehrsprachiger Bildungsbürger und Nachdichter französischer sowie englischer Werke und somit ein Akteur des Kulturtransfers. Bereits als Gymnasiast veröffentlichte Schaukal manierierte Verse, als „frühgereifter“ Poet findet er Erwähnung in der Deutsch-Österreichischen Literaturgeschichte von Nagl, Zeidler und Castle, die ihn 1937 als den ersten mährischen Dichter der Moderne bezeichnet. ${ }^{433}$

\subsection{Abfuhr vom,Gründer' Jung-Wiens: Schaukal und Hermann Bahr}

Drei Jahre vor der Veröffentlichung des Saar-Aufsatzes, in dem Schaukal Bahr direkt attackierte, hatte er selbst noch die Nähe zum Literaturvermittler gesucht. Hermann Bahr war bis Mitte der 1890er Jahre damit beschäftigt, sein „Projekt einer autonomen österreichischen Literatur“ im Transfer mit der französischen Literatur und in Abgrenzung zum Berliner Naturalismus zu etablieren. ${ }^{434}$ Er datierte das Aufkommen der Bezeichnung Jung-Österreich für „eine Gruppe, vielleicht eine Schule von jungen, meist Wiener Litteraten“ auf circa $1890,{ }^{435}$ also auf das Jahr, in dem er zusammen mit Eduard Michael Kafka die Zeitschrift Moderne Dichtung ins Leben gerufen hatte. Die Moderne Dichtung war dem Naturalismus deutscher Prägung verpflichtet und setzte die ,neue، Linie der österreichischen Literatur unter anderem mit dem poetischen Realismus in Bezug. ${ }^{436}$ Im Juli-Heft kündigte Kafka an, dass „die österreichische Dichterjugend von heute im vorliegenden Heft zum erstenmal in geschlossener

432 Schaukal: Tristia. Neue Gedichte aus den Jahren 1897-98. Leipzig 1898.

433 Eduard Castle, Johann Willibald Nagl und Jakob Zeidler (Hg.): Deutsch-Österreichische Literaturgeschichte. Bd. 4: Von 1890 bis 1918. Wien 1937, S. 1372.

434 Norbert Bachleitner: Eine soziologische Theorie des literarischen Transfers. Erläutert am Beispiel Hermann Bahrs. In: Ent-grenzte Räume. Kulturelle Transfers um 1900 und in der Gegenwart. Hg. von Helga Mitterbauer und Katharina Scherke. Wien 2005, S. 147-156, hier S. 154. 435 Bahr: Das junge Oesterreich. In: KS. Bd. IV: Studien zur Kritik der Moderne. Weimar 2006, S. $70-89$, hier S. 75.

436 Vgl. Konrad Heumann: Was ist modern? Hofmannsthals Publikationstaktik in Eduard Michael Kafkas Zeitschrift „Moderne Dichtung“. In: Tradition in der Literatur der Wiener Moderne. Hg. von Wilhelm Hemecker, Cornelius Mitterer und David Österle unter Mitarbeit von Gregor Schima. Berlin/Boston 2017, S. 7-37. 
Reihe aufmarschiert.“437 Neben Texten von Robert Hamerling (1830-1889) und Leopold von Sacher-Masoch (1836-1895) finden sich darin der Erstdruck von Schnitzlers dramatischer Dichtung Anatols Hochzeitsmorgen sowie Gedichte von Jung-Österreich. ${ }^{438}$ „Damit hatte die nachfolgende Generation zum ersten Mal einen Namen und einen explizit ausgewiesenen Publikationsort“, so Konrad Heumann. ${ }^{439}$

Wie die Moderne Dichtung zählte auch das Salzburger Volksblatt in einem Essay über das literarische Wirken Jung-Österreichs den zu dieser Zeit bereits verstorbenen Karl Maria Heidt zur neuen Dichtergeneration; alle anderen Namen, so auch der von Schaukal, stimmten nicht mit denen überein, die in der von Bahr und Kafka herausgegebenen Modernen Dichtung erstmals publiziert wurden. ${ }^{440}$ Ihre Vertreter wären mit den gängigen Begriffen der Zeit nicht zu kategorisieren und, darauf legte Bahr in seinem frühen Aufsatz über das junge Österreich besonderen Wert, nicht mit denen des „Jüngsten Deutschland“ gleichzusetzen. Denn im Gegensatz zum „agitatorische[n] Eifer der Berliner“ Kollegen suchten die Wiener ihren Platz neben den Vorbildern aus der Zeit des Bürgerlichen Realismus, an der Seite Ferdinand von Saars und Marie von Ebner-Eschenbachs. ${ }^{441}$ Diese augenscheinliche Dialektik zwischen Tradition und Fortschritt gestaltet die Erforschung der Wiener Moderne so faszinierend wie problematisch. „In uns wuchert die Vergangenheit noch immer und um uns wächst die Zukunft“, so bringt Hermann Bahr diese doppelte Perspektive auf den Punkt, ${ }^{442}$ und auch Hofmannsthal schildert in seinem Aufsatz „Gabriele D’Annunzio“ das Lebensgefühl einer Generation „Spätgeborener“, wenige Tausende in den europäischen Städten, die

437 Edurd Michael Kafka: Anmerkung des Herausgebers. In: Moderne Dichtung, Bd. 2, H. 1 (1. Juli 1890), S. 414.

438 Vgl. Moderne Dichtung, Bd. 2, H. 1 (1. Juli 1890), S. 461-465. Zu Schnitzlers Mitarbeit an der Modernen Dichtung/Modernen Rundschau vgl. Konstanze Fliedl: Arthur Schnitzler. Poetik der Erinnerung. Wien u. a. 1997, S. 53-78.

439 Heumann zählt folgende Beiträger für das erste Heft der Modernen Dichtung auf: Friedrich Adler (1857-1938), Karl Maria Heidt (1866-1901), Franz Herold (1854-1943), Victor P. Hubl (1865-1891), St. Ille (?), Josef Kitir (1867-1923), Sophie von Khuenberg (1863-1937), R.P. Löhn (d.i. Robert Plöhn, 1861-1935), Hermann Menkes (1865-1931), Anton August Naaff (1850-1918), Theodor von Sosnosky (1866-1943) und Siegfried Volkmann (?), außerdem Robert Fischer (1860-1939), Felix Salten (1869-1945) und Felix Dörmann (1870-1928), vgl. ders.: Was ist modern?, S. 18.

440 Vgl. Hans Seebach: Werke junger Österreicher. In: Salzburger Volksblatt, Nr. 76/1902 (4. April 1902).

441 Bahr: Das junge Oesterreich, S. 71 und 73.

442 Bahr: Die Moderne. In: KS. Bd. II: Die Überwindung des Naturalismus. Weimar 2004, S. 11-15, hier S. 12. 
sich mit antiken Möbeln umgeben und über ein besonders feines Nervenkostüm verfügen. ${ }^{443}$

Der Name Richard Schaukal fehlt sowohl in der Abhandlung Bahrs zum Jungen Österreich als auch in den meisten österreichischen Literaturgeschichten, die sich vor allem um die Besucher des Café Griensteidl drehen und Alfred Zohner - Mitglied der Schaukal-Gesellschaft - als Referenz ausweisen. ${ }^{444}$ Bahr nimmt in seinem Aufsatz „Das junge Oesterreich“ jedoch auch vorweg, dass er manche Dichter „ohne rechten Grund aus der Gruppe“ heraushalte, um im selben Atemzug Carl von Torresani-Lanzenfeld (1846-1907), Heinrich von Korff und Richard Specht in die Riege ihrer Vertreter einzureihen. ${ }^{445}$

Schaukal schätzte Bahrs Bedeutung für den zeitgenössischen Literaturbetrieb richtig ein, sandte ihm 1896 seine Verse zu und drängte selbstbewusst zur Veröffentlichung in der Zeit. Die Antwort des Kritikers ist nicht erhalten, doch aus Schaukals Reaktion lässt sich schließen, dass er eine Publikation in der von ihm herausgegebenen Wochenzeitung abgelehnt und dessen literarische Arbeiten als „unreif“ bezeichnet hat, worauf der Geschmähte erwiderte: „Ist Jugend ,unreif‘?“ Den von Bahr erhobenen Vorwurf der Manieriertheit wies Schaukal mit dem Hinweis zurück, er wäre lediglich so manieriert wie „Sie, Bierbaum, George, Hofmannsthal, Altenberg, Wassermann, Schubart, Dehmel [...]“, und in dem für Schaukal so typischen Selbstbekenntniseifer insistierte er auf Zugehörigkeit: „Wir schwelgen in unseren Kostümen, wir wühlen berauscht in unseren kostbaren Worten. Und keiner hat wie ich das l'art pour l'art in die Sinne gebrannt."446

Schaukal positionierte sich als ästhetizistischer Dichter, der die zeitgenössischen Literaturmechanismen verstand und sich dessen bewusst war, dass er an Hermann Bahr, der über zahlreiche Kontakte zu den entsprechenden internationalen Verlagen verfügte, nicht vorbeikam. Doch der Versuch, Bahrs Interesse mit literaturästhetischen Bekenntnissen zu wecken, blieb erfolglos. Auch die Koketterie, dass er in Alfred de Musset (1810-1857), Théophile Gautier (1811-1872), Jens Peter Jacobsen (1847-1885) und Stefan George, vor allem aber in Hofmannsthal „verliebt“ sei, erfüllte ihren Zweck nicht. ${ }^{447}$ Immerhin schickte Bahr Schaukal

443 Hofmannsthal: Gabriele D’Annunzio. In: GW. Bd.: Reden und Aufsätze I. Frankfurt am Main 1979, S. 174-184, hier S. 174.

444 Vgl. Alfred Zohner: Café Griensteidl. In: Castle/Nagl/Zeidler (Hg.): Deutsch-Österreichische Literaturgeschichte, S. 1715-1717.

445 Bahr: Das junge Oesterreich, S. 75.

446 Brief Schaukals an Bahr, 12. Juli 1897, Nachlass Hermann Bahr im Theatermuseum Wien (im Folgenden zit. als NL-B, TMW).

447 Brief Schaukals an Bahr, 12. Juli 1897, NL-B, TMW. 
seinen neuen Roman. Wahrscheinlich handelte es sich um das am 27. März 1897 veröffentlichte Werk Theater. Der zu dieser Zeit bereits als Kritiker tätige Briefpartner ergriff die Gelegenheit und versuchte, Bahr mit einer ungefragten Rezension zu beeindrucken. Er schätze zwar den ironischen Ton und die Wiener Charaktere der „Skizze“, könne aber aufgrund der uneinheitlichen Erzähltechnik die Bezeichnung „Roman“ nicht gelten lassen. ${ }^{448}$ Zuvor schon urteilte der um Eindruck heischende Schaukal: „Als Essayist habe ich Sie unendlich gern. (Als Dichter freilich gar nicht). “449

Mit seinem letzten Brief dürfte Bahr auf Schaukals zwischen Schmeichelei und Affront changierende Ansuchen um Vermittlung mit einer definitiven Abfuhr reagiert haben. Er bedauere, „daß die ,Wasser“ zwischen uns so ,tief““ seien, so Schaukal, der in seinem vierten und letzten Brief an Bahr noch einmal ausdrücklich wiederholte, was ihm jener wohl abgesprochen hatte: „daß ich ein Dichter bin.“450

Schaukal war, vielleicht auch ausgelöst durch die Kritik an Theater, in Wien literarisch isoliert. Eventuell kam der Dichter auch schlicht zu spät, die Spirale der von Bahr verkündeten Überwindungen und Entwicklungen hatte sich weitergedreht und das Junge Wien um 1897 bereits unterschiedliche künstlerische Wege eingeschlagen. Bahrs Projekt der Etablierung einer spezifisch österreichischen Literatur auf der Grundlage seiner Pariser Bildungsjahre war nicht durchzusetzen. Der Vermittler Bahr „,schien bald darauf die Geduld verloren zu haben, vielleicht sah er auch die Unvereinbarkeit von ästhetizistischer Kunstauffassung und regionalliterarischer Profilierung. Zudem verloren die ästhetizistischen Konzepte mit der Zeit ihren innovativen Charakter. So wandte sich Bahr schon Mitte der neunziger Jahre neuen Ideen zu.“451

Bahr hatte eine sehr konkrete Vorstellung davon, wie die von ihm protegierte Wiener Dichtergruppe besetzt und beschaffen sein sollte: als abgeschlossener Kreis, der persönlich wie ästhetisch harmoniert und das Bild eines einheitlichen, auf ihn ausgerichteten Zirkels abgibt. Ein autonarratives „Wir“ nennt im Vorwort von Bahrs Kritikensammlung Renaissance (1897) die Jung-Wiener beim Kose- oder Vornamen (,lieber Hugo, lieber Poldi“) und beschwört einen „stillen Kreis“, der einst auf die „große Welt“ Einfluss nehmen möge. ${ }^{452}$ Paul Wertheimer rezensierte

448 Brief Schaukals an Bahr, 9. April 1897, NL-B, TMW.

449 Brief Schaukals an Bahr, undatiert, NL-B, TMW.

450 Brief Schaukals an Bahr, 12. Juli 1897, NL-B, TMW.

451 Bachleitner: Eine soziologische Theorie des literarischen Transfers, S. 154.

452 Bahr: An Leopold von Andrian und Hugo von Hofmannsthal. In: KS. Bd. V: Renaissance. Neue Studien zur Kritik der Moderne. Weimar 2008, S. 9-10. 
Bahrs Sammelband, der auf die Tradition und Wiedergeburt einer Jung-Wiener Dichtergeneration anspielte, mit den leicht ironischen Worten:

Wir haben in der That, meine ich, einen ganz eigenen Wiener geselligen und geistigen Ton, von einem so bestimmten Kolorit, daß man von einer Wiener ,Kunstrenaissance“ schwärmt - als ob das Leben im Café Griensteidl oder Pucher ein Wirken an italienischen Fürstenhöfen wäre [.. .]. ${ }^{453}$

Andererseits war Bahr um 1896, als Schaukal bei ihm vorstellig wurde, noch damit beschäftigt, sein Wiener Wirken in Deutschland publik zu machen, wozu ihm in erster Linie Journalisten dienen sollten, „die selbst zum Kreis um Bahr gehörten. “454 Während seiner Zeit in Berlin stand Franz Servaes unter dem Einfluss Bahrs; von Wien aus instruierte er den Redakteur, wie dessen 1897 für Die Zeit verfasster Artikel „Jung Wien. Berliner Eindrücke“ angelegt sein sollte. ${ }^{455}$

Schaukal verfügte zu dieser Zeit wohl (noch) nicht über die entscheidenden Kontakte und ausreichende Reputation im publizistischen Feld. Zudem trat er während einer Phase der ästhetischen und literaturkritischen Neuorientierung Hermann Bahrs an den Kritiker heran. Die französisch angehauchte Dekadenz Wiener Prägung hatte er bereits überwunden, doch die konservative Wende die Entdeckung der Provinz- und Barockliteratur als neue und zugleich alte kulturelle Parameter - noch nicht vollzogen. Schaukal verpasste Bahrs ästhetische Volte um wenige Jahre, die Kontaktaufnahme scheiterte - abgesehen von persönlichen Animositäten - wohl auch aufgrund des falschen Timings.

\subsection{Hassliebe Kaffeehaus: Schaukal und Karl Kraus}

Ab 1904 richtete Schaukal seine Poetik neu aus, wie die 1906 und 1907 herausgebrachten Werke Großmutter, Literatur und Giorgione belegen. Spätestens mit dem ebenfalls 1907 erschienenen Andreas von Balthesser sei er ,in die Heimat der Seele eingekehrt“, so Schaukal rückblickend über seine programmatische Abkehr vom Ästhetizismus. ${ }^{456}$ Doch in diesen Jahren der Orientierung reflektierte er den ausbleibenden Durchbruch noch nicht so abgeklärt. Am 22. Mai 1905 beklagte sich Schaukal gegenüber seiner Mutter: „Die einflußreichen gesicherten ,satten“ Kreise aber halten mich von ihrem Zirkel ab.“ Als Gründe dafür

453 Paul Wertheimer: Deutsches Kunstleben. IV. Wien. In: Die Gesellschaft, 14. Jg., H. 2 (Januar 1898), S. 132.

454 Sprengel/Streim: Berliner und Wiener Moderne, S. 108.

455 Vgl. Sprengel/Streim: Berliner und Wiener Moderne, S. 104-105.

456 Schaukal: Beiträge zu einer Selbstdarstellung, S. 100. 
nannte er den Vorwurf der Arroganz sowie den Umstand, dass „die Mehrzahl dieser Kreise jüdische Klique“ sei, die sich gegen alles Neue zur Wehr setze, wohingegen die „älteren Blätter“ seine Texte nicht druckten, da sie ihn zu den „verabscheuungswürdigen ,Modernen““ zählten. ${ }^{457}$

Richard Schaukal reagierte auf die ihm entgegengebrachte Ablehnung, indem er von sich das Bild des autonomen und genialen Einzelgängers inmitten eines desolaten, korrupten und verwerflichen Literaturbetriebes lancierte. Als unmoralischer Ort per se galt manchen Kritikern das Kaffeehaus. Es bedeute, so der 1891 von Edmund Wengraf vorgebrachte Appell, den „Ruin der Wiener Gesellschaft“, „verschlinge“ Bildung sowie Intelligenz. ${ }^{458}$ Hinzu kam ein von Berthold Viertel (1885-1953) formulierter Kritikpunkt, der auch für den standesbewussten Schaukal von Bedeutung war: Das „Café würfelt die Stände in unordentlicher Weise zusammen.“459

Dass Schaukal während seiner Studienzeit in Wien das künstlerische und gesellschaftliche Leben verschiedener Kreise kennengelernt hatte und auch im Café Griensteidl verkehrte, beschreibt er 1934 in seiner autobiographischen Selbstdarstellung. ${ }^{460}$ Schaukals Begleiter während der ersten Ausflüge in Wiens Künstlerwelt war Karl Kraus, der sich später mit dem Pamphlet Die demolirte Litteratur (1897) von den Besuchern des Kaffeehauses distanzierte.

In einem Brief vom 2. Mai 1901 an Arthur Schnitzler schilderte der von einer Reise nach München zurückgekehrte Schaukal, wie ihn die bayerische Hauptstadt an seine Studentenzeit und an das Flair des berüchtigten Wiener Cafés erinnert habe: „Ich war an die ekligsten Zeiten des Café Griensteidl gemahnt worden, wohin mich und einige gleichalterige Juristen 1892 u. 1893 der Drang, die Wiener ,Größen` kennen zu lernen, ein ernster Provinzgymnasiastendrang, geführt hatte.“461

In der Selbstdarstellung urteilte er dann über das in der Zwischenzeit ,demolirte Kaffeehaus deutlich milder. Immerhin räumte Schaukal rückblickend ein, im Herbst 1892 dort „mit der lebendigen Literatur zuerst in Berührung gelangt“ zu sein. ${ }^{462}$ Seine und, wie Schaukal von sich auf Kraus schloss, auch dessen Erwartungen an das Café Griensteidl wurden enttäuscht, die Empfindung des „Wunderbaren“, das in der Kaffeehausluft „schwebte“, kehrte sich

457 Zit. nach Girardi (Hg.): Thomas Mann. Briefe an Richard Schaukal, S. 155-156.

458 Wengraf: Kaffeehaus und Literatur.

459 Brief Viertels an Hermann Wlach, 1908, in: Greve/Volke (Hg.): Jugend in Wien, S. 93.

460 Schaukal: Beiträge zu einer Selbstdarstellung, S. 13.

461 Zit. nach Urbach (Hg.): Richard Schaukal - Arthur Schnitzler: Briefwechsel (1900-1902), S. 20.

462 Schaukal: Beiträge zu einer Selbstdarstellung, S. 31. 
für die Studenten in ein Gefühl der Ablehnung. ${ }^{463}$ Schaukal sollte von der Mehrheit der Wiener Literaten enttäuscht bleiben. Einzig mit Kraus und Altenberg, die für kurze Zeit dem Kreis des Jungen Wien nahestanden, verkehrte er noch in späteren Jahren. 1934 betonte Schaukal:

Man hat mich oft gedankenlos zur sogenannten Wiener Literatur gezählt. Nichts kann falscher sein. Ich habe dieser schwülen [...], aus dem Feuilleton stammenden und immer wieder zur Zeitung zielenden, im übrigen mit der Bühne tändelnden, überwiegend jüdischen Schriftstellerei - in der ich den seelenvollen Dichter Peter Altenberg und [...] Karl Kraus mit nichten begreife - nur eine kleine Weile als junger neu-gieriger Ankömmling meine Aufmerksamkeit geschenkt, bin ihr [...] ausgewichen und hinfort, innerlich wie äußerlich, ferngeblieben. ${ }^{464}$

Allerdings verlief die Wertschätzung asymmetrisch. Zwar besprach Karl Kraus bereits 1893 Schaukals Lyrikdebüt Gedichte, doch konnte er sich den Spott über die diffuse ästhetische Ausrichtung nicht verkneifen und riet ihm ironisch, „die Stimmungskarriere“ einzuschlagen. ${ }^{465}$ Die ihm von Schaukal überreichten, mit persönlichen Widmungen versehenen Bücher quittierte der Herausgeber der Fackel mit kurzen Dankes-Telegrammen. In einem späteren Schreiben betonte Schaukal, dass Kraus der einzige deutschsprachige Schriftsteller sei, von dem er jede Zeile lese und den er über alle Maßen wertschätze. „Sie sind nicht nur eine künstlerische Potenz, sondern ein ethischer Wert in dieser Sauzeit“, so Schaukal in einem Schreiben Ende 1913. ${ }^{466}$ Auch wenn Kraus nie ausführlicher auf die Briefe reagierte, so zählte er den gleichaltrigen Bewunderer wegen seiner Aphorismen zu den „heimischen Lyrikern, die durch Zeilen wertvoller sind als die beliebteren durch Bücher.“467

Kraus' satirisch pointierter Stil färbte auf Schaukals Aphoristik ab. ${ }^{468}$ Die Sinnsprüche brechen die Syntax geläufiger Redewendungen auf und verkehren ihren Sinn ins Gegenteil, so etwa in Schaukals Wendung „Hochstapelei kommt nach dem Fall“, oder sie thematisieren die Geschlechterrollen mit einer für die Zeit typischen misogynen Tendenz, wenn Kraus schreibt: „Man muß endlich

463 Schaukal: Karl Kraus, S. 19.

464 Schaukal: Beiträge zu einer Selbstdarstellung, S. 46.

465 Karl Kraus: Wiener Lyriker. In: Das Magazin für Litteratur, 62. Jg., Nr. 31 (5. August 1893), S. 499-500.

466 Brief Schaukals an Kraus, 1. Dezember 1913, S-NL, WB.

467 Karl Kraus: Der Reim. In: Die Fackel, Nr. 757-758 (April 1927), S. 1-37, hier S. 28.

468 William M. Johnston zählt Schaukal zu den bedeutenden Aphoristikern seiner Zeit; vgl. Johnston: Karl Kraus und die Wiener Schule der Aphoristiker. In: Literatur und Kritik, H. 211-212 (1987), S. 18-19. 
wieder dahinter kommen, daß man nicht mehr an der Krankheit, sondern an der Gesundheit einer Frau zugrunde geht.“469

\subsection{Bruderzwist: Schaukal und Hugo von Hofmannsthal}

Während Schaukal Karl Kraus’ ästhetisch-moralische Positionen einhellig teilte, wirkte sich Hofmannsthals Einfluss, dem er attestierte, „im Treibhausdunst verfrühter Überbildung“ aufgewachsen $\mathrm{zu}$ sein, ${ }^{470}$ nicht weniger produktiv auf ihn aus. Die Attribuierung des Frühreifen und Genialen geht auf Hermann Bahrs „Loris“-Aufsatz (1892) zurück, der auch insgesamt zur Stilisierung des Jungen Wien beigetragen hat. Darin schildert Bahr seine erste persönliche Begegnung mit Hofmannsthal, den er unter dem Pseudonym Loris als treffsicheren Kritiker bereits kannte und schätzte, sich aber als älteren, lebenserfahrenen Wiener imaginiert hatte. ${ }^{471}$

Zweifelsohne spielte Neid eine Rolle für die Missgunst, die Schaukal gegen den wesensähnlichen, aber schlicht erfolgreicheren Hofmannsthal hegte. In der Akademischen Vereinigung hörte er 1892 die erste öffentliche Vorlesung des, so Schaukal, „sattsam unnatürlichen“ und in kleinem Kreis schon berühmten Hofmannsthal. ${ }^{472}$ Er beschäftigte und verglich sich mit dem Altersgenossen, nach 1900 kehrte sich seine Faszination in Ablehnung. ${ }^{473}$

Die schriftlich erhaltenen Aussagen der Dichter verdeutlichen ein Distanzverhältnis und ihre Verunglimpfungen zielten darauf ab, den Konkurrenten in ein zwielichtiges Bild zu rücken. Schaukal urteilte über Hofmannsthal, er sei eklektizistisch. ${ }^{474}$ In einer unveröffentlichten „Skizze zu einem Porträt“ äußerte er spöttisch:

In kleinen Circeln ging der melodiöse Name Loris herum, Geheimnis wogte wie eine Heliotropenwolke um den Träger dieses zugleich altertümlich-pretiös und knabenhaft-verschwiegenen Pseudonyms. Man hatte die undeutliche Vorstellung von etwas

469 Beide Zit. nach Pietzcker: Richard von Schaukal, S. 262.

470 Schaukal: Karl Kraus, S. 53.

471 Vgl. Bahr: Loris. In: KS. Bd. IV: Studien zur Kritik der Moderne. Weimar 2006, S. 112-118, hier S. 114.

472 Schaukal: Beiträge zu einer Selbstdarstellung, S. 31; vgl. auch Greve/Volke (Hg.): Jugend in Wien 1987, S. 127.

473 Vgl. Schaukal: Hugo von Hofmannsthal. In: WE. Bd. 5: Über Dichter. München/Wien 1966, S. 110-119; sowie auch in: Hofmannsthal im Urteil seiner Kritiker. Hg. von Gotthart Wunberg. Frankfurt am Main 1972, S. 349-354.

474 Vgl. Greve/Volke (Hg.): Jugend in Wien, S. 372. 
Hermaphroditisch-Perversem, von cherubinischer süsser Lüsternheit und Hölderlinischem Eleusinertum. Bald waren sich die mehr oder weniger snobistisch angehauchten „Geistigen“ darüber einig, dass man es mit einem Phänomen zu tun habe, einem dichterischen kleinen Mozart, einem Götter-liebling. Man war mit verzückten Augenbrauen darauf aus, das Wunderkind zum enfant gaté zu krönen. Die Caféhauscoenakel flüsterten. [...] Der „wirkliche“ Hugo Hofmann Edler von Hofmannsthal stieg derweilen, Gamaschen über den blanken Schuhen, den gelben Überzieher schlapp um magere Hüften, die Stufen der Wiener Universität hinauf, grüsste mit gespreiztem Unterarm und näselte wienerisch-theresianisch mit der eben erst flügge gewordenen jeunesse d'orée [sic!] der Wiener „zweiten Gesellschaft“, ehe er sich auf eine kurze Stunde in einen Hörsaal der philosophischen Fakultät begab [. . . ${ }^{475}$

Später zählte Richard Schaukal selbst zur sogenannten ,zweiten Gesellschaft', da er 1918 in den Adelsstand erhoben wurde, dem er qua Geburt nicht angehörte. Hofmannsthal ging mit ihm ebenfalls hart ins Gericht und widersetzte sich direkt seiner Etablierung im künstlerischen Feld. Alfred Walter Heymel (1878-1914) drängte er in einem Brief vom 16. März 1907, Josef Hofmiller (1872-1933) auszureden, eine Rezension über Schaukals Andreas von Balthesser zu verfassen. Der Verfasser des Balthesser sei „eine scheusälige Nullität“ und ein „äffische[r] Erzliterat.“ „Es handelt sich nicht darum daß der Kerl mir besonders antipathisch ist“, so Hofmannsthal weiter, „sondern daß er absolut eine Null ist, eine Mischung von Mäusedreck und Parfüm, wie sie nicht ekelhafter geträumt werden kann. Wie kann der nette seriöse Mensch [Josef Hofmiller, CM] auf so etwas hereinfallen, auf solche Ladenschwengellitteratur.“ “476

Bei aller Animosität lassen sich künstlerische Analogien im Schaffen der beiden Dichter nicht bestreiten. Eine gewisse ästhetische Dialogizität oder Palimpsestuosität, die je nach Auffassung als Epigonalität bezeichnet wurde, besteht in ihrer Lyrik. ${ }^{477}$ Den Stellenwert ihrer frühen Dichtung belegt die gleichzeitige Veröffentlichung in Otto Julius Bierbaums Modernem MusenAlmanach auf das Jahr 1894: Hofmannsthals Der Thor und der Tod und Schaukals „Blut“, „Plein-air“, „Pierrot (nach Verlaine)“ und „Aus Verlaines Buch der Weisheit" sind Beispiele der symbolistischen und impressionistischen Richtung. Bis hinein in die Wortwahl gleichen sich in dieser frühen Schaffensphase Schaukals und Hofmannsthals Verse; die Übereinstimmungen sind sprachlicher und thematischer Art. So adaptiert Schaukals Gedicht „März“ (1901) Motive von Hofmannsthals „Vorfrühling“ (1892), beide durchzieht ein wehmütiger

475 Zit. nach Pietzcker: Richard von Schaukal, S. 24-25.

476 Werner Volke (Hg.): Hugo von Hofmannsthal - Alfred Walther Heymel: Briefwechsel. Teil I: 1900-1908. In: Hofmannsthal-Jahrbuch zur europäischen Moderne, Bd. 1 (1993), S. 19-98, hier S. 73.

477 Vgl. Oesterheld: Schaukal und der George-Kreis, S. 75. 
„Duft“ des Frühlingswindes, der sich zum Todeshauch erhebt. „An den Mond“ (1896, Schaukal) und „Erlebnis“ (1892, Hofmannsthal) sind neuromantische, von Synästhesien geprägte Oden an Thanatos. Das erste Gedicht „giesst“ Mondlicht „wie aus Silberbechern“ in die Nacht, eine direkte Referenz auf Hofmannsthals „,silbergrauen Dufte“, den der Mond „durch Wolken sickern“ lässt. ${ }^{478}$

Stilistische, motivische und stoffliche Parallelen ihrer Dichtung bestehen wiederum zur Lyrik Stefan Georges. ${ }^{479}$ Schaukals Gedicht „Nixe im Wasserfall“ und Hofmannsthals „Erlebnis“ und „Vor Tag“ (1907) weisen den im deutschsprachigen Raum bis dato ungewöhnlichen vers libre auf, ein Kennzeichen der modernen, von Gabriele D'Annunzio und dem französischen Symbolismus beeinflussten Lyrik. ${ }^{480}$ Die künstlerische Zuneigung zu den idealtypisch verklärten Kunstepochen Renaissance, ${ }^{481}$ Barock oder Rokoko ist dem Werk beider Dichter eingeschrieben und lässt sich unter anderem in Hofmannsthals „Prolog zu dem Buch ,Anatol““ (1892) sowie in Schaukals „Rococo“ (1896) nachweisen. Doch in kontrastiver Abkehr von Hofmannsthals sentimentalischen Versen „frühgereift und zart und traurig“ - erscheinen in Schaukals Gedichten der frühen Phase auch Heroenbilder, die sich thematisch auf Mittelalter und Ritterlichkeit beziehen und den Dichter als Minnesänger inszenieren. ${ }^{482}$ „Ritt ins Leben“ (1899), „Ritterlicher Spruch“ (1897), „Sehnsucht des Knappen“ (1899) und die mannigfaltigen Schlossmotive stehen charakteristisch für virulente Verse, die den dekadenten Motivkreis konterkarieren. ${ }^{483}$

Mit der literarischen Hinwendung zur Vergangenheit verarbeiteten nicht nur die Autoren des Jungen Wien den kunstfernen Alltag. Hofmannsthals Brief an Richard Beer-Hofmann (1866-1945) vom 15. Mai 1895 ist das vielzitierte Beispiel einer umfassenden Reflexion über Positionen und Gegenpositionen zum Ästhetizismus. Darin beschreibt der Verfasser neben der Vergangenheitsbeschwörung weitere Überlebensstrategien in einer subjektentfremdeten Welt, die zu dieser

478 Schaukal: März; An den Mond. In: Schaukal: Ausgewählte Gedichte. Leipzig 1904, S. 1 und S. 6. Hofmannsthal: Vorfrühling; Erlebnis. In: GW. Bd.: Gedichte und Dramen I. Frankfurt am Main 1979, S. 17-18 und S. 19.

479 Vgl. Johann Sonnleitner: Richard von Schaukal. In: Kindlers Neues Literaturlexikon. Bd. 14. München 1991, S. 866-868; sowie Oesterheld: Schaukal und der George-Kreis, S. 75-76.

480 Vgl. Pietzcker: Richard von Schaukal, S. 18.

481 Vgl. Cornelius Mitterer: Kunst, Kommunikation, System. Richard Schaukals Rückgriff auf die Renaissance in „Giorgione“ und „Literatur“. In: Tradition in der Literatur der Wiener Moderne, S. 220-237.

482 Vgl. Pietzcker: Richard von Schaukal, S. 72.

483 Vgl. Schaukal: Ausgewählte Gedichte, S. 25 („Ritt ins Leben“), S. 40 („Ritterlicher Spruch“), S. 80 („Sehnsucht des Knappen“) und S. 81 („Ein Schloss“). 
Zeit auch Schaukal beschäftigten: Solipsismus und „Centrumsgefühl“, also die Ausweitung des Ichs auf die Welt, wie sie für Schaukals poetologische Genieästhetik bezeichnend ist, werden darin ebenso thematisiert wie die Errichtung „Potemkin'scher Dörfer“ im eigenen „Gesichtskreis“ als Mittel bewusster Selbsttäuschung. ${ }^{484}$ Dabei nahmen die Dichter der Wiener Moderne schon früh die ästhetizismuskritische Haltung ein, dass Poesie und Leben nicht miteinander vereinbar sind, so Hofmannsthal in „Poesie und Leben“ (1896). Die Trennung von Kunst und Leben wird räumlich-symbolisch sowohl im Anatol-Prolog als auch in Schaukals „Rococo“ vollzogen. Das Watteau- und Canaletto-Ambiente der beiden Gedichte offenbart sich als umzäunter Garten, den sich Hofmannsthals lyrisches Ich öffnet, wie es im vierten Vers heißt, wohingegen seine „Pforten“ für Schaukals Stimme im Gedicht „verriegelt“ bleiben. Er schildert den Garten, der für die Jung-Wiener zum traditions- wie bedeutungsreichen Topos avancierte, als Sinnbild der domestizierten Natur, zugleich aber auch als goldenen Käfig des exklusiven Dichterraums. Schaukals Gedichtband ist in fünf „Bücher“ unterteilt, das Kapitel „Die Taxusmauern. Buch des Künstlers“ antwortet auf Hofmannsthals „Taxushecke“ im „Prolog“ und greift intertextuell die GartenMetaphorik auf, um die Trennung von Leben und Kunst zu versinnbildlichen.

Diese räumliche Dichotomie findet vor allem auch in den frühen Erzählungen der beiden Dichter ihren Platz. Solche symbolischen Orte sind Ausgangspunkte plötzlicher Erkenntnis. Die Epiphanie, die meist unmittelbar mit großen Umwälzungen (Tod und Liebe) literarisch einhergeht, setzt Schaukal in „Mathias Siebenlist und das Schloß der hundert Liebhaber“ (1906) in einer zentralen Passage ein. Der gleichnamige Protagonist der Erzählung sitzt am Totenbett seiner Mutter, einer alleinerziehenden armen Wäscherin, als er mit der geballten Wucht der Erleuchtung die trostlose Nichtigkeit ihrer und seiner eigenen Existenz empfindet. „Mit der Deutlichkeit einer Vision“ ${ }^{485}$ spürt Mathias das soziale Stigma, das durch seinen Buckel konkret sichtbar ist und sich durch den Kontrast zum Antagonisten Ralf, dem aus reichem Hause stammenden Kindheitsfreund, verstärkt. Mathias erfährt schlagartig die Nichtigkeit seines bisherigen Daseins, doch daraus entfaltet sich im weiteren Verlauf der Erzählung keine Sozialkritik, wie man annehmen könnte. Schaukal beschreibt vielmehr den Weg des dilettantischen Künstlers, den Mathias Siebenlist einschlägt, indem er Geige zu spielen lernt, sich in die romantisch-phantastische Traumwelt eines Schlosses flüchtet und schließlich dem

484 Brief Hofmannsthals an Beer-Hofmann, 15. Mai 1895, in: Eugene Weber (Hg.): Hugo von Hofmannsthal - Richard Beer-Hofmann: Briefwechsel. Frankfurt am Main 1972, S. 47-48, hier S. 47.

485 Schaukal: Mathias Siebenlist, S. 135. 
Wahnsinn verfällt. Schaukals Prosa orientiert sich an E.T.A. Hoffmanns Kunstmärchen, vor allem am Goldenen Topf mit seinen zwei möglichen Lesarten, der magisch-märchenhaften und der realistisch-pathologischen. Auch Schaukals Protagonist ist ein Schlafwandler zwischen zwei Welten. Die der Realität offenbart die gängigen Macht- und Herrschaftsverhältnisse zu Mathias’ Ungunsten, die andere ist ein erotisch-märchenhafter Traum, in dem der Protagonist letzten Endes auch physisch verharrt. Die prekäre Situation führt im weiteren Verlauf der Erzählung also nicht zu einem subversiven Impetus, sie mündet in Introspektion, Selbstzerstörung und Eskapismus. Der Fluchtpunkt ist eine ästhetische Scheinwelt, das Schloss der hundert Liebhaber, in dessen Zentrum die Phantasmagorie der verführerischen Gräfin Decerti steht: „Ein Schloß entstand vor des Buckligen Seele.“486

Anstatt einer benachteiligten Klasse literarisch Gehör zu verschaffen, was bei Schaukal immerhin angedeutet wird, bleibt die unterprivilegierte Bevölkerungsschicht in seiner Erzählung konturlos und stumm. Dies ist ein Wesenselement der Wiener Moderne, das in Hofmannsthals auf den 1. Mai 1890 datiertem JugendGedicht „Tobt der Pöbel in den Gassen, ei, mein Kind, so laß ihn schrei'n“ Ausdruck findet. ${ }^{487}$

Schaukal und Hofmannsthal ging es in ihrer dichterischen Frühphase um die Gegenüberstellung von Kunst und Alltag, nicht um die soziale Frage. ${ }^{488}$ Das Proletariat flößte beiden Unbehagen ein und das Individuum stellte etwas zu Komplexes in den Augen der Dekadenz-Dichter dar, als dass es zum Produkt seines Milieus hätte erklärt werden dürfen. Richard Schaukal war sich 1906, dem Jahr der Entstehung von „Mathias Siebenlist“, gleichwohl der Zwecklosigkeit einer rein ästhetischen Weltabwendung bewusst, und so ist die Novelle zugleich als Kritik an die radikale Verinnerlichung zu lesen. ${ }^{489}$

Auch für Hofmannsthal waren es gerade die Wahnsinnigen, die in die „geistige Souveränität“ und „Praeexistenz“ entfliehen, womit der Dichter unter anderem einen glorreichen, „aber gefährlichen Zustand“ mancher „Auserlesener“ meinte, die durch „Supposition des quasi-Gestorbenseins“ das „Ich als

486 Schaukal: Mathias Siebenlist, S. 147.

487 Auch Richard Specht legt in seiner Biographie über Schnitzler die mangelnde Sozialkritik in dessen Werk offen; vgl. Specht: Arthur Schnitzler. Der Dichter und sein Werk. Eine Studie. Berlin 1922, S. 63-64.

488 Vgl. Libor Marek: Die Erfahrung der Moderne im Werk Richard von Schaukals. Zlín 2011, S. 61 .

489 Vgl. Marek: Die Erfahrung der Moderne im Werk Richard von Schaukals, S. 81. 
Universum“ in solipsistischer Auffassung wahrnahmen. ${ }^{490}$ Hofmannsthal bezeichnete sein Märchen der 672. Nacht (1895) als „ins Märchen gehobenen Gerichtstag des Ästhetismus“; ${ }^{491}$,Praeexistenz“ und Ästhetizismus werden einer literarischen Prüfung unterzogen. Wie Siebenlist führt auch der junge Kaufmannssohn des Märchens ein einsames und selbstbezogenes Leben, aber im Gegensatz zu diesem ist er zu Beginn noch wohlhabend und von Schönheit umgeben. Im Verlauf der Erzählung wird der Kaufmannssohn von objektiv nicht bestimmbaren Angstgefühlen heimgesucht und es beginnt ein labyrinthischer Parcours der Selbstreflexion, an dessen Ende unweigerlich sein Ableben steht. Die letzte Entscheidung des jungen Mannes, sich spontan einem hohlwangigen, den Tod personifizierenden Soldaten, der gerade sein Pferd säubert, aus Mitleid „durch ein Geschenk für den Augenblick“ zu nähern, löst seinen körperlichen Niedergang aus. ${ }^{492}$ Ein schnöder Huftritt beendet das glanzvolle Leben des Protagonisten, dem im Moment des Todes die ganze Banalität seiner Existenz bewusst wird. ${ }^{493}$

Eine ähnliche Erkenntnis, das Leben zwar im Ästhetischen, aber doch sinnlos verwirkt zu haben, erfährt Claudio in Der Thor und der Tod (1893), und auch der im Hedonismus des Augenblicks versunkene Andrea in Gestern (1891) muss sich eingestehen, dass ihm ebendieses Gestern nicht gleichgültig sein kann, wenn es den Tag des Betrugs durch Arlette, seiner Geliebten, bedeutet.

Hofmannsthal und Schaukal verband in ihrer frühen Schaffensperiode die Auseinandersetzung mit dem Ästhetizismus, ihre Werke reflektierten den Konnex und die Dissoziation beziehungsweise Unvereinbarkeit von Leben und Poesie.

\subsection{Snobs, das sind die anderen: Schaukal und Arthur Schnitzler}

Während Schaukal zunächst Hofmannsthal als den Wiener Dichter rühmte, der neben Altenberg von nachhaltiger Bedeutung sein werde, da sich in ihm der „frühreife Ausdruck des internationalen Symbolismus“ zeige, sei Arthur

490 Hofmannsthal: Ad me ipsum. In: GW. Bd.: Reden und Aufsätze III. Frankfurt am Main 1980, S. 597-627, hier S. 599.

491 Zit. nach GW. Bd.: Erzählungen, erfundene Gespräche und Briefe, Reisen. Frankfurt am Main 1979, S. 666.

492 Hofmannsthal: Das Märchen der 672. Nacht. In: GW. Bd.: Erzählungen, erfundene Gespräche und Briefe, Reisen, S. 45-63, hier S. 60-61.

493 Vgl. Hofmannsthal: Das Märchen der 672. Nacht, S. 62-63. 
Schnitzler mit „Anatol die Charakteristik seines Kreises gelungen.“ “994 Dagegen notierte der Verfasser des Anatol-Zyklus am 20. März 1902 lapidar in sein Tagebuch: „Schaukal’s Snobismus.“495 Als Snob, ein Modeausdruck der Zeit, dessen sich Richard Schaukal ebenso gern und häufig bediente, bezeichnete Schnitzler auch Hugo von Hofmannsthal. ${ }^{496}$ „Der Snob ist ein Mensch, der scheinbare Selbsterhöhung auf dem Weg tatsächlicher Selbsterniedrigung anstrebt. Er ist im eigentlichen Sinne der Masochist der Gesellschaftsordnung“, so ein Aphorismus von Schnitzler. ${ }^{497}$ Als Snob verstanden die Dichter den affektierten Dandy, einen für das Gesellschaftsgefüge abkömmlichen Schöngeist, womit sie letztlich auf sich selbst anspielten.

Der 26-jährige Schaukal versuchte im Herbst 1900 Anschluss an die dichterischen Kreise Wiens zu finden und hatte Schnitzler aus Mährisch-Weißkirchen, wohin er 1899 als Verwaltungsbeamter berufen worden war, seinen im selben Jahr erschienenen Lyrikband Tage und Träume zukommen lassen. Schnitzler zeigte sich von den „wunderschönen Landschaftsstimmungen“ angetan und ermunterte den jüngeren Dichter zu weiteren Büchersendungen. ${ }^{498}$ Auch dieser nun folgende Briefwechsel gestattet Einblicke in Schaukals dichterisches Sendungsbewusstsein und in sein bisweilen ungeschicktes Vorgehen bei der Suche nach künstlerischer Teilhabe. Schaukal bestürmte den zwölf Jahre älteren Kollegen aus Wien mit langen Erläuterungen seines Kunstempfindens, die sich meist anhand negativer Äußerungen zu Schnitzler vertrauten, sogar freundschaftlich verbundenen Schriftstellern wie Bahr, Beer-Hofmann und Hofmannsthal entluden. Als „Bibliophiler“ erbat Schaukal wenig schüchtern die Zusendung eines Exemplars der anfangs nur in geringer Auflage von 200 Stück in Privatdruck erschienenen Reigen-Ausgabe, die er dann tatsächlich auch postwendend erhielt. ${ }^{499}$ Seine Briefe dokumentieren eine von Neid imprägnierte Auffassung über die „häßlichen Literatentage“ der Gegenwart. Ziel seiner Invektiven war zunächst der 1900 veröffentlichte Roman Renate Fuchs von Jakob Wassermann, den Schaukal als „Litera-

494 Zit. nach Zohner: Café Griensteidl, S. 1744.

495 Schnitzler: Tagebuch. Bd.: 1893-1902, S. 366.

496 Vgl. Hartmut Scheible: Arthur Schnitzler in Selbstzeugnissen und Bilddokumenten. Reinbek bei Hamburg 1976, S. 116.

497 Arthur Schnitzler: Buch der Sprüche und Bedenken. Aphorismen und Fragmente. Wien 1927, S. 99.

498 Brief Schnitzlers an Schaukal, 5. November 1900, in: Urbach (Hg.): Richard Schaukal Arthur Schnitzler: Briefwechsel (1900-1902), S. 18 (AS1).

499 Brief Schaukals an Schnitzler, 19. Mai 1901, in: Urbach (Hg.): Richard Schaukal - Arthur Schnitzler: Briefwechsel (1900-1902), S. 30 (RS6). 
turjuden“ und „Snob“ bezeichnete. ${ }^{500}$ Schnitzler verband mit Wassermann ein zwiespältiges Verhältnis, dem Werk traute er aber immerhin zu, die Vorstufe zum in Deutschland noch ausstehenden „großen Roman“ zu sein. ${ }^{501}$ Ins Kreuzfeuer von Schaukals Kritik gerieten des Weiteren der Literaturbetrieb im Allgemeinen sowie seine Affektiertheit. Dabei gerierte er sich ironisch-dialektisch als „Phantast und Beamter“, der fast feudal sei, aber eigentlich doch ein „Anarchist“. ${ }^{502}$

Auch Schnitzler zeigte sich vom Kaffeehaustreiben mitunter angewidert: „Vertrage Griensteidl nicht; die Atmosphäre Kulka etc. deprimiert mich“, wetterte er am 20. Februar 1892 gegen das Café und seine Besucher. ${ }^{503}$ Eventuell rührte daher eine gewisse Toleranz für den acht Jahre später um Kontakt ansuchenden Schaukal, auch wenn Schnitzlers Anteilnahme für den dichtenden Beamten aus Mähren nicht sehr groß gewesen sein dürfte. Er antwortete mit unpersönlichen, im Verlauf der langsam versiegenden Korrespondenz immer knapperen Briefen. Die Zurückhaltung Schnitzlers mit einer divergierenden Kunstauffassung zu erklären, greift allerdings zu kurz. Zu einem wesentlichen Teil ist die mangelnde Resonanz wohl auf Schaukals wüsten, selbstischen Tonfall zurückzuführen: Nachdem er sich umständlich als „Kritiker vor allem, boshafter Causeur, mit den verschiedensten Menschen gut Freund und eigentlich niemandes Freund, Melancholiker aus Anlage, Sanguiniker aus Blut, sinnlich, ehrgeizig und allen Ehrgeiz belächelnd, vor allem Mensch der Contenance, der Form, Weltmann aus Erziehung“ eingeführt hat, folgt die Litanei gegen Renate Fuchs:

Muß ich Ihnen jetzt Wassermanns Buch noch auseinanderlegen? Zeigen, wie unglaublich geschmacklos, lächerlich ungeschickt, stillos dieses Machwerk ist. Eine geschraubte, gewundene, mühsame, ächzende, stöhnende Diction ohne Elan, ohne Schwung, ohne Elastizität; vergebliches Bemühen um unbekannte Sphären, Geistreichelei aus d. Caféhaus $[\ldots] .^{504}$

Thematische Parallelen und ähnliche Einflüsse zeigen sich im Theaterschaffen, etwa in der Affinität beider Dichter zu Wiener Vorstadtkomödie und Commedia

500 Brief Schaukals an Schnitzler, 2. Mai 1901, in: Urbach (Hg.): Richard Schaukal - Arthur Schnitzler: Briefwechsel (1900-1902), S. 20 (RS3).

501 Brief Schnitzlers an Olga Gußmann, etwa 25. Juli 1900, in: Therese Nickl und Heinrich Schnitzler (Hg.): Arthur Schnitzler: Briefe 1875-1912. Frankfurt am Main 1981, S. 389.

502 Brief Schaukals an Schnitzler, 2. Mai 1901, in: Urbach (Hg.): Richard Schaukal - Arthur Schnitzler: Briefwechsel (1900-1902), S. 21 (RS3).

503 Schnitzler: Tagebuch. Bd.: 1879-1892, S. 366.

504 Brief Schaukals an Schnitzler, 2. Mai 1901, in: Urbach (Hg.): Richard Schaukal - Arthur Schnitzler: Briefwechsel (1900-1902), S. 22 (RS3). 
dell'arte. Auf die Verbindung von Schnitzler und Schaukal spielte auch Franz Blei in seiner Satire Briefe an einen strebsamen jungen Mann an. An Schaukal gerichtet heißt es darin:

Sie [.. .] grüßen im Theater etwa wohl nach der Richtung, wo Herr Arthur Schnitzler sitzt, den Sie natürlich dazu gar nicht zu kennen brauchen und er Sie nicht, und sagen Sie zu Ihrer Nachbarin in der Loge: „Der gute Schnitzler wird immer dicker.“ Aber sagen Sie nicht etwa, Sie wären befreundet mit ihm, denn die gute Dame könnte Lust bekommen, durch Sie Herrn Schnitzler kennenzulernen. ${ }^{505}$

Schnitzler lobte Schaukals Scenen aus einer Gesellschaft junger Leute, das dieMünchner Dramatische Gesellschaft zusammen mit seinem Der tapfere Cassian und Paul Mongrés (1868-1942) Der Arzt seiner Ehre für einen Einakterabend inszenieren wollte, jedoch aus rechtlichen Gründen absagen musste. ${ }^{506}$ Ähnlichkeiten finden sich außerdem in der Auseinandersetzung mit zeitgenössischen Themen: Doppelmoral, verdrängte Begierden und der Tod sind die gängigen Konstanten ihrer Werke. Auch die Liebes-Reigen entwerfen ein unkonventionelles Bild institutionalisierter Mann-Frau-Verbindungen. ${ }^{507}$ (Un-)Treue, der Ehestand und die sich daraus ergebenden Zwänge, die Unfähigkeit der Menschen, zueinander zu finden, wie sie Schaukal in Mimi Lynx, Eros, Rückkehr und Einer, der seine Frau besucht durchspielt, thematisiert Schnitzer etwa in Zwischenspiel und Das weite Land. Schnitzlers dramenästhetischen Rekurs auf Typen der österreichischen und französischen Literatur hebt Richard Specht in seiner 1922 erschienenen Biographie hervor:

Das ist mir so ungemein sympathisch im Anatol, daß Schnitzler es mit Glück versucht, im Milieu und Dialog ein Stück Wienertum festzuhalten und der typisch gewordenen Pariser Cocotte, dem Pariser Lebemann das Wiener Pendant an die Seite zu stellen, eine dankbare und bisher unversuchte Aufgabe. ${ }^{508}$

Schaukals vom französischen Dandytypus beeinflusster Andreas von Balthesser erinnert an die von Specht dargelegten typologischen Charaktere, wie sie Schnitzler auf die Bühne brachte.

Jahrzehnte nach dem Kontakt äußerte sich Schaukal antisemitisch über den einst umschmeichelten Adressaten seiner Briefe. Zu diesem Zeitpunkt hatte

505 Franz Blei: Briefe an einen strebsamen jungen Mann. In: Blei: Schriften in Auswahl. Mit einem Nachwort von A. P. Gütersloh. München 1960, S. 626-637, hier S. 629-630.

506 Vgl. die Anmerkung in: Girardi (Hg.): Thomas Mann: Briefe an Richard Schaukal, S. 182.

507 Vgl. Schaukal: Pierrot und Colombine oder Das Lied von der Ehe: ein Reigen in Versen. Leipzig/Berlin 1902.

508 Specht: Arthur Schnitzler, S. 51. 
er längst eine literaturästhetische und ideologische Volte vollzogen. Schnitzlers oft pikante und zugleich realistische Darstellung vor allem seiner Protagonistinnen veranlasste Schaukal, der 1902 noch den skandalumwitterten Reigen für seine Sammlung erbeten hatte, genau 30 Jahre später zu der Äußerung, der kurz zuvor verstorbene Arzt und Schriftsteller sei ein „Bekenner des jüdischen Eros“ gewesen. ${ }^{509}$ Er unterschlägt dabei jedoch das drei Jahrzehnte zuvor vor allem in seinem eigenen Frühwerk gängige Motiv der Erotik. Noch vor Hofmannsthal hatte er sich den um 1900 verbreiteten Geschlechterdiskursen gewidmet. ${ }^{510}$

In der Novelle „Die Sängerin“ (1905) etwa schildert Schaukal einen aus Gründen der bürgerlichen Standesrepräsentation und forcierten Partizipation am gesellschaftlichen Leben Wiens gewohnheitsmäßigen Theaterbesucher namens Alexander Schreiner, einen bourgeoisen Dandy, der sich den Flirt mit einer in die Jahre gekommenen italienischen Sängerin herbeiphantasiert, durch ihre Zurückweisung moralisch-gesellschaftlich verkommt und sie schließlich ermordet. Die Novelle schlägt eine Brücke zu Oscar Wildes Dorian Gray (1891); in beiden Texten nimmt das Unheil im Theater seinen Lauf. Die Welt der Bühne ist vor allem in der Dekadenzliteratur ein motivisch aufgeladener Ort der Illusion und des schönen Schreckens, in dem Grenzräume ineinanderfließen. Die von gesellschaftlichen Konventionen unterdrückten Triebe erfahren durch Gewalt eine „Abfuhr“ (Freud), der Tod resultiert aus der Begegnung mit der femme fatale (Schaukals Sängerin) oder femme enfant (die Schauspielerin in Dorian Gray). Die Tragik wird durch das groteske Gebaren der männlichen Protagonisten und ihre libidinösen Verhaltensweisen konterkariert. Eine ironisch-tragische Brechung erfolgt mit dem Fokus auf die psychologische Seelenlandschaft der Protagonisten, Schnitzlers Leutnant Gustl (1900) ist eines der prominentesten Beispiele dafür. Der innere Monolog drückt dabei einen verunsicherten, gesellschafts- und standesgebundenen Habitus aus; Gustl greift ebenso wie Schaukals Schreiner auf Soziolekte und Phrasenfragmente zurück, um Haltung zu wahren. Wenn der eitle Herr Schreiner seine Hände begutachtete, ,geschah es mit dem verschnörkelten Motto ,gepflegte Nachlässigkeit‘. Dazu kam, daß er seiner selbst nie ganz sicher war, immer irgendwelche eingebildeten Gefahren bestand, sich immer irgendwelchen angstvoll gewärtigten Unannehmlichkeiten ausgeliefert sah. "511 Ein nicht näher

509 Schaukal: Arthur Schnitzler-Apotheose. In: Deutschlands Erneuerung, 16. Jg., H. 2 (1932), S. 111-113, hier S. 111.

510 Vgl. Pietzcker: Richard von Schaukal, S. 87-88.

511 Schaukal: Die Sängerin. In: WE. Bd. 4: Erzählungen. Hg. von Lotte von Schaukal und Norbert Langer. München/Wien 1966, S. 57-120, hier S. 63. 
bestimmbares Gefühl der Unsicherheit befällt auch Heinrich, den Protagonisten in Schaukals Erzählung Mimi Lynx (1904) während einer Zugfahrt:

Und zwischen den Speichen seiner Rede wanden sich windschnell die Gedanken, und an ihnen hielten sich die Gedanken über die Gedanken geklammert, und wenn er ein wenig die Zügel seines Monologs fallen ließ, hörte er das alles mit den feinen Ohren seines Gewissens und fürchtete sich vor dem Wirrwarr seiner Seele. ${ }^{512}$

Form und Inhalt, die hypertrophe Syntax, Wortrepetitionen und die Aussage fallen in dieser Sequenz zusammen. Die Eisenbahn steht für die technisch bedingte Selbstentfremdung des modernen Menschen. Wie Paul in Richard BeerHofmanns Der Tod Georgs (1900) betrachtet auch Heinrich sein Leben aus der Distanz des Teilnahmslosen, der in „einer vollständigen Spaltung seines Wesens“ auf sein Handeln blickt. ${ }^{513}$ Die Welterfahrung ist lediglich eine Scheinerfahrung, was die Auflösung traditioneller Ausdrucksformen impliziert und in der Literatur der Wiener Moderne zu den eben dargestellten Verfahren neuer Ausdrucks(un)möglichkeiten in Texten wie Leutnant Gustl, Mimi Lynx, Der Tod Georgs oder Hofmannsthals Chandos-Brief führte.

Schaukal verfasste um die Jahrhundertwende Texte, die durchaus als wesensverwandt mit den Werken Schnitzlers, Hofmannsthals oder Beer-Hofmanns bezeichnet werden können. Im Sinne der engeren Kreisstruktur war Schaukal zwar kein Jung-Wiener, doch die ästhetisch-poetologischen und sozialen Beziehungen führten ihn in die Nähe dieses informellen Künstlerzirkels. Der Dichter besuchte das Café Griensteidl, wenn auch nicht regelmäßig und nur zu Beginn seiner Studienzeit, er stand in Kontakt mit Eduard Michael Kafka, Hermann Bahr, Arthur Schnitzler und Karl Kraus, wohl auch mit Hugo von Hofmannsthal, wie der Briefwechsel mit Arthur Schurig verrät. Gewiss ist, dass er keine Einladungen von Richard Beer-Hofmann, Hofmannsthal oder Schnitzler zu ihren regelmäßig und im privaten Rahmen veranstalteten Vorlese-Nachmittagen erhielt, und er begleitete die Dichter auch nie in den Prater, ins Theater oder auf ihren Ausflügen mit dem Fahrrad.

Schaukals literarische Position und seine geistige Nähe zum Jungen Wien werden durch die Publikationen in Pan und Die Insel, im Modernen MusenAlmanach, Simplicissimus und Jugend deutlich, für die auch Hofmannsthal, Bahr und Felix Dörmann schrieben. Die Zugehörigkeit kann vor allem während der vom literarischen Jugendstil beeinflussten Phase als künstlerische Nähe bei physischer Distanz bezeichnet werden. Schaukal setzte sich mit ähnlichen kul-

512 Schaukal: Mimi Lynx. In: WE. Bd. 2: Um die Jahrhundertwende. München/Wien 1965, S. 44-69, hier S. 50.

513 Schaukal: Mimi Lynx, S. 47. 
turellen und literarischen Themen auseinander, schlug dieselben ästhetischen Pfade ein und entwickelte sich bis zur Jahrhundertwende in eine vergleichbare Richtung. Für William M. Johnston steht Schaukal „einmütig“ mit Bahr, Altenberg, Leopold von Andrian (1875-1951) und Beer-Hofmann in der Reihe der Wiener Impressionisten. ${ }^{514}$ Wie sie kehrte er sich vom Ästhetizismus ab. Noch 1902 bezeichnete er sich als schönheitsgläubigen Formverfechter, nach 1904 ging seine Lyrikproduktion gegenüber den essayistischen und literaturkritischen Werken zurück. Ähnlich verhielt es sich auch mit Hofmannsthals lyrischem Schaffen, das nach der Jahrhundertwende (mit Ausnahme der Gedichteinlagen in seinen Libretti) beinahe ganz erlosch.

Eine letzte, ironische Referenz an das Junge Wien, dessen Vertreter sich zu jener Zeit in unterschiedliche ästhetische Richtungen entwickelt hatten, ist der näselnde Lebemann und kauzige Dandy Andreas von Balthesser, für den Hugo von Hofmannsthal Modell stand. ${ }^{515}$ Schaukal adaptierte und rezipierte Werke des Jungen Wien und grenzte sich gleichzeitig von ihnen ab. Er suchte den Austausch und mied ihn gekränkt, sobald er Ablehnung erfuhr.

\subsection{Hypermoderne-Premieren-Abende}

Am 27. August 1907 kontaktierte der Dramatiker und Journalist Otto Eisenschitz Schaukal. Er bat den nach der Veröffentlichung von Andreas Balthesser auf dem Zenit seines Schaffens Stehenden um die Teilnahme an einem „litterarisch-musikalischen Unternehmen“, das in Wien unter dem Titel „Hypermoderne-Premieren-Abende“ in unregelmäßigen Abständen Lieder und kurze Werke aufführen sollte. Diese sollten von Schauspielerinnen dargeboten oder von den Dichtern selbst vortragen werden. Die Künstlerinnen und Künstler würden an den Einnahmen beteiligt werden, so Eisenschitz. Der Organisator argumentierte im Brief an Schaukal netzwerkstrategisch mit „moralischen und materiellen Vorteilen“ bei der zukünftigen Verlagssuche. Dieser zeigte sich interessiert, stieß sich aber, wie zu erwarten, an der Bezeichnung ,hypermodern“. Eisenschitz konzedierte diesen Vorbehalt und strich den ersten Teil des Titels. Er informierte Schaukal außerdem darüber, dass auch Hofmannsthal, Schnitz-

514 William M. Johnston: Der Wiener Impressionismus. Eine neue Wertung einer einst beliebten Kategorie. In: Akten des Internationalen Symposiums ,Arthur Schnitzler und seine Zeit‘. Hg. von Giuseppe Farese. Bern u. a. 1985, S. 201-212, hier S. 203.

515 Vgl. die handschriftliche Notiz Schaukals, abgedruckt in: WE. Bd. 2: Um die Jahrhundertwende. München/Wien 1965, S. 230. 
ler und Wassermann ihre Zusagen für die „Premieren-Abende“ gegeben hätten. ${ }^{516}$ Schaukal bestätigte seine Teilnahme und stellte ein kurzes, unveröffentlichtes Manuskript zur Verfügung, das Eisenschitz zur Premiere am 8. November 1907 vortragen lassen wollte. ${ }^{517}$ In der Zwischenzeit ist das für Schaukal störende Substantiv ,Moderne‘ in den Titel zurückgekehrt, das Projekt wurde zudem um einen Monat verschoben und sollte als „Moderne-PremierenAbende“ stattfinden. Eisenschitz erkundigte sich bei Schaukal nach möglichen Interessenten, an die Reklame versandt werden könnte. ${ }^{518}$

Als erster Aufführungsort wurde der Festsaal des Österreichischen Ingenieur- und Architektenvereins bestimmt. Werke von Detlev von Liliencron, Otto Julius Bierbaum, Hermann Hesse, Hugo Salus, Franz Karl Ginzkey, Herbert Eulenberg (1876-1949), Gustav Falke (1853-1916), Thomas Mair und August Strindberg (1849-1912) waren für die Premiere zusammengestellt worden. Die Schauspielerin Lia Rosen sollte neben Texten von Richard Dehmel, Schnitzler, Hofmannsthal, Falke, Bierbaum, Salus, Hesse, Richard Beer-Hofmann und Rilke auch ausgewählte Gedichte und Verlaine-Übersetzungen von Schaukal vortragen. Für die Rezitation der Novellenauszüge von Thomas Mann und von Liedern Felix Weingartens (1863-1942) und Bogumil Zeplers (1858-1918) war eine weitere, in den Briefen nicht namentlich genannte Sängerin vorgesehen. Der Prolog sollte von Herbert Eulenberg verfasst werden. ${ }^{519}$

Eisenschitz bot Schaukal an, seine Gedichte selbst vorzutragen, da jedoch die Antwortschreiben an den Organisator nicht erhalten sind, ist dessen Reaktion unbekannt. Eisenschitz musste das Projekt ohnehin wenige Tage vor der Premiere absagen, dabei trug sein Schreiben vom 6. November bereits den Briefkopf „Moderne-Premieren-Abende, literarisch-musikalische Novitäten“. Wie der Verfasser mitteilte, haben die Wiener Theaterdirektoren - Eisenschitz nennt keine Namen - den Schauspielerinnen kurzfristig die Erlaubnis entzogen, an der Veranstaltung mitzuwirken. ${ }^{520}$ Das vielversprechende Vorhaben, für das bereits renommierte Künstler gewonnen werden konnten, wurde danach nicht wieder aufgegriffen.

Aus dieser kurzen Schilderung der Entstehung eines engagierten künstlerischen Projekts der Wiener Moderne und seines unwiederbringlichen Scheiterns im letzten Augenblick wird ersichtlich, dass Schaukal spätestens mit der

516 Briefe Eisenschitz' an Schaukal, 27. August, 1. September und 5. September 1907, S-NL, WB.

517 Vgl. den Brief Eisenschitz' an Schaukal, 5. Oktober 1907, S-NL, WB.

518 Vgl. den Brief Eisenschitz' an Schaukal, 11. Oktober 1907, S-NL, WB.

519 Vgl. den Brief Eisenschitz' an Schaukal, 12. Oktober 1907, S-NL, WB.

520 Vgl. den Brief Eisenschitz' an Schaukal, 6. November 1907, S-NL, WB. 
Veröffentlichung von Balthesser auch in Wien zum Kreis angesehener Dichter gezählt wurde. Zumindest von den Organisatoren solcher Veranstaltungen, die aus Gründen des Effekts auf ein diffuses Schlagwort der Zeit zurückgegriffen haben. Eisenschitz trieb die abgegriffene Floskel sogar noch auf die Spitze, indem er der von konservativer Seite diffamierten Bezeichnung ,Moderne“ das Präfix ,Hyper‘ voranstellte. Mit Blick auf die Beiträger zeigt sich die Dialektik aus künstlerisch-literarischer Tradition und Progression. Die ältesten Vertreter, Liliencron (Jahrgang 1844) und Strindberg (Jahrgang 1849), sollten ebenso Teil der Premieren-Abende sein wie die deutlich jüngeren, bereits erfolgreichen Hofmannsthal und Schaukal (beide Jahrgang 1874), Mann und Rilke (beide Jahrgang 1875). Dazwischen stehen die in den 1860er Jahren geborenen Schnitzler (Jahrgang 1862), Dehmel (Jahrgang 1863) und Beer-Hofmann (Jahrgang 1866). Auch wenn die ,Modernen-Premieren-Abende' nie stattgefunden haben, belegen sie dennoch die künstlerische Vernetzung in Wien, die über die österreichischen und generationalen Grenzen hinausging und zum Teil auch ästhetisch entfernte Akteure in einer avancierten Veranstaltung zu einen versuchte. Nicht nur der generationenumspannende künstlerische Austausch ist als internationaler Kulturtransfer ein Wesenszug der ästhetischen Moderne. Auch die Tatsache, dass der Künstlerabend im Festsaal des renommierten Österreichischen Ingenieur- und Architektenvereines stattfinden sollte, ist Ausdruck der Zeit. Architektur, zivilisatorischer Fortschritt und sozialethische Themen verbanden sich im ersten Jahrzehnt des 20. Jahrhunderts mit dichterischen Belangen zu interdisziplinären Themenfeldern, die auch Schaukal behandelte.

\subsection{Individualisten und Gruppenakteure der Anti-/Moderne}

In Anlehnung an Zygmut Baumans Modernity and Ambivalence (1991; dt. 1992) hebt Libor Marek gerade die Heterogenität und das Oszillieren zwischen Moderne und Antimoderne als Charakteristikum von Schaukals Werk hervor. ${ }^{521}$ Als ein solches Merkmal gelten auch seine Zwischen-Positionen beziehungsweise die Positionenwechsel als Gruppenakteur und Individualist. Isolation ist im sozialen Raum nicht ohne Kapitalverlust möglich und widerspricht den Erfolgsbestrebungen. Andererseits war Subjektivismus gerade eine poetische Reaktion auf die Entwicklungen der Moderne. Schaukal inszenierte seine Weltabgewandtheit als Geste der Genialität, doch später führte das unfreiwillige

521 Vgl. Marek: Die Erfahrung der Moderne im Werk Richard von Schaukals, S. 18. 
Ausscheiden aus vielen Feldern der sozialen Welt zu einer vom Dichter immer wieder reflektierten Vereinsamung.

Nach Hermann Bahrs Auffassung kennzeichne den modernen Schriftstellertypus gerade die Abkehr von literarischen Schulen, Regeln oder Traditionen. Er erkenne lediglich das Gesetz „seiner Nerven, seiner Sinne, seines Instinktes und seiner Subjektivität“ an. ${ }^{522}$ Der junge Schaukal war von einer Superioritätsauffassung getragen, die ihn sein schriftstellerisches Können und Genie nicht infrage stellen ließ: Das schaffende Individuum erhebt sich selbst zum künstlerischen Maß aller Dinge und steht über den poetologischen Regeln und Zwängen, Schulen und Kreisen, so Schaukals genieästhetisches Idealbild der Kunst und des Künstlers an sich, ${ }^{523}$ denn „der Dichter darf alles“. ${ }^{524}$ In seinem Gedicht „Herkunft“ tönt das lyrische Ich: „Sage mir einer, von wem ich stamme! / Meine Scheite lodern in EIGENER Flamme, / Aus MEINEM Forst sind die Stämme geschlagen, / MEIN Boden hat seine Bäume getragen“. 525

Wie Kraus und Loos reagierte auch Schaukal auf die Krisen der Zeit mit einem besonderen Fokus auf den (männlichen) Genius, der sich gegen die zunehmend effeminierte Kunstentwicklung durchzusetzen habe. ${ }^{526}$ In seiner Selbstwahrnehmung dürfte er sich also kaum als Epigone betrachtet haben, höchstens als Überlieferer kunstreiner literarischer Traditionen. Die Aversionen gegen Literaturzirkel und Meisterfiguren (auch wenn er als junger Dichter der Aura Stefan Georges erlag) gehörten dabei zum festen Bestandteil seines Bekenntnisrepertoires. Als ihm Arno Holz (1863-1929) die Lyrik des Dichters Georg Stolzenberg als die „zurzeit unmittelbarste“ nahelegte, antwortete er, dieser repräsentiere für ihn nicht mehr als einen „Schüler“. 527

Die literaturtheoretische und -ästhetische Zwischenstellung Schaukals manifestierte sich vor allem auch in seiner Poetik, die sich aus den teils gegenläufigen Positionen von Arno Holz (Naturalismus) und Stefan George (Symbolismus) synthetisierte. ${ }^{528}$ Das umfangreiche Briefkonvolut belegt den regen Kontakt zwischen Holz und Schaukal, der vor allem während der ersten fünf Jahre des 20. Jahrhunderts bestand und mit Unterbrechungen bis in die 1920er Jahre fortdauerte. Schaukal fühlte sich mit dem Dichter und Dramatiker geistig verbunden, ihm ge-

522 Jacques Le Rider: Das Ende der Illusion. Die Wiener Moderne und die Krisen der Identität. Aus dem Franz. von Robert Fleck. Wien 1990, S. 34.

523 Vgl. Wicke: Richard Schaukal und die Lyriktheorie der Jahrhundertwende, S. 82.

524 Schaukal: Arno Holz. In: Das litterarische Echo, 5. Jg. (1902/1903), S. 887.

525 Schaukal: Herkunft. In: Ver Sacrum, 2. Jg., Nr. 1 (Januar 1899), S. 2.

526 Vgl. Le Rider: Das Ende der Illusion, S. 162.

527 Dies geht hervor aus dem Brief Holz' an Schaukal, 17. Mai 1900, S-NL, WB.

528 Vgl. Wicke: Richard Schaukal und die Lyriktheorie der Jahrhundertwende, S. 80-82. 
genüber bewies er sogar die selten gezeigte Fähigkeit, sich kritisieren zu lassen. ${ }^{529}$ Die ästhetische Zuneigung zu Holz verdeutlicht vor allem aber Schaukals ambivalente literarische Ausrichtung, die mit neuen poetischen Formen haderte, sie aber auch nicht ausblenden konnte. Die Angleichung der lyrischen Sprache an die natürliche Ausdrucksweise und der bisweilen naturwissenschaftliche Charakter von Holz' Lyrik opponierten zwar zu Schaukals symbolistischen Gedichten der frühen Phase. Die Poetik des Phantasus-Autors ging allerdings nicht mit dem Berliner Naturalismus konform, wie Schaukal erkannte. Ähnlich Jens Peter Jacobsen, den der österreichische Dichter immer wieder als Einflussgeber erwähnte, deutete auch Holz den Naturalismus-Begriff ganz individuell. Er und Jacobsen entwickelten eine eigenständige Form des Naturalismus, die das präzise Betrachten in den Mittelpunkt rückte und damit auf den Impressionismus vorgriff. ${ }^{530}$ Die „Technik des genauen Hinsehens“ war ebenso wie die Innenschau und subjektivistische Auseinandersetzung entscheidend für eine neue Poetik vieler junger Dichter, ${ }^{531}$ so auch für Beer-Hofmann, der sich in seiner frühen Prosa und Lyrik auch als „Verinnerlicher“ des Naturalismus zeigte. ${ }^{532}$ Die Schriftsteller in Wien vermengten das Berliner naturalistische Modell mit europäischen und den nach wie vor präsenten österreichischen Einflüssen von Biedermeier bis Realismus; daraus resultierte die polymorphe literarische Situation jener Jahre, die spätestens ab 1892 zur Formulierung unterschiedlicher Positionen zum Naturalismus und zu anderen ästhetischen Fragen führte. ${ }^{533}$ Auch deshalb ist bis in die gegenwärtige Forschung hinein eine literaturhistorische Spannung wahrnehmbar, die zwischen gesamtdeutscher Einordbarkeit der Literatur jener Epoche und - vor allem mit Blick auf den Naturalismus - der Verortung eines österreichischen ,Sonderwegs' schwankt. ${ }^{534}$ Edmund Wengraf, Friedrich Michael Fels (ca. 1864-1899), Karl Kraus und andere hielten an einer Form des Naturalismus fest, wie man sie aus heutiger Sicht am ehesten mit der Strömung in Berlin in Verbindung bringt. Hofmannsthal, Leopold von Andrian, Beer-Hofmann, Schnitzler und Bahr suchten hingegen nach neuen Ausdrucksmöglichkeiten durch die Überwindung des Naturalismus. ${ }^{535}$ Die

529 Vgl. den Brief Holz’ an Schaukal, 5. April 1901, S-NL, WB.

530 Vgl. Wunberg: Das Junge Wien, S. LXXVI.

531 Lorenz: Wiener Moderne, S. 47.

532 Anton Mayer: Theater in Wien um 1900. Der Dichterkreis Jung Wien. Wien 1997, S. 99.

533 Die Unstimmigkeiten wurden durch die einzige Theateraufführung des ,Vereins für modernes Leben` ausgelöst. Gespielt wurde im Mai 1892 im Theater in der Josefstadt eine Übersetzung von Maeterlincks L'Intruse; vgl. Lorenz: Wiener Moderne, S. 52.

534 Vgl. zuletzt Roland Innerhofer und Daniela Strigl: Einleitung. In: Sonderweg in Schwarzgelb? Auf der Suche nach einem österreichischen Naturalismus in der Literatur. Hg. von Roland Innerhofer und Daniela Strigl. Innsbruck 2016, S. 7-17.

535 Vgl. Lorenz: Wiener Moderne, S. 52-54. 
Einflüsse des Symbolismus und Impressionismus, aber auch der naturalistischen Mittel, übten auf Schaukal einen nicht zu unterschätzenden Effekt aus. „Der Symbolist muß den Naturalisten verstehen“, meinte Schaukal, um dann spöttischen Auges auf die Kategorisierungs- und Begriffsmanie blickend fortzufahren: „[I]ch hasse diese Schlagworte, weil sie ganz zertreten und deformiert sind, aber sie sind wenigstens Prägnanzsurrogate ${ }^{\text {“536 }}$ Auch in dieser Hinsicht entwickelte er sein schriftstellerisches Bewusstsein parallel zu dem des Jungen Wien: „[D]as Unbehagen am Naturalismus, ohne ihm jedoch etwas Besseres entgegensetzen zu können, war letztlich Tenor und Stimulanz der gesamten Wiener und österreichischen Literatur im letzten Jahrzehnt vor der Jahrhundertwende; es war ihr Ausgangspunkt“, so Gotthart Wunberg. ${ }^{537}$

Dies drückte sich in einer ambivalenten Auseinandersetzung der JungWiener mit den österreichischen Autoren der vorangegangenen Generation aus. Saar war, wie dargelegt, ein Idol für Hofmannsthal, Schnitzler und Schaukal. ${ }^{538}$ Der Novellist des Realismus, der in einem trübsinnigen Brief vom 22. Juni 1906 an Ebner-Eschenbach fatalistisch zur Kenntnis nahm, dass die Zeit über ihn „bereits hinweggegangen“ sei, ${ }^{539}$ war sowohl Orientierungspunkt einer vergangenen Erzähltradition, als auch Ziel mancher Kritik, vor allem was die Lyrik betraf. $^{540}$ Im selben Brief urteilte Saar über Schaukal: „Unlängst schrieb ein ,Junger' im ,Litt = Echo': man könne mich, den alten vornehmen Herrn, nur mehr ,historisch' betrachten. Gegen eine solche ,Eselei` kämpft man vergebens an. Also: sei’s!“541

\section{Resümee: Erfolg und Misserfolg - eine Netzwerkangelegenheit}

Mit Blick auf das München-Netzwerk, in das Schaukal integriert war, ergibt sich folgende Schnittmenge an Autoren, die für dieselben Kunst- und Literaturzeitschriften der Stadt Beiträge verfassten sowie mit Schaukal und zum Teil

536 Schaukal: Intérieurs aus dem Leben der Zwanzigjährigen. In: WE. Bd. 2, S. 169-170.

537 Wunberg: Das Junge Wien, S. LXXXIV.

538 Vgl. Lorenz: Wiener Moderne, S. 43; Specht: Arthur Schnitzler, S. 97.

539 Brief Saars an Ebner-Eschenbach, 22. Juni 1906, in: Kindermann (Hg.): Briefwechsel zwischen Ferdinand von Saar und Marie von Ebner-Eschenbach, S. 157.

540 Vgl. zum Beispiel Schaukal: Ein Meister der Novelle; bei allem Lob äußert er Einwände gegen Saars Lyrik.

541 Brief Saars an Ebner-Eschenbach, 22. Juni 1906, in: Kindermann (Hg.): Briefwechsel zwischen Ferdinand von Saar und Marie von Ebner-Eschenbach, S. 157-158. 
auch untereinander korrespondierten: Dazu gehörten Graphiker, Illustratoren bzw. bildende Künstler wie Th. Th. Heine und Kubin sowie literarische Akteure wie Otto Julius Bierbaum, Richard Dehmel, Hermann Hesse, Thomas Mann, Rainer Maria Rilke, Alexander Roda Roda und Hugo Salus.

Schaukal selbst attestierte den folgenden Personen maßgeblichen Einfluss auf sein dichterisches Schaffen: Hesse, Thomas Mann, Emil Strauß (1866-1960), Salus, Rilke, Bierbaum, Wilhelm von Scholz, Paul Remer (1867-1943) und Gerhard Ouckama Knoop. ${ }^{542}$ Gemessen an den Überschneidungen im literarischen Feld kristallisieren sich Bierbaum, der auch Mitherausgeber von Pan war und Schaukal 1894 in seinen ebenfalls in München publizierten Modernen MusenAlmanach aufnahm, Thomas Mann und schließlich Richard Dehmel als wesentliche Bezugspersonen heraus. Das ist insofern interessant, als die wichtigsten Akteure für Schaukals literarische Karriere nur temporär mit ihm verbunden waren, die Verbindungen (Kanten) also eine insgesamt schwache sowie asymmetrische Struktur aufwiesen. Spätestens nach 1910 stand er mit keinem der Akteure (Knoten) aus dem München-Netzwerk mehr in Kontakt. Der sehr kurze Austausch mit Bierbaum erstreckte sich über lediglich ein Jahr (1902), Thomas Mann beendete die Korrespondenz 1905, zwei Jahre nach seinem Bruder Heinrich. Der letzte Austausch mit Rilke und Salus erfolgte 1907, und 1910 brach der Briefverkehr mit Hesse sowie mit Alexander Roda Roda ab.

Ein über Schaukal verlaufender Brückenschlag zwischen München, Berlin und Prag wurde über die neuromantische Linie intendiert, aber nicht konsequent fortgesetzt. Gegenüber Blei und Mann erwähnte Schaukal immer wieder den damals hochgeschätzten, heute vergessenen E.T.A.-Hoffmann-Forscher Hans von Müller, ${ }^{543}$ der zwischen 1899 und 1905 fester Bestandteil des Berliner ,Montagstisches‘ war, eines Künstlerkreises rund um Otto Erich Hartleben (1864-1905). Blei, Otto Julius Bierbaum und auch Alfred Kubin gehörten zu Hartlebens 1903 ins Leben gerufener ,Halkyonischer Akademie für unangewandte Wissenschaften'. Müller stand nicht nur mit Kubin in Verbindung, sondern auch mit dem Redakteur der Zeitschrift Die Insel und dessen Herausgeber Bierbaum, der in Pan erste Gedichte Schaukals veröffentlicht hatte. ${ }^{544}$ Doch Schaukal frequentierte lieber Aristokraten- als Künstlerkreise, reiste nur selten in die deutschen Literaturmetropolen und blieb somit - auch topographisch -

542 Vgl. den Brief Schaukals an Hesse, 14. Oktober 1904, H-NL, LAM.

543 Vgl. etwa einen Brief Manns an Schaukal, in: Girardi (Hg.): Thomas Mann: Briefe an Richard Schaukal, S. 85 (TMSch 53).

544 Vgl. Mühlher: Hans von Müller, S. 110-114; vgl. auch Hans-Dieter Holzhausen: Aus den Papieren eines bekannten Hoffmann-Forschers. Hans von Müller zum 125. Geburtstag am 30. März 2000. In: E.T.A. Hoffmann-Jahrbuch, Bd. 8 (2000), S. 81-105, hier S. 86. 
in der literarischen Peripherie. Erst 1903 zog er berufsbedingt nach Wien, verbrachte dann allerdings die meiste Zeit seines Lebens im Vorort Grinzing.

Abgesehen von Balthesser erregte Richard Schaukal als Literaturkritiker und Essayist Aufmerksamkeit im deutschen Sprachraum. Doch dies führte nicht $\mathrm{zu}$ einer dauerhaften Festigung seiner Position im literarischen Feld. Schaukals Beiträge erschienen in renommierten Zeitungen und Zeitschriften der Moderne, trugen aber nicht zu seiner Etablierung in den bedeutenden literarisch-publizistischen Netzwerken bei. Ebenso wenig resultierte aus seiner Tätigkeit und den Anbindungsversuchen eine dauerhafte Vermittlung an die von ihm bevorzugten Verlagshäuser; er konnte sein zweifelsohne beträchtliches Sozialkapital, das im publizistischen Feld auch zu ökonomischem und symbolischem Kapital führte, nicht bündeln und derart einsetzen, dass es ihn zum Großschriftsteller befördert hätte. Vor allem der Kontakt zu Franz Blei zählte zu den gewinnbringenden Verbindungen Schaukals in den entscheidenden Jahren ab circa 1900. Der Literaturvermittler zeichnete nicht nur für die Aufnahme seiner Beiträge in der Zeitschrift Insel verantwortlich, sondern stellte auch die Weichen zum Insel-Verlag. Ohne Erfolg blieb hingegen Schaukals frühe Kontaktaufnahme zu Hermann Bahr, der die Werke des jungen Dichters nicht in der Zeit veröffentlichen wollte.

Schaukals literarische Kanten weisen in aller Regel uniplexe Strukturen von geringer Dichte und schwacher Beschaffenheit auf, auch wenn sie sich geographisch wie disziplinär sehr weit und zu vielen unterschiedlichen Akteuren der Moderne spannten. Er kann auch nicht als cut point oder Brückenakteur bezeichnet werden, da er die unterschiedlichen künstlerischen Cluster nicht zusammenführte. Schaukal verfolgte mit seinen Briefen selten freundschaftliche Zwecke, eher intentionale, die stets mit der Positionierung im literarischen Feld zusammenhingen. Schwache Relationen müssen aber nicht zwangsläufig von Nachteil sein. Mit Blick auf den Kontakt zwischen Schaukal und Thomas Mann lässt sich Mark Granovetters Theorie von der Stärke schwacher Beziehungen für einen zumindest teilweise günstigen Informationstausch in beruflichen Belangen erläutern. Der Soziologe konstatiert, dass schwache Beziehungen häufig Hinweise auf zum Beispiel freie Arbeitsstellen geben. Ganz in diesem Sinne waren Thomas Manns Briefe an Schaukal gespickt mit Informationen über Verlage, Zeitungen, Kollegen und Redakteure. Der deutsche Autor verwies auf geeignetere Publikationshäuser, nannte potentielle Veröffentlichungsorgane und schloss andere für Schaukals Arbeiten aus. Wenn auch seine Interventionen vor allem zu Verlagshäusern erfolglos geblieben sind, im Wissens- und Informationstransfer der frühen Korrespondenz nahmen Schaukal und Mann zunächst eine gleichberechtigte, symmetrische Position ein. 
Indem Schaukal seinen Einflussbereich im Zeitungsmetier geltend machte, verfügte er über entscheidendes Sozialkapital, das er zur künstlerischen Aufwertung der eigenen literarischen Werke heranziehen konnte, also zur Steigerung des symbolischen Kapitals. Für Schaukal bedeutete dies, dass er im sozialen Raum verschiedene, laufend wechselnde Positionen einnahm und das als Literaturkritiker gewonnene ökonomische und soziale Kapital auf das kapitalarme Feld der Literaturproduktion zu verlagern suchte. Dies ist ihm lediglich in der frühen Schaffensphase und mit nur mäßigem Erfolg gelungen, was zum großen Teil auf seine ständige Konfliktbereitschaft, auf mangelndes Taktgefühl und ein oft fehlendes Gespür für Quid-pro-quo-Entscheidungen zurückgeht.

\section{Exkurs: Schaukal als Vermittler zwischen Kunst und Politik}

Schaukals Sakralisierung der Kunst und die anachronistische Hinwendung zu einem kulturell einflussreichen Adel sind Versuche, die Autonomie des Kunstwerks zu wahren. Sie stellen eine Reaktion auf die neuen ,Regeln der Kunst“ dar, wie sie sich im Laufe des 19. Jahrhunderts durchzusetzen begannen. Bourdieu beschreibt den wechselseitigen Einfluss von Politik, Industrialisierung (mächtige Großindustrielle, Zeitungswesen, Buchmarkt) und Salonkultur im Frankreich Napoleons III. und erläutert, wie diese Institutionen und ihre Akteure ein bestimmtes Feld für die Literatur erzeugten und spezifische Spielregeln festlegten. ${ }^{545}$ Kultur sei eine umkämpfte Sphäre in der sozialen Welt, die darin tätigen Künstler streben nach ökonomischer Unabhängigkeit, da diese das Schaffen einzigartiger Werke begünstige. Maßgebliche künstlerische Neuerungen, die Bourdieu in seiner Vorlesung über den französischen Maler Édouard Manet (1832-1883) „symbolische Revolution“ nennt, würden vordergründig von Akteuren mit großem Kapitalvolumen und günstiger Kapitalsortenstruktur initiiert:

Manet ist ein Beispiel dafür, und sicher haben seine Dispositionen zum Revolutionär damit zu tun, daß er ein Privilegierter ist, und vor allem vielleicht, daß der Erfolg der Revolution, die er initiiert hat [...], nicht vorstellbar wäre, wenn er nicht über viel Kapital verfügt hätte, nicht nur über akademische, akademisch beglaubigte Kompetenz, sondern auch über soziales Kapital, über Beziehungen und also über an seine Freunde gebundenes symbolisches Kapital usw. ${ }^{546}$

545 Vgl. Bourdieu: Die Regeln der Kunst, S. 83.

546 Pierre Bourdieu: Manet. Eine symbolische Revolution. Vorlesungen am Collège de France 1998-2000. Aus dem Franz. von Bernd Schwibs und Achim Russer. Berlin 2015, S. 24. 
Aus nicht ganz uneigennützigen Gründen wollte Schaukal, dass eine ganz bestimmte Klasse nicht nur politische und gesellschaftliche Herrschaft ausübt, sondern auch kulturell dominiert und die Kunstproduktion beeinflusst. Die Verbindung von politischer, wirtschaftlicher und kultureller Herrschaft, wie sie vor der Ökonomisierung und Industrialisierung von Kunst bestanden habe, sollte restauriert werden. Nicht die Zeitung oder bürgerliche Mäzene, sondern staatliche, kirchliche oder adelige Fördergeber hätten das künstlerische Feld zu strukturieren, um - so die kultur-, aber auch kapitalismuskritische Illusion Schaukals - Kunst vor einer kommerziellen Vereinnahmung zu bewahren. „Wahre Freiheit kann einem Staatswesen nur ein bedeutender aristokratischer Staatsmann gewähren, der den Schwindel der falschen Freiheit, die verdummende Dogmatik des Zeilenliberalismus bis auf den seichten Grund durchschaut [...]. Das Aristokratische ist unwiderleglich wie alles Natürliche“, so Andreas Balthesser in einer Diktion, die mit Antonio Gramscis Begriff des organischen Intellektuellen korreliert. ${ }^{547}$

Ähnlich wie Bourdieu bezeichnet auch Gramsci in seinen zwischen 1929 und 1935 verfassten fragmentarischen Gefängnisheften die entscheidenden Austragungsorte für Klassenkonflikte als ,Felder‘. Wesentlich für die Verbreitung und Unterstützung einer Ideologie sei die Presse, nicht nur Zeitschriften und Zeitungen, sondern die gesamte literarische wie wissenschaftliche Publikationslandschaft, Bibliotheken - man denke nur an die von Schaukal so verachteten Leihbibliotheken,$-{ }^{548}$ Schulen, Clubs und Zirkel. Auch Felder wie die Architektur sieht Gramsci als Ideologieträger, die zur Durchsetzung klassenspezifischer Interessen und zum Machterhalt beitragen. ${ }^{549}$ Damit sind Bereiche angesprochen, die für Schaukal von grundlegender Bedeutung waren. In Verbindung mit Gramscis Hegemonie-Begriff zeigt sich, dass der Dichter, Kritiker und Beamte den Wert der kulturellen Dominanz für eine angestrebte ständestaatliche Ordnung begriffen hat.

Der von den Faschisten inhaftierte neomarxistische Intellektuelle Gramsci suchte während seiner Gefangenschaft nach Erklärungen für das Ausbleiben revolutionärer Erhebungen zu Beginn des 20. Jahrhunderts in den west- und mitteleuropäischen Ländern. Er kam unter anderem zu dem Schluss, dass nicht nur ökonomische Bedingungen, sondern auch kulturelle Faktoren die Heraus-

547 Schaukal: Leben und Meinungen des Herrn Andreas von Balthesser. In: WE. Bd. 2, S. 268. 548 Vgl. Schaukal: Zettelkasten eines Zeitgenossen. Aus Hans Bürgers Papieren. München 1913, S. 38-39.

549 Vgl. Antonio Gramsci: Gefängnishefte. Kritische Gesamtausgabe. 10 Bde. Hg. von Klaus Bochmann und Wolfgang Fritz Haug. Hamburg 1991-2002. Bd. 2 (1991), H. 3, §(49), S. 373. 
bildung und Festigung von Herrschaftsstrukturen determinieren. Ein auf Einzelpersönlichkeiten ausgerichteter Ideologismus und der zum historischen Ökonomismus degenerierte historische Materialismus könnten mit Blick auf den (kulturellen) Hegemoniebegriff überwunden werden. ${ }^{550}$ Entscheidend für die Sicherung der Hegemonie einer herrschenden Gruppe ist die Eingliederung sogenannter subalterner Klassen. Dies kann in Form von (scheinbaren) Zugeständnissen erfolgen, die mit der Interessenswahrung der dominanten Kultur übereinstimmen. Die Vertreter einer herrschenden oder auf Herrschaft abzielenden Klasse sind dann am erfolgreichsten, wenn sie als geschlossene Gruppe „organischer Intellektueller“ auftreten, das heißt, wenn sich erstens ihre Ideologie mit der ausgeübten (beruflichen) Tätigkeit „verdichtet“ und sie zweitens durch privates Engagement und nicht mit offiziellen Parteiprogrammen an die „ganze Masse an Intellektuellen“ herantreten, die im Land „verstreut“ und „vereinzelt“ leben und nicht organisiert sind. ${ }^{551}$ Durch diese Art der Verdichtung, wie es Gramsci nennt, üben die organischen Intellektuellen eine besondere Anziehung auf alle übrigen, nicht-organisierten Mitglieder einer Gesellschaft aus. Diese Wirkung trägt dazu bei, jene Verstreuten von der Richtigkeit ihrer Ideologie zu überzeugen. Dabei ist die Integration einflussreicher Intellektueller (Gramsci verwendet den Terminus ,Eroberung`) für die Etablierung und Wahrung der Hegemonie ganz entscheidend. Grundsätzlich sei jeder ein Intellektueller - auch Fließbandarbeit setze das Bewusstsein für die mechanische Umsetzung der Tätigkeit voraus -, so Gramsci. Allerdings übe nicht jeder Intellektuelle zugleich auch eine Funktion aus. Neben den genannten organischen existieren auch traditionelle Intellektuelle, zum Beispiel Kleriker, Philosophen und Künstler. In diese Intellektuellenkategorie gehören auch Amtsadelige und Wissenschaftler. Jene seien sich keiner strukturellen Zugehörigkeit bewusst und reklamieren eine Sonderposition in der Gesellschaft, die aber pseudoautonom bleibt, da sie meist von der herrschenden Klasse instrumentalisiert werden. Die vom italienischen Theoretiker als organisch bezeichneten Intellektuellen fühlen sich hingegen mit einer Klasse verbunden, sie entstammen also einem Milieu, dem sie zugeordnet werden können und an das sie angeschlossen bleiben (wollen). Gelingt es einer nach Dominanz strebenden sozialen Gruppe, den traditionellen Intellektuellentypus für die Vermittlung der Ideologie zu gewinnen - Gramsci spricht von ,assimilieren' -, ist eine entscheidende Grundvoraussetzung für den Erwerb und die Festigung (kultureller) Hegemonie gegeben. ${ }^{552}$

550 Vgl. Gramsci: Gefängnishefte. Bd. 3 (1992), H. 4, § 38, S. 502.

551 Gramsci: Gefängnishefte. Bd. 1 (1991), H. 1, § 44, S. 101-102.

552 Vgl. Gramsci: Gefängnishefte. Bd. 7 (1996), H. 12, § 1, S. 1497-1505. Vgl. Dominique Grisoni und Robert Maggiori: Guida a Gramsci. Mailand 1975. 
Mit seinen kulturkritischen Aussagen assimilierte sich Richard Schaukal im Sinne Gramscis selbst. Er stellte sich mit seinem literarischen Schaffen und der ideologischen Energie in den Dienst einer von ihm favorisierten, dominanten Klasse. Als Kritiker und Dichter kam ihm dabei die Funktion des ideologischvermittelnden Intellektuellen zu, der Adel, Klerus beziehungsweise der Christlichsozialen Partei Österreichs kulturelle Hegemonie zuzuschreiben versuchte. In der Funktion als Kulturvermittler brachte Schaukal seine kulturpolitischen Intentionen und Auffassungen aktiv ein, aufgrund seiner politischen Orientierung und sozialen Herkunft wurde er von gewissen Kreisen im künstlerischen Feld beachtet. Die veränderten Kontakte nach dem Ende der Monarchie belegen Schaukals organisatorische Kompetenz als Intellektueller (nach Gramsci), der auf die „politische Segmentierung der Gesellschaft“ Österreichs zwischen 1918 und 1933 reagierte.

Die politische Segmentierung der Gesellschaft hat das Kulturverhalten der Menschen [. . ] beeinflußt und im System der Literaturvermittlung zur Herausbildung von ideologisch definierten Teilmärkten oder besser: marktähnlichen Gebilden geführt; Produktion, Distribution und Konsumation waren hier in einer Weise verkoppelt, die das freie Spiel von Angebot und Nachfrage außer Kraft setzte. ${ }^{553}$

Fast jeder dritte Österreicher trat zu dieser Zeit einer Partei bei. ${ }^{554}$ Alle Bereiche und Funktionen des Literaturbetriebs wurden politisch besetzt, wie auch die erwähnte Ernennung Adolf Vetters zum Staatstheaterpräsidenten zeigt, auf die die Christlichsozialen mit Schaukals Erhebung zum Gegenkandidaten reagierten; dies stellt ein Beispiel für die Instrumentalisierung Schaukals und seine Assimilierung zum traditionellen Intellektuellen im kulturpolitischen Feld Österreichs nach 1918 dar.

Schaukals Bekanntenkreis reagierte auf dessen Engagement für die österreichische Idee unterschiedlich. Schurig brachte keinerlei Verständnis dafür auf, und der um Neutralität bemühte Kubin äußerte ihm gegenüber: „Leider kommen immer wieder Stunden dazwischen wo man alle Energie gebrauchen muß um nur unpolitisch zu bleiben."555 Auch die einschlägige Presse band Schaukal in ihre Kriegs- und Ideologiediskurse ein. Danzer's Armee-Zeitung verteidigte den Dichter im Juni 1918 gegen Angriffe aus dem sozialdemokratischen Lager und setzte den Vorwürfen der lyrischen Kriegstreiberei dessen literarisches Österreich-Bekenntnis entgegen:

553 Bachleitner/Eybl/Fischer: Geschichte des Buchhandels in Österreich, S. 244.

554 Vgl. Bachleitner/Eybl/Fischer: Geschichte des Buchhandels in Österreich, S. 244.

555 Brief Kubins an Schaukal, 17. Februar 1919, S-NL, WB. 
Der Dichter zeigt, als Deutscher, herzlichstes, aufnahmebreites Verständnis für seine nicht-deutschen Brudervölker im Reiche: was so vielen unserer Politiker als unlösbares Problem dünkt, erschließt sich ihm als natürliche Selbstverständlichkeit, was jenen als Mangel Österreichs erscheint, ist ihm Vorzug und Wesen Österreichs. Richard von Schaukals „Österreichische Züge“ [eine 1918 bei Müller in München erschienene Essaysammlung, $\mathrm{CM}$ ] offenbaren mehr von Österreichs Sein und Werden als eine ganze politische Bibliothek. ${ }^{556}$

Schaukals Interesse galt nicht allein der Steigerung seines Einflusses als Dichter und Beamter auf die Kulturpolitik. Schon vor Kriegsausbruch strebte er direkt ins Feld der Politik. Für diesen Schritt wählte er einen Bekannten seines Vaters zum Mittelsmann, den österreichischen Juristen, Wissenschaftler und Politiker Josef Redlich, der unter anderem in der K.u.k.-Statthalterei Brünn tätig war und als Abgeordneter im Mährischen Landtag saß..$^{557}$

Schaukal wandte sich im April 1908 erstmals mit einer Büchersendung an Redlich, bevor er, jedoch erst einige Jahre später, am 14. Juni 1912 seine politischen Ambitionen äußerte. Er teilte Redlich seinen Wunsch mit, selbst Volksvertreter zu werden. Dafür bat er den erfahrenen Politiker um Unterstützung, und Redlich befürwortete Schaukals Absichten: „Ich halte Sie für eine sehr aktive Natur, die sich nicht damit begnügt, bloss durch künstlerisches Wirken sich auszuleben." Er schlug vor, dass Schaukal Mitglied des heterogenen, im Prinzip aber großdeutsch ausgerichteten Deutschen Nationalverbandes werden sollte, „weil ich jede Vermehrung der nicht grossen Zahl von Intellektuellen unter den Deutschen und überhaupt im Abgeordnetenhaus mit besonderer Freude begrüsse." Schaukal interessierte sich für ein politisches Amt in Neutitschein, dem Geburtsort seiner Frau Fanny Hückel. Redlich riet jedoch von den böhmischmährischen Städten ab. Er sei zwar mit „der angesehensten Industriefamilie“ der Stadt verwandt, aber die „deutschradikalen Kandidaten“ hätten aufgrund der traditionell starken Sozialdemokratie und jüdischen Wählerschaft dort keine großen Erfolgsaussichten. Redlich nannte einige „lokale Machthaber“, mit denen er in Kontakt treten solle. ${ }^{558}$ Auf Schaukals Widerwillen, sich einem Parteiprogramm unterzuordnen, reagierte Redlich beschwichtigend und ermutigend:

556 [Anon.]: Literatur. In: Danzer’s Armee-Zeitung, Nr. 23-24/1918 (6./13. Juni 1918), S. 6.

$557 \mathrm{Vgl}$. Fritz Fellner und Doris A. Corradini (Hg.): Schicksalsjahre Österreichs. Die Erinnerungen und Tagebücher Josef Redlichs, 1869-1936. Wien/Köln/Weimar 2011.

558 Brief Redlichs an Schaukal, 14. Juni 1912, S-NL, WB. Konkret verwies Redlich auf den Landtagsabgeordneten Preissenhammer, einen Herrn Rohrer aus Brünn und den Landtagsabgeordneten Dr. Fischel, der Einfluss auf die liberale und jüdische Wählerschaft in Weißkirchen und Leipnik ausübe. 
Sie taugen selbstverständlich für keine bestehende Partei, aber ich kann sie über diesen Punkt nur nochmals nachdrücklich beruhigen. Was man bei uns Partei nennt, drückt einen Menschen überhaupt nicht und es ist einer so reichen Individualität wie Ihnen ein leichtes, die wenigen Konventionen mitzumachen, aus denen bei uns der sogenannte Parteiverband besteht. Sie würden aber vielfach grosse Anregungen auch für Ihr künstlerisches Wirken finden, wenn Sie in das merkwürdige Stück Leben hineinsähen, das man in Oesterreich aktive Politik nennt [. . .]. Denn ich bin sicher, mag Ihr Schicksal als Politiker sich praktisch mehr oder minder erfolgreich gestalten, die deutsche Literatur wird sicher durch das, was Sie auf Grund Ihrer Eindrücke und Beobachtungen schaffen werden, einen sehr wertvollen und erfreulichen Zuwachs erhalten. Herr von Balthesser wird vielleicht aus dem Grabe, in das Sie ihn versenkt haben, fröhlich auferstehen und wird uns in derselben geistvollen und künstlerisch vollendeten Form ein Brevier politischer Lebenskunst bieten [.. . ..$^{559}$

Da sich die deutschnationalen bürgerlichen Parteien aber auf Gustav Bodirsky (1864-1934) als Kandidaten einigten, legte Schaukal seine politischen Pläne beiseite und verzichtete auf eine Kandidatur. ${ }^{560}$

Erst nach dem Krieg belebte Schaukal seine politischen Ambitionen und wagte einen neuerlichen Vorstoß in jenes Feld. Im Dezember 1918 teilte er Alois Essigmann mit, dass er für eine Partei zu kandidieren plane. Dieser empfahl Schaukal die Kandidatur als Parteiloser. Aus Hetzendorf schickte er einen Vierpunkteplan:

1. Vorläufiger Titel: „Wahlgemeinschaft der Parteilosen.“ 2. Wahlparole: Parteilose! Wählt nicht Parteileute, die nur nach straffen Parteigrundsätzen entscheiden! Wählt Persönlichkeiten, die befähig sind, jeden Einzelfall zu beurteilen! 3. Agitation: Schneeballsystem, d.h. jeder der Wahlgemeinschaft geworbene wirbt 10 Neue u.s.f. 4. Finanzierung: Zunächst Bevorschussung aus Privatmitteln um anfangen zu können, sodann per Mitglied der Wahlgemeinschaft ein kleiner Beitrag [.. ..$^{561}$

Für die Gründung einer „Wahlgemeinschaft der Parteilosen“ würden 18.000 bis 20.000 Unterschriften benötigt. Maximilian Liebenwein und der Mitherausgeber der Zeitschrift Gewissen, Rudolf Falk, boten ihre organisatorische Hilfe an. ${ }^{562}$ Essigmann verlieh der Hoffnung Ausdruck, Schaukal möge der Sprung in die Nationalversammlung gelingen, um es dort den „Fortschrittlern“ zu zeigen. Er merkte aber auch an, dass dies als Parteiloser sehr viel schwieriger sei. Deshalb schlug Essigmann eine Kandidatur für die Christlich-

559 Brief Redlichs an Schaukal, 21. Juni 1912, S-NL, WB.

560 Vgl. den Brief Redlichs an Schaukal, 21. Juni 1912, S-NL, WB.

561 Brief Essigmanns an Schaukal, 11. Dezember 1918, S-NL, WB; Hervorh. im Orig. als Unterstreichungen.

562 Brief Essigmanns an Schaukal, 11. Dezember 1918, S-NL. WB. 
soziale Partei vor, die gegen die „Masse der Proletarier“ mehr ausrichte als „tausend einzelne“. 563

Kurz darauf ließ Schaukal auch dieses Vorhaben fallen, wozu ihm Essigmann merklich erleichtert beglückwünschte. Bereits am 6. Dezember 1918 hatte er geraten, Schaukal solle einen „Strohmann inspirieren“, wenn er „auf die Gestaltung politischer Dinge einwirken wolle“. ${ }^{564}$ Auch einen agitatorischen Aufruf an die Deutschösterreicher weigerte sich Essigmann zu unterzeichnen oder im Gewissen abzudrucken. ${ }^{565}$ Schaukals politisches Wirken blieb also auf den kulturellen Bereich beschränkt.

Seine politischen Bemühungen stießen im Bekanntenkreis mitunter auf negative Resonanz. Arthur Schurig zählte zu den größten Skeptikern von Schaukals Engagement nach dem Krieg, an dem dieser als Offizier an der Front in Belgien und Frankreich teilgenommen hatte, während Schaukal aufgrund eines Magenleidens und seiner höheren Beamtenposition nicht einberufen worden war. Er konnte nicht nachvollziehen, warum sein Dichterfreund politische Artikel verfasste und nun sogar Politiker werden wollte, ${ }^{566}$ denn die Tätigkeit im politischen Feld würde die Chancen auf literarischen Erfolg drastisch senken. ${ }^{567}$ Schurig prognostizierte Schaukal, dass sich sein Antisemitismus hinderlich auf die Verlagssuche auswirken werde. Zwar wollte er sich bei Kippenberg wegen einer möglichen Publikation einsetzen, zugleich gab er aber zu bedenken: „Ihre politische Tätigkeit passt nicht in die Insel.“568 Der Briefwechsel zwischen Schurig und Schaukal nahm über die Jahre einen schrofferen Ton an, die Konflikte entzündeten sich an der auf den Markt und nicht auf wissenschaftliche Editionsrichtlinien ausgerichteten Chamisso-Ausgabe, die Schurig 1920 herausgegeben hatte. Inoffiziell dürften aber auch Schaukals politisches Engagement und die Enttäuschung darüber, dass Schurig ihn nicht an den Insel-Verlag vermitteln konnte, ausschlaggebend für die Entfremdung gewesen sein. In einem der letzten Briefe schreibt er Schaukal: „Ich empfinde geradezu Abneigung, wenn ich Ihre journalistischen Ergüsse lese. Und ich verliere fast den Mut, Ihre Gedichte, die ich einst gern gelesen habe, je wieder in die Hand zu nehmen, weil ich die Vision vom Polemiker Schaukal dabei habe und mir der Künstler entschwebt. “569

563 Brief Essigmanns an Schaukal, 16. Dezember 1918, S-NL, WB.

564 Brief Essigmanns an Schaukal, 6. Dezember 1918, S-NL, WB.

565 Vgl. Essigmanns Brief an Schaukal, 9. Dezember 1918, S-NL, WB.

566 Vgl. den Brief Schurigs an Schaukal, 28. Januar 1919, S-NL, WB.

567 Vgl. den Brief Schurigs an Schaukal, 19. Dezember 1919, S-NL, WB.

568 Brief Schurigs an Schaukal, 24. August 1919, S-NL, WB; Hervorh. im Orig. als Unterstreichung.

569 Brief Schurigs an Schaukal, 10. Juli 1921, S-NL, WB. 
Ein weiterer ideologischer Gesinnungsgenosse Schaukals war der zu Lebzeiten vielgelesene, heute nahezu vergessene Schriftsteller Emil Strauß. Der Freund von Hermann Hesse wechselte seit 1902 bissige Briefe mit Schaukal, dessen Bücher er als „artistisch conventionelle Manier“ einer ästhetizistischen Mode abkanzelte. ${ }^{570}$ Schaukals Kontaktaufnahme ist unter anderem damit zu begründen, dass Strauß bereits ein angesehener Autor des Fischer-Verlags war. Der Briefwechsel wurde unregelmäßig fortgesetzt, bis es aufgrund einer Negativrezension 1923 zum Bruch kam. Strauß hatte Schaukal sein Drama Vaterland zugeschickt, und dieser kritisierte die dramenästhetischen Schwächen harsch: Das Theaterstück sei „gestaltete und konstruierte Litteratur“, enthalte „zu viel unbelebtes Ideematerial“, imitiere bereits existierende Stücke, sei reine Tendenz und im Grunde genommen nicht mehr wert als das Papier, auf dem es gedruckt wurde; nach dem ersten Akt habe er aufgehört zu lesen. Schaukals Kritikpunkte sind nicht im Original erhalten, doch Strauß zitierte sie im Antwortschreiben. Aus diesem geht nicht hervor, ob Schaukals Kritik vordergründig auf technische Schwächen oder auch auf die darin anklingende nationalsozialistische Position des Verfassers abzielte. Wenige Wochen nach Hitlers gescheitertem Putschversuch in München warf Strauß Schaukal im Gegenzug vor, nicht zwischen Gesinnungsfreund und Feind unterscheiden zu können:

Sie gehen mit Herren, die fünfzig oder hundert Jahre tot sind, unentwegt verehrungsvoll mit durch ihre bedenklichen Langweilereien und haben noch ein begütigendes Wort für ihre ödeste Routine (ich meine Stifter und Hoffmann, die ich sehr verehre), aber wir, die wir in so viel ungünstigerer [...] Zeit arbeiten müssen, wir haben solche Nachsicht und Einfühlung viel nötiger [...]. ${ }^{571}$

Schaukals kulturpolitischer Aktivismus nahm zu Beginn der 1920er Jahre zu und erstreckte sich vor allem auf Österreich. Dies drückte sich auch in den ab Mitte der 1920er Jahre ausgestrahlten Radiobeiträgen aus. So sprach Schaukal zum Beispiel 1927 gemeinsam mit Emil Lucka (1877-1941) über die Arbeitspläne der Wiener Volksbildungsanstalten. ${ }^{572}$ Einen Akt der Solidarität mit der politischen Führung in Wien stellten seine „Weiheverse zur Enthüllung des Denkmals für Dr. Karl Lueger“ (1844-1910) dar. Das für den am 18. September 1926 im Burgtheater abgehaltenen Festakt verfasste Gedicht wurde am

570 Brief Strauß' an Schaukal, August 1902, S-NL, WB.

571 Brief Strauß' an Schaukal, Dezember 1923, S-NL, WB.

572 Die Ausstrahlung erfolgte am 28. Mai 1927 um 18:05 Uhr und dauerte eine Stunde. Vgl. die Ankündigung in der Arbeiter-Zeitung vom 22. Mai 1927, S. 11. Die Mitteilungen der RichardSchaukal-Gesellschaft verzeichnen zwischen dem 9. November 1934 und dem 7. April 1936 insgesamt 8 Radiovorlesungen für den Wiener Rundfunk (RAVAG). Schaukal sprach über Dichter und las eigene Gedichte vor. 
nächsten Tag in der Reichspost abgedruckt. ${ }^{573}$ In den 1920er Jahren begrüßten nationale Zeitungen wie die Reichspost, „daß immer stärker der Österreicher in ihm durchbricht. Angeleimte und angeklebte Schlacken fallen allmählich ab, der Kern liegt offen glühend zutage und die Umwege führten doch zum Ziel: das österreichische Herz pulst uns entgegen.“574

Schaukals Einsatz für die Bewahrung und für die Bewahrer einer „legitimen“ Kultur (Bourdieu) richtete sich dabei vor allem und immer wieder gegen das Judentum. Seine Antisemitismen sind Ausdruck einer Strategie der Neupositionierung im künstlerischen Feld, das von einer starken Spannung aus Etablierten und sich Etablierenden bestimmt war. Dass diese in allen Feldern ausgetragenen Kämpfe nicht einfach nur generationalen Ursprungs waren (Jung gegen Alt) oder auf ungleichem Einkommen beziehungsweise unterschiedlichen strukturellen Mitteln beruhten (Reich gegen Arm), ist ein entscheidender Punkt. Die Auseinandersetzungen im literarischen Feld wurden am erbittertsten zwischen Personen derselben Schicht geführt, weil ihre Voraussetzungen ähnlich waren und ihre Machtinstrumente - Kapitalvolumen und -struktur - kaum divergierten. Die maßgebliche Differenzierung erfolgte unter anderem über nicht rational vollzogene Unterteilungen in christlich-deutschnationale und im weitesten Sinne ,jüdische“ Akteure. Karl Luegers Ausspruch „Wer ein Jud ist, das bestimme ich“ untermauert diese zynische Grundhaltung einer Distinktionsweise, ${ }^{575}$ die nicht nur für die Politik, sondern auch für den kulturellen Bereich galt. Dort, wo soziale Distinktion nicht möglich war, weil sich die Akteure strukturell zu sehr ähnelten, wurde eine ethnisch-religiöse Grenze gezogen. Profilierung erfolgte über hetzerische Abwertungsdiskurse. Darin liegt eine Parallele zur gegenseitigen Diskreditierung von intellektuellen Frauen und jüdischen Männern um 1900, die damit das Ziel verfolgten, über die Ausgrenzung des anderen sich selbst zu profilieren. ${ }^{576}$

Die antisemitischen Bekundungen Schaukals sind Teil eines diskursiven Kampfes mit Akteuren, die vielleicht wirklich besser vernetzt waren oder ganz generell eine vorteilhaftere Kapitalsortenstruktur aufweisen konnten. Sein Essay Karl Kraus. Versuch eines geistigen Bildnisses kann in diesem Zusammenhang als Ausdruck verborgener rassistischer Diskurse bezeichnet werden;

573 Vgl. Schaukal: Weiheverse. Zur Enthüllung des Denkmals für Dr. Karl Lueger. In: Reichspost, Nr. 256/1926 (19. September 1926), S. 15.

574 Dr. M. Enzinger: Hoffnung in Österreich. In: Reichspost, Nr. 74/1923 (17. März 1923), S. 1.

575 Vgl. Judith Fritz: „Wer ein Jud ist, das bestimme ich“. Der christlichsoziale Antisemitismus Karl Luegers. https://ww1.habsburger.net/de/kapitel/wer-ein-jud-ist-das-bestimme-ich (zuletzt aufgerufen am 31. Juli 2019).

576 Vgl. Christina von Braun: Versuch über den Schwindel. Religion, Schrift, Bild, Geschlecht. Zürich 2001, S. 497. 
der Satiriker spielt darin nur mehr eine untergeordnete Rolle. Der primäre Zweck des Textes liegt in Schaukals Positionierung als Literaturkritiker und Ideologe. Gegenüber dem Übersetzer Richard Flatter drückte er in Anspielung auf die politische Farbsemantik den Wunsch aus, sein Kraus möge als „Gelbbuch“ überdauern. „Ich bin unschuldig an der Takt- und Geschmacklosigkeit, dass mein Essay über Kraus als aufreizendes Rotbuch - ,Fackel'nachahmung [sic!] und Sozibrandmal zugleich - herausgebracht worden ist. “577

Aus einer informellen Institution, die Bourdieu als maßgebliche Konstituente für das künstlerische Feld bezeichnete, blieb Schaukal letztlich ausgeschlossen: aus dem Salon. Auch die Wiener Salons leisteten einen nicht unwesentlichen Beitrag zur Netzwerkgenerierung. Sie wurden von Salonnieren wie Berta Zuckerkandl-Szeps (1864-1945), Josephine und Franziska von Wertheimstein (1820-1894 bzw. 1844-1907) oder Sophie von Todesco (1825-1895) geleitet und erlebten Ende des 19. Jahrhunderts eine Blüte. ${ }^{578}$ Josephine von Wertheimstein entstammte der Familie Gomperz aus Brünn. Schaukal stand mit ihrem Bruder, dem Unternehmer Julius von Gomperz (1823-1909) und mit einigen weiteren Mitgliedern der Familie in Briefkontakt. Der Besuch eines Salons ist aber nicht bezeugt und hinsichtlich Schaukals despektierlicher Grundhaltung auch kaum vorstellbar. Er konstruierte aus dem Konkurrenzkampf mit jüdischen Intellektuellen ein regelrechtes Narrativ, das er sogar in Briefen an Dichter mit jüdischem Hintergrund oder im Freundeskreis (zum Beispiel an Schnitzler gerichtet) so unbeholfen wie wüst zu Papier brachte. Schaukal stellte dabei einen ästhetisch-autobiographischen Zusammenhang her zwischen den Schwierigkeiten mit der Presse, seinen Angriffen auf den technischen „Fortschritt“ und dem „rationalen, doktrinären und mechanisch-materialistischen Geist der Zeit und seinem fähigsten Ausdruck und Vertreter“, dem „internationalen Judentum“. 579

Auf der anderen Seite stehen freundschaftliche Kindheitserinnerungen an die einstigen Konkurrenten um den Klassenvorrang, die zeigen, dass Schaukals Antisemitismus insbesondere das literarische Feld betraf: „In der Schule saß ich vorn unter den fleißigen Juden, mit deren einem ich vergebens um den Vorrang eiferte; ich blieb der Sekundus. [...] Unsrer Freundschaft hat der Wettstreit nicht geschadet, sie ist heute noch in Herzlichkeit aufrecht“ .580

577 Brief Schaukals an Flatter, 8. Juli 1933, S-NL, WB.

578 Vgl. Timms: Dynamik der Kreise, S. 68-69; sowie Michael Schulte: Berta Zuckerkandl: Saloniere, Journalistin, Geheimdiplomatin. Zürich 2006.

579 Schaukal: Beiträge zu einer Selbstdarstellung, S. 39-40.

580 Schaukal: Beiträge zu einer Selbstdarstellung, S. 52. 
Bereits in frühen kritischen Essays und Büchern wie Giorgione und Literatur argumentiert Schaukal zudem gegen die marktwirtschaftliche Partizipation seiner dichtenden Kollegen an den Entwicklungen der Kunst, weil er eine bürgerlichmerkantile - in diesem Kontext auch jüdische - Vereinnahmung der kulturellen Hegemonie befürchtete. Als K.u.k.-Beamter und Dichter war Schaukals Handlungsort der des Überbaus. Er wurde als Angestellter der herrschenden Klasse und „Funktionär der Hegemonie“ vom christlichsozialen Lager instrumentalisiert ${ }^{581}$ und hat in diesem Kontext seinen Einfluss auf die ökonomische Basis im Sinne der Machtdurchsetzung einer Klasse geltend gemacht, wie mit Bezug auf Gramscis Theorie ersichtlich wurde.

Schaukals Position spiegelt die Krise einer zahlenmäßig großen und verunsicherten Gesellschaftsschicht zu Beginn des 20. Jahrhunderts wider, die vom Liberalismus enttäuscht war, über kein eigenes Klassenbewusstsein verfügte, soziale Erhebungen sowie den Verlust von politischem Einfluss und gesellschaftlichem Prestige fürchtete und daher die Hegemonie literarisch-produktiv auf traditionelle Herrschaftsformen projizierte. Schon in Schaukals 1907 veröffentlichten Giorgione heißt es wehmütig:

\footnotetext{
Heut ist es der „bildenden Kunst“ nicht mehr vergönnt, aus stiller Werkstattweihe, gehegt von der Liebe und Achtung der Könige, der Fürsten, der Patrizier, aufzuerstehen im Glanz der Hochaltäre, der Ratssäle und Paläste, heut ist sie durchaus ein gewagtes Unternehmen des Einzelnen, heut muß die Kunst auf den Markt, die Ausstellung. ${ }^{582}$
}

Die Dichter im Staatsdienst hatten ihren Teil zur Wahrung kultureller Hegemonie der dominanten Klassen und Institutionen beigetragen (Thron und Altar, Adel und Armee $)^{583}$ und die Vielvölkermonarchie auf zweifache Weise gestützt: bürokratisch wie literarisch, also in den Feldern Politik und Kultur. Nach dem Ersten Weltkrieg befürchtete eine große Zahl sehr unterschiedlich positionierter Akteure, strukturell vom Proletariat verdrängt oder absorbiert zu werden. Ein Teil der bürgerlichen Schriftsteller reagierte mit dem Versuch, eine Aristokratie des Geistes zu etablieren und ihr Wirken für die Bewahrung der kulturellen wie politischen Hegemonie einzusetzen. Schaukal verkörpert diese Entwicklungen: er nahm eine historisch gewachsene Elite in die Pflicht, Kunst zu fördern, um die Verknüpfung von Kultur und Ständeordnung zu bewahren.

581 Ludwig Paulmichl: Bürgerliche Gesellschaft, Hegemonie, Intellektuelle. Zur konzeptuellen Ausweitung des Intellektuellen im Hinblick auf die revolutionäre Strategie und Organisation Antonio Gramscis. Diss. Univ. Wien, 1988, S. 132.

582 Schaukal: Giorgione, S. 107.

583 Vgl. Timms: Dynamik der Kreise, S. 18. 